\title{
Free Speech and Racial Harassment: Policy Responses at Three Research Universities
}

\author{
Thomas W. Jennings Jr. \\ Charlottesville Virginia
}

B.S., James Madison University, 1982

M.A., James Madison University, 1983

A Dissertation Presented to

the Faculty of the University of Virginia

in Candidacy for the Degree of Doctor of Philosophy

Curry School of Education

University of Virginia

March 1993

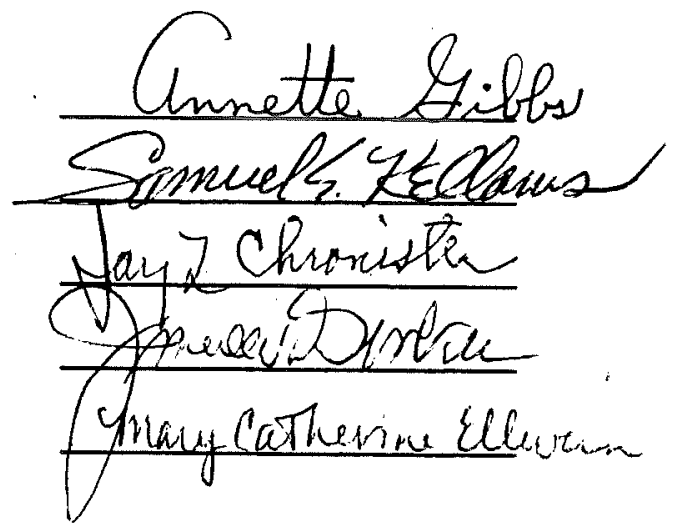


Diss.

Educ.

1993

.5455 
(C) Copyright by

Thomas W. Jennings, Jr.

All rights reserved

May 1993 


\section{Free Speech and Racial Harassment: Policy Responses at Three Research Universities Abstract}

This qualitative case study describes the factors and conditions related to discriminatory verbal harassment (DVH) student conduct codes at the University of Wisconsin, Stanford University, and the University of Virginia. The study examines the extent to which DVH policies enhanced civility among different racial groups, it describes the campuses' DVH policy debates, and examines race relations at the three universities following efforts to address DVH. The study provides information regarding advantages and disadvantages of such policies, opinions of various constituents during policy debates, and analyses of racial conditions at Stanford and Wisconsin after their policies' promulgation. Each university is examined for its: 1)historical, structural, and organizational factors and conditions, 2) racial climate prior to the adoption (or rejection, in Virginia's case) of its DVH policy, 3) political factors and conditions, 4) progression of proposed policies and their supporters and oppenents' arguments, and 5) Conditions following the adoption (or rejection) of the policy (i.e., race relations afterward, policies' application, policies' effects on academic behavior).

Important factors in DVH policies' development include the university's public/private status, wording and structure of its existing student conduct codes, its campus traditions and historical figures, and its process for adopting non-academic student regulations. Major public racial incidents at each university involved whites' offending blacks. The incidents served as rallying points for student minority coalitions that supported adopting harassment policies. Other political factors included: faculty involvement, presidential and governing board involvement, and the strength of the student coalitions. DVH policy supporters argued for more welcoming and hospitable environments for minority students, free from intimidation and harassment. The policies (especially later in their development) became symbols of the universities' support for minority students. DVH policy opponents contended that the policies infringed on students' free speech rights, are vague and overbroad, and sacrifice the university's most important value: free thought and expression. Relevant First Amendment law is reviewed and discussed along with recent Court cases affecting DVH policies. 
Center for the Study of Higher Education

Educational Leadership and Policy Studies

Curry School of Education

University of Virginia

Charlottesville, Virginia

\section{APPROVAL OF THE DISSERTATION}

This dissertation, Free Speech and Racial Harassment: Policy Responses at Three Research Universities, has been approved by the Graduate Faculty of the Curry School of Education in partial fulfillment of the requirements for the degree of Doctor of Philosophy.

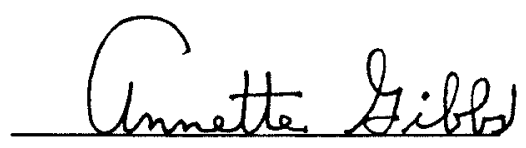

Name of Advisor

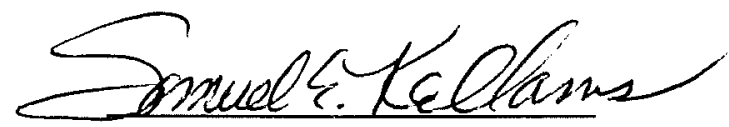

Committee Member

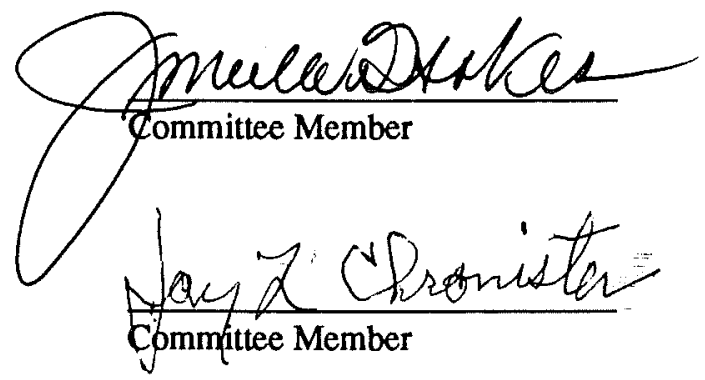

Mary (aThenus Ellutar

Committee Member

March 31, 1993 Date 


\section{Table of Contents}

$\underline{\text { Page }}$

Chapter One - Introduction to the Study 1

Purpose of the Study 2

Rationale for the Study 2

Research Questions $\quad 5$

Chapter Two - Review of Related Literature 6

$\begin{array}{ll}\text { I. Dynamics of Race on Campus } & 6\end{array}$

II. First Amendment Protection and Anti-Harassment Policies 12

$\begin{array}{ll}\text { Content-Based Restrictions } & 13\end{array}$

Content-Neutral Restrictions $\quad 22$

Analogy to Work-place Harassment 23

III. Critique of University Harassment Policies 24

University of Wisconsin $\quad 25$

Stanford University $\quad 28$

University of Virginia $\quad 32$

IV. Arguments for Freedom from Harassment 35

V. Arguments for Freedom of Speech 38

Collegiate Free Speech Act of 1991

VI. Freedom of Speech and Political Correctness (PC) 43

Historical Political Threats to Academic Freedom 44

Student Activism and Political Correctness $\quad 50$

Definitions of Political Correctness $\quad 53$

\section{Chapter Three - Research Methods 60}

$\begin{array}{ll}\text { I. Type of Study } & 60\end{array}$

$\begin{array}{ll}\text { II. Site Selection } & 60\end{array}$ 
$\begin{array}{ll}\text { III. Data Collection } & 62\end{array}$

$\begin{array}{ll}\text { IV. Interviews } & 63\end{array}$

V. Data Presentation 65

VI. Credibility of the Case Studies 66

$\begin{array}{ll}\text { VII. Limitations of the Study } & 69\end{array}$

$\begin{array}{ll}\text { VIII. The Researcher } & 72\end{array}$

\section{Chapter Four - The University of Wisconsin 74}

I. Historical, Structural, Organizational Factors and Conditions 74

Historical Factors and Conditions $\quad 74$

Structural Factors and Conditions $\quad 75$

The University of Wisconsin System $\quad 75$

The University of Wisconsin Madison $\quad 77$

Organizational Factors and Conditions $\quad 79$

Administrative Process - Adopting Nonacademic Regulations 79

Key Personnel in the Development of the Policy 80

II. Racial Climate Prior to the Adoption of UWS-17 81

Major Public Incidents 83

Anonymous Racial Incidents and Other Race-related Circumstances $\quad 91$

Recruitment and Retention 95

Students Behaviors, Values and Attitudes 102

Ethnic Minority Students' Perspectives on Race Relations $\quad 102$

White Students' Perspectives on Race Relations 106

$\begin{array}{ll}\text { III. Political Factors and Conditions } & 108\end{array}$

$\begin{array}{ll}\text { Political Activities } & 109\end{array}$

Reports and Institutional Self-Studies $\quad 112$

$\begin{array}{ll}\text { IV. Discussion and Development of UWS-17.06 } & 117\end{array}$

Impetus for the UWS-17.06 Debate $\quad 117$

Progression of UWS $17.06 \quad 118$

Supporters of UWS 17.06 and Their Reasons for Support 134

Opponents of UWS 17.06 and Their Reasons for Opposition 138

V. Conditions Following the Adoption of UWS-17 141

Racial Relations After September 1, 1989 
Application of UWS 17.06

Effects of UWS 17.06 on Faculty and Students' Academic Behavior $\quad 153$

The Second Revision of UWS $17.06 \quad 155$

$\begin{array}{ll}\text { Conclusion } & 158\end{array}$

\section{$\begin{array}{ll}\text { Chapter Five - Stanford University } & 160\end{array}$}

I. Historical, Structural, Organizational Factors and Conditions $\quad 160$

Historical Factors and Conditions $\quad 160$

$\begin{array}{ll}\text { Structural Factors and Conditions } & 163\end{array}$

Organizational Factors and Conditions 165

Administrative Process for Adopting Non-Academic Regulations 165

Key Personnel in the Fundamental Standard Interpretation Development 167

II. Racial Climate Prior to the Adoption of the Fundamental Standard Interpretation 169

$\begin{array}{ll}\text { Major Public Incidents } & 172\end{array}$

Anonymous Racial Incidents and Other Bias-Related Circumstances $\quad 184$

Recruitment and Retention $\quad 186$

$\begin{array}{lr}\text { Students' Behaviors, Values, and Perspectives } & 188\end{array}$

Ethnic Minority Students' Perpectives on Race Relations 188

White Students' Perspectives on Race Relations 191

III. Political Factors and Conditions 193

$\begin{array}{ll}\text { Political Activities } & 195\end{array}$

Reports and Institutional Self-Studies 198

IV. Discussion and Development of the Fundamental Standard Interpretation 202

Progression of the Fundamental Standard Interpretation 202

Supporters of the Fundamental Standard Interpretation 211

Opponents of the Fundamental Standard Interpretation 216

V. Conditions Following the Adoption of the Fundamental Standard Interpretation 222

Racial Relations After June 11, $1990 \quad 223$

Application of the Fundamental Standard Interpretation 227

Effects of the Fundamental Standard Interpretation on Academic Behavior 228

$\begin{array}{ll}\text { Conclusion } & 231\end{array}$ 


\section{Chapter Six - The University of Virginia}

I. Historical, Structural, Organizational Factors and Conditions 233

Historical Factors and Conditions $\quad 234$

Structural Factors and Conditions 239

Organizational Factors and Conditions 241

Administrative Process - Adopting Non-Academic Regulations 241

Key Personnel in the Development of a 13th Standard 243

II. Racial Climate Prior to the Decision to Reject a 13th Standard of Conduct 245

Major Public Incidents 247

Anonymous Racial Incidents and Other Race-Related Circumstances $\quad 258$

Recruitment and Retention $\quad 262$

Students' Behaviors, Values, and Perspectives 263

Ethnic Minority Students' Perspectives on Race Relations 263

White Students' Perspectives on Race Relations 267

$\begin{array}{ll}\text { III. Political Factors and Conditions } & 268\end{array}$

$\begin{array}{ll}\text { Political Activities } & 272\end{array}$

Reports and Institutional Self-Studies $\quad 273$

IV. Discussion and Development of the Proposed 13th Standard 275

Progression of the 13th Standard 275

Supporters of the 13th Standard and Their Reasons for Support 283

Opponents of the 13th Standard and Their Reasons for Opposition 284

V. Conditions Following the Rejection of a 13th Standard of Conduct 286

Racial Relations After November, $1990 \quad 286$

Application of the Standards of Conduct 292

Conclusion 293

\section{Chapter Seven - Summary and Conclusions 298}

I. Historical, Structural, and Organizational Factors and Conditions 298

Public and Private Institutions $\quad 299$

Existing Student Conduct Codes $\quad 300$

$\begin{array}{ll}\text { Campus Traditions and Values } & 301\end{array}$

Procedures for Adopting Non-Academic Regulations 303

II. Racial Climate Prior to the Discriminatory Verbal Harassment Policy Decision 305

Characteristics of Public Racial Incidents 305

Recruitment and Retention 307 
$\begin{array}{ll}\text { III. Political Factors and Conditions } & 308\end{array}$

Minority Student Coalitions $\quad 308$

Level of Faculty Involvement $\quad 309$

Level of Involvement Among Governing Boards and Presidents $\quad 310$

IV. Discussion and Development of a Policy on Discriminatory Verbal Harassment 311

V. Conditions Following the Discriminatory Verbal Harassment Policy Decision 313

Racial Relations $\quad 313$

Policy Application $\quad 314$

Student Self-Censorship $\quad 315$

$\begin{array}{lll}\text { VI. Conclusion } & 316\end{array}$

$\begin{array}{ll}\text { Policy Options } & 317\end{array}$

$\begin{array}{ll}\text { The Future } & 319\end{array}$

$\begin{array}{ll}\text { Bibliography } & 321\end{array}$

$\begin{array}{ll}\text { Legal Citations } & 337\end{array}$

References With No Author(s) Listed 339

\section{Appedices}

$\begin{array}{lll}\text { Appendix A } & \text { Interview Questions } & 342\end{array}$

$\begin{array}{lll}\text { Appendix B } & \text { Interview Verification Form } & 344\end{array}$

Appendix C University of Wisconsin Policy 345

$\begin{array}{lll}\text { Appendix D } & \text { Stanford University Policy } & 346\end{array}$

Appendix E University of Virginia Policy 347

Appendix F Collegiate Free Speech Act of 1991

Appendix G Cartoon Samples $\quad 350$ 


\section{To Roni, for her kind support and enduring patience.}

I am very grateful for the support, advice, encouragement (and occasional prodding), and good humor of Annette Gibbs, who served as my advisor throughout the Ph.D. degree process.

I give special thanks for their advice on drafts of this document to members of my dissertation committee: Sam Kellams, Mary Catherine Ellwein, Jerry Stokes, and Jay Chronister. Thanks also to the following persons who reviewed drafts of individual chapters or related documents: Michael Boyd, Karen Dowd, Robert O'Neil, Patricia Hodulik, Mary Rouse, Sally Cole, Jim Lyons, Ernie Ern, Bob Canevari, and Reggie Aggarwal.

With gratitude for financial, personal, or logistical support in completing this research I would like to thank John Casteen, Robert O'Neil, Leonard Sandridge, Ernie Ern, Chip German, Jay Lemons, Colette Capone, Tammy Wilkins, Tammy Evans, Linda Burkhead, Barbara Reid, Kristin Foss, Palmer Soderburg, Tom Truesdell, Sally Cole, and Pat Hodulik.

As with any research that relies on interview data, this research would not have been possible without the participation of many individuals. I offer my thanks to the many students, administrators and faculty members who talked with me about their experiences and perceptions of race relations, free expression, civility, and other important matters. Most of these individuals took time to review and return copies of their interview transcripts, for which I am also grateful. Thanks to Stanford University, the University of Virginia, and the University of Wisconsin for the cooperation and assistance I received on this project at each campus. 


\section{Chapter 1}

\section{Introduction}

In the mid-1980s a series of well-publicized incidents involving students' race, gender, creed, and national origin occurred at American colleges and universities. By the late-1980s the situation had grown in frequency and severity. Some examples of these racial incidents include:

- A fraternity sponsored an "ugly woman contest" during which fraternity members appeared in blackface ${ }^{1}$,

- Racial jokes told on the air at a campus radio station2,

- Flyers distributed to black students stating, "The Knights of the Ku Klux Klan are Watching you"3

- Fraternity brothers painted "KKK" and "we hate niggers" on the nude bodies of two white pledges and dumped them at the nearby predominantly black campus of Rust College. 4

- Students walk into a classroom to find the phrase, "A mind is a terrible thing to waste, especially on a nigger," written on the blackboard. 5

The National Institute Against Prejudice and Violence identified approximately 250 campuses at which acts of racial hatred occurred from 1986-1989 alone. ${ }^{6}$ In its recent report on campus life, the Carnegie Foundation for the Advancement of Teaching reported that more than half of the presidents surveyed at

$1 \mathrm{M}$. Collison. "Judge cites First-Amendment protection in overturning suspension of fraternity," The Chronicle of Higher Education. September 4, 1991, at A45-46.

2Weiner, "Racial Hatred on Campus," Nation, Feb. 27, 1989, at 260.

${ }^{3}$ Klanwatch Intelligence Report No. 42 , February 1988.

${ }^{4}$ N. Gibbs, "Bigots in the Ivory Tower," Time, May 7, 1990, at 104-106.

5Hundley, "Black Students Take Action," Chicago Tribune, April 23, 1989, Section 1 at 4 .

${ }^{6} \mathrm{H}$. Ehrlich. Campus Ethnoviolence and the Policy Options, Baltimore (MD): National Institute Against Prejudice and Violence, April 1990. 
doctoral and research institutions indicated that racial intimidation and harassment was a problem.7

\section{Purpose of the Study}

The purpose of this research was to describe the deliberative processes regarding discriminatory verbal harassment policies at each institution; to determine what outcomes, if any, have resulted from the enactment (or rejection) of such policies; and to determine the extent to which policies regulating discriminatory verbal harassment have been effective in enhancing civility among persons of different races at three Research I Universities; ${ }^{8}$. This examination provides educators with information regarding the advantages and disadvantages of anti-harassment policies, the opinions of various constituents in the decision-making process, and information about the changes resulting from the implementation of the universities' policy decisions at each institution.

\section{Rationale for the Study}

In response to deteriorating inter-racial relations and increasing numbers of incidents of racial intolerance some campuses enacted policies which restrict racial expression (and negative expression toward other protected groups) among members of the campus community. The policies emerged in several different forms, but their purpose was to create an environment in which students were protected from harassing speech and behavior directed toward them because of their race, gender, national origin, handicap status, age, or other immutable characteristics. The effectiveness of anti-harassment policies in attenuating these problems should be of concem to those who have adopted such policies, to those who are considering the adoption of similar policies, and to those interested in reducing racial tension on campus. Some antiharassment policies have been in place for more than four years and little was known about the impact of the policies on the relationships among races or on the behaviors of students and faculty members in

${ }^{7}$ Carnegie Foundation for the Advancement of Teaching. "Campus Life: In Search of Community," (1990) at 18.

${ }^{8}$ The universities chosen for the research were the University of Wisconsin, Stanford University, and the University of Virginia. Chapter Three explains the rationale for these choices. 
response to the policies. This study focuses on three institutions that debated the issue of discriminatory verbal harassment policies and reached three different conclusions about the best approach to take on this particular approach to promoting campus civility.

The policies' supporters argued that students would be able to concentrate better on their academic pursuits free from harassment, and that despite colleges' best educational efforts, racism and discrimination continued to persist on campus. Proponents of policies regulating discriminatory verbal harassment also argued that the policy embodied a statement of values that institutions should adopt to show their commitment to eliminating racism and promoting equality among races, and that racially harassing expression is in no way a step toward the discovery of truth and therefore is not critical to academic freedom.

Opponents of discriminatory verbal harassment policies held freedom of expression and academic freedom as fundamental rights of individuals and argued that freedom of expression should not be restricted because of unpleasant or unpopular content. Opponents' were concerned with the reach of censorship in academe and the danger to higher education and society of policies which limit free and open debate. They argued further that academic freedom is an attribute of higher education which makes it unique in American society and therefore deserves great protection. Civil libertarians argued that enforced silence on issues is not an acceptable way to resolve the problems associated with it and that one of the ways colleges can meet their goal of eliminating racial harassment is through the creation of opportunities for even more dialogue about such difficult problems. In other words, one of universities' obligations could be perceived of as correcting the negative notions about members of other races brought to the community by some of its members and that to identify these notions universities should allow all ideas to be expressed so that erroneous ideas can be identified and the misinformed and uninformed be educated.

Discriminatory verbal harassment policies were adapted to the needs of particular campuses and were based on legal precedent. Some policies restricted a narrow class of speech -- likely to lead the "average" addressee to fight -- which falls into the class of "fighting words." Policies that prohibit fighting words restrict face to face communications directed at an individual or small group of individuals which, when applied, protect persons from the most outrageous forms of racism on campus, such as racial 
taunting, or racial epithets and invectives. Other policies restrict speech that intentionally creates or could reasonably have been foreseen to create an "intimidating, hostile, or demeaning environment " for education or university-related work. Another group of policies written to restrict racial harassment defined racial behaviors as outrageous acts intended to intimidate or humiliate students on account of race and that reasonably cause them to suffer "severe emotional distress."

Each type of anti-harassment policy has particular implications for the type of cases brought to the adjudication process and for the criteria used to judge persons charged under the policy. Unique circumstances at many universities led to the adoption or rejection of campus-specific anti-harassment policies, and these specific conditions can be important to the outcomes of the policy. What the campus community valued in the policy's formation may influence the perceptions community members have about the policy's effectiveness and the initial values may influence the reach of the policy. Adopting antiharassment policies forces the institution to make a decision about restricting the content of expression and to balance the rights of its students and employees to an environment free from harassment and their right to unfettered discussion about issues which include topics of race, gender, sexual orientation, or other potentially controversial issues. Restricting speech becomes especially problematic when professors and students are hindered or discouraged from discussing social and political issues and when academics are prevented from pursuing controversial research questions for fear of reprisal.

Achieving an environment which preserves the individual's rights to both freedom of expression and freedom from harassment is of value to students, faculty, and administrators. The societal issues underpinning the harassment of students and employees are similar and the arguments advanced to protect students' academic endeavors can be supported on the same grounds as those which protect academic-related work. The adoption and implementation of discriminatory verbal harassment policies serve as one approach to address the problems of racism and deteriorating campus community.

Literature in this area has focussed on the legality of the policies and the potential outcomes of adopting or rejecting anti-harassment policies. This study was completed to 1) describe the conditions that led to DVH policies; 2) describe the relationships among an anti-harassment policy, campus community relations and academic freedom; and 3) describe campus racial conditions related to specific policies. 
Specific research questions addressed in this report are listed below.

\section{Research Questions}

1. What considerations and events preceded the adoption or rejection of a policy on discriminatory verbal harassment at each of the three institutions included in this study?

a. What organizational, political, structural, or historical conditions existed at each site that affected the deliberation of , or the outcomes of the institutional policy decision regarding racial harassment?

b. What specific events were important in the decision to adopt or reject the policy?

c. Why was one legal precedent selected over another (i.e., "fighting words" instead of "intentional infliction of severe emotional distress")?

d. What evidence is available to substantiate the quality of the inter-racial relations among students, faculty, and staff prior to the decision to adopt or reject the policy?

e. Who supported the policy and why did they support it?

f. Who opposed the policy and why did they oppose it?

2. What outcomes resulted from the decision to adopt or not adopt a policy regulating discriminatory verbal harassment?

a. What is the perception of the quality of inter-racial relations among students, faculty, and staff after the adoption or rejection of the policy?

b. What issues have been important in the adjudication of persons charged with harassment?

c. What impact, if any, has the policy had on the academic behavior of faculty and students?

d. Have the policies contributed to ameliorating racial relations on campus?

e. What events or processes occurred after the policy took effect that affected civility and served to lessen racial tension?

f. What other changes on campus can be attributed, at least in part, to the implementation of a policy regulating discriminatory verbal harassment? 


\section{Chapter Two}

\section{Review of Related Literature}

This section begins by describing the dynamics of race relations on college and university campuses. Next, it presents the First Amendment and other legal issues associated with campus discriminatory verbal harassment (DVH) policies. It then critiques the policies proposed (and in two cases, promulgated) at each of the three universities in this research, and details the arguments both for and against college harassment codes. Finally, this chapter describes the historical and current perceived threats to free expression at universities, including the "political correctness" controversy of the late 1980s and early 1990s.

\section{Dynamics of Race on Campus}

In a recent report, the Carnegie Foundation for the Advancement of Teaching concludes that "deeply rooted prejudices not only persist, but appear to be increasing"l on college campuses across the nation. Racial tension on some campuses have provoked a new wave of student separatism, while at other campuses it has become a crisis. The report indicates that problems of racial strife were most noticeable at large doctoral and research institutions; more than half of the presidents surveyed indicated that racial intimidation and harassment was a problem. ${ }^{2}$

The Carnegie Foundation's conclusions are substantiated by recent campus events. Since 1986, more than 250 American campuses have reported incidents of harassment and violence against persons

1 The Carnegie Foundation for the Advancement of Teaching, "Campus Life: In Search of Community," 1990, at 2, 17-23. The main goal of the report was to "clarify both academic and civic standards, and above all, to define with some precision the enduring values that undergird a community of learning." The report outlines six principles which are proposed as working ideals for any college or university community. The report calls for higher education communities to be "purposeful," "open," "just," "disciplined," "caring," and "celebrative." 
because of their race, religion, ethnicity, or sexual orientation. ${ }^{3}$ One reported difference between recent racial conflicts and conflicts from decades earlier is that disputes among persons of different ethnic backgrounds today take on overtones of race even when the dispute is not originally perceived as racially motivated. 4 Another feature of recent conflicts is that the way administrators have handled the conflicts has provoked as much dissent and protest as the incidents themselves. 5

The list of incidents of racially motivated acts reportedly has grown, and the institutions involved are often the most sought-after institutions in America: Dartmouth College, Williams College, Harvard University Business School, University of Michigan, Swarthmore and other institutions have reported incidents of racial harassment or intimidation. ${ }^{6}$ Virginia Tech disciplined an all-white fraternity for an incident at Kenyon College in which the Virginia Tech fratemity required its pledges to take pictures of themselves kissing black women. ${ }^{7}$ Members of a Pennsylvania State University fraternity held a Rosh Hashanah party to mock the Jewish New Year and "celebrated" by decorating their house with Stars of David and giving guests name tags with stereotypical Jewish names. ${ }^{8}$ Members of a University of Mississippi fraternity wrote "KKK" and "We Hate Niggers" on two nude pledge's bodies and then left them

${ }^{3} \mathrm{H}$. Ehrlich, Campus Ethnoviolence and the Policy Options, Baltimore (MD): National Institute Against Prejudice and Violence, April 1990, at iii.

${ }^{4}$ D. Manger, "Racial Tensions Continue to Erupt on Campuses Despite Efforts to Promote Cultural Diversity," The Chronicle of Higher Education, June 6, 1990, at A1.

$5 / d$.

6Public Broadcasting Stations (PBS) Videocassette Service, Alexandria, Virginia, Frontline: "Racism 101," (FRON 612K, 1987). This documentary provides detailed interviews and information about the practices of the Dartmouth Review (a publication of conservative views run by Dartmouth students but not funded by Dartmouth College) and the tensions at The University of Michigan which led to the creation of U.M.'s first anti-harassment policy statement.

7No author. Chronicle of Higher Education, December 6, 1989, at A2.

${ }^{8} \mathrm{C}$. Leatherman. "More Anti-Semitism Is Being Reported on Campuses, but Educators Disagree on How to Respond to It," Chronicle of Higher Education, February 7, 1990 at A1, 40. 
at a predominantly black college campus nearby ${ }^{9}$ At Arizona State University, some fraternity members shouted "nigger" and "porch monkey" at three passing black students who were mistaken for persons involved in an earlier dispute with one of the fraternity members. ${ }^{10}$ This partial list is representative of hundreds of complaints of racially motivated attacks that have occurred at all types of colleges and in every geographic region of the country.

These acts represent only the most obvious forms of intentional acts of racism on American campuses. Other more subtle forms of racism often go unnoticed by white students, but are plainly obvious to minority students. Injury can result from unintentional, unconscious racism, and from the unavoidable clashes of values and perspectives among racial groups. 11 When only the outrageous forms of racism are acknowledged by the university majority community, minority students may conclude that the injury they experience from unconscious racism is ignored by the majority community, and such a reaction can exacerbate their discomfort in the classroom, in the residence hall, on the playing field, and in interpersonal interactions.

Racism is a troublesome subject, and it is a particularly difficult issue among blacks and whites in this country. The prevailing definition of racism among whites has been described as the "perpetrator perspective," in which

racial discrimination [is seen] as something that is caused by individuals, or individual institutions, producing discrete results that can be identified as discrimination and thereafter neutralized....The perpetrator perspective presupposes that apart from the misguided conduct of particular actors the rest of our society is working... All we need to do is root out the villains. Having done so, we can say with confidence that it was all their fault. 12

9N. Gibbs. "Bigots in the Ivory Tower," Time, May 7, 1990, at 104.

10L. Gordon. "Race Relafions and Attitudes at Arizona State University," in The Racial Crisis in American Higher Education (P. Altbach and K. Lomotey, eds.) Albany: SUNY Press, 1991, at 234.

11D. Brown, "Racism and Race Relations in the University," Virginia Law Review, Vol. 76,1990 , at 300 .

12P. Freeman, "School Desegregation Law: Promise, Contradiction, Rationalization," in Shades of Brown: New Perspectives on School Desegregation 31 (D. Bell, ed. 1980), noted in D. Brown, Id. at 308-9. 
This definition can be applied in the obvious cases of racial insult on campus, but it falls short from the victim's perspective. Another point of controversy is the perspective from which racist acts are defined. The attitudes of the white majority serve as the norm for understanding and interpreting racist acts, but because blacks have a different social, educational and economic history in this country their interpretations of the same acts often will differ. Nevertheless, the majority has a stronger hand in shaping the basis for understanding and responding to racism. ${ }^{13}$ For example, black students may perceive overt racist acts to be connected to one another, while white students tend to view such acts as discreet events perpetrated by fringeradicals who do not represent the attitudes of the vast majority of students. ${ }^{14}$ Law Professor Mari Matsuda argued that racism is acted out both through covert disparate treatment and unconscious racist statements, and through obvious disparate treatment, racial hate expression, and violence and genocide. Matsuda claims that

[f]rom the victim's perspective, all of these implements inflict wounds, wounds that are neither random nor isolated. Gutter racism, parlor racism, corporate racism, and government racism work in coordination, reinforcing existing conditions of domination. Less egregious forms of racism degenerate easily into more serious forms. 15

Racially motivated behaviors are perhaps even more disturbing in the collegiate environment because American society holds higher education responsible for maintaining the highest ideals of reason, decorum, and civility in pursuit of the scholarly enterprise. When those ideals seem threatened, colleges and universities are called to respond. However, universities are large, slow-moving objects that resist change, serve multiple constituencies, and react more quickly to external change factors than internal ones. This assessment of campus racism acknowledges that certain attitudes and behaviors impede academia's lofty

${ }^{13} \mathrm{D}$. Brown, /d. at 306.

14Public Broadcasting Stations video, supra note 6. See also M. Matsuda, "Public Response to Racist Speech: Considering the Victim's Story," Michigan Law Review, Vol. 87, 1989 at 2327: "The typical reaction of non-target-group members is to consider the incidents isolated pranks, the product of sick-but-harmless minds. This in part a defensive reaction: a refusal to believe that real people, people just like us, are racists. This disassociation leads logically to the claim that there is no institutional or state responsibility to respond to the incident. It is not the kind of real and pervasive threat that requires the state's power to quell." Matsuda also lists over 30 racists incidents in the late 1980 s at universities across America, at 2333.

15M. Matsuda, /d. at 2332, 2335 
goals and are perpetuated by a variety of factors.

An understanding of the nature and effects of racist expression is an important prerequisite to a discussion of racial harassment policies. In order to demonstrate the need for a harassment policy, a campus group usually must show that its members experience racial discrimination. The campus community then weighs the potential harm to members of the community if racist expression is allowed to persist. A discussion of the nature and impacts of race-based expression is presented in the remainder of this section.

Racial insults have the potential for great harm because they rest solely on the unalterable fact of skin color and, in the case of Black Americans, rely on the historical facts of slavery and race discrimination in America. Racism is a belief in the genetic superiority of the traits of one race over another, and the discriminatory behaviors which promote this belief are said to be racist. As noted earlier, racist behaviors may result from a conscious decision to discriminate against a particular race, or from unconscious attitudes and beliefs which influence one's behavior toward members of another race. Racial insults are intentional acts that present an affront to a person's dignity and his right to be treated with respect.16

Mental and emotional distress are among the most extreme harms caused by racial insults. As an adaptive measure, for example, some minority students may feel it necessary to avoid certain social situations, avoid reading certain publications, and remain reticent in class discussions in order to avoid being confronted with racist expression. Some reports indicate that minority students are choosing colleges where they are likely not to have to face the unpleasantness of racism. ${ }^{17}$

Another way minority students have reacted to the increase in racist expression on university

16R. Delgado, "Words That Wound: A Tort Action for Racial Insults, Epithets, and NameCalling," Vol. 17, Harvard Civil Rights \& Civil Liberties Law Review, 1982, at 143, 145. Delgado argues that racism and race-labeling has a more profound impact on children, at 147 . "Minority children possess even fewer means for coping with racial insults than do adults... The child who is the victim of belittlement can react with only two unsuccessful strategies, hostility or passivity. Aggressive reactions can lead to consequences which reinforce the harm caused by the insults; children who behave aggressively in school are marked by their teachers as troublemakers, adding to the children's alienation and sense of rejection. Seemingly passive reactions have no better results; children who are passive toward their insulters turn the aggressive response on themselves; robbed of confidence and motivation, these children withdraw into moroseness, fantasy, and fear."

${ }^{17 C}$. Finn, Jr., "Why Can't Colleges Convey Our Diverse Culture's Unifying Themes?" The Chronicle of Higher Education, June 13, 1990, at A40. 
campuses is to attempt to promote pride and dignity among members of their group. In addition, some students have begun to challenge the status quo by demanding changes in faculty racial composition and in traditional curricular requirements, 18 and by pursuing a more central position in the decisions of the university. For example, some black students have questioned the lack of support from the white faculty, administration and others at their institutions. ${ }^{19}$.

If one acknowledges that speech can perform effectively a variety of positive functions such as advancing the American political process and promoting autonomy through self-expression, then it follows that speech in the form of racial insults can also be effective in wounding the targets of such speech. Richard Delgado contends that the victims of racial insult are informed that their dignity, self-worth, merit, and status are a function of their race. 20 In the university environment, minority students often live in communities in which speech receives vigorous protection and where they experience subtle and/or overt racism. Their personal and cultural histories may predispose them to be more keenly aware of the presence of racism at the university. The result of this experience is that many perceive the environment to be less welcoming toward them than their white peers. According to D. Brown, to the extent that racism persists on campus, either in the classroom or the rest room, minority students "are deprived of the opportunity to

18M. Collison, "Fight the Power: Rap Music Pounds Out a New Anthem for Many Black Students," The Chronicle of Higher Education, February 14, 1990, at A1, 29. A popular rap music group, "Public Enemy," wrote a song which is said to exemplify an emerging attitude among black students; the key lyrics are "Fight the power, you've got to fight the powers that be." The phrase, 'powers that be,' refers to the leadership and supporters of predominantly white institutions and other institutions which are prejudiced or complacent in their treatment of blacks.

19 See A. Wilburn, "In the Heart," The Cavalier Daily, University of Virginia, November 13,1990 , at 3; "It is hard for me to believe that I, an Afro-American student, am welcomed here; but I have my rights and the administration has its games....there are barriers within the Engineering School, the Commerce School and other areas of the University that subtly voice, "preferably white." The American educational system has ignored a majority of our race's contributions and achievements. In addition, it has misconstrued concepts of our culture." Also see M. Combs, "A Separate Pride," The Virginia Advocate, November, 1990, at 8, 16; in which the chairman of the Black Student Alliance (BSA) "outlined the goals of the BSA as a "fight" against the University community...the BSA will be there "to fight for you," the Black students, because the "University is not yet supportive of our survival as a people." Also see V. Martin, "Ignorance Exemplified by Racist Sign," The Cavalier Daily, University of Virginia, November 6, 1990, at 2. 
receive an education in an environment free of harassment, hurt, and humiliation."21

Yet colleges and universities have responded in a variety of ways to continued overt racist behavior. Typically, university administrators are quick to denounce publicly blatant acts of racism. Educational programming occurs in residence halls and student unions to provide forums for students to voice their responses to the acts and to help students understand and cope with racist acts. Many colleges either have or are considering additional curricular requirements which specify a range of class choices for students in religion, history, sociology, or other disciplines taught from other than the Eurocentric tradition. When institutions can identify a perpetrator of a racist act, administrators generally discipline students through existing disciplinary codes. When those codes were found deficient, some institutions developed policies and procedures designed specifically to address racial harassment. The constitutionality and the application of theses policies are discussed in the following sections.

\section{First Amendment Protection and Anti-Harassment Policies}

The anti-harassment policies in force at many universities seek to prohibit expression which communicates messages of hatred or violence toward individuals or groups based on their race, gender, ethnicity, religion, physical handicap, and/or sexual orientation. These particular messages are determined by the institution to prevent students from completing their academic work and participating fully in campus life. Supporters of DVH policies believe that expression intended to demean, degrade, or stigmatize can create a hostile educational environment so that the educational goals of the institution are not realized. But such policies may threaten the exercise of free expression because they are clearly content-based. The following discussion traces the boundaries of the First Amendment as they relate generally to higher education and specifically to DVH policies.

21See Brown, supra note 11 at 323. "Black students attend class (and take exams) often having just confronted offensive reminders of either overt racial hostility or subtle racial insensitivity--perhaps in the campus newspaper, on posters at the bus stop, the structure of classroom discussion--that serve as distractions from academic performance that White students do not endure." See also K. Bonner, "Two Students Discover Derogatory, Racist Sign," The Cavalier Daily, University of Virginia, November 6, 1990, at 1; Students discovered a professionally produced sign on which was printed, "Welcome to Virginia Our Peanuts are Bigger \& Our Governor is a Nigger." 


\section{Content-Based Restrictions}

The U.S. courts have historically been unwilling to impose content-based restrictions on speech, and thus have done so only where the speech in question is particularly incendiary. Justice Holmes first argued in Schenck $v$. United States that " $[\mathrm{t}]$ he question in every case is whether the words used are used in such circumstances and are of such a nature as to create a clear and present danger that they will bring about the substantive evils that Congress has a right to prevent. It is a question of proximity and degree." 22 The 'clear and present danger' dictum was developed during wartime and was concerned with the obstruction or overthrow of the government. It was kept alive through a series of dissents until the court adopted it in 1927.23 More than twenty years later the Court confronted the problems of communism in American society, which was perceived to be a greater threat than the espionage cases from World War I. The 'clear and present danger' test was rejected in 1951 in favor of one in which the court determines "whether the gravity of the 'evil' discounted by its improbability, justifies such invasion of free speech as is necessary to avoid the danger."24 This balancing test relies on the benevolence of those who administer the law, it removes the temporal connections of the "present," and it affords less protection to ideas that the Government finds threatening.

These cases formed the base for the Court's landmark decision in Brandenburg v. Ohio, 25 in which members of the Ku Klux Klan (KKK) successfully challenged an Ohio statute which prohibited the use of terrorism to effect change and prohibited associations with persons who advocated or taught criminal

22Schenck v. United States. 249 U.S. 47 (1919).

23 Whitney v. California 274 U.S. 357 (1927).

${ }^{24}$ Dennis v. United States, 341 U.S. 494 (1951). Court assumes that overthrow of the government is a substantial enough interest for Government intervention and that since the goal of communism is to overthrow the U.S. government, then the existence of the conspiracy in its early stages creates a danger sufficient to subject such speech to regulation. Justice Douglas argued against killing the conspiracy in its infancy and that 'clear and present danger' should apply to communism. 
syndicalism. Relying on Dennis v. United States, the Court stated, the constitution did not allow a State to forbid or limit advocacy of force or of law violation "except where such advocacy is directed to inciting or producing imminent lawless action and is likely to incite or produce such action."26 This test is protective of speech and incorporates the ideas of the proximity and the degree of danger of speech with a measure of the words actually used.

Situations on campus which could require an application of the Brandenburg formulation are those which involve demonstrations and controversial speakers. Suppose the president of the White Student Union at the University of Florida ${ }^{27}$ invited a nationally known member of the KKK to speak at an open meeting of the organization. Under Brandenburg, speakers could say whatever they wanted so long as they did not intentionally incite or produce imminent lawless action; one could even advocate imminent lawless action so long as the speech was not likely to produce the action. One problem with this case is that the legal test applied does not distinguish clearly between the speaker whose aim is to incite lawless behavior and the speaker who makes abstract statements concerning his or her personal beliefs. The test relies heavily on the reaction of the listeners to determine both the intent of the speech and the likelihood of producing action. Another problem is that a speaker who advocates white supremacy is likely to attract a hostile crowd. 28 When the Court determines whether the speech was an incitement based on the crowd's reaction after the fact, dissenters in the crowd are encouraged to behave in such a way to make lawless

\section{$26 / d$}

27R. Wilson, "New White-Student Unions on Some Campuses Are Sparking Outrage and Worry," The Chronicle of Higher Education, April 18, 1990, at A1, 36. Temple University (Philadelphia) was the only other institution formally recognizing a white student organization; however, several other institutions (predominantly in the Southeast U.S.) had active groups. Some formed in reaction to their perceived exclusion, because they are white, from internship and scholarship programs. The groups fueled the debate about whether they should be able to say and do things deeply offensive to their classmates.

28This statement also applies to other student groups who sponsor controversial speakers. See K. Liu, "Muhammad Speech Deters Progress," The Cavalier Daily, November 20, 1990, at 3; Alim Muhammed, national spokesperson for Louis Farrakan, spoke at the invitation of the Black Muslims at the University and provoked emotionally charged responses from his views on Black nationalism and separatism. There were no reports of violence from this speech. 
behavior imminent so that the speaker is forced to stop speaking. ${ }^{29}$ The main advantage of the test is that it allows speakers great latitude to comment on matters of race, politics, or other matters of interest, and it allows the university community to hear a variety of opinions and engage in debate about the value of those opinions.

Another area of speech which relies on the breach of the peace standard was set apart by the Court in its definition of "fighting words." 30 The Court defined a class of speech whose proscription was not thought to raise constitutional questions; this includes "the lewd and obscene, the profane, the libelous, and the insulting or "fighting" words--those which by their very utterance inflict injury or tend to incite an immediate breach of the peace." 31 In Chaplinsky, the Court did not rely on the victim's definition of fighting words because this would have given the recipient of the remarks the latitude to define the words which lead to a fight. A speaker may not know what words would offend the listener and it may inhibit the speech of those who would test this limit. As with the Brandenburg approach, fighting words defined from the hearer's perspective also invite a hostile response--if the target does not like the speech, the best way to stop it is to start a fight and claim that the speech provoked the reaction.

At least three issues of unclear terminology are present in the Court's elaboration of the fighting words test. 32 First, the Court referred to the fictitious "average addressee" and not to the actual addressee in its definition of the standard. This suggests some objectivity in defining the level of speech which is determined reasonably to provoke a violent reaction when it is spoken. It also implies that the complete

29This practice generally is known as the "heckler's veto."

30 Chaplinsky v. New Hampshire, 315 U.S. 568 (1942).

31/d. at 572. The Court further explained the test to be "what men of common intelligence would understand would be words likely to cause an average addressee to fight... The English language has a number of words and expressions which by general consent are 'fighting words' when said without a disarming smile.... The statute, as construed, does no more than prohibit the face-to-face words plainly likely to cause a breach of the peace by the addressee, words whose speaking constitutes a breach of the peace by the speaker--including 'classical fighting words', words in current use less 'classical' but equally likely to cause violence, and other disorderly words, including profanity, obscenity, and threats." 
context in which the speaker finds himself should be considered. That is, the average addressee may refer to someone of the same gender, race, religion, or other protected class as the actual addressee. Second, the Court suggests that the speaker should know what words fall under the rubric of fighting words if the speaker is a person of "common intelligence." It remains unclear what protection would be afforded persons of uncommon intelligence, either bright or dim. Third, the Court assumed that the words it described are known by general consent and that when the words are said "without a disarming smile" they are known to lead to violence. Proponents of anti-harassment policies may argue that even with a "disarming smile" the wounds of the words leave the victims no less scarred.

Several university discriminatory harassment policies base restrictions on the 'fighting words' test. The reliance is based, in part, on language in the case of Doe v. University of Michigan ${ }^{33}$ in which the District Court said of fighting words that "[u]nder certain circumstances racial and ethnic epithets, slurs, and insults might fall within this description and could constitutionally be prohibited by the University. In addition, such speech may also be sufficient to state a claim for common law intentional infliction of emotional distress." 34

The Court has relegated certain categories of speech to a position of lower value in the hierarchy of First Amendment values and therefore does not entitle them to receive absolute constitutional protection. For example, the Court has upheld prohibitions on profanity broadcast over the public broadcast media ${ }^{35}$

${ }^{33}$ Doe v. University of Michigan. 721 F. Supp. 852 (E.D. Mich. 1989).

$34 / d$. at 862 . The precedent of tort law and the intentional infliction of emotional distress' recourse is another possible means of justifying anti-harassment policies. For a full treatment of the issues involved in this approach see R. Delgado supra note 16; see also J. Love, "Discriminatory Speech and the Tort of Intentional Infliction of Emotional Distress," Washington and Lee L. Review, Vol. 47, 1990, at 123; See also, R. Post infra note . For a policy statement incorporating this approach see The University of Texas at Austin, "Report of President's Committee on Racial Harassment," 1989, at 4-5. See also, M. Steger; "A cautious approach: racist speech and the First Amendment at the University of Texas," The Journal of Law and Politics, Spring 1992, at 609-648.

${ }^{35}$ F.C.C. V. Pacifica Foundation, 438 U.S. 726 (1978). The Court articulated an interest in protecting children from offensive speech and it suggested that profanity, like obscenity, is of lower speech value. 
and on sexually explicit speech at a high school assembly. ${ }^{36}$ In Cohen $v$. California 37 the Court distinguished offensive speech from fighting words by explaining that fighting words often contained offensive language but that they were always directed personally at the addressee, while offensive language was not limited to personal attacks. Those persons who may have been offended by the message on Cohen's T-shirt were advised to "avoid further bombardment of their sensibilities simply by averting their eyes,"38 but if Cohen's shirt bore the words of a racial epithet instead of a politically oriented expletive, it is unclear whether the advice of averting one's eyes would be sufficient. The case of Beauharnais $v$. Illinois ${ }^{39}$ is illustrative of a case of racist speech directed toward a group of people. The court was "precluded from saying that speech concededly punishable when immediately directed at individuals cannot be outlawed if directed at groups with whose position and esteem in society the affiliated individual may be inextricably involved."40 The Court suggested that Beauharnais resembled cases of libel.

The lesson of Cohen for the realm of higher education is that a public university cannot limit speech on its campus simply because it does not agree with the message of the speaker(s) or because it finds the message offensive. Content-based restrictions, especially in the area of political speech, continue to be subjected to strict scrutiny. In a 1989 flag-burning case the U.S. Supreme Court held, "If there is a bedrock principle underlying the First Amendment, it is that the Government may not prohibit the expression of an

${ }^{36}$ Bethel School District No. 403 v. Fraser, 478 U.S. 675 (1986). The Court noted that the content of the student's speech was inconsistent with the mission of the public school, distinguishing this case as one of less value than cases involving student political speech.

37 Cohen v. California. 403 U.S. 15 (1971). Cohen wore a t-shirt in a California courthouse which bore the words "fuck the draft" which he argued (successfully) was in protest of the Viet Nam war. The outcome indicated that offensive speech is of higher value than obscene speech and of lower value than political speech; Cohen's expression was both offensive and political, and was protected by the Court under the First Amendment.

$38 / d$.

${ }^{39}$ Beauharnais v. Illinois. 343 U.S. 250 (1952).

$40 / d$. The holding in Beauharnais is limited to the publication, sale, or exhibition of written material which negatively depicts persons on the basis of race, color, or religion, or which produces a breach of the peace. Publications dealing with race in Illinois had to state the facts and be made in good faith toward the groups affected. 
idea simply because society finds the idea itself offensive or disagreeable. 41

Three recent (1991-92) court cases -- two Federal District Court cases and one U.S. Supreme Court case -- directly address the issue of discriminatory harassment codes. These cases were decided after research for this dissertation had begun. The first case occurred when a George Mason University (GMU) fraternity claimed that the University had violated the fraternity members' First Amendment rights. 42 The fraternity held an event known as the "Dress a Sig" contest in which participants (Sigma Chi fraternity members) dressed as caricatures of "ugly women." During the event, which occurred at the GMU student union building, one contestant appeared in black face, black wig and curlers, and used pillows to represent breasts and buttocks. GMU officials punished Sigma Chi by prohibiting the group's social and sports activities for two years. The Virginia District Court found no material disruption of educational activities as a result of the event. The Court ruled against GMU and its disciplinary sanction, stating:

In this case, however, GMU did not seek to regulate any conduct whatsoever. It was not the conduct of renting the auditorium, holding Derby Days, raising money for charity, providing entertainment, or performing a skit which prompted GMU to discipline the members of Sigma Chi. To the contrary, it was the expressive message conveyed by the skit which was perceived as offensive by several student groups which prompted GMU to discipline the fraternity. This skit contained more than a kernel of expression; therefore, the activity demands First Amendment protection....Although the university disagreed with the message propounded by the fraternity's activity, GMU may not discipline the students by infringing on their First Amendment rights based on the perceived offensive content of the activity. 43

The university had no discriminatory harassment policy when administrators disciplined the fraternity and, as of January 1992, GMU had no plans to adopt a harassment code. 44

In October, 1991, a Wisconsin Federal District Court overturned UWS-17, finding that the rule

41 Texas v. Johnson, 109 S. Ct. 2533 (1989); See also Hustler Magazine v. Falwell, 485 U.S. 46, (1988); Collin v. Smith, 578 F.2d 1197, 1205-07 (7th Cir.), cert. denied 439 U.S. 916.

(E.D. Va. 1991).

42lota XI Chapter of Sigma Chi Fraternity v. George Mason University. WL 195325, *1 $43 / d$.

44National Association of Student Personnel Administrators. "University Battles Free Speech Issue," NASPA Forum, December 1991 - January 1992, at 1, 4. 
was overbroad and vague, and it did not meet the requirements of the fighting words doctrine. 45 Judge Warren interpreted the fighting words doctrine as applying only to "words which tend to incite an immediate breach of the peace," 46 where a breach of the peace "must tend to bring the addressee to fisticuffs," 47 and "it must be directed at the person of the addressee." 48 The Court determined that UWS-17 covered a number of situations where no breach of the peace was likely, and therefore the policy was broader than the fighting words doctrine allowed. Further, the Court determined that UWS-17 placed restrictions on the content of students' speech, thus making inapplicable Supreme Court precedents outlining content-neutral restrictions on the time, place and manner of expression. For three reasons the Court rejected the university's argument that UWS-17 was Constitutional because the policy's language paralleled Title VII's employment harassment rules; 1) Title VII addresses employment, not educational, settings; 2) even if Title VII applied, agency theory (which holds agencies responsible for its employees' actions) would not hold a school liable for its students' actions since students generally are not the school's agents; and 3) Title VII, as a statute, is superceded by the requirements of the First Amendment. 49 The Court found the rule ambiguous for failing to clarify whether the speaker must actually create a hostile educational environment or merely intend to create such an environment. 50

The most recent of the three cases, the June 1992 U.S. Supreme Court ruling in R.A.V. v. St.

45 The U.W.M. Post, Incorporated v. Board of Regents of the University of Wisconsin System. 774 F.Supp. 1163 (E.D. Wis. 1991). This case was decided one week prior to the researcher's data collection visit to the University of Wisconsin.

46/d. at 1170 , citing Gooding v. Wilson, infra note 76.

47/d. at 1171, citing Texas v. Johnson, supra note 41.

48/d., citing Cohen v. California, supra note 37.

$49 / d$. at 1177 .

$50 \%$. at 1180 . Examples of UWS-17's application convinced the Court that the rule required no proof that a student's speech had any effect on the hearer or the educational environment. 
Paul, will have a significant impact on many campuses' discriminatory harassment policies. 51 A St. Paul, Minnesota ordinance prohibited the display of any "symbol, object, appellation, characterization or graffiti, including, but not limited to, a burning cross or Nazi swastika, which one knows or has reasonable grounds to know arouses anger, alarm or resentment in others on the basis of race, color, creed, religion or gender..."52 The State Supreme Court rejected the trial court's finding that the statute was impermissibly content-based and overbroad; the Court reasoned that the rule was valid because it comported with the Chaplinsky construction of the fighting words doctrine. The Minnesota court also decided the rule was not impermissibly content-based because it was narrowly tailored to serve a compelling state interest in promoting safety and order through the elimination of intentional bias-related threats. The U.S. Supreme Court agreed unanimously that the Minnesota Supreme Court ruling should be overturned, but in a 5-4 vote disagreed on the reasons.

Justice Scalia, writing for the majority in R.A.V., distinguishes between "constitutionally proscribable content' and 'content discrimination unrelated to the constitutionally proscribable content' In his example, "a State might choose to prohibit only that obscenity which is the most patently offensive in its prurience--i.e that which involves the most lascivious displays of sexual activity. But it may not prohibit, for example, only that obscenity which includes offensive political messages."53 Under this rationale, certain modes of delivering fighting words may constitutionally be outlawed only because of the particularly offensive manner in which the words are delivered. According to Scalia,

...the reason why fighting words are categorically excluded from the protection of the First Amendment is not that their content communicates any particular idea, but that their content embodies a particularly intolerable (and socially unnecessary) mode of expressing whatever idea the speaker wishes to convey. St. Paul has not singled out an especially offensive mode of expression -it has not, for example, selected for prohibition only those fighting words that communicate ideas in a threatening (as opposed to a merely obnoxious) manner. Rather, it has proscribed fighting words of whatever manner that communicate messages of racial, gender, or religious intolerance. Selectivity of this sort creates the possibility that the city is seeking to handicap the expression of particular ideas. That possibility would alone be enough to render the ordinance presumptively

51 R.A.V. v. City of St. Paul, Minnesota. No. 90-7675, The United States LAW WEEK (60 LW 4667), June 23, 1992.

52/d. at 4668.

53/d. at 4670 (emphasis in original). 
invalid..."54

The four-justice minority crafted three separate opinions concurring in the result, but dissenting from the majority in the rationale for striking the St. Paul ordinance. In the first concurring opinion, Justice White claims that "should the government want to criminalize certain fighting words, the Court now requires it to criminalize all fighting words....a ban on all fighting words or on a subset of the fighting words category would restrict only the social evil of hate speech, without creating the danger of driving viewpoints from the marketplace." 55 White accuses the Court of legitimating hate speech as a form of public discussion and placing it on equal constitutional footing with political expression and other forms of speech long considered to have great social value, thereby diminishing the importance of society's most valued expression. Justice White faults the St. Paul ordinance for failing to meet the requirements of the fighting words doctrine (discussed earlier in U.W.M. Post v. University of Wisconsin), finding the rule overbroad and invalid on its face for making criminal "expressive conduct that causes only hurt feelings, offense, or resentment, and is protected by the First Amendment."56 Justice Blackmun's concurrence suggests the majority had other motives in its decision:

I fear that the Court has been distracted from its proper mission by the temptation to decide the issue over "politically correct speech" and "cultural diversity," neither of which is presented here. If this is the meaning of today's opinion, it is perhaps even more regrettable. I see no First Amendment values that are compromised by a law that prohibits hoodlums from driving minorities out of their homes by burning crosses in their lawns, but I see great harm in preventing the people of Saint Paul from specifically punishing the race-based fighting words that so prejudice their community. 57

Justice Stevens concurrence discusses the even-handedness of the St. Paul ordinance and denies that the rule suppresses the exchange of ideas. Stevens writes,

Contrary to the Court's suggestion, the ordinance regulates only a subcategory of expression that causes injuries based on "race, color, creed, religion or gender," not a subcategory that involves discussions that concern those characteristics....As we have long recognized, subject-matter

54/d. at 4672 (emphasis in original).

$55 / d$. at 4674 .

56/d. at 4677 .

$57 / d$. at 4678 . 
regulations generally do not raise the same concerns of government censorship and the distortion of public discourse presented by viewpoint regulations....The St. Paul ordinance is even-handed. In a battle between advocates of tolerance and advocates of intolerance, the ordinance does not prevent either side from hurling fighting words at the other on the basis of their conflicting ideas, but it does bar both sides from hurling such words on the basis of the target's "race, color, creed, religion or gender."...The St. Paul ordinance simply bans punches "below the belt" -- by either party. It does not, therefore, favor one side of any debate. 58

The majority opinion seems to invalidate university discriminatory harassment codes that single out certain categories or groups for protection from fighting words. Thus, university policies prohibiting verbal harassment based on the target's race, ethnicity, national origin, religion, creed, gender, sexual orientation, etc., would contain the same fatal flaws as the St. Paul ordinance. The policies enacted at Stanford University and the University of Wisconsin include such categorical provisions (See Appendices C and D). Presumably, this would make them invalid for the same reasons as the St. Paul ordinance.

Constitutional law experts suggest that the majority's opinion will have far-reaching effects, both on campus fighting words-type policies and on "penalty enhancement" statutes enacted by many States. 59 Penalty enhancement statutes allow judges to assign greater punishments to perpetrators of bias-motivated acts (i.e., criminal behavior targeting a victim because of his or her race, gender, religion, etc.). College of William and Mary Constitutional Law Professor Rodney Smolla confirms that R.A.V. renders many college speech codes unconstitutional, saying, "the Court went out of its way to enact a barrier against a content-based regulation of speech that has broad implications for all of First Amendment law and goes well beyond the immediate problem it had before it."60

\section{Content-Neutral Restrictions}

The Court has been significantly more tolerant of content-neutral restrictions on speech taking place on public property than it has been of content-based restrictions. Two important concepts characterize

$58 / d$. at 4683 (emphasis in original).

59R. O'Neil. "Free Expression Requires Tolerance," Richmond Times Dispatch, June 29, 1992. See also, R. Marcus; "Supreme Court Overturns Law Barring Hate Crimes," The Washington Post, June 23, 1992, at A1.

60R. Marcus, Id. 
the Court's approach. First, Court decisions have applied two distinct levels of review to speech occurring on public property; one governs streets and parks, the other governs all remaining publicly owned property. Speakers receive the most protection in parks and streets because of the role these places have played in American history, and less protection on other public property because of the non-speech related purposes to which that property is dedicated. Colleges and universities typically fall under the second category because of their educational mission and their need to provide an environment which supports that mission. To support the educational mission, universities "may enforce reasonable time, place, and manner restrictions...if the restrictions are content-neutral, are narrowly tailored to serve a significant government interest, and leave open ample alternative channels of communication."61 Second, "incidental" regulation of symbolic speech on public property may be limited in the furtherance of important governmental interests. 62

\section{Analogy to Workplace Harassment}

In Meritor Savings Bank v. Vinson ${ }^{63}$ the Court extended the Title VII remedy for sexual harassment beyond situations where employers demand sexual favors as an explicit or implied quid pro quo for employment benefits to include situations where non-quid pro quo harassment has created a "hostile

61 United States v. Grace, 461 U.S. 171 (1983). See also Grayned v. Rockford, 408 U.S. 104 (1972), in which the Court narrowed the question to whether the expression at issue is incompatible with the normal activity of a specific place at a specific time.

62See Clark v. Community for Creative Non-Violence, 468 U.S. 288 (1983); Tinker v. Des Moines School District, 393 U.S. 503 (1969); and United States v. O'Brien, 391 U.S. 367 , at $377(1967)$ in which the Court articulated the circumstances under which symbolic speech can be regulated: "a government regulation is sufficiently justified if it is within the constitutional power of the Government; if it furthers an important or substantial governmental interest; if the governmental interest is unrelated to the suppression of free expression; and if the incidental restriction on alleged First Amendment freedoms is no greater than is essential to the furtherance of that interest."

63Meritor v. Vinson, 477 U.S. 57 (1985). 
work environment." 64 Some campus policies have adapted the E.E.O.C. language upheld in Meritor and applied it to other forms of discriminatory harassment.

The Wisconsin Federal District Court in U.W.M Post flatly rejected the workplace analogy. 65 The U.S. Supreme Court majority in R.A.V. carves out an exception to its rule against ordinances containing content discrimination. The exception permits "a particular content-based subcategory of a proscribable class of speech can be swept up incidentally within the reach of a statute directed at conduct rather than speech." 66 In his concurrence, Justice White concludes that the majority's rationale would cause workplace harassment claims based on sexual harassment to fail First Amendment review, because "the regulation does not prohibit workplace harassment generally; it focuses on what the majority would characterize as the 'disfavored topi[c]' of sexual harassment. 67

\section{Critique of University Harassment Policies}

This section contains analyses of the discriminatory harassment policies proposed at each of the Universities in this research and analyzes the strengths and weaknesses inherent in each approach. The actual policies are shown in the appendices; reference numbers in the analyses refer to numbers in that university's policy. Legal references cited indicate the source of the language adopted by each university. The policies presented below represent examples of three forms anti-harassment statements have taken.

64/d. at 58. "Title VII" refers to Title VII of the Civil Rights Act of 1964 [42 U.S.C. $\$ 2000$-2(a)(1)]. Under this act it is unlawful employment practice for an employer .... to discriminate against any individuals with respect to his compensation, terms, conditions, or privileges of employment, because of such individual's race, color, religion, sex, or national origin."

${ }^{65}$ See U.W.M. Post v. Wisconsin, supra note 45 and the accompanying text.

66 See R. A.V., supra note 51 at 4671.

$67 / d$. at 4676 . 


\section{University of Wisconsin 68}

(See Appendix C)

The University of Wisconsin policy on racial harassment (UWS-17) states that the university may discipline a student "...for racist or discriminatory comments..." although neither "racist" nor "discriminatory" is defined in the policy. The terms themselves do not indicate whose definition will be applied: the perpetrator's, the target's, or the university disciplinary system's. The reason for treating discriminatory expression separately from other racist expression may be to account for cases in which a racist expression is directed toward several individuals of different races, treating all persons with equal contempt rather than singling out one particular race.

The expression must demean the individual(s) according to one of the protected categories listed and it must "create an intimidating, hostile or demeaning environment" for activities at the university (\$(2)(a)2).69 This policy applies to student expression only; however, the potential for faculty members to create such an environment is arguably greater since their influence in classroom relationships with students is greater. As indicated earlier, the "hostile environment" rationale, borrowed from Meritor, 70 was rejected as applied to students in educational settings in U.W.M. Post v. University of Wisconsin.71

Section (2)(a) indicates that the expression may only be sanctioned if it is directed at one person or at one person per incident. This section of the policy relies on the language in Chaplinsky which said that

68University of Wisconsin System. "Student Nonacademic Disciplinary Procedures." Chapter UWS 17, August 1989, at 65-66.

69This statement is an adaptation of the Equal Employment Opportunity Commission's Guidelines on Sexual Harassment [29 C.FR $\$ 1604.11$ (a) (1985)]. Sexual harassment is where "such conduct has the purpose or effect of unreasonably interfering with an individual's work performance or creating an intimidating, hostile, or offensive work environment" [\$1604.11 (a)(3)].

70 See Meritor, supra note 63.

71 See U.W.M. Post, supra note 45. 
the prohibited expression must be intentionally directed at one individual, ${ }^{72}$ and which therefore seems to reject the idea of group defamation outlined in Beauharnais. This section also requires that the speaker intend the expression to demean the individual of the protected class at whom it was directed and the speaker intend the expression to create an intimidating, hostile, or demeaning environment for that individual. It appears that if the speaker can validly claim other intentions underlying the expression, the complaint will be dismissed.

Section (2)(b) indicates that any information considered by the defendant or the complainant to be of importance will be included in determining the defendant intent to cause the two articulated harms. University disciplinary cases require a showing of due process, that is, one in which the accused student has an opportunity to present his or her case before an impartial judicial system. However, the university is not required to follow courtroom procedures either in the presentation of evidence or in allowing for legal representation. The main requirements in university judicial proceedings are that the university has a system which is fair on its face, and that the university follows its own policies and disciplinary procedures. $^{73}$

Section (2)(c) lists four examples to show how the policy may be interpreted by the university in different situations. In the first example, the speaker makes demeaning remarks to an individual with the intention of creating a 'hostile environment.' In the second example, the speaker places visual or written material in an individual's work or living space with the intent of creating a 'hostile environment.' In both examples, the speaker would be determined to be in violation of the policy. In theory, under section (2)(a) 2 , not only did the speaker have to intend to create a 'hostile environment,' the effect of the communication had to actually create such a condition. But the examples indicate that, in practice, intent alone is sufficient to sustain a conviction. Intent would have to be inferred from the actual behavior since determining the speakers' intentions from their explanation of their intentions would be problematic.

72P. Hodulik "Prohibiting Discriminatory Harassment by Regulating Student Speech: A Balancing of First Amendment and University Interests," Journal of College and University Law, Vol. 16, No. 4, Spring 1990, at 573.

73 See Dixon V. Alabama State Board of Education, 294 F. 2d 150 (1961); Board of Curators v. Horowitz, 435 U.S. 78 (1978); Goss v. Lopez, 419 U.S. 565 (1975). 
The third example suggests that 'serious' damage or destruction of an individual's property based on a protected personal attribute is a violation. The policy does not address the impact of 'frivolous' damage or 'minor' damage. Also, the 'hostile environment' clause is absent in this example, perhaps because it is assumed that an environment becomes hostile when one's property is seriously damaged.

The fourth example suggests that expression of derogatory opinions of race or ethnicity toward protected groups during classroom discussions is not a violation of the policy. The explanation for the acceptability of this behavior, offered in the policy, invites questions. The example states that the expression described above is allowed because it is directed toward the class as a whole, and not toward a specific person. If the expression was directed at an individual, was in the context of a class discussion, and had the effect of creating a 'hostile environment' for that student and other students similarly situated, the outcome is unclear. The policy seems to indicate that the expression is allowable because there was no evidence of an intention to create a 'hostile environment.' If the expression was directed at the whole class and was intended to create a 'hostile environment,' again, the outcome is unclear.

The dictionary meaning of "demean" is to degrade, and the dictionary meaning of degrade is to lower in grade, rank, or status. ${ }^{74}$ It is possible that under Wisconsin's first adopted revision of UWS-17, when two students are engaged in discussion and one student makes a statement of fact which portrays the race of the other student as lower in rank or status, and the statement results in the hearer feeling intimidated or hostile, that such expression may be in violation of the policy. It is even possible, theoretically, for students of the same race who hold opposite views on affirmative action as a matter of public policy (for example), and who make disparaging remarks about their own race's views, to both intentionally demean the race of the individual and thus create a 'hostile environment.'

The Wisconsin policy was found to suffer from overbreadth and vagueness, the same flaws as the University of Michigan policy which was rejected in Doe 75 As indicated earlier, a Wisconsin Federal

74Webster's New Collegiate Dictionary, G. \& C. Merriam Co. (1979).

${ }^{75}$ Doe v. Michigan, supra note 33. The University of Michigan policy was judged not only as written, but as applied by the university's judicial process. The court found the university's application of its policy more problematic for its overbreadth than the actual 
Court determined that UWS-17 swept in constitutionally protected speech. This allowed the application of the policy to go beyond the narrowly-defined class of speech it sought to prevent. ${ }^{76}$ Such a policy is void on its face if it is so vague that persons "of common intelligence must necessarily guess at its meaning and differ as to its application."77 The definitions of the terms "racist comments" and "discriminatory comments" have different connotations in American society and among university students. The examples offered by the university seemed only to cloud the issue of what was racial harassment under the policy and what was not.

\section{Stanford University 78}

(See Appendix D)

Stanford's policy on discriminatory harassment -- the Fundamental Standard Interpretation (FSI) -represents an attempt to clarify the boundary between free expression and discriminatory harassment. Section one of the policy restates the "marketplace of ideas" philosophy of free expression, eloquently

written document. The words "victimize" and "stigmatize" were found to be vague in terms of how they would be determined to result from racial harassment. This critique of the Wisconsin policy was done without the benefit of knowing how the policy was applied at the various campuses of the Wisconsin system.

76 See Gooding v. Wilson, 405 U.S. 518 (1972) in which the Court held that a Georgia statute outlawing the use of "...opprobrious words or abusive language, tending to cause a breach of the peace..." was overbroad in light of Chaplinsky because it did not rise to the level of 'fighting words.' In this case, a black appellant had said to a police officer during his arrest, "White son of a bitch, l'll kill you....you son of a bitch, l'll choke you to death," and "You son of a bitch, if you ever put your hands on me again, l'll cut you all to pieces."

77 Connally v. General Construction Company, 269 U.S. 385, 391 (1926).

78Stanford University. "Fundamental Standard Interpretation: Free Expression and Discriminatory Harassment." Stanford University Student Conduct Policies, Office of the President, June 1990, at 5-6, 17-22. The original Fundamental Standard reads: "Students at Stanford are expected to show both within and without the University such respect for order, morality, personal honor and the rights of others as is demanded of good citizens. Failure to do this will be sufficient cause for removal from the University." 
articulated by Justice Holmes in Abrams $v$. United States. 79 The first paragraph of the policy also extols the value of free inquiry and requires wide latitude for the expression of unpopular opinions. It is important to note that the policy addresses only students' rights and responsibilities. This document does not apply to professors, other university employees, and visitors to the campus.

Section two of the policy mandates equal educational opportunities and a non-discriminatory environment. This section borrows the phrase, "hostile environment" from Meritor v. Vinson 80 and suggests that those who must live in such an environment have less than equal access to educational benefits. Section three of the document defines prohibited harassment as "intimidation by threats of violence" and "personal vilification of students" according to a protected characteristic. Section four of the policy serves to define the phrase 'personal vilification.'

Section four of the FSI contains the crux of the policy. Physical threats can be outlawed without adding language about any protected class of persons and the drafters of the policy apparently decided this part of the anti-harassment policy needed no further explanation. Personal vilification required a more specific interpretation and the policy identifies three standards, all of which must be satisfied in order for a communication to be personal vilification. The communication must 1) be intended to insult or stigmatize persons based upon the particular protected class to which they belong; 2) be addressed directly to those individuals; and 3) be considered "fighting words."81 Stanford's definition of fighting words adapted the protected classes of persons to the language contained in Chaplinsky v. New Hampshire. 82

${ }^{79}$ Abrams v. United States, 250 U.S. 616 (1919). U.S. Supreme Court Justice Oliver Holmes, Jr. argued in his famous dissent that "where men have realized that time has upset many fighting faiths, they may come to believe even more than they believe the very foundations of their own conduct that the ultimate good desired is better reached by free trade in ideas--that the best test of truth is the power of the thought to get itself accepted in the competition of the market, and that truth is the only ground upon which their wishes safely can be carried out." at 630 . The search for truth rationale can be traced to John Stuart Mill in On Liberty (1859).

80 Meritor, supra note 63.

81 Chaplinsky, supra note 30.

82/d. 
The use of Chaplinsky as the sole basis of the policy may involve some legal risks because it is unclear whether that case is still good law. In Gooding $v$. Wilson, the court narrowed the definition of fighting words and provided significant breathing room for offensive speech. ${ }^{83}$ Stanford Law Professor Gerald Gunther found that, since Chaplinsky was decided, repeated appeals to the Supreme Court to acknowledge the applicability of the "fighting words" doctrine have met with repeated refusals, and "one must wonder about the strength of an exception which, while theoretically recognized, has ever since 1942 not been found apt in practice." 84 Nadine Strossen argues that the modern Court ignored the dictum in Chaplinsky's first prong ("words which by their very utterance inflict injury") and attended only to those words that "tend to incite an immediate breach of the peace" as fighting words. ${ }^{85}$ Therefore, according to Strossen, the only "fighting words" that can now constitutionally be prohibited are those that will lead immediately to lawless action. 86

Since a Stanford student accused of harassing another student must have expressed something which meets all three segments of section four of the policy in order to be sanctioned, it is not the violence alone which Stanford seeks to proscribe. If Stanford simply wanted to forestall violent reactions to any offensive speech directed by one student to another, the FSI could have been written to address all fighting words of any kind. But the policy seeks only to eliminate fighting words which are addressed to an individual because of that person's race, gender, or other protected characteristic. Therefore, violence is not what the Stanford policy attempts to eradicate. What the FSI is designed to curtail are the ideas which may provoke a violent reaction. In other words, the policy is designed to restrict certain methods of expressing racist ideas not because the potential violence is bad, but, because the racist ideas are bad. The structure of the policy and its accompanving rationale statement (not included in the Appendix) indicate that its

83Gooding v. Wilson, supra note 76

84G. Gunther, "Letter to Professor George Parker, Chair of the Student Conduct Legislative Council at Stanford University," Stanford University Campus Report, May 3, 1989 , at 18.

${ }^{85}$ N. Strossen, "Regulating Racist Speech on Campus: A Modest Proposal?" Duke Law Journal, June 1990, at 509.

$86 / d$. 
underlying rationale is a content-based restriction of speech. This approach would be troubling to the U.S. Supreme Court, in light of the R.A.V. decision, since the FSI and the St. Paul ordinance in R.A.V. contain similar categories, or classes of persons, separated for greater protection from harassment. 87

Perhaps one reason the Court traditionally has focussed on the part of the fighting words doctrine which did not offer protection for expression inciting an immediate breech of the peace was its awareness of the difficulty involved in determining which words commonly are known to inflict injury. Another possible reason for the Court's traditional approach is the inherent difficulty in determining what injury is sufficient to warrant government interference in citizens' First Amendment rights. The committee that fashioned the FSI chose not to publish the words and symbols it assumed to be "commonly understood to convey direct and visceral hatred for human beings." 88 Perhaps it is understood by many members of the Stanford community that certain terms would be deemed unacceptable by members of protected classes of people; however, the absence of such a list may concern many others.

Other critics of the fighting words approach to anti-harassment policies argue that the policies do not go far enough to protect minorities and women from harassing speech. At least one Stanford professor argued for a policy which would have been broader in scope by prohibiting racist speech in all common areas, with the exception of organized and announced rallies and speeches, and would not have protected persons who were vilified on the basis of their membership in a dominant majority group. 89 Another problem with the fighting words doctrine is the infrequency with which situations of face to face verbal assaults occur. Policies based on the fighting words doctrine address only the most outrageous forms of racism on campus and offer no solace for students who experience more subtle and more common forms of racist behavior.

Fighting words policies, like Stanford's, represent a compromise among competing proposals. Proponents of an absolutist position on freedom of expression may be persuaded that face to face insults

${ }^{87}$ R.A.V., supra note 51.

88Stanford University, supra note 78.

${ }^{89} \mathrm{C}$. Lawrence, "If He Hollers Let Him Go: Regulating Racist Speech on Campus," Duke Law Journal, June 1990, at 431, 450. 
detract from the educational experience and may agree to restrict epithets and racial slurs. Those who argue for broader restrictions against damaging racial speech may be persuaded to adopt the fighting words approach as a step in moving the institution toward recognition of the unique and difficult circumstances faced by minority and women students. Thomas Grey, a Stanford law professor who wrote most of the FSI, described this conflict as an element of paradox in the tension between the perspectives of civil liberties and civil rights. 90

\section{University of Virginia91}

(See Appendix E)

The University of Virginia has no regulation specifically limiting discriminatory harassment among students. However, parts of the University's non-academic regulations may be applied to situations involving harassment. A separate University policy on sexual harassment proscribes specific types of expression of a sexual nature.

The student conduct policy, written in the language of the traditional South, states that University students "are expected to conduct themselves as ladies and gentlemen both within the University and elsewhere."92 In the introductory paragraph of the "Conduct" section, the regulations state that students can be expelled by the president or his designee for "bad conduct" that may "injure or discredit the

90T. Grey, "Civil Rights vs. Civil Liberties: The Case of Discriminatory Verbal Harassment," Social Philosophy \& Policy, Vol. 8, No. 2, Spring 1991, at 81-107. Grey noted that proponents of both civil liberties and civil rights perspectives faulted the Stanford policy for being 'merely symbolic.' $\mathrm{He}$ argues that symbolism is often important and that, in this case, universities should support their goals for civility by promoting policies which reinforce institutional values.

43.

91 University of Virginia, "University Regulations," Graduate Record 1990-91, at 23- 
University."93 The regulations do not indicate whether "bad conduct" is different from "prohibited conduct," of which there are twelve enumerated categories.

The University's commitment to freedom of expression is found in the section titled "Standards of Conduct."94 The Standards promote freedom of expression so long as it does not involve the "willful disruption of the educational process, destruction of property, and interference with the orderly process of the University or with the rights of other members of the University." It is possible for a person engaging in demonstrable harassment to interfere with the rights of other members of the University community in pursuing their educational goals or their work and therefore violate this fundamental standard. Since the University regulations do not clarify the boundaries of an individual's rights regarding speech, one may validly assume that the University relies on the general First Amendment principles discussed earlier to guide the application of this standard.

Five areas of "prohibited conduct" may offer protection for students against harassment. Section (1) prohibits the "physical or sexual assault of any person..." Assaults involving students of different races would be filed under this provision. Section (2) outlaws damage to University or personal property. Racially-motivated damage to property could be adjudicated under this condition. Section (4) allows punishment for "intentional disruption or obstruction of teaching, research, administration, disciplinary procedures, other University activities, or activities authorized to take place on University property." Discriminatory conduct that interferes with any University-related activity could fall under this fourth proviso. Section (8) of the Conduct policy prohibits disorderly conduct, including behaviors "which breech the peace or are lewd, indecent, or obscene, and which are not constitutionally protected speech."95 One may reasonably infer from this passage that the University relies on the Supreme Court's interpretation of what is constitutionally protected speech when making determinations about discriminatory speech or disorderly conduct. Section (10) of the Conduct policy indicates that violations of state and federal laws

$93 / d$

$94 / d$

$95 / d$. at 28 . 
may be brought before the University Judiciary Committee as sanctionable offenses. Applicable statutes in Virginia provide for injunctive relief, civil damages, or both for victims of racial intimidation or violence 96 , they allow for class 4 felony charges for conspiring to incite racial insurrection, 97 and they provide for punishment for using abusive language to another person (i.e., fighting words). ${ }^{98}$ In light of the University's regulations regarding student conduct and applicable state laws, it may be argued that adequate protection exists for students against racial harassment. But it could also be argued that the University has several incomplete policies related to the issue of racial harassment and that students cannot be certain what protection they do have under certain circumstances. Several plausible scenarios could be developed which

96Section 8.01-42.1, Code of Virginia, "Civil action for racial, religious or ethnic harassment, violence or vandalism." The relevant sections state the following:

a.) An action for injunctive relief or civil damages, or both, shall lie for any person who is subjected to acts of (i) intimidation or harassment or (ii) violence against his person: or (iii) vandalism directed against his real or personal property, where such acts are motivated by racial, religious, or ethnic animosity.

b.) Any aggrieved party who initiates and prevails in an action authorized by this section shall be entitled to damages, including punitive damages, and in the discretion of the court to an award of the cost of the litigation and reasonable attorneys' fees in an amount to be fixed by the court.

c.) The provisions of this section shall not apply to any actions between an employee and his employer, or between or among employees of the same employer, for damages arising out of incidents occurring in the workplace or arising out of the employeeemployer relationship. (1988, c.492).

97Section 18.2-485, Code of Virginia, "Conspiring to incite to insurrection." "If any person conspire with another to incite the population of one race to acts of violence and war against the population of another race, he shall, whether such acts of violence and war be made or not, be guilty of a Class 4 felony."

98Section 18.2-416. Code of Virginia, "Punishment for using abusive language to another." A copy of this statute was found among UVA's University Judiciary Committee documents, indicating the committee was aware of the law. The relevant section states:

If any person shall, in the presence or hearing of another, curse or abuse such other person, or use any violent abusive language to such person concerning himself or any of his relations, or otherwise use such language, under circumstances reasonably calculated to provoke a breach of the peace, he shall be guilty of a Class 3 misdemeanor... This section addresses itself to a direct confrontation of individuals in which one curses or abuses the other or uses violent abusive language concerning the other or his or her relations under circumstances which would precipitate an immediate, forceful and violent reaction by a reasonable person. 
might be considered violations (or not) under the various parts of the University Regulations outlined above.

Two general University anti-harassment policies may provide better guidance. The "NonDiscrimination Policy"99 of the University insures that the University and its employees do not engage in discriminatory practices against protected classes of persons. The University's policy on sexual harassment ${ }^{100}$ uses the identical language of the E.E.O.C. guidelines which were used in the Wisconsin policy. 101 These two policies provide additional protection for persons who may be victims of harassment or personal vilification.

\section{Arguments for Freedom From Harassment}

The main purpose for the earlier discussion of racism on campus and of the effects of racist expression was to describe the magnitude of the problems affecting colleges and universities in America. The students, faculty, and administration in institutions of higher education reflect the racial situation in the United States as a whole and, to a increasing degree, the global situation among races of people. Universities are being asked (often demanded) to take a position on the balance between the freedom to express personal or academic views on any topic and the promotion of human dignity among members of the university community. The arguments for adopting a policy to protect students from racist expression on campus are presented in this section. Proponents of the policies at the universities in this study used many of these arguments to convince their respective campus communities to adopt the policies.

The primary justification for any university policy must be that it supports the mission of the institution. The mission statements of most traditional universities contain language about the creation, transmission, and storage of knowledge, and about attending to the needs of its learners. One of the most effective arguments for proponents of anti-harassment policies is that racial insults, epithets, and personal

99University of Virginia, supra note 91 at 34.

$100 / d$, at 36 .

101 See E.E.O.C., supra note 69. 
abuse may hinder the ability of all members of the educational community to participate equally in the educational process of their particular institution. Victims of harassment often must change their behavior to adapt to the climate of the university and therefore are restricted in their personal freedom. ${ }^{102}$ Classroom discussion may be inhibited by the lack of protection against abusive expression. Since abusive expression forces members of victim-groups to view all members of dominant groups with suspicion, it causes the victim-group members to be reticent in class for fear of reprisal for unpopular opinions, and it leads dominant-group members to speak cautiously when talking with victim-group members. 103 Therefore, allowing racial insults and other abusive expression to exist actually can impede academic freedom. Prohibiting such expression could enhance equality and autonomy for the victims and promote the necessary level of trust for academic freedom to thrive. Proponents of this rationale suggest that the college or university is different from society as a whole, and that offensive speech may be punished when it interferes with the academic process, even though the First Amendment protects that speech outside of academe. 104

It is argued that speech-restrictive policies may be effective in limiting the spread of racist ideas-ideas which allowed to go unchecked may serve to influence the ideas and behaviors of others. ${ }^{105}$ Also, it is argued that racist speech is so damaging to its victims that, like obscenity, it should be prohibited. ${ }^{106}$ In other words, racist ideas are inherently dangerous and wrong and should be stopped by government intervention. It is argued further that racist and harassing expression is so offensive that it may cause friction among different groups and this friction will lead to breaches of the peace.107 The Court in

102 Matsuda, supra note 14 at 2337.

$103 / d$. at 2339.

${ }^{104}$ D. Tatel, "Clear, Narrow Policies on Offensive Speech May Not Run Afoul of the First Amendment," The Chronicle of Higher Education, February 7, 1990, at B1. at 445-6.

105D. Kretzmer, "Freedom of Speech and Racism," Cardozo Law Review, Vol. 8, 1987, 106 Tatel, supra note 104 at B2. 
Chaplinsky made this observation:

It has been well observed that such utterances are no essential part of any exposition of ideas, and are of such slight social value as a step to truth that any benefit that may be derived from them is clearly outweighed by the social interest in order and morality. "Resort to epithets or personal abuse is not in any proper sense communication of information or opinion safe-guarded by the Constitution, and its punishment as a criminal act would raise no question under that instrument."108

Another rationale suggests that society should affirm the ideals of social and political equality and that people, particularly minorities, should not be made to suffer through the indignity of living in a society which protects such offensive speech.109 Further, racism is arguably a uniquely compelling reason because of the destructive historical experience in modern times and the formal international condemnation of racism.110 Corollaries to these arguments are that people are entitled to be free from racial incitement because human dignity should receive as much protection as free speech, and that consent of the governed is necessary for the effective functioning of any government or institution. Freedom from racial incitement is analogous to the 'right not to hear,' which suggests that under certain circumstances persons should have the choice about what they wish to hear or not hear. Residential students may be considered analogous to the captive audience that is protected by the First Amendment in other contexts--as supporting (paying) members of the university community they are involuntarily forced into an awkward position when their campus provides a forum for hate groups. 111 'Consent of the governed" implies that those who are subject to the laws of the community have some avenue for affecting the formation and implementation of those laws. It is difficult for any person to consent to protecting speech which attacks the core of an individual's self-worth, dignity, and status in the community. As long as racial insults receive institutional protection or incidents of overt and subtle racism meet administrative neglect, some outsiders to the community's

108 Chaplinsky, supra note 30 at 572 . The Court quoted the statement on epithets from Cantwell v. Connecticut, 310 U.S. 296, at 309-310.

${ }^{109}$ Kretzmer, supra note 105.

$110 / d$. at 458 . See also Matsuda, supra note 14 at $2341-48$ for a full description of the International Law of Human Rights.

111 Matsuda, supra note 14 at 2372, citing FCC v. Pacifica Foundation, 438 U.S. 736 (1978) and Consolidated Edison v. Public Service Commission, 447 U.S. 530 (1980). 
decision-making process may not grant their consent.

Finally, supporters of anti-harassment policies contend that adherence to objective, legal, speechprotective traditions tends to ignore the real experience of the victims of harassing speech. The standard of whether expression is racist, discriminatory, or persecutorial in the current system is said to be defined by the dominant group instead of the group which receives the messages, and this definition ignores an important part of the message--the meaning accorded the message by its hearers. 112 Allowing racial insults means that certain members of society bear a disproportionate share of the price for freedom of speech. Minority group members are most often subjected to the direct attack of the abusive speaker and even if members of the majority are offended or disappointed by the ideas expressed in the speech, they may not experience the hurt felt by the target-group members.

\section{Arguments for Freedom of Speech}

The university mission in the 20th century has been built around the discovery of new knowledge and the search for truth through a strong commitment to academic freedom. 113 Academic freedom embodies both the freedom to teach and the freedom to learn in an environment which is dedicated to the search and discovery of new truths. The Court's view of the mission of the university is that the "college classroom with its surrounding environs is peculiarly the 'marketplace of ideas,' and we break no new constitutional ground in reaffirming this Nation's dedication to safeguarding academic freedom."114 In this section the arguments of those who oppose speech-restrictive codes are presented. Again, many of these arguments were heard at the universities in this study.

$112 / d$. at 2364 . See also, C. Lawrence, supra note 89 at 459 ; "Often we are too quick to say we have heard the victims' cries when we have not; we are too eager to assure ourselves we have experienced the same injury, and therefore we can make the constitutional balance without danger of mismeasurement." See also $C$. Lawrence, "Acknowledging the Victim's Cry," Academe, November-December 1990, at 10-14.

113L. Joughin (ed.), Academic Freedom and Tenure: A Handbook of The American Association of University Professors, Univ. of Wisconsin Press, Madison (1964).

${ }^{114}$ Healy v. James, 408 U.S. 169,180 (1971), quoting Keyishian v. Board of Regents, 385 U.S. 589, 603 (1967). In Keyishian, the Court also discussed the dangers that are present when a "pall of orthodoxy" is placed over the classroom. 
One of the strongest arguments against anti-harassment policies is that they are content-based. Allowing legislative regulation of the content of speech puts the government in a dangerous position of thinking for the citizens it serves. Civil libertarians ask who, or what institution is to be trusted to make the decisions about what ideas are true or false. They consider the possibility of benign neglect or abuse of discretion by government officials too great to allow the legislature to make distinctions of this nature. 115 Even when a majority of citizens object vehemently to racist expression there is thought to be a danger in accepting any content-based restriction.

The premise of such rules is that sexist, racist, and ethnically demeaning speech is so deeply abhorrent that the normal rules do not apply. Such a claim could hardly be more compelling. Yet the exception we make today to combat anti-Semitism or racism or sexism may well return to haunt us tomorrow in a quite different context that may seem equally compelling to some people. ${ }^{116}$

Justice Holmes gave a related argument in his dissent in Abrams v. United States, stating that "the best test of truth is the power of the thought to get itself accepted in the competition of the market."117 That is, freedom of expression is essential to reach the truth and whether race-related statements are true or false, the mere expression of the ideas will spark discussion in the marketplace and thus lead to the truth. A rationale specific to universities argues that in order to preserve the unique environment of freedom of inquiry and expression, the university community must be able to tolerate a significant amount of conflict and turmoil because a "living" marketplace of ideas is not a tranquil place. An effective and thriving university is often fraught with intellectual, moral, emotional, aesthetic, and social unrest behind the facades of etiquette and civility. 118

Some argue that allowing racist and offensive speech keeps the public aware of its prevalence and

115 Kretzmer, supra note- 105 at 471.

116R. O'Neil, "The Pitfalls of Stifling Campus Speech," Association of Governing Board Reports, January-February, 1990, at 14. Also, see G. Gunther, "Freedom for the Thought We Hate," Academe, December-January 1990, at 10-12.

117 Abrams, supra note 79. at $\mathrm{B} 3$.

118R. Rodgers. "To the editor," The Chronicle of Higher Education, November 8, 1989, 
danger, and an awareness of the need to fight it. It has also been argued that by prohibiting racist speech, the discussion of racist ideas will move "underground" where it is more difficult to detect and control, and the oppositional groups to racist speech may become complacent in thinking that the problem is solved.119 It is perhaps in the area of race where this society has the most to gain by shared knowledge about the similarities and differences among diverse groups of people. Policies which define "acceptable" and "unacceptable" speech about race will 'chill' all speech about race. It is reasonable to assume that some persons may err on the side of caution to avoid becoming ensnared by a campus policy against racist remarks, or even to avoid being misperceived of as a racist by one's peers.

Opponents argue that racist expression defined by the victim-group members may discourage the free exchange of ideas. An ethnocentric definition of racism requires also that members of other communities or groups be aware of all of the statements and forms of expression which will result in the victim-group member experiencing loss of esteem, status, and other important, but intangible, qualities. As American society and its universities become more heterogenous it may be unreasonable to think that the members of each culture know what will offend or what will be found humorous, by other students and faculty in classroom discussions and other settings. Any racial remark can be perceived in a multitude of ways, according to the personal and cultural histories of the actors and observers. Allowing one of the actors to define what is racist, offensive, and wrong may not resolve the issue.

R.C. Post contends that for a culturally diverse society to sustain public discourse the society must value and wish to preserve its heterogeneity. 120 Powerful communities attempt to use the authority of the government to impose their own norms on expression generally, just as Jerry Falwell tried to impose his definition of the 'outrageous' onto Hustler Magazine's satire. Common law torts of defamation and invasion of privacy symbolize similar efforts to apply the norms of the predominant culture to the laws of

119 Matsuda, supra note 14 at 2352.

120R. Post, "The Constitutional Concept of Public Discourse: Outrageous Opinion, Democratic Deliberation, and Hustler Magazine v. Falwell," Harvard Law Review, Vol. 103, 1990 , at 601,634 . 
the entire community.121 The First Amendment demands state neutrality in the 'marketplace of communities' because it views membership in these communities from a "voluntaristic" conception of community life--one which is developed from individual choice. 122 The individualist conception of First Amendment doctrine requires that each individual be free within public discourse from the enforcement of all civility rules in order to be able to advocate and practice new forms of communal life through speech.123

The potential for overbreadth and vagueness have continually plagued policies restricting harassing speech. A broad definition of the speech targeted for restriction will include not only the targeted speech, but also constitutionally protected speech. Yet narrow definitions of harassing speech are likely to be ineffective because the clever, would-be racist can evade the reach of the policy and still impact his target. The narrow definition of harassing speech may be effective in preventing breaches of the peace, preserving individual dignity, and affirming society's rejection of racism, but it will not begin to halt the spread of racist ideas. 124 Some terms used in anti-harassment policies have unclear meanings. The words "stigmatize" and "victimize" in the University of Michigan policy (1988) were found to be vague in Doe, 125 and the terms "racist comments" and "discriminatory comments" appear to be troublesome in the Wisconsin example shown above. The policies' shortcomings demonstrate the difficulty in defining the specific activity to be prohibited.

David Kretzmer and others have given several other explanations why racist speech prohibitions are not advisable policies. First, if the restrictions are based on the legal groundwork of group libel there are inevitable problems distinguishing between statements of fact and statements of opinion. ${ }^{126}$ In addition,

$121 / d$.

$122 / d$.

$123 / d$. at 647.

124 Kretzmer, supra note 105 at 489.

125 Doe v. Michigan, supra note 33.

126 Kretzmer, supra note 105 at 496. 
proving the truth or falsity of racist statements may turn into a battle of proving the truth or falsity of racist doctrines, which may turn against the plaintiff. ${ }^{127}$ Second, if the breach of peace model is used it is difficult to argue that if the abuses themselves do not make the speaker liable, that a hostile audience response should do so. 128 Third, once laws prohibiting racist speech are enacted, even if ineffective or harmful, they are extremely difficult to repeal because those who reject the law are labeled as racists. 129 Fourth, a law is not effective if violations are unenforced or unenforceable--enforcement is not guaranteed by the passage of anti-racism laws. ${ }^{130}$ Fifth, trials of hate-speech crimes may gain publicity or even arouse sympathy for the speaker by portraying him or her as a victim. If a racist is acquitted, the outcome could be perceived of as a victory of the accused or as a government endorsement of racist behavior. ${ }^{131}$ Finally, the adoption of anti-hate legislation may create the false impression that the complex problems of racism and other forms of discrimination have been legislated away, and this may stall other attempts to promote equality and civility. 132

\section{Collegiate Free Speech Protection Act of 1991133}

In March 1991, U.S. Representative Henry J. Hyde (R-Illinois) condemned the trend among colleges toward enacting discriminatory harassment policies. He announced legislation (See Appendix F)

$127 / d$.

$128 / d$, at 498 .

$129 / d$. at 503.

$130 / d$. at 507. See also, S. Dodge; "Campus Codes That Ban Hate Speech Are Rarely Used to Penalize Students," The Chronicle of Higher Education, February 12, 1992, at A3536.

$131 / d$. at 510.

132 Strossen, supra note 85 , at 560 .

${ }^{133} \mathrm{H}$. Hyde, "Hyde criticizes trend on college campuses to restrict free speech, introduces speech protection act," Press release from U.S. Representative Hyde's office, March 1991. 
that will provide students with the legal authority to challenge those rules. Hyde is the senior republican on the House Subcommittee on Civil and Constitutional Rights, and was joined by the American Civil Liberties Union in sponsoring the legislation. In a public statement Hyde recognized the importance of academic freedom and expressed concern that students learn to deal with unpopular opinions. The proposed legislation targets students for protection and would hold independent colleges and universities to a standard similar to that of the First Amendment of the Constitution. The future of the bill is uncertain.

\section{Ereedom of Speech and Political Correctness:}

Debates about universities' values occur with some frequency, but the recent clamor over the openness and civility of institutions of higher education has divided the competing voices in some new ways. Some conservative writers have made a connection between the adoption of discriminatory harassment codes and the emergence of certain attitudes and modes of thought on many campuses. "Political Correctness," or "PC," as it has become known, has various definitions and includes multiple issues. Basically, it involve support for "underdogs" in American society including, but not limited to, racial groups, non-Protestant religious groups, women, gays and lesbians, physically handicapped persons, children, and occasionally animals and the environment. On college campuses, issues of contention include admissions practices, curricular changes, financial investment policies, harassment codes, diversity, and affirmative action. The subject receives substantial publicity in the popular media, and has been debated widely in academic circles. The notion of political correctness was part of the debate on the university campuses in this study; indeed, many persons perceived a close nexus between discriminatory harassment policies and political correctness.

Traditionally, battle lines in the struggle over college governance issues have been drawn between faculty, administrators, and students as a whole. However, the recent waves of criticism directed toward colleges for their Eurocentric curricula and their treatment of members of minority groups may change the way the sides are chosen. For example, English Professor Janet McNew characterized two sides, which she 
dubs the "Ancients" and the "Moderns."134 In her construction, Ancients believe in a common culture and identifiable values found in a cluster of classical texts, while Modems typically associate values with politics and attempt to reveal the Ancients' group values and individual interests. A recent cluster of issues has emerged as a strong force on many campuses and opponents of these issues have derisively referred to certain values, beliefs and actions held by the proponents to be "politically correct." One value identified as a tenet of the "PC" ideology was the restriction of discriminatory speech toward historical "outsiders." In other words, the "PC" view would advocate policies promoting open and positive educational environments for all students, even if creating those environments involved restricting some speech. This section on political correctness describes the potential links among historically excluded members of the academic community, the beliefs about the university which they may hold, and the deliberation over the adoption of speech-restrictive codes.

\section{Historical Political Threats to Academic Freedom}

Many contextual considerations bind the values and attitudes which are considered to be politically correct in the collegium including, but not limited to, the institutional setting, mission, history, curricular offerings, racial mix, and external influences. Those values which are held by many students and faculty often are shaped by the issues and anxieties of the day, whether those issues are fear of communism, anger with government policies toward foreign military intervention, or adapting to an influx of non-traditional students. The issues of importance in the 1990s were not created in a social and historical vacuum and have instead evolved through a maze of related events. Some traditionalists and civil libertarians joined sides in the recent debate over the impact of $\mathrm{PC}$, and many interpreted $\mathrm{PC}$ be a threat to academic freedom.

The concept of academic freedom was imported from Germany in the 1890 s by professors who had studied in German universities. It had two major tenets: Lernfreiheit, or the freedom of the student to learn and choose one's course of study, and Lehrfreiheit, the professors' freedom to research and teach without

${ }^{134} \mathrm{~J}$. McNew. "Whose politics? Media distortions of academic controversies," The Virginia Quarterly Review, Winter 1992, at 1-23. 
government intervention. ${ }^{135}$ This protection was thought to be important by academicians who, on occasion, encountered some difficulty in explaining to the public the need for instruction in classical liberal studies, or the value of considering many different views on a conclusion which had already been adopted by the general public. The 1915 "Declaration of Principles" of the American Association of University Professors (AAUP) indicated how public opinion can affect academic freedom.

The tendency for modern democracy is for men to think alike, to feel alike, and to speak alike. Any departure from the conventional standards is apt to be regarded with suspicion. Public opinion is at once the chief safeguard of a democracy and the chief menace to the real liberty of the individual. It almost seems as if the danger of despotism cannot be wholly averted under any form of government. In a political autocracy there is no effective public opinion, and all are subject to the tyranny of the ruler; in a democracy there is political freedom, but there is likely to be a tyranny of public opinion. 136

One of the goals of the AAUP was to create a haven from such tyranny on the college campus so that reasoned discourse could lead to reasoned action. Colleges have had considerable difficulty in maintaining their grounds as refuges from tyranny both from external and internal forces.

Fear of communism consumed the attention of Americans following World War II and public anxiety about the political leanings of citizens spread to educational institutions. In 1949, the AAUP passed a recommendation which "reaffirm[ed] its belief that institutions of higher education, both public and private, should be free from all political interference."137 Despite the AAUP's stance, David Holmes found that hundreds of professors lost their jobs during the McCarthy communist hunt and many more retained their jobs only by avoiding controversy. 138 Faculty loyalty oaths, further evidence of Americans' fears of subversive group activity, found their way to college campuses around this same time. Some faculty members who were required to sign such a pledge challenged the oaths as impinging their rights of speech and association under the First Amendment.

135L. Veysey. The Emergence of the American University. Chicago: University of Chicago Press, at 384 (1964).

136"Declaration of Principles," Academe, May-June 1989, at 9.

137 Recommendation of the 35th Annual Meeting, AAUP Bulletin, Spring 1949, at 10.

138D. Holmes, Stalking the Academic Communist: Intellectual Freedom and the Firing of Alex Novikoff, Hanover (NH): University Press of New England, 1989. 
The case of Wieman v. Updegraff 139 involved the constitutionality of a loyalty oath required of all state officers and employees, including faculty members. The Supreme Court held that the loyalty oath violated due process since the state refused to hire persons who had been members of any organization listed as subversive by the U.S. Attorney General whether or not they had full knowledge of the purposes and activities of the organization. Justice Frankfurter wrote that the loyalty oath "has an unmistakable tendency to chill that free play of the spirit which all teachers ought especially to cultivate and practice; it makes for caution and timidity in their associations by potential teachers." 140 Five years later, a guest lecturer at the University of New Hampshire was investigated for his subversive associations. The resulting case, Sweezy v. New Hampshire ${ }^{141}$, marked the first time that a majority of the Supreme Court specifically acknowledged the existence of academic freedom. 142

The essentiality of freedom in the community of American universities is almost self-evident. No one should underestimate the vital role in a democracy that is played by those who guide and train our youth. To impose any straight jacket upon the intellectual leaders in our colleges and universities would imperil the future of our Nation. No field of education is so thoroughly comprehended by man that new discoveries cannot yet be made. Particularly is that true in the social sciences, where few, if any, principles are accepted as absolute. Scholarship cannot flourish in an atmosphere of suspicion and distrust. Teachers and students must always remain free to inquire, to study and to evaluate, to gain new maturity and understanding; otherwise our civilization will stagnate and die. 143

139 Weiman v. Updegraft, 344 U.S. 182 (1952).

$140 / d$. at 195.

141 Sweezy v. New Hampshire, 354 U.S. 234 (1957).

142K. Katz, "The First Amendment's Protection of Expressive Activity in the University Classroom: A Constitutional Myth." University of California-Davis Law Review, Vol.16, 1983, at 904.

143 Sweezy, supra note 141 at 250. Sweezy was convicted of contempt for failing to answer questions about the content of his lecture at the university, but the Supreme Court reversed the conviction since it was unclear whether the state legislature had authorized the attorney general to gather the information in the first place. The justices' main concern was over the encroachment of political authority on the classroom. 
Loyalty programs continued into the 1960 s until the case of Keyishian v. Board of Regents 144 dealt the final blow. The common threat of orthodoxy came from outside higher education, from the fears of the government and the American public. But, even though professors were a part of the broader public, the intrusion into academic life was seen as one imposed from the political conditions of the outside world, not one of the faculty imposing rules on themselves. This was a battle of segments of the academic community against the ambitious search for communist threats by the government. The cases recounted above denote only those professors who chose to fight the loyalty oaths; determining how many professors chose to acquiesce and sign the oaths because they perceived the battle of asserting their rights too futile or too costly remains unclear.

Professors found themselves in court for their involvement in other controversial political situations as well. The question of whose "facts" or perspective would control the classroom discussions of social issues tended to arise in two contexts: 1) efforts to mandate the content of the instructional matter, and 2) attacks on professors whose presentations or class materials contained facts or opinions which offended a powerful social group or interest. 145 For example, until 1968, Creation Theory was the only explanation for the origin of the earth allowed by law to be taught in the public institutions in Arkansas. ${ }^{146}$ Faculty who taught evolution were in violation of state law and were denied the opportunity to select the curriculum. In Arkansas, the "politically correct" views (and coincidentally, legally correct) on the earth's origin depended upon one's beliefs in fundamentalist Christian doctrine.

144 Keyishian v. Board of Regents, supra note 114. The Court found that an individual must intend to support and promote the illegal objectives of proscribed organizations; mere knowledge of the illegal activities of the organization was not enough to justify any sanction of public employment. Justice Brennan wrote for the majority and noted that safeguarding academic freedom is of value to all persons, not just the teachers involved.

$145 \mathrm{M}$. Sproule, "Whose Ethics in the Classroom? On the Politics of Ethics," paper presented at the 71st Annual Meeting of the Speech Communication Association, Denver (CO), November 7-10, 1985.

${ }^{146}$ Epperson V. Arkansas, 393 U.S. 97 (1969). The Supreme Court found that requiring teachers at public schools and universities to instruct Creation Theory as the sole explanation of the earth's origin created a conflict of interest by the state in establishing religious beliefs and therefore was in violation of the First Amendment. Arkansas argued that the law was never enforced, but the Court refused to accept this argument as a reason to keep the law on the books. 
A decade later, Grant Cooper's Marxist views were the root of his contract non-renewal at the University of Arkansas at Little Rock.147 Professor Cooper, a non-tenured professor in his fourth year at Arkansas, announced to his classes in American and World Civilization that he was a member of the Progressive Labor Party (PLP) and that his course was taught from a Marxist perspective. After considerable attention from local and state-wide media and a lawsuit against Cooper by 23 state legislators ${ }^{148}$, the Chancellor of the university summoned Cooper and asked him, if instructed by the university, would he teach his course from an "objective" point of view. Cooper replied that he felt he would be intellectually dishonest if he did not disclose his views, and that he could not be entirely objective toward other perspectives. No factors relating to Cooper's teaching performance were discussed at this meeting. Less than ten days later, Cooper was notified his contract would not be renewed. The U.S. District court found that the university had hastily prepared a list of reasons for Cooper's termination which were intended to mask the real reason for his dismissal--that the university was under pressure not to have an avowed Marxist "corrupting" the minds of his impressionable students. The Court found that the efforts of the university and the state legislators to restrict Cooper's politically unpopular ideas violated the First Amendment, and reinstated him without tenure and with back pay.

Some professors were denied salary increases and promotions because of their participation in picketing their institution 149 or their activity in faculty associations and lobbying efforts. 150 Outspoken professors who complain about campus work conditions are often at odds with administrators, legislators,

147 Cooper v. Ross. 472 F.Supp. 802 (1979).

$148 / d$. at 805 . The legislators wanted Cooper fired because a state law prevented any person affiliated with a Nazi, Fascist, or Communist organization from working as a state employee. The legislators were undoubtedly responding to public pressure to do something about the unpopular professor. Interestingly, the university joined with Cooper in the lawsuit against the legislators and succeeded in having the law struck as unconstitutional.

149 Kim v. Coppin State College. 662 F. 2d 1055 (1981).

150 Allaire v. Rogers. 658 F.2d 1055 (1981). The University of Texas at Austin argued that salary increases are determined by a faculty member's accomplishments in scholarly activities, and that the lobbying and protesting activity of the plaintiffs had detracted from the time they would have spent on their work; since their work output was lower, they received a smaller increase. 
and others who prefer that faculty attend to their responsibilities of teaching, research, and service, rather than protesting or lobbying. However, the Court has ruled that unless false statements are made recklessly or knowingly, public employees cannot be dismissed for speaking on matters of public importance. ${ }^{151}$ In other words, public college employees maintain their rights as citizens to comment on matters of public importance. At private institutions, the right to comment on matters of public importance at the institution may only be extended to faculty members because of the protection of the AAUP. In any case, professors should be clear in their criticisms as citizens and clarify that they are not institutional spokespersons. 152

In the cases cited above, one's general understanding of what was politically palatable was derived from the norms of the majority and the generally accepted patterns of behavior and thought, guided by the predominant social and political forces of the time. Although the courts have provided solid protection for free expression in the classroom, the point at which a professor's speech interferes with the effective functioning of the institution to the point where the institution's interests must prevail has not been well defined, especially in light of the complex issues of academic freedom, conflict of interest, and public

151 Pickering v. Board of Education. 391 U.S. 563 (1968). Six possible exceptions to this rule were discussed: 1) a great need for confidentiality, 2) a close working relationship which would be severely undermined by public criticism, 3) disruption of the educational process, 4) disruption of the teacher's relationship with the institution's administration, 5) failure to try to resolve grievances with superiors prior to public disclosure, and 6) statements relative to an employee's competence.

152 AAUP 1940 Statement of Principles on Academic Freedom and Tenure (Reprinted from L. Joughin (ed.), Academic Freedom and Tenure: A Handbook of the American Association of University Professors, Madison: University of Wisconsin Press, 1969, at 33-39). "Academic Freedom" section (c) states: "The college or university teacher is a citizen, a member of a learned profession, and an officer of an educational institution. When [s] he speaks or writes as a citizen, [s] he should be free from institutional censorship or discipline, but [this] special position in the community imposes special obligations. As a [person] of learning and an educational officer, [s] he should remember that the public may judge [the] profession and [the] institution by his [or her] utterances. Hence, [s] he should at all times be accurate, should exercise appropriate restraint, should show respect for the opinions of others, and should make every effort to indicate that [s] he is not an institutional spokes[person]." 
policy. ${ }^{153}$ The recent changes in Eastern Europe and the Soviet Union have changed Americans' perceptions of communism perhaps enough to be less threatened by someone teaching in a university with beliefs like Grant Cooper. A university community's attitude toward a particular ideology can change over time as can public attitude. The next sections examine other ways in which the understanding of what is "politically correct" has evolved over time.

\section{Student Activism and Political Correctness}

Many observers outside of academe perceive that college professors and administrators hold liberal political and social views, and that professors generally are critical of society. 154 One of the most outspoken groups that held this view surfaced in the 1980s, calling themselves "Accuracy in Academia" (AIA).155 This conservative group was instituted to monitor classrooms in colleges and expose the "inaccuracies" and "liberal bias" of the faculty. An AAUP spokesperson called the AIA a "menace to academic freedom," similar to the communist hunts conducted by Joseph McCarthy in the 1950s.156 The AAUP Committee on Academic Freedom and Tenure condemned the activities of the AIA because the group had announced it was looking not just for errors or departure from the truth, but for departures from the organization's conservative ideological perspective. 157 As with most threats to academic freedom, the AAUP was concerned with the potential change in behavior among professors and students if they knew that their utterances would be published because a particular group was trying to further its ideological ${ }^{153} \mathrm{E}$. Gilbertson, "The Constitution and Academic Freedom," paper presented at the Annual Meeting of the American Association of State Colleges and Universities, New Orleans (LA), November 24, 1987.

154S. Rothman, "Academics on the Left" Society, Vol. 23, No. 3, March-April 1986, at $44-49$.

155S. Heller, "Watchdog Group Says Students at 110 Colleges Now Monitoring Classrooms for "Liberal Bias," Chronicle of Higher Education, October 16, 1985, at 27-29.

$156 / d$.

157 No author. "Accuracy in Academia' A New Obstacle to Academic Freedom," Academe, Vol. 71, No. 6, November-December 1985. See also: No author; "On 'Accuracy in Academia' and Academic Freedom,"Academe, Vol. 71, No. 5, September-October 1985. 
aims. The AIA has had little influence in higher education despite their initial flurry of activity, and has evolved into a milder conservative political student newspaper. ${ }^{158}$

The ideological concern expressed by the AIA paralleled a growing trend for students on the political left to attempt to censor conservative speakers on campus. At larger institutions, conservatives fear that proponents of the radical left have been more successful in monopolizing the debate, and at least three national organizations reject the democratic ethic of free speech: The International Committee Against Racism, the Spartacus Youth League, and the Committee in Solidarity with the People of El Salvador.159

General activism by students in the 1980s and 1990s, according to Tony Vellela, has focused on eight major areas:

1) divestment of financial interests in South Africa,

2) Central American Politics,

3) connections between the military and the university,

4) racism,

5) economy and general welfare,

6) women's issues,

7) gay, lesbian, and bisexual rights, and

8) the Central Intelligence Agency. 160

A resurgence in the popularity of environmental issues could be added to this list as campuses address issues of waste management, recycling, the disposal of hazardous materials, land development, and deforestation.

The academic culture functions to support changes/improvements in these areas.

In general, activist efforts in these areas are directed toward freeing the "oppressed" and toward

158S. Heller, "One Year Later, Faculty Members Notice Little Impact from Accuracy in Academia." Chronicle of Higher Education, October 22, 1986, at 11-12. See also, H. Ewbank, "Case Studies of the AlA Movement," paper presented at the 72nd Annual Meeting of the Speech Communication Association, Chicago, (IL), November 13-16, 1986. Ewbank found that at least 17 university faculty members had been the direct objects of negative publicity by AlA, and pointed to two professors who received media attention: A professor at Texas A\&M filed a defamation and libel suit against AlA because the publicity could affect his future employment and promotion achievements; A professor at Arizona State University sought a campus policy restricting unregistered individuals ("campus spies") from attending classes for the purpose of gathering information to be used against the university or individual professor.

159L. Csorba, "Appeasing the Censors: A Special Report on Campus Free Speech Abuses." Published by "Accuracy in Academia," Washington, D.C., 1986.

160T. Vellela. New Voices: Student Political Activism in the ' 80 s and '90s. South End Press: Boston, 1988. 
validating and supporting a myriad of special interest groups on campus. The issues are often characterized as a battle between a large, dominant, oppressive authority, such as the U.S. government or the "White paradigm" which supports it, and a powerless group of victims who must struggle to overcome the wrongs done to them by the dominant authority. In characterizing issues as 'David and Goliath' contests, the American ethic of fundamental fairness is violated and the 'Davids' are perceived to be more righteous, and therefore entitled to be protected, or even given preferential treatment because of their 'victim' status. Even the environmental protests portray the conflict as one between the oppressive forces of big business and the helplessness of average citizens to control the environment around their homes, schools, and offices.

Allan Bloom argues a broader set of reasons for the changes he perceives in academic culture. He notes,

"[t]he recent education of openness...pays no attention to natural rights or the historical origins of our regime, which are now thought to have been essentially flawed and regressive. It is progressive and forward-looking. It does not demand fundamental agreement or the abandonment of old or new beliefs in favor of the natural ones. It is open to all kinds of men, all kinds of lifestyles, all ideologies. There is no enemy other than the man who is not open to everything. But when there are no shared goals or vision of the public good, is the social contract any longer possible?"161

Bloom attacks the notions of the equality of ideas, the acceptability of all behaviors, and the relativity of cultural forces, and found these notions to be prevalent on college campuses. He perceives the mounting rejection of anglo-european culture to be guided by a blind adherence to the concepts of openness and relativism toward the values of various cultures and the refusal of academics and others to engage in critical evaluation of the values which the American people and their governments have rejected throughout their history. 162 In essence, the acceptance of all values means that none is truly valued. Bloom's critics respond by arguing that he blames African-Americans for creating a separate intellectual world, and that he blames universities for retreating from traditional education which stresses the supremacy of

161 A. Bloom. The Closing of the American Mind, New York: Simon \& Schuster, 1987, at 27. 
Western ideals. ${ }^{163}$ Further, critics charge, his attitude toward the superiority of the United States and its history resists self-criticism and approaches an ethnocentric adoration of American culture. 164

\section{Definitions of Political Correctness}

The phrase, "politically correct," is most often applied by political conservatives to anything they perceive threatens free speech about gender, race, sexual orientation, wealth, age, ethnic origin, nationality, and other related issues. One writer asserts that political correctness has "acquired an unmistakable conservative chic: It is the fashionable way to refer to anyone or anything -- films, the naming of college women's athletic teams...you name it -- where consideration of the matter shows the slightest hint of a liberal bent." 165 The following formulations offer a glimpse at the notion of PC and underscore the problems associated with creating a working definition.

According to Gordon Davies, director of the State Council of Higher Education in Virginia, "[i]t means, if anything at all, the replacement of civil discourse with slogan. It is an arbitrary standard brought into play at the point where people with different opinions won't tolerate one another, and that creates a very brittle, non-responsive intellectual structure that fails."166 A Richmond Times-Dispatch reporter believes the PC debate is concentrated in two different areas: the regulation of behavior and speech on campus, and the direction of curricular reform. 167 Conservative editorials in the Richmond newspaper offered polemic criticism of PC ideologies. One educational analyst wrote:

163F. Hayes. "Politics and Education in America's Multicultural Society: An AfricanAmerican Studies Response to Allan Bloom." Journal of Ethnic Studies, Vol. 17, No. 2, Summer 1989 , at 71-88.

${ }^{164} \mathrm{C}$. Reitz, "Bennett, Bloom and Boyer: Toward a Critical Discussion," paper presented at a Conference of the Southwest Community College Humanities Association, Kansas City (MO), November 2-4, 1988.

165L. Daniels. "Diversity, Correctness, \& Campus Life," Change, Sept.-Oct. 1991, at 18.

166R. Walker, "State university presidents discuss 'political correctness." Richmond Times-Dispatch, March 17, 1991, at 1-2. 
Thought Police. Multiculturalists. Fascists of the Left. The legions--gasp!--of the Politically Correct....Explaining PC isn't easy, because it isn't really an ideology in the true sense of the word. Instead, it is an ill-defined, set of loosely related beliefs championed by a mixed bag of radical feminists, Afrocentrists, militant homosexuals and other denizens of "the left." Many of these beliefs are extreme; many of them are not. But if the PC movement has a central tenet, it is this: that American universities, derived as they are from the intellectual traditions of Western Europe, are inherently biased institutions. The Bible, the Constitution, the works of Shakespeare, Jefferson, Melville, and Locke--all amount to propaganda in the power play by the universal villain of hard-line PCers, the heterosexual white male. 168

The conflict for college campuses occurs in the combination of these two definitions. When minority group members assert arguments of a systematic bias against them, that supposed bias tends to categorically discredit any statement made by white heterosexual males as naive or hostile to minority interests. Persons who do not support the interests of "victim groups" are labelled 'racist,' 'sexist,' 'homophobic,' or some other brand of insensitivity and are assumed to be supportive of a societal structure which is inherently oppressive to minority groups. Proponents of $\mathrm{PC}$ issues are accused of having a low tolerance for dissent and have themselves been labelled 'new ayatollahs' who function on campus as part of PC's "militant religion."169 The concern of many conservatives seems to be that the PC proponents appear to have exclusive control over the labelling process, for they argue that no one knows more about racism than one of its victims. Arthur Schlesinger, Jr. described the campus process as follows:

Moderates who would prefer fending for themselves as individuals are bullied into going along with their group. Groups get committed to platforms and to we-they syndromes. Faculty members appease. A code of ideological orthodoxy emerges. The code's guiding principle is that nothing should be said that might give offense to members of minority groups (and, apparently, that anything can be said that gives offense to white males of European origin)...The code imposes standards of what is called, now rather derisively, "political correctness." What began as a means of controlling student incivility threatens to become, formally or informally, a means of

${ }^{168}$ A. Hodges, "U.Va. recruiting ban: a skirmish in the PC war?" Richmond TimesDispatch, February 17, 1991, at 1, 5. It is important to note that the Times-Dispatch editorial staff treated rudely those it identified as "liberal academics," describing them as "hyenas of the American left" (3/9/91), "sybarites" (3/9/91), "left-leaning elites" (3/9/91), "the career civil rights herd" (2/14/91), "noisy PC activists" (2/12/91), "law school eggheads" (2/12/91), "denizens of the left-wing fever swamp" (3/5/91), "accreditation munchkins" (3/10/91), and "storm troopers of Political Correctness" (3/10/91).

169J. Leo. "The academy's new ayatollahs," U.S. News \& World Report, December 10, 
controlling curricula and faculty too. 170

A Newsweek feature story claimed that $\mathrm{PC}$ has its philosophical roots in the subordination of freedom of speech to the guarantees of equal protection. 171 Perhaps the growing acceptance of speech-restrictive codes on campuses (prior to the Supreme Court's ruling in R.A.V.) indicated a greater value being placed on the creation of environments free from harassment than on the protection of individual rights to expression. Politically, PC was said to resemble Marxism in a broad sense, as an attempt to redistribute power and wealth from the privileged groups (white males) to "oppressed" groups. 172 The article detailed PC euphemisms describing minority groups "differently able" instead of "disabled," "nontraditional age student" instead of "older student," and at Sarah Lawrence College, "womyn" instead of "women."173 To some, the form of language has become more important than its meaning. 174 The notion of political correctness has even been chronicled in comic strips (see Appendix G).

The phrase, 'politically correct,' connotes an either/or mentality. If one is not 'politically correct' then he or she must be 'politically incorrect.' Little opportunity exists for debate between the two extremes-there is a right way and a wrong way to conceive of the world and to behave in it. Structuring the argument in bi-polar terms serves to stifle debate, increase hostility, and decrease levels of trust among various groups. Increasingly, the group lines are drawn along immutable human characteristics, but each minority group has a common enemy--the white male power structure in corporate and collegiate America. Framed this way, the movement seems to be striving for a total rejection of the European influences on

170 A. Schlesinger, Jr. The Disuniting of America: Reflections on a Multicultural Society, New York: Norton \& Co., 1991, at 114-115.

$171 \mathrm{~J}$. Adler, et.al. "Taking Offense: Is this the new enlightenment on campus or the new McCarthyism?" Newsweek., December 24, 1990, at 48-55.

$172 / d$.

$173 / d$. See also, No author; "Ugh! Oops," The New Republic, February 18, 1991, at 39. This list of terms was collected and used by newsprint journalists to minimize the possibility of ethnic, racial, gender, or other groups who might be offended by insensitive language. Among the defined phrases and terms to be avoided because of their potential for offense were:

articulate, banana, barracuda, oriental, soulful, swarthy... 
American society. Because almost every aspect of American society is purported to have been shaped by white males--the government, Christianity, capitalism, education, language, history, literature, athletics, media, art-every aspect of American culture has become suspect.

Dinesh D'Souza calls this the 'victims' revolution,' claiming that colleges are being led toward a state of intellectual totalitarianism. 175 D'Souza expresses concern that cynical university leaders have promoted a cresting wave of "thought control, special pleading, cultural separatism and intellectual dishonesty" which inundates American campuses and subverts the true purpose of education, to create free persons through liberal education. 176 He claims that at American universities all groups, except white males, have the latitude to define their needs and rights, including the views which others should have of them. This process, he argues, creates a new racism based not on the 'prejudice' of the dominant group, but on the 'conclusions' of those who have experienced the faults, gaps, and traps of American society. He writes:

Many high-priced colleges are not inculcating in students those qualities of critical thought and reflection that are the essence of a liberal education. Instead university leaders have created a sham community where serious and honest discussion is frequently drowned out by a combination of sloganeering, posturing, and intimidation. Yet the zeal with which some activists embrace the shibboleths of race and gender can drive them to outlandish positions. They resort to name-calling and threats when they cannot sustain their convictions in debate. Excessive and unsubstantiated attacks on motives are the most serious obstacle to a truthful and civil debate over issues of race and gender. ${ }^{177}$

Author Shelby Steele characterized the phenomenon as "the new sovereignty," whereby a group constructs itself around a perceived grievance(s) in order to gain power and act autonomously. 178 Once autonomous, Steele says a group perpetuates its existence by creating and sustaining grievances in order to maintain a 'victim' status.

175D. D'Souza, Illiberal Education: The Politics of Race and Sex on Campus. New York: Free Press, 1991.

${ }^{176} \mathrm{E}$. Fox-Genovese, "Education and Its Discontents." Washington Post: Book World, April 7, 1991, at 6. This article reviews D'Souza's book, lliberal Education.

177D. D'Souza, "Cap and Goon: Facing Up to the New Intolerance on Campus." Washington Post, April 7, 1991, at D1, 4.

178S. Steele. "The New Sovereignty," Harper's Magazine, July 1992, at 47-54. 
Robert Holland has written a stinging critique of the PC movement. As he conceives it, PC included the issues of affirmative action, fractionalization of special interest groups, "hate-speech" codes, recruiting bans on government agencies which discriminate against homosexuals, campus"civility plans," and the movement toward multiculturalism. Holland defines PC as an "overweening solicitude for the feelings of protected groups at the expense of individual rights, including free speech," and described Virginia colleges' campus civility plans as "intellectual bilge water."179 Holland's views (although extreme) may explain some of the public's recent disdain for some of the cultural changes in higher education. It is either ironic, revealing, or manipulative that Holland, a white conservative, pointed to Virginia State University (a predominantly black institution) as the 'island of sanity' among Virginia schools struggling with campus conflict. By exalting the apparent ease with which a predominantly black institution handles race relations, Holland contradicts himself by acknowledging that a black college can operate under different parameters than predominately white colleges. What he unknowingly implies is that the power structure supporting the predominantly white campus is the root of the PC movement, providing the reason and the motivation for its existence. Holland attributes the "PC silliness" to "white liberal angst;" however, he fails to concede that a long tradition of arrogant and insensitive conservatism led the minority groups to reject the predominantly white paradigm.

The conservative and PC groups disagree over whether or not there is even a problem to fight about. Many conservative writers assume that minority groups have little cause for complaint. Recent studies of college students' perceptions of racial inequality indicate that black and white students differ in the importance they ascribe to racial issues. At SUNY-Stoney Brook a 1988 survey ${ }^{180}$ revealed that $92 \%$ of black students perceived racial inequality, while $48 \%$ of white students reported that perception. In addition, $88 \%$ of black students surveyed supported affirmative action policies, while only $48 \%$ of white

179R. Holland, "An Island of Sanity in Virginia's PC Ocean." Richmond Times-Dispatch, February 20, 1991. Holland borrows some anecdotes and phrases straight from. The New Republic magazine, a conservative publication which dedicated most of the February 18, 1991 issue to racism on campus and various forms of the $\mathrm{PC}$ debate.

180C. Martin-Stanley, Psychosocial Factors Affecting Perceptions of Racial Inequality and Affirmative Action Policy Attitudes Among College Students. Ph.D. dissertation, DAl $50 / 068,1988$, at 2671. 
students reported their support. Significant racial differences were also found to exist along the measures of perceived increased prejudice, group identity, perceived intergroup conflict, and societal explanations for inequality. A study completed by the Southern Regional Education Board ${ }^{181}$ (SREB) of 5,000 students at 40 institutions of higher education in 14 states revealed differences between black and white students at predominantly white institutions regarding affirmative action policies, although students of both races reported less support than the Martin-Stanley study reported above. The SREB report noted that white students at predominantly black institutions complained about similar problems as black students at predominantly white campuses, with the exception that the white students could easily find reaffirmation and support of the majority culture by simply leaving the campus environment. The different experiences and attitudes of minorities and whites on campus may provide clues to the roots of the recent conflicts. Minority members can become frustrated trying to convince some people that a serious problem exists. The more they are ignored, the more frustrated, angry, and alienated they may become.

Critics of Bloom, D'Souza, and other anti-PC authors agree that the writers fail to evaluate the bases of their values and behaviors, and they refuse to engage in self-criticism. Some argue instead that conservatives continue blindly to glorify values and societal structures supportive of their own notions of what is right, what is valuable, and what is ideal. That so many different groups of people have focused on the same weakness of American culture caused PC supporters some concern. However, the anti-PC response has been to force many minority groups together into one group of 'minorities,' and dismiss the larger groups' claims as shallow, self-serving, and antithetical to democratic principles. Some supporters of the multicultural movement see the PC label as a 'straw man' created by the conservatives in order to bolster their own political ideologies and to discredit minorities with non-traditional ideas about the role of the university:182 Duke English Professor Cathy Davis accused the anti-PC cadre of "political hypocrisy," (PH) noting that

instead of proposing a conservative agenda, the new PH tactic is to claim unbiased objectivity,

181 S. Loughlin, "The Student View in Black and White." Sarasota Herald Tribune (FL), December 12, 1990. The article described the SREB report titled: "Racial Issues on Campus: How Students View Them."

182 Hodges, supra note 168. 
then to denounce the faults of the present-day academy from that ostensibly non-ideological stance, and finally to demand reforms that turn out to be highly ideological and politicized (although never acknowledged as such)...I am far more suspicious of PH than I am of PC, partly because it seems to be so much more powerful. The level of irrationality and hysteria directed against American university just now makes me wonder if we're in for a resurgence of real, old-fashioned McCarthyism....[I]t is PH's cynical appropriation of the whole PC issue that marks it as a more insidious and potentially dangerous enemy to the life of the mind and the business of the academy than the "totalitarianism" from which it claims it would protect us. 183

Some writers believe that the descriptions of college campuses that have dominated the mainstream media have grossly exaggerated the influence of PC. 184 Debates in academic and legal circles have been characterized as genuine, while the wider public debate has been labelled, "scuzzy, effluent with polarities, scare tactics, half-truths, and cartoonish exaggerations."185 Michael Olivas criticizes Dinesh D'Souza (on his book, Illiberal Education) for exaggerating his case, getting his facts wrong, and characterizing isolated and out-of-context remarks as representative of a larger movement. 186

Each side claims the other is too influential in campus decisions. Both the left and the right seem to prefer to characterize the other in extreme terms which serves to widen the chasm between them and further limit the possibility of reasoned discussion. Because discriminatory harassment policies are associated with PC, they are viewed with skepticism by critics of multiculturalism. Because the policies are believed to promote more hospitable environments, they are promoted by supporters of multiculturalism.

183C. Davidson. "PH' Stands for Political Hypocrisy," Academe, Sept. - Oct. 1991, at 8-14.

184 H. Collins. "PC and the Press," Academe, January-February 1992, at 12-16.

185C. Stimpson. "Meno's Boy: Hearing His Story--\& His Sister's," Academe, November-December 1991, at 25-31.

186 M. Olivas. "That D'Souza Book," Change, September-October 1991, at 56-60. 


\section{Chapter Three}

\section{Research Methods}

\section{Type of Study}

This descriptive study used qualitative methods to describe the process by which three universities responded to the problems of racial tension and racial harassment through their deliberation and adoption or rejection of policies that prohibit discriminatory verbal harassment. The researcher conducted on-site visits at each institution to gather information regarding both the discussion of adopting the policy and the situations following the final decision made to accept or reject a policy. Three universities were selected in order to provide comparative information among universities while operating within a limited budget. A study of the experience of only one institution would have relied heavily on the idiosyncracies of that institution, while survey data collected from numerous institutions would have inadequately explained conditions and factors affecting the policy (eg., campus racial relations, the historical, organizational, structural and political factors, the development of the various policies, or their implementation). The multiple-site case study approach satisfied the requirements for meaningful and descriptive information at more than one location.

\section{Site Selection}

The universities were selected based on several criteria: classification as a research institution, type of anti-harassment policy, public/private status, geographic location, percentage of minority student population, and experience with litigation of its anti-harassment policy. The final selection of the sites was determined by the researcher, choosing among the institutions that best satisfied the selection criteria and those that granted permission to conduct the research. Potential sites considered for the study included Emory University, Stanford University, and the Universities of California, Connecticut, Kansas, Michigan, North Carolina, Virginia, and Wisconsin. 
The University of Virginia, the University of Wisconsin and Stanford University provided the best combination of characteristics in the selection criteria. The Carnegie Foundation for the Advancement of Teaching classified these three universities as Research I universities. Both Wisconsin and Stanford adopted different forms of a policy prohibiting discriminatory verbal harassment as part of their student judicial codes, while the University of Virginia did not alter its student conduct policy to address this issue. In this study, the inclusion of institutions both with and without such policies was important in understanding the process and events leading to the adoption of the new policies. This distinction also was believed to be important in understanding the different outcomes resulting from each university's policy decisions. Public/private status of the institutions was considered important insofar as the Constitutional rights of free expression apply only to public universities as a matter of law. Geographic location of the universities was considered important as a means of contrast and as a means of understanding the different cultural, ethnic and racial relationships in different geographic regions of the United States. Although the universities were not regarded as prototypes of their geographic regions, their locations were considered to be a possible influence in the deliberations over new student conduct rules on harassment. The institutions in the study had predominantly white student populations and enrolled different percentages of minority students. Highly selective, predominantly white universities were chosen for the study because related literature indicated that these types of institutions were experiencing some of the most intense racial tension. The percentage of minority students was judged important in understanding the types and levels of influence on campus of large and small groups of minority students. One university (Wisconsin) was included, in part, because of an on-going legal challenge to its policy. This was considered useful in describing some of the connections among a major university, the legal system and the broader public issues raised by the university's verbal harassment policy.

The researcher made preliminary contact with the three selected institutions. Communications with Stanford law professor Thomas Grey and University of Wisconsin System general counsel, Patricia Hodulik were preceded by introductory letters from Mr. Robert O'Neil, Director of the Thomas Jefferson Center for the Protection of Free Expression. Mr. O'Neil was familiar with the research and knew Mr. Grey and Ms. Hodulik professionally. Soon after Mr. O'Neil sent his letter the researcher sent a letter, 
resume, and a summary of the proposed study to Mr. Grey and Ms. Hodulik. At UVA, direct contact was made with Emest Em, vice president for student affairs. Each initial contact person was asked about the feasibility of the study, the potential interest at the institution, the procedures necessary to secure permission for the research, and the names of those persons most closely involved with the policy at each institution. The chief student affairs officer at each of the three universities granted permission for the study and stated both support for the data collection and an interest in receiving the results. 1

\section{Data Collection}

On-site visits at Stanford and Wisconsin occurred during October and November, 1991. Each visit lasted six days during which the researcher conducted personal interviews, collected written documents, reviewed campus newspapers from 1985-1991, attended selected campus events, and recorded observations of campus life. Data collection and personal interviews at U.Va. spanned an eight week period late in the 1991 Fall semester. ${ }^{2}$ A few group interviews were conducted to discover the ways in which some members of each of the three campus communities conceptualized the issues of racial harassment and free expression on their respective campuses, to lend consensus and validity to the opinions expressed, and to increase the number of contacts.

Documents were reviewed and/or collected from several sources. Back issues of campus newspapers from 1985-91 were available at central libraries at each university. Presidential papers on UWS17, the Madison Plan, and Design for Diversity were retrieved from the archives of UW-Madison Memorial Library. Several interview participants at the University of Wisconsin provided copies of internal

1Each campus has a body that approves cases of research involving human subjects, presumably to insure ethical treatment and informed consent of research participants. Senior administrators at each university indicated verbally that this type of research was not subject to the restrictions of their 'human subjects' committee. An official at Wisconsin requested only that interview participants receive written notification of how the results would be used, and that request was honored at all three universities.

2The researcher lived in Charlottesville, Virginia throughout the data collection phase of the study, thus allowing more flexibility in scheduling and completing interviews, observations and other data collection. 
documents including correspondence, position papers, memoranda, and working papers. At Stanford's Office of the Dean of Students, an extensive (if not complete) file was maintained on the deliberations surrounding the Fundamental Standard Interpretation. The file includes news clippings (campus and external sources), internal employee correspondence, minutes from meetings, official campus reports, position papers, a collection of other universities' DVH policies, relevant journal articles, student essays and reports, and assorted other documents. Other relevant documents, including a videotaped panel discussion, were available at the Stanford Law School library. Some relevant documents at the University of Virginia were located in the Offices of the Board of Visitors, the University Judiciary Committee, and the President. UVA Interview participants provided copies of some relevant internal correspondence. Virginia, by far, had fewer documents relating to a DVH policy than either Wisconsin or Stanford. Documents at each institution were used to verify and/or refute interview data. Local documents also provided the basis for a valid chronology of events, especially when documenting racial relations before and after the policy debates.

\section{Interviews}

Prior to the campus visits, the following individuals were identified as primary interview contacts:

1. Chief Student Affairs Officer

2. University Legal Counsel

3. Chief Judicial Officer (administrator)

4. Chief Judicial Officer (student)

5. Director of Afro-American Affairs or Studies

6. Black student organization president or other officer

7. Student Council president or other officer

8. Professor of Sociology

9. Professor of Constitutional Law

10.Director of Student Activities

11. Campus AAUP representative

12. Students who did not hold elected leadership positions on campus (regular students)

13. Other persons recommended before and during the campus visit. ${ }^{3}$

${ }^{3} \mathrm{~A}$ few persons were not available for interviews. Neither Stanford nor Wisconsin had a chief student judicial officer because their judicial policies are applied primarily by administrators. At Stanford, the director of the African-American student center did not arrive at the pre-arranged interview time, and he did not return the researcher's subsequent phone calls to re-schedule. Also at Stanford, no professor of sociology was available to be interviewed for the study; instead, additional law professors and a professor of religion were interviewed. At the UW-Madison, the role of director of student activities is performed by the Office of the Dean of Students, where key staff members participated in interviews. 
Persons on this list were selected because of the likelihood of their involvement in the development of a policy on discriminatory verbal harassment, the implementation/adjudication of the policy, or the experience of being subjects under the policy. Professors of sociology and constitutional law were selected because they were likely to have handled race-sensitive material in classroom discussions, and it was predicted that they would be able to comment on the impact of the policy in the classroom. Students in major elected leadership positions were selected because of the likelihood of their familiarity with the issues of racial relations and the universities' administrative functions. This familiarity was regarded to have potentially shaped their perceptions of the issues in ways different than those of the general student body. Students not in elected leadership positions were not considered archetypes of the entire student body, but they served as a check against any attitudes or beliefs held particularly among campus student leaders.

The researcher scheduled interviews in advance and generally met participants in their offices for 30 90 minutes. A few interviews occurred in campus dining facilities. An interview protocol was developed and utilized during interviews (See APPENDIX "A"). Although participants were asked questions from the protocol sheet, not every question was asked of each participant. Some participants were familiar with only a few topics among the many questions on the protocol sheet. In most cases the researcher asked questions in addition to those on the prepared list in response to participants' interview statements. A total of 15 interviews were conducted at Stanford, including two interviews with student groups; nine of the interviews were audiotaped. At the University of Virginia, 13 individuals and one student group were interviewed, for a total of 14 interviews; eleven of the interviews were tape recorded. Eleven individual interviews and one group interview were completed at the University of Wisconsin-Madison and two were conducted with senior administrators at the UW-System, for a total of $14 ; 13$ of the interviews were audiotaped. The number of interviews completed and transcribed during the entire study totalled 43 ( 33 of which were tape recorded). A total of 57 persons participated in formal interviews for this study.

Participants were asked to sign an interview verification form (see APPENDIX "B") acknowledging that the interview occurred, informing them of the purpose of the research and indicating how the interview data would be treated. Participants were informed that the information they revealed 
during the interview would not be attributed to them in the final report, or in any other potential use of the study. However, material in the dissertation gathered from other sources may identify them by name or position. The guarantees of confidentiality were made with the hope of creating interview environments in which the participants would speak candidly about this potentially volatile issue. ${ }^{4}$ Participants also were told they would be notified in writing when the final report was sent to the chief student affairs officer at their institution.

Modified transcripts from the interviews were created by the researcher from audio recordings (when utilized during an interview), from notes taken during interviews, and from expanded notes created immediately after un-taped interviews. Modifications in the transcripts included some grammatical corrections and the omission of phrases such as "um," "uh," etc. A typed copy of the transcript and a cover letter was mailed to each interview participant. Participants were asked to review the transcription, suggest any corrections, and confirm in writing that they had reviewed it. Confirmations and/or corrected transcripts were received as follows: nine from Stanford (60\%), eleven from Virginia (79\%), and ten from Wisconsin (71\%), for a total of 30 out of a possible $43(70 \%) .5$ Among those who did not respond that they had reviewed their transcript were five students (or student groups), five faculty and three administrators. Most participants who returned their transcripts made no comments or changes. Most of those who did suggest modifications changed typographical and grammatical errors in the transcript. Five participants suggested substantive changes, deletions or additions to parts of their transcripts. All quotations in this report reflect the suggestions made by interview participants in their confirmation responses.

\section{Data Presentation}

Since the researcher guaranteed interview participants that information gained during the interviews

4During six of the interviews participants were not asked to sign an interview confirmation form because of the particular circumstances of those interviews. However, these participants were also promised that their comments would be revealed anonymously in the final report.

5 In calculating these percentages multiple confirmations from group interview participants were counted as only one response, and group interviews with no confirmations received were counted as only one non-response. 
would be reported anonymously, a coded identification system for interview participants was developed. Each participant was assigned a number . This number was used for purposes of transcribing interviews, for participants' review of their own transcripts, and for citation purposes throughout the text. For example, a citation of information received from a particular interview participant might be noted as follows:

"\#S-6 at 4" indicating Stanford University interview number six at page four;

"W-2 at 12 indicating University of Wisconsin interview number two at page twelve; or

"V-13 at 1 indicating University of Virginia interview number thirteen at page one.

Contextual information about quoted sources is included to help readers assess an informant's background. Quotations about race-related issues indicate the speaker's race. Almost all quotations indicate the speaker's role or position (i.e., student, faculty member, administrator). Clues to an informant's background help provide a context in which the speaker makes statements. The rationale for this is that the life experiences, for example, of a black administrator and a white faculty member may be different and therefore may lead them to different positions on the same issue. Labels of gender, sexual orientation, religion, physical handicap or other personal traits were not applied because this research focusses primarily on racial issues. These traits, although interesting, do not relate as directly to the issues of race and position at a university.

\section{Credibility of the Case Studies}

This study relied on qualitative data and therefore employed methods to portray each campus as described by the employees and students of that institution. Conditions and events both preceding and following the decision to implement or reject a campus's anti-harassment policy are described. The testimony of campus informants and relevant documents form the basis of each case study chapter.

Several steps were taken to enhance the credibility of the findings. First, the researcher engaged in periods of intense data collection for at least six days during an academic session at each university. During each campus visit the researcher conducted approximately 15 formal interviews and some informal interviews with students, attended relevant campus events (including student government meetings) and 
forums, ate meals in campus facilities, and reviewed campus student newspapers, relevant reports, correspondence and other available written documents. Prior to the visits, the researcher read literature related to that institution's experiences with new conduct codes and racial harassment. The researcher's familiarity with the University of Virginia and membership in the student body provided opportunities for long-term observation and reflection on campus matters related to this study.

Second, the researcher engaged in persistent observation ${ }^{6}$ in order to discover the most relevant indepth material related to campus racial conditions and speech-related conduct policies. The use of an interview protocol with items related directly to the research questions of the study facilitated the collection of pertinent information from informants. Interview participants were selected carefully for their knowledge and experience with their institution's harassment policy. The review of campus documents and publications (during the relevant time period) provided information about campus racial relations and the institution's experience during and after the policy debate. The relatively short campus visits allowed the researcher to recognize and respond quickly to conflicting data or to gain confirmation of data from a second source.

Third, the technique of triangulation 7 was used to verify information gathered from an individual source. Generally, the confirming citations are noted within the same sentence or, at least, within the same paragraph. Occasionally, statements were included that were not supported by data from another source, but these statements are treated as negative cases (i.e., a negative case was one that was not in agreement with the prevailing theory or it did not match the predominant way in which a phenomenon was represented to have occurred).

6 Y. Lincoln and E. Guba, Naturalistic Inquiry. Sage Publications: London. at 305 (1985). Persistent observation is the process of identifying and studying a limited number of research questions and entering the environment to find in-depth information about those questions.

7/d. at 305. Triangulation requires the identification of two different sources which provide the same information about an issue; this limited the possibility of the inclusion of false information from informants or written sources. 
Fourth, a peer de-briefer 8 helped guard against researcher bias in the interpretation of findings. A doctoral student at the Center for the Study of Higher Education in the Curry School of Education at the University of Virginia served as the peer. He has seven years of professional experience in university student life, and he was familiar with this study throughout its development. The peer de-briefer advised the researcher on approaches to handling specific interview participants, read selected transcripts, and read selected drafts of the report.

Fifth, member checking 9 -- offering interview participants the opportunity to review their transcripts -- helped confirm interview data. In addition, two key participants at each campus reviewed a draft of the chapter written about their particular institution. Campus reviewers included the chief student affairs officer who served during the time period being studied, and at least one other person who was identified by the researcher as knowledgeable about the subject and the campus environment.

Finally, the researcher maintained a sufficient audit trail, 10 to enhance the study's dependability and confirmability. Research records indicate the sources of data and the methods used to analyze the data, A research journal, recorded by the researcher, notes important events during the course of the study, descriptions of interview participants, special circumstances of the interviews, the rationales for the treatment of certain groups of data, and any irregularities or events that may have affected the study. Drafts of the development of the coding categories were maintained along with various drafts of the report itself.

Interview data gathered during on-site visits were analyzed using the constant comparative method

8/d. at 308. The peer de-briefer checked the assumptions and conclusions of the researcher and allowed the researcher to test theories with someone who perhaps held different assumptions about the issues.

9ld. at 314. Member checking required the researcher to perform certain tasks to verify the accuracy of information; for example the researcher provided informants with transcripts of their interview and asked the informant to read it and verify that the information printed is what was said. This was especially important for interviews conducted without the aid of a audio tape-recorder.

10Id. at 316-27. The audit trail is complete enough to permit another person to reach the same conclusions using the researcher's data. 
similar to the one set forth by Glaser and Strauss. 11 The researcher created categories for the interview data and then integrated the data according to their properties. Themes were delimited based on the integration of these categories. For example, one category developed titled "Academic behavior of faculty and students." This category included interview data related to classroom dialogue, research, or writing affected or feared to have been affected by the new campus harassment policies (or the proposed policy at UVA). The case descriptions show the purposes of the policies as envisioned by various campus constituents, and as applied by campus community members. Categories of data remained consistent across all three institutions, but data from each site were analyzed and written separately. Campus documents were not included in this analysis. Instead, they were used to establish a chronology of events, to verify and elaborate upon interview data, and to record the opinions and positions of the institutions and their key actors.

\section{Limitations of the Study}

Readers should analyze each case study and the summary section and draw conclusions regarding the transferability of the results of this study in their own situations. The cases detailed in this report include a "thick" description of the events and conditions found on each campus in order to facilitate readers' assessments of the similarities among the sites studied here and the readers' environments. Conclusions made in the final chapter refer only to the important features revealed among the three sites in this study.

The researcher engaged in a relatively short period of observation both at Stanford University and at the University of Wisconsin. The conditions and community members present during his one-week visits influenced his observations of campus life. The visits allowed for much greater insight into campus life (as opposed to no visit), but campus conditions change, and the impressions gained from a week long visit may hinge on the week chosen for the visit. Nevertheless, some community values and traditions endure, and these were certainly present during the data collection period. At Stanford and Wisconsin, campus interview participants and relevant documents provided sufficient information for understanding the ethos and structure of the environment. The researcher had more experience, from both an administrative and

\footnotetext{
11G. Glaser, and A. Strauss. The Discovery of Grounded Theory, Chicago: Aldine,
} 1967. 
student perspective, at the University of Virginia. This experience allowed the researcher to evaluate more quickly and with more confidence the information provided by various sources of data. Impressions of campus life at UVA, therefore, were formed over a period of three years rather than a period of six days.

Due to the constraints of finances, human resources and time, the study included a limited participant pool. Each campus visit involved an average of 19 participants in 14 interviews. It could be argued that more interviews would have increased the accuracy of the information collected. However, the participants were selected carefully and deliberately for their involvement and knowledge of the policies in the study. Others were identified as knowledgeable during the course of the study (especially at Wisconsin) but were not contacted. Interview participants confirmed that most individuals central to the success and accuracy of the study had been or were scheduled to be interviewed.

The evolving nature of the research topic is a difficult limitation to assess. For example, one week before the researcher visited the University of Wisconsin a United States Federal District Court overturned the University's policy because it violated the First Amendment of the United States Constitution. Several months later, after further discussion on campus, the Wisconsin Board of Regents voted to amend the policy and promulgated the amended version. Shortly thereafter, the United States Supreme Court ruled on a St. Paul, Minnesota, ordinance and left the Wisconsin policy with little legal support; the Wisconsin Regents subsequently retracted the policy. Descriptions of campus racial relations run throughout the report, yet racial relations evolve over time, seldom remain static, and seem to invite a variety of interpretations.

The researcher's reliance on student publications as a source of data may be another potential weakness of the study. Even the best daily student newspapers publish misstatements, misquotes, inflammatory quotes, and erroneous information in their features and editorials. Likewise, students' letters to the editor may be prepared hastily, and factual corrections can be difficult to find. Both WisconsinMadison and UVA published two daily student newspapers, and the researcher's reliance (predominantly) on one source at each institution may have affected the tone of the case studies if the newspapers used most often by the researcher published articles and editorials with a particular political ideological base. These primary sources were The Badger Herald at Wisconsin-Madison and The Cavalier Daily at UVA. Because 
of the relative scarcity of administrative documentation on the development of the proposed 13th Standard at UVA, the student newspapers there were utilized more frequently as a source of information.

A situation and potential limitation to the study peculiar to the University of Virginia involved a previous contact between the researcher and the 1990-91 Black Student Alliance (BSA) organization. One year before this research began, the researcher became involved in a semester-long qualitative research project with the BSA toward the fulfillment of the requirements in a doctoral course in qualitative research. The course required that students study an organized educational or social setting. The researcher selected the BSA for the setting and, with the permission of the BSA leadership, he completed the assignment. At the end of the academic term the final report was delivered to the chairman of the BSA who, unknown to the researcher, transferred to another university at the end of the term and took the report with him. The former BSA chair never delivered the report to the other BSA members, and they did not know that the report had been completed and delivered as promised. When the researcher contacted the leaders of the 1991-92 BSA, they requested copies of the research report completed in 1990. One leader of the BSA expressed skepticism about a representative of the organization consenting to an interview until BSA members had an opportunity to see the report. This was understandable, since they had not received a copy of it the year before. An officer in the BSA did grant an interview for this study after receiving a copy of the 1990 report, but seemed somewhat reserved during the interview. Two other black UVA students participated in interviews

The information collected during campus interviews may have been affected by the level of familiarity between interview participants and the researcher. The researcher's acquaintance as a student with the University of Virginia, along with his internship positions, may have influenced the information received during the UVA interviews. The offices of the Senior Vice President and the President are involved in many institutional policy decisions. The researcher made the acquaintance (through the internship) of several UVA interview participants prior to their interviews. The participants who were unknown to the researcher prior to the interviews were apprised of the researcher's central administration internship assignments before the interview. Notification allowed participants to decide what information to reveal to the researcher, in case they were concerned that their remarks might not be kept confidential. Nothing 
indicated that any of the interview participants at UVA were anything less than candid. However, it limits the study insofar as it is possible that some administrators and/or student leaders may have had reason either to withhold information or to present it in ways that were most advantageous to their particular situation. It is unclear whether this situation is any more problematic than the situations at Stanford or Wisconsin. Interview participants there may have been reluctant to reveal information or may have presented information in certain contexts because they did not know the researcher well enough to trust him with inside information. Most participants at UVA knew that the researcher was a UVA doctoral student and not, for example, a reporter in disguise. Wisconsin and Stanford participants met the researcher for the first time at the interview. The researcher's responsibilities included building rapport and inspiring trust among the participants so that they would speak candidly about their campus and its handling of this contentious issue. Participants' either knowing or not knowing the researcher could have affected the quality and quantity of information collected during the interview process.

\section{The Researcher}

Qualitative research relies heavily on the ability and diligence of the researcher. The products of this type of research can be influenced by the researcher's attitudes and personal experiences. Since the research instrument in this study is the researcher, himself, it is important to have some understanding of his background and any other information relevant to the research. Below is a brief summary.

I was born and raised in Dover, Delaware. I am male, 32 years old, and caucasian. I attended James Madison University (Virginia) from 1978-84, earning a Bachelor's and Master's degrees in psychology. While a student, and for five years as a professional, I worked in various student affairs roles at James Madison University, the University of North Carolina-Charlotte, and Davidson College (director of residence life). I began work toward the Ph.D. degree at the University of Virginia in September 1989 at the Center for the Study of Higher Education. During my second and third years--and throughout most of the work on this research -- I served as the doctoral intern in the offices of the senior vice president and the president at UVA. Also during that time period I assisted with an internal investigation into possible 
violations of N.C.A.A.12 rules in UVA's Athletic Department and its related booster club. ${ }^{13}$ In preparation for this study I completed courses at the UVA Law School on the First Amendment, equal protection, legislative interpretation, and legal issues in higher education. At UVA's School of Education, I completed course work in qualitative research focussing on student racial relations. Most of the course work completed at UVA's School of Education covered broad-ranging current and historical issues at American colleges and universities. I have presented numerous programs and workshops about discriminatory verbal harassment at national and regional student affairs conferences.

12National Collegiate Athletics Association

${ }^{13}$ From a research perspective, the athletics investigation was a single-site case study of UVA's athletic operations. 


\section{Chapter 4}

\section{The University of Wisconsin}

This chapter describes the considerations and events preceding and following the adoption of the 1989 revisions to $\$ 17.06$ (2) of the Student Nonacademic Disciplinary Procedures of the University of Wisconsin System. The policy was designed to curtail students' discriminatory verbal harassment by prohibiting certain kinds of expressive conduct (see Appendix " $\mathrm{C}^{\text {") }}$. This case study focusses on the University of Wisconsin System and more specifically on the UW-Madison because of its position as the flagship university, its particularly difficult circumstances regarding race relations, and its role as a leader in the development of UWS-17.

The first section presents the historical, structural and organizational factors and conditions that provided the context in which the University of Wisconsin System (UWS) and the University of WisconsinMadison (UW-Madison) developed its policy. Next, a description is provided of the racial climate prior to the adoption of the revised policy. The third section presents the political factors and conditions important to the development of $\S 17.06$ (2) (hereafter referred to as UWS-17). The fourth section includes a general chronology of events during the drafting of the rule and a discussion of the rationales of the policy's supporters and opponents. The last section delineates some of the outcomes of the University's adoption of UWS-17, including its application and its impact on racial relations and academic behavior.

\section{Historical. Structural, and Organizational Factors and Conditions Historical Factors and Conditions}

The University of Wisconsin was founded in 1849 under the provisions of the state constitution.

Now known as the University of Wisconsin-Madison, the original campus was a land-grant institution located in the state capital. In the early 20 th century the University became well known for "The Wisconsin Idea." Clark Kerr noted that the University of Wisconsin, particularly during the presidency of Charles Van Hise (1903 to 
1918), entered the legislative halls in Madison with reform programs, supported the trade union movement through John R. Commons, developed agricultural and urban extension as never before. The University served the whole state."l

The University prides itself on its commitment to academic freedom and the search for truth through the creation and dissemination of knowledge. Abraham Lincoln, a symbol of freedom for many Americans, presides in bronze effigy over the quadrangle in the old section of campus. Behind Lincoln's statue, on the outside of the main administration building for UW-Madison, a bronze placque memorializes an often quoted passage signifying the University's commitment to truth. It reads:

Whatever may be the limitations which trammel inquiry elsewhere, we believe that the great State University of Wisconsin should ever encourage that continual and fearless sifting and winnowing by which alone the truth may be found. 2

The main administration buildings of the University and the Capital are each situated in plain view of the other. The visible proximity of the state govemment offices, the higher education system offices and the Madison campus may serve as a constant reminder of the inter-relationships and influences among the three entities.

\section{$\underline{\text { Structural Factors and Conditions }}$}

\section{The University of Wisconsin System}

The University of Wisconsin System (UWS) is a public, multi-campus system of higher education which includes 26 campuses. The Board of Regents is responsible for policy decisions affecting all of the institutions in the system. The total number of students in the UWS in 1987 was nearly $162,000,{ }^{3}$ and of

1C. Kerr. The Uses of the University (Cambridge: Harvard University Press, 1982), at 16.

2The statement was adopted by the Wisconsin Regents following a controversy in 1894 . The statement appears in various places in campus publications, including the campus map.

${ }^{3 K}$. Shaw. Design for Diversity. A report to the Board of Regents, April 7, 1988, at Appendix 2(D). The 1986-87 academic year is the most appropriate year to report statistical information since several of the factors leading to the development of Wisconsin's policy on discriminatory verbal harassment occurred during that year. 
that total, almost 140,000 were undergraduates. 4 Undergraduate enrollments at individual four-year campuses ranged from a low of 1,873 at UW-Superior to 32,004 at UW-Madison.5 All of the four-year campuses are attended predominantly by white students (92\%); black students comprise $2 \%$ of the total enrollment, Hispanic students--1\%, Asian students--1.2\%, American Indian students--0.5\%, and foreign students--2.8\% (total minority enrollment--7.4\%). 6 In October 1987, then UWS President Shaw reported that $15 \%$ of black high school graduates in Wisconsin attended colleges in the UWS; compared to $36 \%$ of whites. 7 Trends in total minority enrollment in the UWS from 1977 through 1987 indicated a $17 \%$ increase overall; Asian enrollments increased 2.6 times, Hispanic enrollments increased by $37 \%$, and American Indian enrollments increased by $7 \% .^{8}$ However, black enrollments had steadily decreased each year since their peak in the 1980-81 academic year, and in 1987 black enrollments were $15 \%$ lower than in 1980.

The state of Wisconsin's 1987 population was $95 \%$ white, $4 \%$ black, $1 \%$ Hispanic, $0.7 \%$ American Indian, and $0.5 \%$ Asian. 9 During the next three years the state experienced increases in the population of every minority group. By 1990 the population was 5\% black, 2\% Hispanic, $1 \%$ Asian,

\section{4 /d., at Appendix 2(E).}

$5 / d$. Eleven of the campuses had enrollments between 4,500 and 11,000 undergraduates. UW-Milwaukee had over 20,000 undergraduates.

6 Id., at Appendix 2(D).

7K. Shaw. "Report to the UWS Board of Regents on Minority Students, Faculty and Staff," October 29, 1987. President Shaw was succeeded by Katherine Lyall who serves as interim UWS President.

8U.W.-System. "Enrollments, Term 1, All Levels, By Year," May 4, 1987. See also: K. Shaw supra note 3 at Appendix 2(D). The first document shows fall enrollments for the academic years 1977-78 through 1986-87. The second document indicates the fall enrollment for the academic year $1987-88$.

9 The Chronicle of Higher Education Almanac. September 1, 1988, at 85. 
$0.8 \%$ American Indian, and $92 \%$ white. 10 In contrast to Virginia and especially California, Wisconsin was the least ethnically diverse state.

\section{The University of Wisconsin-Madison}

The University of Wisconsin-Madison is the flagship institution of the state system. It is a Research I institution (Carnegie Foundation classification) with a health sciences center, veterinary school, agricultural component and a full range of traditional disciplinary offerings for undergraduate and graduate students. The main campus is situated on about 900 acres of land adjacent to Lake Mendota in the city of Madison. A variety of architecture styles and structures are represented throughout the campus facilities. The University employs over 15,000 persons. 11 Minority groups members comprised $6 \%$ of UWMadison's 2200 faculty in 1986-87.12 The UW-Madison has an operating budget in excess of $\$ 1$ billion ( $28 \%$ of which comes from state appropriations). ${ }^{13}$ In 1987 the UW-Madison ranked third in the United States in monies received for research and development (over \$250 million). 14

In the 1987 fall semester UW-Madison was the fifth largest university in the United States, enrolling approximately 43,400 students, 15 of which 32,000 were undergraduates. ${ }^{16}$ Among all

${ }^{10}$ The Chronicle of Higher Education Almanac, August 28, 1991, at 102.

11UWS Campus Map, 1990-91.

12K. Shaw, supra note 3 at Appendix 2(A). Actual numbers of each racial/ethnic group in the faculty at UW-Madison were as follows: black--24, Asian--84, American Indian--2, Hispanic--25, white--2113.

13 Supra note 11.

14 Id.

${ }^{15}$ The Chronicle of Higher Education Almanac, "Campuses with the Largest Enrollments, Fall 1987," September 6, 1989, at 19.

16 Id. See also K. Shaw, Design for Diversity, supra note 3. 
undergraduates, approximately 2,400 students identified themselves as members of minority groups. 17 The actual numbers of undergraduate minority students on the Madison campus included 721 Asians (2\%), 541 Blacks (2\%), 369 Hispanics (1\%), 102 Native Americans (0.3\%), and 676 foreign students (2\%). ${ }^{18}$ The total number of minority students had increased steadily from 1976 through 1986 from $4 \%$ to $5 \%, 19$ but the campus was attended by a large white majority.

These demographic realities set UW-Madison apart from the other institutions in this study because its enrollment was two and a half times that of the University of Virginia and more than three times that of Stanford University. The UW-Madison also had, by far, the lowest percentage of minority students of the three institutions. In addition, the number of students from traditionally disadvantaged groups was much smaller at the UW-Madison than either Stanford or Virginia. The numbers of ethnic minority students on the Madison campus reflected some of the demographic realities in the state of Wisconsin which differed from the demographic situations in Virginia and California. Among undergraduate students, the UW-Madison draws more from within state borders than either Stanford or Virginia. One result of the UW-Madison's large size and small minority presence may be an exacerbated condition of "spot-lighting" minority students. In other words, since there are so few minority students on campus, they are more likely to stand out and be perceived as 'different' by whites. The small number of ethnic minority students may lead to their increased sense of isolation and separation from a student body,

17University of Wisconsin System. "Minority Headcount Enrollment," lable prepared by UWS administration, October 21, 1987. The UWS defined under-represented minorities to include blacks, Hispanics, and American Indians; these groups together totalled 1,455 students (approximately $3.4 \%$ of the total enrollment). Black student enrollment at UW-Madison was $1.7 \%$. The largest number and the greatest percentage of black students $(1,471 ; 6.3 \%)$ in the state system attended UW-Milwaukee.

18K. Shaw. Design for Diversity, supra note 3. The predominant number of foreign students were from Asian countries.

19U.W.-Madison. "Document 1628A/2; Enrollment History" (no date; last data indicated are from the 1985-86 academic year). It is probable that Madison's experience with minority enrollment mirrored the UWS in the levels of increases among Asian and Hispanic students and stasis or decrease among American Indian and black students. See \#W-11 at 1 (This notation refers to University of Wisconsin interview number 11 at page 1 ; references to other interview data are recorded in this manner). 
faculty and staff dominated by whites.

\section{Organizational Factors and Conditions}

\section{Administrative process for adopting nonacademic regulations:}

Because of the size and complexity of the UW-Madison campus and its relationship to other campuses within the UW System, a lengthy set of procedures exists to ensure that any and all proposed changes to administrative rules receive the full consideration of all affected constituencies, including the general public. The bulk of regulations regarding student life on Wisconsin campuses are contained in the University of Wisconsin System's Chapter UWS 17 Student Nonacademic Disciplinary Procedures. ${ }^{20}$ Some regulations are written to allow for local implementation. On the UW-Madison campus, the Student Conduct Policy Committee (SCPC) is responsible for reviewing student conduct issues and making recommendations to the chancellor. The committee is composed of faculty and students and a member of the student affairs staff, ex officio. Typically, during the review process, Committee members will meet with various groups on campus that may be affected by the policy to solicit advice and support as appropriate. This may include student government organizations, special interest groups, the faculty senate or others. Upon receipt of the Committee's recommendations, if the chancellor concurs and the issues have effects beyond the campus regulations, the report may be sent to the system offices for further review. After further study, the system president brings the issue before the Board of Regents, which then acts on the policy recommendation.

If a policy change is approved by the Regents, a series of rule-making procedures is implemented. These steps include a public hearing on the proposed changes held by the Regents, a review of the proposed rules by the Legislative Council Rules Clearinghouse (part of the State Legislature), the transmittal of the proposed rules by Board action to the presiding officers of each house of the Legislature, and a review period

20University of Wisconsin System, Chapter UWS 17 Student Nonacademic Disciplinary Procedures, as published in the UWS Register, August, 1989, No. 404. This section describes the general rules for proposing and promulgating policies. The discussion about UWS-17 is described in section IV of this chapter. 
for each Legislative committee (there is the possibility of another public hearing at this point). 21 If no committee action is taken in 30 days, the rules are returned to the Board for promulgation. If either of the Legislative committees recommends a modification, the Board must reconsider the proposed rules. If a Legislative committee objects to the proposed rules, the rules are referred to the Joint Committee for Review of Administrative Rules. The Joint Committee may hold another public hearing and it has the power to either prevent promulgation of the rules or to reject the committee's findings and return the rules to the Board for promulgation.

It has been estimated that after the Regents approve the initial proposal that to promulgate the rule through this process in the best of circumstances takes a minimum of six months. ${ }^{22}$ Rules can be implemented on an emergency basis, thereby altering some of the legislative process outlined above. The emergency procedures allow for the proposed rules to become effective upon publication in the official state newspaper and remain effective for 150 days, during which time the usual legislative rule-making process would be implemented.23

\section{Key Personnel in the Development of the Policy}

The UWS President during the initial UWS-17 discussions, Kenneth Shaw, served from 19851991. The chancellors of the individual campuses report to the President of the UWS who, in turn, reports to the System Board of Regents. The Governor appoints UWS Board of Regents members. Most Board

21J. Temby. Memo to the UWS Board of Regents, April 12, 1989. Copies distributed on the Madison campus on April 14, 1989, by acting chancellor, B. Cohen, to the University Committee, the Student Conduct Policy Committee and David Ward.

22Minutes of the Regular Meeting of the Board of Regents of the University of Wisconsin System, UWS, April 7, 1989, at 22. 
members, just prior to the time of the UWS-17 discussion, were Democrats. ${ }^{24}$ The System administration prepares materials for the Regents' monthly meetings. Key personnel at the system level who were involved in the discussion about UWS-17 included President Shaw, the Senior System Legal Counsel and the Special Assistant to the President for Minority Affairs. The Special Assistant position was created as part of a multifaceted plan to address disadvantaged students' issues, adopted by the Regents in April 1988, titled Design for Diversity; the person in this role began in August 1988. At the UW-Madison, Chancellor Donna Shalala began in January 1988, replacing Acting Chancellor Bernard Cohen.

Other important participants in the policy's development included faculty members and student affairs administrators. The Dean of Students' Office has responsibility for enforcing nonacademic student conduct policies. Responsibility for the development and advocacy of a regulation which would delineate the boundary between free expression and discriminatory verbal harassment was delegated to the faculty cochairpersons and members of the Student Conduct Policy Committee. The Committee, and later the Regents, sought legal advice from three professors at the UW-Madison Law School as UWS-17 developed. 25

\section{Racial Climate Prior to the Adoption of UWS-17:}

\section{Introduction}

Most of the data presented here refer to UW-Madison events and conditions during the 1980s, and specifically from 1986-89. Statements about the racial climate presented in this section reflect the beliefs

24 \#W-6 at 4. "This was a Board that was appointed primarily by the Democratic governors, so it did not have a conservative image." Another interview participant stated that there were some republican appointees too, including one of the policy's strongest supporters (see \#W-3, comments made during a review of the Wisconsin draft chapter).

25 See \#W-13 at 1. One of the co-chairs of the SCPC in 1987-88 was a law professor familiar with workplace harassment codes from her former role as chief legal counsel to the U.S. Department of Labor under President Carter. She continued to assist the SCPC in the development of UWS-17 after her term expired. One of the co-chairs of the SCPC in 1988-89, a physics professor, had served as the main spokesperson for UWS-17 during 1987-88. Two third-year law students assisted the SCPC in developing the legal arguments for the policy. The three law professors, who held divergent opinions on the limits of the First Amendment, served as consultants to the SCPC as drafts of the policy were written. 
of campus informants, newsprint features and editorials, institutional self-studies, other public documents and some internal correspondence. This section chronicles several major public situations with racial content important to the discussion of UWS-17. Less public and other bias-related circumstances are also described. Next is a summary of the University's experiences with the recruitment and retention of minority students. The last part of this section presents students' perceptions of campus race relations.

The demographic make-up of the institution may have influenced the racial climate on campus in various ways, including the ways in which the campus attended to issues of importance to members of minority groups. Movements toward improving the representation and treatment of under-represented groups on campus generally met with approval among whites at Madison. ${ }^{26}$ However, there was some agreement that whites had little interaction with minorities in general and with blacks in particular. ${ }^{27}$ Some whites were not concerned with the level of the minority presence on campus, nor were they aware of problems faced by minority group members. 28 One white faculty member remembered:

When I got here in the mid-1980s the perception of racial issues on campus amongst the majority of white folks was summed up in an article in the Daily Cardinal in which the paper had surveyed people on campus and asked them to rank 25 problem areas in the United States generally. Racial/civil rights issues came in at \#24. It was just assumed not to be a problem.... The reality is, not just at this university, that very few white people know what the f--- is going on in black communities. Whites can't talk about it or respond to racism because they don't see it.

Segregation is the reality. It is a reality on campus and in the town of Madison.29

Other respondents indicated there was insufficient attention to minority concems and a history of negative experiences for persons of color. A black administrator noted a contrast in the level of attention to minority concerns; "...I know that before recent times, things were not occurring on campus and there was

$26 \# W-5$ at $6-7 ; \# W-12$ at 3.

$27 \# W-12$ at $2 ; \# W-7$ at $1 ; \# W-5$ at 2.

$28 \# W-1$ at 1,$3 ; \# W-5$ at $8-9 ; \# W-7$ at $4 ; \# W-12$ at 8. 
not a commitment to diversify the campus or institute programs that met the needs of students of color."30

A white administrator characterized the types of negative experiences faced regularly by some students:

What they [minority students] described were more patterns of suspicion that weren't being dealt with fairly or consistently. They also made it clear that there were plenty of incidents where they would be yelled at from a passing car, comments were made on the street, or other similar things. They let us know that just because we had not heard about these incidents or that they weren't being reported, we should not misunderstand them. ${ }^{31}$

This interview participant also remembered that the University had recognized racial problems before and had made repeated attempts during the 1970s and 1980s to address the racial milieu at Madison:

[t]he University made annual reports of its numbers and experiences, there would be a new effort made--a new study, a new report from time to time, and adjustments were made to funding initiatives. I mention this because it is fair to say that there was a period of increasing frustration... I don't want to say that this was true for most faculty and staff or citizens of the community--but certainly for those watching these figures, and for new faculty, staff and students who were interested in this area who would look at this institution's experience, there would be frustration with what had or had not happened.... This is some of the background. It is one of interest and commitment by some people to do something about recruitment and retention, and frustration at what was happening to us. 32

In March 1987, acting UW-Madison Chancellor Bernard Cohen spoke to faculty and staff warning against racism on campus. ${ }^{33}$ The newspaper feature reporting the speech indicated no specific incidents precipitating the comments. Instead, the article suggested that the remarks responded to well-publicized racial incidents at other universities and in communities around the United States.

\section{Major Public Incidents}

Beginning in May 1987, a series of race-related incidents began to unravel the Madison campus community. Many of the incidents involved fratemity members and fraternity-sponsored events. The

$30 \# W-7$ at 7.

$31 \# \mathrm{~W}-11$ at 2. See also, K. Rotker. "Minority students face insensitivity," The Daily Cardinal, February 11, 1986, at 1.

$32 \# \mathrm{~W}-11$ at 1. 1987, at 1 .

33K. Locke. "Cohen warns against racism on campus." The Badger Herald, March 31, 
fraternities were believed to be representative of the larger white student population, and were not necessarily perceived as a pocket of racism. ${ }^{34}$ There was some disagreement whether these incidents served as the genesis for Wisconsin's verbal harassment policy; however, there is agreement that these occurrences speeded the policy's development. The majority of respondents pointed to the major public racial incidents as the impetus for UWS-17 and as a dominant factor in creating a sense of urgency for its adoption.

The first (and perhaps most important) incident occurred in May, 1987. Each spring the Phi Gamma Delta fratemity (Fiji) held a social event called the "Fiji Island Party"35 where party-goers dressed in Hawaiian garb and painted their bodies black. ${ }^{36}$ As an advertisement for the party, the fraternity placed in front of its house a large (10-15 feet tall) painted sign-board depicting a black man with a bone through his nose. ${ }^{37}$ The Badger Herald's feature article about the party indicated that the Black Student Union (BSU) at Madison had twice confronted the Fiji's expressing their disgust over the caricature of the "Fiji Islander" portrayed on the sign-board. 38 A white administrator recalled that,

at that time, the leadership in the UW-Madison Black Student Union was very strong and talented. There was a protest against the sign-board by both black and white students on a Friday. The signboard was removed immediately and tumed face down behind the house. Within a few hours it was removed by the fraternity itself, who readily agreed that the sign-board was racist and insensitive. The sign was then taken to the side or the back of the house. During the early morning hours of

34Panel Discussion on UWS-17, sponsored by the Wisconsin ACLU, UW-Madison Memorial Student Union, October 22, 1991; comments of M. Mendoza, at 11. The three panelists included Mr. Mendoza (Chair of the legislative concerns committee of the Wisconsin Student Association), Patricia Hodulik (UWS Senior System Legal Counsel) and Jeffrey Kassel (Attorney for the firm of LaFollett \& Sinykin who represented the ACLU plaintiffs' challenge against the University and UWS-17). Approximately 40 persons attended the event.

35The Fiji Island incident was mentioned more often, and in more detail, than any other racial incident during the campus visit in response to questions about the racial climate during the late 1980s and inquiries about the genesis of Wisconsin's policy prohibiting hate speech; see $\# W-12$ at $2 ; \# W-11$ at $2-4 ;-\# W-10$ at $1 ; \# W-13$ at $1 ; \# W-2$ at $1 ; \# W-7$ at 1.

36K. Locke. "Fiji fraternity party called racist," The Badger Herald, May 4, 1987, at 1 .

37 Id. See also, \#W-4 at 2.

38/d. Allegedly during the confrontations, many of the Fiji members watched from their windows and laughed at the exchange between the BSU and Fiji representatives. 
Sunday someone put the sign-board back up--[it was never determined] who did this--which then sparked another major protest. 39

The incident was especially damaging because the same sign-board had been used for many years to advertise the party without protest by community members. The recurring advertisement was perceived by some persons as proof that racism had been present for many years and had gone unrecognized by whites. The fraternity used as their primary defense that the caricature was inadvertent racism and not intentional; they attempted to separate Fiji islanders from African Americans and to separate entertainment from cultural symbols. 40 A white administrator believed the campus community reacted as if it were,

embarrassed and somewhat shocked. This caricature that the fraternity men believed and intended, I think, to be a south sea islander with a bone through his nose and a loin-cloth, was a shop-worn character that had been placed on their lawn before the event for the past 12 years-every year. There was nothing new about it. The community was chagrinned and embarrassed that this had been going on and they had not seen it. Which was exactly the point the black students wanted to make, and unfortunately it was a point that was lost in the discussion. 41

The combination of on-going behind the scenes racist incidents and the public racial overtones of the Fiji party sparked students into action, led by the BSU. The BSU openly and deliberately used the Fiji party to symbolize a "larger truth" at Madison. 42 According to a white faculty member, several leaders in the BSU,

after the Fiji incident decided that something had to be done. They couldn't just sit back and listen to it any more. They sat down and thought very clearly.... They talked about the ways in which you could form an effective movement. It was a very conscious forming of a movement, a very conscious awareness of the ways in which the larger publicity context, locally, could be used to put pressure on the University administration. 43

$39 \# \mathrm{~W}-4$ at 2 . In the week following the initial confrontation, during a protest of the caricature and the party, Fiji's president apologized for the incident and claimed that Fiji members were not involved in placing the sign-board back up a second time; see B. Bennaker. "300 rally over alleged campus racism," The Badger Herald, May 5, 1987, at 1. Wisconsin interviews \#W-11 at 2 , and \#W-12 at 5 confirm the strength of the BSU leadership from 198788.

$41 \# W-11$ at 3. See also \#W-4 at 2.

$42 \# W-11$ at $2 ; \# W-7$ at $2 ; \# W-4$ at 2.

$43 \# W-12$ at 3. See also \#W-7 at 2. 
Students and other community members placed tremendous pressure on the University to take forceful action against the fraternity. 44 Open forums, meetings between students and administrators, marches and rallies were held to raise the awareness and the level of support for change in the racial climate on campus. The BSU leadership developed alliances with other student minority groups in order to develop a more forceful approach in addressing the campus racial climate with the administration at UW-Madison. The cooperative effort among the BSU, Wunk Sheek (Native American student group), Asian American, Latino, Chicano and Puerto Rican student groups came to be known as the "Minority Coalition." 45 The blame shifted, in part, away from the Phi Gamma Deltas and toward the entire campus environment; the protests targeted the University administration as the vehicle for change. 46

In the wake of the Fiji Island party, University administrators found quickly that no student conduct rules addressed the behavior of the fraternity. Despite this fact, senior administrators at the UWMadison suspended the Fiji's for three months and ordered them to discontinue Fiji Island parties. ${ }^{47}$ The Fiji fraternity did not challenge the administrative ruling, perhaps because they were concerned more with regaining the community's respect. Challenging the suspension would have placed them in the precarious position of arguing against punishment for an act that they had admitted was insensitive to African Americans. The Fiji members prudently accepted a punishment for their action, with or without an applicable rule, if only to assuage the public sentiment against them. A white administrator described the University's response to the Fiji Island incident as,

...important because that is where this issue of not having a rule first came to light. Here is

44B. Bennaker, supra note 39 at 1. See also, $\# W-11$ at 3.

45M. Daily. "Committee issues minority report," The Badger Herald, December 2, 1987 , at 1 .

46K. Locke. "Minorities blame entire campus." The Badger Herald, May 6, 1987, at 1. Also, S. Irwin. "Regents pledge to address racism." The Badger Herald, May 8, 1987, at 1.

47B. Regeth. "Sigma Alpha Epsilon cleared, Fiji suspended," The Badger Herald, June 15, 1987, at 1. See also, \#W-11 at 4. See also, M. Graves. "Hypocrites: Chancellors bend under pressure," The Badger Herald, June 15, 1987, at 9. Graves accused the administration of acting out of fear of being labelled 'racist.' 
strong community demand to act, and alleged racist incident, and no rule around. An administrator acts and it quickly becomes clear to him, as it was clear to others earlier, that this isn't going to work. Then we were in the position of trying to convince the fraternity to act in what we thought were its best interests and in the best interest of the University. 48

The Fiji party helped raised public awareness of the presence of inter-racial insensitivity or naivete, particularly among whites. The incidents following the Fiji party challenged the "white naivete" argument as it then became difficult to believe that white students could be unaware of the racial hostility fueled by the Fiji party advertisement.

Accounts of previously unreported racist events surfaced after the Fiji incident. In one of these events members of the Sigma Alpha Epsilon (SAE) fraternity allegedly held an off-campus party at which guests ate fried chicken and watermelon, and told racist jokes. The fraternity received no University sanction because SAE did not advertise the party, nor did fraternity funds pay for the event. ${ }^{49}$ However, some community members expressed outrage that event was held.

In the 1987 fall semester, several race-related incidents occurred after the Fiji Island party that "took off on their own momentum."50 The Fiji's suspension ended in September 1987. By November, some of the group's members were back in the news. Two Fiji members crashed a Zeta Beta Tau (ZBT) fraternity party, made racist and anti-zionist comments, and became involved in a fight. 51 The University temporarily suspended the Fiji's pending an investigation into the incident, and the Fijis suspended the two members involved in the altercation.52 The University's investigation revealed that the Fiji fraternity was not responsible for its members' actions in this incident; the University then rescinded the temporary

$48 \# W-11$ at 4.

${ }^{49} B$. Regeth, supra note 47 at 1 . See also, $\# W-13$ at $1 ; \# W-11$ at 4.

$50 \# W-11$ at 2.

51H. Gilliam. "Fijis face second suspension; Rouse calls investigation," The Badger Herald, November 2, 1987, at 1. 1987 , at 1 .

52R. Davis. "Fijis suspend two for ZBT incident," The Badger Herald, November 4, 
suspension. 53 Also during this semester, four white males violently assaulted a black freshman. ${ }^{54}$ The assailants were not identified positively as UW students. Regardless of the student or non-student status of the attackers, some black students believed the incident served to worsen relations among blacks and whites. 55

In April 1988, the University of Illinois' Acacia fraternity members disrupted two Afro-American studies classes and harassed one of the class's professors. The following week, black student leaders attended an open party at the UW-Madison's Acacia fraternity and demanded an apology.56 Initially, the Madison Acacia members denied any knowledge of the presence or activities of the Illinois group. Later, the Madison chapter revealed its members knew more about the event than they had indicated previously. 57 The Madison chapter was suspended for one year (for lying about its knowledge of the Illinois group's

53B. Regeth. "Fraternity suspension dropped," The Badger Herald, November 9, 1987, at 1. See also: M. Milligan. "University takes no action against Fiji fraternity," The Badger Herald, January 11, 1988, at 1. The University issued a 35-page report on the findings of its investigation. 1987 , at 1.

54(No author). "Rouse stops Fiji and Kappa Sig discipline," The Badger Herald, October, $55 \# W-1$ at 1.

56K. Koff. "Acacia apologizes, WBSU plans rally," The Badger Herald, April 18, 1988, at 1. This article focussed only on the black students' protest at the party. There was no mention of the incident which sparked the protest in this article or in any other article in The Badger Herald until May 6, 1988. Readers may have been left with the impression that black students were protesting against an imaginary incident since the class disruption was not reported along with the protest. The BSU led a march down Langdon Street (the location of most UW-Madison fraternities) and a rally at Bascom Hall protesting the Acacia incident -- see N. Kutynsky, "Threat to sue Acacia delivered at racism rally," The Badger Herald, April 19, 1988 , at 1 . Also protested at the rally was an alleged attack earlier in the week by a white man against a black woman. Wisconsin informant, \#W-2 at 2 , indicated that the attack occurred on State Street and that the white man called the black woman "nigger" while he beat her; white students were said to have passed by and done nothing while the incident occurred.

57M. Daily. "Fraternity punished by Shalala," The Badger Herald, May 6, 1988, at 1. 
actions) and the national organization revoked the Illinois chapter's charter. 58 A black administrator noted the impact of the Acacia incident on UW-Madison students:

So you have a group of fraternity members from Illinois focus on a classroom that they have heard has the most 'niggers' in it, go in there and set off a stink-bomb, and then run away.... What do you do when you walk out of that classroom and realize that your class has been picked out and disrupted because it's a class about Africa and it has African American students in it (who, by the way are not the majority in that class, but may be there in greater proportion than in some other classes)? Can you not, as a black student, ask yourself what is going on? Those kinds of situations can lead people to violent reactions. And it causes people to go through some serious mental gymnastics over how to deal with those incidents. ${ }^{59}$

The ZBT fraternity held an event in October, 1988, which later became known as the "ZBT Slave Auction." Some of the fraternity pledges at the party dressed in black face and mimicked black celebrities such as Oprah Winfrey and Michael Jackson. Audience members bid on the impersonators' time and services in an auction. Minority groups denounced the event as racist, then joined the attorneys for the ZBT fratemity and turned their attack on the University. 60 The Minority Coalition blamed the University for not taking sufficient action in previous incidents to curb this type of behavior while the ZBT attomeys accused University officials of being "out for blood" over any incident related to race. ${ }^{61}$ There is some agreement about the behaviors which occurred and about the event's importance in advancing the University's resolve in finding an end to race-related incidents. However, the event prompted various interpretations. An Hispanic student leader said,

[t]here were strong confrontations between members of the BSU and ZBT, to the point where it became physically violent. This polarized feelings of students. The incident was recorded on videotape and is on file in the Multicultural Center. Some of the members of the BSU directly confronted the perpetrators of the act and asked them why they did it. What followed that incident were speeches at the University Union, marches up Langdon Street, and protests in front of the ZBT house. The BSU was calling for the expulsion of the ZBT fraternity and all of its members

$58 / d$

$59 \# \mathrm{~W}-5$ at 7.

60J. Stein. "Groups claim ZBT auction is UW's fault," The Badger Herald, October 26, 1988, at 1. See also: J. Stein. "ZBT lawyer, BSU: UW is to blame," The Badger Herald, October 27, 1988, at 1.

$61 / d$. 
from the University. 62

The student did not indicate that he had ever watched the video, only that he knew of its existence. By focussing on and implicitly supporting the BSU's actions, the student characterized the event as racially motivated and catalogued the party as one of the events which led UWS to adopt UWS-17. Others on campus did not perceive the party as racist and challenged the 'slave auction' label. A white professor stated,

I saw a video of the whole $\mathrm{ZBT}$ incident, and other than the fact that there was language that would make a sailor blush there was nothing racist in it whatsoever....it was a socalled 'slave auction' and they didn't even use the word slave very often, if at all. It was vulgar and tasteless, but it certainly wasn't racist, even in the perception of some of the black students who watched it. They wanted it to be racist--they were looking for a cause.63

Regardless of the racial animus of the participants, the event was likely to be perceived as racially motivated or, at least, indicative of whites' ignorance of issues of importance to minority group members. Sensitized by the Fiji Island party, the Madison community reacted with less tolerance toward the perpetrators and the University with each subsequent event. Whites no longer needed the minority coalition to identify racial activities--in this unusually tense time "[they] were going to get reported quickly and [they] would be made a major issue." 64 To one white professor, the ZBT incident was important ...

for reinforcing the idea of a simple heightening of awareness....It was a bizarre sequence: the Fiji incident, the minority coalition forming, the Jewish students asking for support (particularly ZBT), and then the ZBT's creating their own outrage. It was just ridiculous....[T] he president of the ZBT's...wanted to go drown himself after it. That situation might have been one where a couple of idiots in the fratemity just got out of control.65

The discussion of the University's response to the issues of minority recruitment and retention

$62 \# W-2$ at 2.

$63 \# W-6$ at 3. See also: S. White. "ZBT cleared by WSA; action enrages students," The Badger Herald, November 15, 1988, at 1. An African American representative of the Wisconsin Student Association was quoted as saying that she did not find the videotape of the event to be racially demeaning.

$64 \# W-11$ at $3 ; \# W-8$ at 3.

$65 \# W-12$ at 3. 
occurred in the context of these public incidents. After controversial incidents like these occur, they can develop a life of their own. The actual facts of the events at the UW-Madison spread among the community by word of mouth and through the media with various interpretations attached to each event. By 1991, some students remembered the events from personal experiences and/or from reading campus newspapers. Rumors and anecdotal accounts formed other students' beliefs about the Fiji Island party and the ZBT auction; many had no direct knowledge or recollection of the incidents.

Three competing perspectives emerged as the predominant interpretations of the major public incidents. Some persons portrayed the events as the manifestation of deep seated racism and as a symbol of troublesome racial inequities. Others perceived the incidents as aberrations used as political fodder by oversensitive minority students furthering their comprehensive and radical agenda for change. Still others, predominantly whites, showed little concern for the incidents or for the concerns of minority students. It is possible that this third group of persons attended to their own academic and social concerns, oblivious to the problems which had surfaced on Langdon Street and unaware that the events had any impact on their lives.

Campus administrators faced the difficult task of maintaining the confidentiality of judicial proceedings against individuals and groups while responding to strong requests for sanctions against the "guilty" parties. Confidentiality rules constrained administrators somewhat from revealing case details as they materialized 66 and, consequently, may have unintentionally created additional suspicion about the administration's responses. These conditions allowed the student press to play a more important role in explaining the different perspectives used to describe the incidents discussed above. When community members' understandings and interpretations of events differ, the University is likely to be condemned by some groups regardless of the course it selects.

\section{Anonymous Racial Incidents and Other Race-related Circumstances}

The leadership of the Minority Coalition used the incidents on Langdon Street to symbolize a 
larger truth about their experiences at the UW-Madison. Some normal daily activities that were taken for granted by many white students provided a source of tension for black, Hispanic and Native American students. Some black students complained of poor relations between the Madison Police Department and African American males because, according to one black student, "they are likely to stop us for no good reason except that we vaguely fit a description of someone they are looking for."67 Other black students recounted experiences at local shops and stores in which they were followed closely and watched as if they were going to steal something. 68 In the city of Madison, some black students reported that white women were likely to clutch their purses and move over to keep a safe distance when an African American male passed by them. 69

Some students' experiences in the classroom were more troubling. Black students informed University faculty and administrators about their experiences of being called upon in class less often, being placed under suspicion during examinations and, in some cases, studying under professors, and with students, who assumed that they couldn't compete because they were black.70 A white administrator observed,

They were...not the kind of incidents which would make for a sharp report. They're not the sort of thing where they could say, 'Professor Jones refused to call on me today, I'm charging racism.' What they described were more patterns of suspicion that weren't being dealt with fairly or consistently. They also made it clear that there were plenty of incidents where they would be yelled at from a passing car, comments were made on the street or similar things. They let us know that just because we had not heard about these incidents or that they weren't being reported, we should not misunderstand them. ${ }^{71}$

$67 \# W-1$ at 2 . See also $\# W-12$ at 4.

$68 \# W-10$ at 4.

$69 \#-1$ at 2.

$70 \#-11$ at 2.

71 ld. See also, \#W-7 at 3; \#W-12 at 1; \#W-1 at 4. Interviewee \#W-5 believed that these incidents were not peculiar to the Madison campus or the UWS. The UW-Milwaukee campus was having its own problems as 'skin-heads' passed out leaflets with a caricature of the black chancellor and stereo battles waged in the residence halls between black and white 
Unreported racial incidents may have remained so because some minority students preferred not to be the focal point of a complaint or because they did not want to be perceived as someone who had a 'problem' or an 'attitude' with the campus environment.72 An understanding existed among black students that each individual's actions reflected either positively or negatively on other black students.

The Dean of Students Office began coordinating reports of bias-related incidents in 1989 and publishes the results of the reports annually. This was done, in part, to control the spread of erroneous information about bias incidents and to provide a factual basis from which to operate. Two of the interpretations of the major public racial incidents also apply here. Some students felt that accusations of racism were invented by the minority community or the administration. These students reacted either with hostility toward the perceived 'special treatment' afforded minority students or with nonchalance toward what they perceived to be made up charges. Others felt that the reported incidents were just the tip of the iceberg, that there were many more cases of harassment than the administration was acknowledging, and that most white students could not understand the indignity of being subjected to racial discrimination and harassment. Administrators and others believed that recording every incident and the disposition of each one would help mediate those perceptions and perhaps inform individuals on both sides. ${ }^{73}$

Some interview participants believed many white students had difficulty understanding what it was

residents over rap and hard rock music (at 2).

$72 \# W-7$ at 4

$73 \# W-5$ at 2; \#W-4 at 5. The results of the on-going tracking system for bias incidents are discussed in section five of this chapter. 
like to be the only minority person in a residence hall, the only minority person in a class and so on.74 It may have been difficult for whites to understand the feelings and experiences of black students facing the Fiji Island party advertisement and other discriminatory obstacles at UW-Madison and throughout American society. According to a black administrator, some minority students are keenly aware of bigotry and stereotypes perpetuated in the media and in universities. ${ }^{75}$ The different life experiences of the majority and minority cultures led members of various groups to characterize UW-Madison events according to their own predilections.

The most consistent primary source of evidence informing the opinions of the informants in this study, across all groups, was information received from students about their experiences at UW-Madison.76 In most cases, it was the stories told by the minority students which were the most persuasive evidence. Many of the events described above, both public and private, played an important role in the UWS-17 debate. During the course of the interviews for this study, every interview participant referred to one or more of the major race-related public incidents as a central factor of the policy discussion.

$74 \# W-5$ at 6.

75Wisconsin ACLU Panel Discussion, supra note 34 at 6.

76 Students' experiences as a source of evidence is addressed directly in Wisconsin interviews \#W-4 at 5; \#W-5 at 8; \#W-7 at 3; \#W-10 at $2 ; \# W-12$ at $1 ;$ and the Wisconsin ACLU Panel Discussion at 7. Every interview participant implied or stated that students' experiences were an important source of evidence. 


\section{Recruitment and Retention of Minority Students}

The University faced serious problems in recruiting and retaining minority students in the middle

and late 1980s. A local white attorney, familiar with the University's situation, stated:

There is no question in my mind, or among the ACLU leaders, that the University of Wisconsin has a serious problem with racism and with attracting and retaining minority students. No one questions the seriousness of the problem.... ${ }^{77}$

Depending on one's position, recruitment and retention were explained in one of two ways. The

first Administrators tended to maintain that the University has been interested in minority enrollment issues for some time (perhaps as far back as the late 1960s, but certainly since the mid-1980s). They believed the major racial incidents described earlier prompted the University to act quickly to resolve enrollment concerns. In contrast to the characterization of 'continuing attention,' minority students tended to believe the University had never really committed its resources to minority enrollment and some considered the response inadequate. Some students believed that the protests and public embarrassment following these incidents to be the only things leading the Regents and the administration into action. Both sets of beliefs, 'continuing attention' and 'inadequate concern,' acknowledged the importance of the major racial incidents in shaping the University's response, but departed over the University's on-going level of commitment to recruiting and retaining minority studènts. The purpose here is to describe how the debate evolved, not to declare a winner.

The UW-Madison has had both successes and failures in its recruitment efforts. A white 
administrator summarized the University's experience during the past 20 years as follows:

This institution has, like many mid-western institutions, since the early 1970 s placed some degree of priority on increasing the recruitment and retention of ethnic minority students. Statistically, the campus made fairly significant progress in increasing its numbers up until the late 1970 s.... At the time the University had six to eight years of consistent focus on recruitment and retention, a fair number of faculty and staff engaged in efforts in one way or another, and a substantial financial investment made in scholarships and services. Then, the numbers of minority students, particularly blacks, began to back off. The University made annual reports of its numbers and experiences, there would be a new effort made, a new study, a new report from time to time, and adjustments were made to funding initiatives....[F]or those watching these figures, and for new faculty, staff and students who were interested in this area who would look at this institution's experience, there would be frustration with what had or had not happened.78

Another white administrator believed that the Board of Regents was interested in minority student

recruitment "before, during and after" the 1987-88 racial incidents. Primary evidence of minority students' administrative support is found in three major institutional reports relating to minority concerns: "The Holley Report,"79 The Madison Plan, 80 and Design for Diversity 81 (these reports are discussed in section three of this chapter). The University had been under continual pressure to enroll minority students from

$78 \# \mathrm{~W}-11$ at 1 . The information about minority enrollment, and black enrollment in particular, is consistent with demographic data presented by President Shaw to the Board of Regents in his report on minority students, faculty and staff in October, 1987. A UW-System chart titled, "Enrollments, Term 1, all Levels, By Year," (May 4, 1987) showed that black enrollments peaked during the 1980-81 academic year, and that black enrollment had fallen by $15 \%$ during the period from 1980-87.

79Steering Committee on Minority Affairs, Final Report, University of WisconsinMadison, November, 1987. At UW-Madison, the report was known as "The Holley Report," named for its chairman, then president of UW-Madison's Black Student Union, Charles Holley.

80D. Shalala. The Madison Plan (printed as a supplement to Wisconsin Week, a newspaper for UW-Madison faculty, staff and students) February 17, 1988.

81K. Shaw, supra note 3. 
the Milwaukee area. ${ }^{82}$ Senior administrators at both the Madison campus and the UWS communicated support for efforts to increase minority participation. 83

Some students portrayed a less supportive administration. One Hispanic student leader asserted that the administrators "tell you what they think you want to hear...I've never seen the administration take a strong leadership role in these issues." 84 Some black students indicated they believed the University's recruitment efforts were inadequate. For example, they remembered the University's promotional materials as showing various white students discussing the University's diversity by referring to international students or to some token black person who lives somewhere in their dorm. ${ }^{85}$ Some Hispanic and white students criticized The Madison Plan for failing in its recruitment measures. ${ }^{86}$ A black student maintained, "It]he Madison Plan was put together in 40 days and worked the first year, but every year since that the number of black freshmen has decreased." 87 The problem was identified accurately, but the explanation was naive or based upon experiences among traditional age undergraduates; the number of black freshmen had been decreasing steadily since the $1980-81$ academic year, not just since 1987 when The Madison Plan

$82 \# W-3$ at 2.

$83 \# W-3$ at $2 ; \# W-6$ at $1 ; \# W-11$ at 4.

$84 \# W-2$ at 4.

$85 \# W-1$ at 6.

86See Wisconsin ACLU Panel Discussion (comments of student participants), supra note 34 at 6-8.

$87 \#-1$ at 7. 
began. Unfortunately, the perception that the plan failed was real, even if it was not entirely accurate.

Some students perceived the three institutional self-reports as providing minorities too little help, too late.

Some thought the reports were a hasty solution to a long-term problem. ${ }^{88}$

It seemed that the University's ability to communicate its long-term efforts to improve recruitment and retention diminished in the aftermath of the 1987-88 racial events. Although several interview participants held that the University sustained its effort and commitment to minority enrollment throughout the difficult times of the 1980 s, the fact that the recent racial events occurred was seen as evidence by some that those efforts were not successful. The incidents on Langdon Street provided strong arguments that a new commitment was necessary for creating environments that would sustain minority enrollment.

Several respondents believed that the fraternity incidents served, and continued to serve, as an inhibitor to minority enrollments at the UW-Madison.89 A high percentage of the prospective minority students lived in Milwaukee, and some black students believed that racial incidents in Madison affected the attitudes and decisions of people in Milwaukee. 90 One black administrator stated,

[T] he unfortunate impact it had for us was. that it negatively affected student enrollment and retention. Parents considering sending a student of color to [UW-Madison] were not reassured by some of these incidents. Students already on campus were asking the simple questions, 'how can this be tolerated?' 'Is there no recourse?'....Parents of prospective students wanted something more than just a plan; they wanted to know that if someone

\footnotetext{
88D. Magner. "Wisconsin to Re-Tool Recruitment Plan as Minority Enrollment Dips 17\%," The Chronicle of Higher Education, October 23, 1991, at A37. See also, \#W-1 at 7; \#W-2 at 2.
}

$89 \# W-1$ at $1 ; \# W-9$ at $1 ; \# W-11$ at $3-4$.

$90 \# W-1$ at 1. 
crosses the boundary on racism on them [their daughters and sons at UW-Madison] that there would be sanctions. 91

One of the ironies at UW-Madison was that (according to several minority students and a black

administrator who participated in interviews) some minority students sabotaged recruiting efforts by telling prospective students not to come to the University. Ethically, these students felt that they could not advise students to come to campus if they found the environment unacceptable.92 The net effect of their actions contributed to an even more isolated existence on campus--not only did they feel uncomfortable on campus in the highly charged racial climate, but their negative comments about the University kept prospective minority students from enrolling. With few new recruits, the already small number of minority students decreased, making more frequent their experiences as the only minority in their class, dorm, etc.

Some black students complained that prospective students did not meet current black students during campus visits. 93 However an administrator and a faculty member countered this, stating that the University regularly put prospective minority students in contact with current minority students, believing that some current students were willing only to complain and not to take corrective action. 94 A black administrator observed,

[s]ome minority students have been approached by the media and have given out negative information about their experiences on campus, which sends out another message to the

$91 \# W-5$ at $2-3$.

$92 \# W-2$ at 3.

$93 \# W-1$ at 6.

$94 \# W-7$ at $7 ; \# W-12$ at 5. 
students we are trying to attract. Prospective students are more likely to believe current students on campus than they are to believe the recruiters they meet. Students are our most viable recruitment tool and we have got to work more closely with them to build a team effort for recruitment... [s]tudents make statements about what is not being done in the area of recruitment, when in fact they have no idea what is being done. 95

The discussion of UWS-17 was linked closely to the University's recruitment and retention

dilemma. The policy debate occurred while other anti-bias measures were devised. These related discussions transpired with an over-arching goal of fostering a more welcoming and hospitable learning environment for all students. The focus was on minority students in particular since their experiences were believed to be less positive than those of white students. Proponents of campus regulations against harassing speech saw the codes as one of several measures to create an educational environment which would more closely meet the needs of current and future minority students. To prospective minority students and their parents, especially blacks, who seemed to be the targets of most of the bias incidents, the regulation of all forms of racism on campus may have been reassuring.

In October, 1991, Chancellor Shalala admitted that the University's recruitment efforts had not reached the enrollment goals it established in The Madison Plan.96 The total number of freshmen minority students at the UW-Madison decreased from 305 in 1990 to 252 in 1991.97 The

95 \#W-7 at 6-7. This participant acknowledged that more needed to be done to communicate to minority students the University's efforts to enroll minority students.

96D. Magner, supra note 88.

$97 / d$. 
number of entering blacks dropped from 105 to 77 during that same time period.98 University

administrators offered several reasons for the declining minority presence: 1) a state-mandated hiring freeze

affecting the Admissions office, 2) turnover in the Admissions office, 3) the small pool of qualified

minority applicants in Wisconsin and 4) competition for those few applicants from other

colleges. 99 Wisconsin administrators did not refer to any of the racial incidents of the late 1980s, nor the

alleged subsequent recruitment sabotage by minority students. 100 Chronicle of Higher Education

reporters spoke with senior student, Mario Mendoza, who commented that recruitment of minorities was

affected by a shift from grants to loans in federal financial aid, and as a result of the recent racial

incidents. ${ }^{101}$ At a panel discussion on UWS-17, sponsored by the ACLU, Mendoza said,

It is very sad that the Madison Plan has failed. A lot of people like me, and many of those in the inner cities, will probably not come here not only because of UWS-17 being overtumed, but also because the University failed in this sense. 102

The University was in the difficult position of having to promote the vision of the UW-Madison of the

future in order to attract minority applicants. It could not rely on an established, comfortable learning and

living environments to attract minority students.

98 Id. See also, \#W-1 at 7, a group interview, in which participants believed that a large proportion of the 77 incoming black students were scholarship athletes.

99 Id.

$100 / d$.

101 ld.

102Wisconsin ACLU Panel Discussion, supra note 34. 


\section{Students' Behaviors. Values and Perspectives}

\section{Ethnic Minority Students' Perspectives on Race Relations}

Minority student informants believed that the small number of minority students, particularly

blacks, at the UW-Madison helped create a sense of camaraderie among them. ${ }^{103}$ Perceiving that they

operated in an uncomfortable environment, some black students found common ground by discussing their concerns with others who had similar experiences. ${ }^{104}$ Even those students who had not been the direct

target of a bias incident felt solidarity with those who had. If there was doubt among some black students about how widespread racial misperceptions and bias were among whites before 1987, the major public incidents (and the reporting of them by the press) began to cement the perception that whites were culturally ignorant and racially insensitive. 105

While many black students grew increasingly concemed about the racial incidents, some remained cautious because they believed that their small numbers and their physical differences from white Madisonians could draw unwanted attention and fuel inappropriate stereotypes.

We have to really watch what we do. What I do as an individual reflects on every other

$103 \# W-5$ at $9 ; \# W-1$ at 6 . Black students are the focus of this section (and throughout much of the study) because most of the racial incidents seemed to be directed at them, and black students' experiences may be the most illustrative of the differences between minority and white students.

$104 \# W-5$ at $9 ; \# W-1$ at 6.

105 See \#W-11 at 2; "The real point that black students were making, and made quite clearly when they were quoted accurately, was that this incident was symbolic of a larger truth in terms of what they had to deal with." 
black male on campus, and everything she does reflects on every black woman on campus. She can't get in an argument with her professor in a lecture hall, because that is perceived to mean that 'all black women are argumentative.' He can't say something wrong to one particular white woman walking down the street, because then 'all black men are after white women.' We are such a small minority on this campus that we cannot be looked at as individuals here. 106

Some black students sensed that they should not speak up for fear of being labelled erroneously, for having their comments blown out of proportion, and for speaking as an individual while being heard as a representative of all black students (or perhaps all black people). ${ }^{107}$ This self-censorship was no less real than any other type which may have been linked to UWS-17. An Hispanic student remarked, "we are being silenced already. Read a magazine, read a newspaper, turn on the TV--by and large the portrayal of people of color is negative." 108

The anonymous and other racial incidents tended to evoke similar reactions among African American students. The experiences of epithets shouted from the passing car, the shopkeeper watching blacks more closely, and differential treatment in class all contributed to some level of alienation of blacks from whites at UW-Madison. The distance between cultures was manifested, for example, in black students' perceptions that they must speak and act carefully. Some alienation among blacks may also be expressed in their frustration over whites' lack of knowledge and interest in African American

$106 \# W-1$ at 3. See also, \#W-5 at 6.

$107 \# W-1$ at 7,$8 ; \# W-10$ at $3 ; \# W-7$ at 4 .

108Wisconsin ACLU Panel discussion, supra note 34, comments of M. Mendoza. 
cultures. 109 After the major racial incidents this sense of isolation prompted some African American students to join other minority students to enhance their political bargaining power and to work toward changing many of the predominant attitudes and values working against their academic and social achievement.110 Many black students who persisted academically did so because UW-Madison had the best academic opportunities for the money, and because after their arrival they wanted to prove to their families, to their white peers and to themselves that no one could prevent them from attaining their goals. ${ }^{111}$

Some administrators and faculty believed that the racial incidents led black students to exaggerate the problems.112 To support their views these informants pointed to the ZBT incident (see pp.17-18) when minority students initially condemned the incident as 'racist' and dubbed it a "ṣlave auction." A white faculty member reported that later, when black student leaders viewed the film of the incident, some admitted that the event was not racist. 113 Previous racial events and the prevailing climate of

$109 \# W-1$ at 3. Taken to the extreme, frustration can lead to violence or the threat of violence. Some black students at UW-Madison used the threat of violence as a means of influencing whites to agree to accept changes, rather than having the disagreements escalate into racial violence; see $\# W-12$ at $4 ; \# W-5$ at 7,8 .

$110 \# W-7$ at 1.

$111 \# W-1$ at 6 . Some black students felt that they should not have to sacrifice the educational quality of UW-Madison in order to attend another school which may have been more comfortable. Some student leaders expressed as a reason for staying the goal of improving the environment.

$112 \# W-5$ at $7 ; \# W-12$ at $5 ; \# W-7$ at $7 ; \# W-6$ at 3.

113. White, supra note 63 at 1 . See also, \#W-6 at 3. 
suspicion and activism were perceived by some faculty to have led students to label an event as 'racist'

before all of the facts were available. Some black students may have believed that mean-spirited bias incidents occurred every day. Those students who continually complained about the environment, without taking positive action to improve the situation, may have worn out their welcome even among supportive faculty and staff. 114

Minority students held differing opinions when UWS-17 was adopted, but most minority student leaders supported the policy. 115 The psychic distance between African American students (and other Coalition members) and the University fostered students' suspicion of the University's motives in any decision.116 An Hispanic student stated:

UWS-17 was perceived by some minority students initially as a half-baked attempt by the administration to solving racial problems....There is still a split among minority students in their interpretation of the policy--some say it's vague and meaningless and others say it's symbolic of the University's values. 117

Eventually, the symbolic role of UWS-17 increased in that students of color could turn to it if there was a

$114 \# W-12$ at $5 ; \# W-5$ at 7.

$115 \# W-7$ at $5 ; \# W-5$ at 2 . See also, Steering Committee on Minority Affairs, supra note 79 at 70-78. This group, led by Charles Holley (then President of UW-Madison BSU), recommended racial/sexual harassment procedures for faculty and staff. The philosophy statement of the subcommittee on "Sexism and Racism Procedures With Possible Grievance Mechanisms" (led by another black student leader) said that racial harassment created an "intimidating, hostile or demeaning" environment.

$116 \# W-11$ at 5; \#W-2 at 2; Wisconsin ACLU Panel discussion, supra note 34 at 7.

$117 \# W-2$ at 3. 
problem of racial abuse. The Court's overtuming the policy disappointed many minority students.118

Some administrators and students perceived the particular wording of the policy to be less important than the University's position against discriminatory verbal harassment. 119

\section{White Students' Perspectives on Race Relations}

Some of what can be said about white students' attributes can be inferred from the racial incidents described earlier. Both black and white informants claimed that white students were concerned about racial issues, but racial issues were reportedly low among whites' priorities. 120 Madison's whites were portrayed as supportive of equal treatment and opposed to harassment of any kind. While perhaps sensitive to minority students' concerns, informants characterized them as not moved to change 'the system.' 121 When asked about the reaction of white students toward the black students' and the Minority Coalition's movement, one white faculty member said,

It was funny; generally it was positive. After all, this is a self-declared progressive radical campus, and all of the radical white students, whether they know any black students or not, were willing to sign up. That created its own tensions because there was a very real attempt by some of the left socialist student organizations to co-opt the

$118 \# W-5$ at $9 ; \# W-11$ at $10 ; \# W-1$ at 3.

$119 \# W-11$ at $10 ; \# W-2$ at 3.

$120 \# W-5$ at $9 ; \# W-12$ at 1 . See also, researcher's Wisconsin observation \#8.

$121 \# W-5$ at 9 . See also, researcher's Observation \#4. 
movement. 122

Evidence of active opposition to the Minority Coalition's goals existed among some whites. Some black students and white faculty member identified The Badger Herald as the student newspaper with the most active editorial staff opposing Minority Coalition initiatives. 123 News reports tended to highlight the extremes of opinion leaving the reader to infer that the individuals who were quoted might be representative of their race, gender, class, etc. One example of a potentially biased situation involved the omission of the Acacia incident facts for nearly a month after the incident. However, other informants indicated that some white students did support the Minority Coalition. 124

Some minority students and administrators perceived that white students were generally insensitive to minority cultures. 125 This may have been due, in part, to what some faculty members described as white students arriving on campus with little or no experience with persons of another culture.126 Local news media may have fostered the impression that new black residents from Milwaukee and Chicago arrived with drugs and criminal tendencies. This situation may have led some whites to associate -- because of

$122 \# W-12$ at 3-4. The respondent did not imply that all UW-Madison white students were radicals. Instead, he meant that those students who were active politically on the left became involved. See also, J. Heldt. "Minority rally absorbs majority student rally." The Badger Herald, November 18, 1988, at 1.

$123 \# W-1$ at $2 ; \# W-12$ at 4 . My own reading of the reports of racial issues in The Badger Herald confirmed this view.

$124 \# W-5$ at $7 ; \# W-10$ at 2.

$125 \# W-7$ at $4 ; \# W-1$ at 3.

$126 \# W-10$ at 2; \#W-12 at 8. See also, Wisconsin ACLU Panel Discussion, supra note 34 at 11. 
perceived similarities in age and skin color alone -- Madison's black college students with stereotypes of black urban criminals. 127 Some faculty believed that insensitivity toward minority groups was sustained partially by the lack of interaction among students of different races. One white faculty member said, "the actuality is that very few blacks and whites interact here."128 However, after the public racial incidents in 1987, the awareness of minority issues among UW-Madison's white students reportedly increased dramatically. 129

\section{Political Factors and Conditions}

Many factors influenced the development and eventual adoption of UWS-17. External forces including the American Civil Liberties Union (ACLU), Wisconsin Legislators, the Wisconsin press, the National Association for the Advancement of Colored People (NAACP) of Milwaukee and several grass roots organizations affected the outcome of the policy. Internal groups like the BSU and the Minority Coalition, the UW-Madison administration and the faculty all played roles in UWS-17. There were, of course, factions to each of these. According to a white faculty member who was involved in the policy's development, the personalities of the various constituencies' leaders impacted the outcome at Wisconsin. ${ }^{130}$ Although the groups' and leaders' influences is detailed in the next section, this section focuses on the

$127 \# W-10$ at $4 ; \# W-12$ at 8.

$128 \#$ W-12 at 2. See also, researcher's Observation \#7.

$129 \# W-12$ at $2 ; \# W-10$ at 4.

$130 \# W-6$ at 7. 
political activities of various groups, including coalitions which formed, demonstrations held, and important relationships among key participants. It is out of these relationships that the three major reports mentioned earlier were produced (in the wake of the major racial incidents).

\section{Political Activities}

It is probably more traditional to associate "political activities" with demonstrations and/or the behavior of elected officials. However, another way of describing political activities acknowledges that students' cultural values and behaviors are intertwined with the political forces of their society. So, for example, when a fraternity holds a social event in which its members denigrate minority cultures, they could also be understood to be making a political statement of their beliefs about the level of respect and power society should afford that particular culture. In other words, the setting in which a group is denigrated may not detract from the political part of the message.

If political messages were implicit in the Fiji Island incident, then the protests of the party can best be described as reactive political pressuring. Some students attributed UWS-17's genesis to the student public pressure in response to the fraternity episodes, rather than suggesting that the episodes themselves gave rise to the policy. ${ }^{131}$ The Minority Coalition advocated the proposed regulation most forcefully, sparking considerable public pressure. The Coalition included students who were black, native American, Asian American, Chicano and Puerto Rican. Leaders from these groups came together on a number of 
issues over which they disagreed with the University administration and faculty (eg., ethnic studies, minority faculty and student recruitment, speech code). ${ }^{132}$ The Fiji party ignited the Minority Coalition to protest initially, and subsequent bias incidents strengthened their resolve to bring about changes. The Coalition staged demonstrations on Bascom Hill, marches down Langdon Street, and confrontations with fraternities involved in bias incidents. The Coalition's efforts prompted the creation of a multicultural center in the UW-Madison Memorial Student Union, including shared office space for the five participating student groups. 133 The group assists the University to identify areas on campus which work to the detriment of minority students. The Coalition continues to exist and both students and administrators reported that Coalition members continue to be suspicious of the University. ${ }^{134}$ An attitude of cooperation and solidarity existed within the group so that individual members would raise issues of common concern with the Coalition before bringing them to the larger community.

LIke other state systems of higher education, some rivalry exists among the UW-System campuses. At UW-Madison, the rivalry was characterized as the other campuses ganging up on the UWMadison in order to achieve equity among all of the institutions. ${ }^{135}$ It may have been a legitimate concern among the outlying campuses that UW-Madison was more likely to 'get its way,' because 1) the at 3 . Report."

132 Generally, the BSU led in asserting the coalition's agenda. See \#W-11 at 3; \#W-12

133This was an important feature included in both The Madison Plan and "The Holley

$134 \# W-11$ at $5 ; \# W-1$ at $7 ; \# W-2$ at 1.

$135 \# W-5$ at $3 ; \# W-6$ at $1 ; \# W-13$ at 1. 
UW-Madison is the flagship institution and 2) the UWS occupies offices on the Madison campus where

UW-Madison leaders are more likely to be in close contact with System administrators. In that

arrangement, it is plausible that any policy put forth by the Madison campus would be attacked by other

campuses, simply because it originated at the UW-Madison. This rivalry proved influential in the

development of UWS-17.

Two external groups played important roles in the policy's development. Some University

officials concluded that Wisconsin legislators attempt to influence policy at the University if and when they get pressure from voters who respond to campus issues. 136 The other group, the Wisconsin ACLU, drew substantial attention to UWS-17 and helped frame the related legal debate. 137 The ACLU was concerned particularly about UWS-17 following Michigan's negative experience in court with its verbal harassment policy. The Michigan policy was available during the drafting and debate at Wisconsin, but the ACLU case against the University of Michigan was decided several months after the Wisconsin Regents adopted UWS-

136 \#W-5 at 5, 9. See also R. Berg. "Officials react to request against UWS-17 appeal," The Badger Herald, October 18, 1991, at 1.

$137 \# W-13$ at 5; \#W-3 at 2; See also: Letter from E. Edgar (Executive Director of the ACLU of Wisconsin) to H. Grover (state legislator; copy of letter sent to Regents) on April 4, 1989, opposing UWS-17. See also, Minutes of the Board of Regents, supra note 22 at 20 (testimony of Eunice Edgar to the Board of Regents). See also, letter from L. Weinstein (Chair, Board of Regents), April 17, 1989, to E. Edgar in response to April 4, 1989 letter from Edgar to Weinstein. Presumably, the letter to Weinstein was identical to the letter to Grover. See also, outline prepared by G. McQuillen, "The University of Wisconsin's anti-speech rule: an ACLU perspective," October 24, 1989 (Outline for comments to the Dane County Bar Association, opposing UWS-17). See also, memo from W. Lynch to j. powell [sic], January 29, 1989 , indicating the ACLU's formation of a coalition to institute a project to address racism (for public relations purposes) prior to filing the UWS-17 lawsuit. 
17.138

\section{Reports and Institutional Self-Studies}

Two UW-Madison reports and one UWS report on minority issues related directly to the

formulation of UWS-17: "The Holley Report", 139 The Madison Plan, ${ }^{140}$ and Design for Diversity. 141

The Holley Report was released in late November, 1987, only a few weeks prior to Donna Shalala‘s arrival as the UW-Madison Chancellor (January 1, 1988). The Madison Plan was issued six weeks after Shalala took office. The UW-System issued Design for Diversity eight weeks after that (April, 1988). Much of the same material is addressed in each of the reports.

The acting vice chancellor, Phillip Certain, created The Holley Committee and charged it with several tasks. These included making recommendations on ways to recruit minority students, ways to improve orientation, and mechanisms for making the environment more comfortable for minority students. ${ }^{142}$ The 25 -member committee began its meetings in late July, 1987 and broke into sub-

138 Doe v. Michigan , 721 F.Supp. 852 (E.D. Michigan 1989); the case was decided on September 22, 1989. UWS-17 was adopted by the Regents in June, 1989 (see L. Weinstein. "Policing Prejudice," AGB Reports, January/February 1990, at 6.

${ }^{139}$ Steering Committee on Minority Affairs, supra note 79.

140 D. Shalala, supra note 80 . The report was released by the Office of the Chancellor on February 9, 1988. meeting.

141K. Shaw, supra note 3. The document was approved by the Board at its May 1988

142Steering Committee on Minority Affairs, supra note 79 at 1. 
committees to address specific concerns.

One of the sub-committees, "Sexism and Racism Procedures with Possible Grievance

Mechanisms," was chaired by another BSU leader, Solomon Ashby. Ashby was identified by one white professor as a primary force on the committee and in the BSU.143 The UW-Madison administrator responsible for applying non-academic policies (including UWS-17) was listed as a member of this subcommittee. The sub-committee's report acknowledged the importance of free inquiry at the University. It also defined racial harassment (but does not address sexism as the sub-committee's title suggests) as:

insulting or demeaning behavior toward others because of their color, cultural, or ethnic background. The sources of such behavior may be general ignorance of and insensitivity to human differences or they may be intentional efforts to intimidate others because of their differences. The effects of racial harassment not only insult the dignity of the individual but it is antithetical to and destructive of a climate in which each individual can achieve his or her full educational potential. Racial harassment may seriously interfere with learning performance and may make the learning environment intimidating, hostile or demeaning. Racial harassment is an insult to the person at whom it is directed and to the University community as a whole. 144

Appendices to the sub-committee's report contained a set of grievance procedures for cases of racial harassment and sets of definitions and rules governing the conduct of the UW-Madison faculty pertaining to racial and sexual harassment. The grievance procedure included a progression of events ranging from mediation to more formal hearings and appeals. The harassment victim controlled the formality of the process. Some students during the 1991-92 academic year looked to the conclusions in the Holley Report

$143 \# W-12$ at 3. See also, K. Koff, "Racism issue absorbs UW," The Badger Herald, April 22, 1988, at 1 . Solomon Ashby was identified as the primary speaker at a rally against racism on Bascom Hill. 
as the best answer to the campus' racial problems. ${ }^{145}$

Immediately after Chancellor Shalala began at the UW-Madison, she convened an ad hoc response committee to begin addressing the campus tensions. 146 The chancellor's group contained some of the same people who had served on the Holley Committee. 147 The product of this UW-Madison group, The Madison Plan, resembled its predecessor in many respects, including its recommendations for changes in the student conduct code and the University's response to harassment. The Madison Plan opened the way for these changes by recommending four initiatives in the student conduct area: 1) it asked the Student Conduct Policy Committee (SCPC) to broaden the student disciplinary policy to allow for penalty enhancements in cases involving crimes motivated by race or other protected categories; 148 2) it requested the dean of students to develop a mediation and counseling program to handle cases in which racial harassment was alleged, but disputed; 3) it recommended the dean of students and student government develop policies to be used to discipline student groups; and 4) it asked the SCPC to propose a succinct statement of the

$145 \# W-12$ at 4; \#W-2 at 2; \#W-1 at 7; See also, Wisconsin ACLU Panel Discussion, supra note 34 at 7.

$146 \# W-11$ at $1 ; \# W-12$ at 6.

$147 \# W-11$ at $6 ; \# W-12$ at 11.

148D. Shalala, supra note 80 . Specifically, the report said that the SCPC "will be asked to consider by April 15 a proposal to broaden UW-Madison student disciplinary policy so that special or more severe sanctions may be sought when a violation of existing student conduct rules involves the race, religion, color, creed, gender disability, sexual orientation, national origin, or ancestry of the victim." A penalty enhancement bill was pending at the same time, and later was made law, in the Wisconsin legislature. 
university's concept of and aspirations for a non-discriminatory community.149 The vice chancellor for academic affairs and the dean of students were responsible jointly for the implementation of measures to create a non-discriminatory environment by September, 1988. Some minority students criticized The Madison Plan for not going as far as the Holley Report in responding to their concerns and for being written from an assimilationist perspective. 150 These students' primary complaint was that The Madison Plan did not recommend the hiring of a vice chancellor for ethnic/minority affairs/affirmative action as was done in the Holley Report. The Madison Plan indicated that ethnic/minority affairs should be the responsibility of each department on campus; this decentralized approach angered some students. Students quoted in a newspaper feature interpreted the report to suggest that they were welcome only if they assimilated with the white majority. 151 Chancellor Shalala stated that " $99 \%$ of the major issues covered and certainly the spirit of the report is consistent with the Holley Report."152

The System administration's report on its efforts to address minority concerns, Design for Diversity, identified seven goals to improve recruitment and retention of minority students--those students from historically or currently disadvantaged ethnic groups. Each institution in the system was required to

$149 / d$. at 4. There is evidence to suggest that the SCPC was well on its way before The Madison Plan was released. See \#W-11 at 6. See also, memo from Student Conduct Policy Committee to D. Shalala, March 20, 1989.

$150 \# W-12$ at 4; \#W-2 at 2; \#W-1 at 7. See also Wisconsin ACLU Panel discussion, supra note 34 at 7 . See also, L. Morgan, "Minority coalition questions Madison Plan in its response," The Badger Herald, February 10, 1988, at 1.

151L. Morgan, Id. at 1.

152L. Gaumnitz. "Madison Plan unveiled by Shalala," The Badger Herald, February 10, 1988 , at 1 . 
submit a comprehensive plan for institutional improvement of minority education. In addition,

[E]ach institution will develop written codes of student and employe conduct to ensure a nondiscriminatory environment. System guidelines will be prepared for institutional use by July 1,1988 . Codes should deal with both individuals and student organizations that might be charged with discriminatory activity and other forms of racism and harassment. These codes shall be in effect no later than January 1989.153

Of the three reports, the Holley Report attempted to create the most specific institutional response mechanism for racial harassment. Neither The Madison Plan nor Design for Diversity committed the groups responsible for its implementation to take any particular form of policy action. Chancellor Shalala's plan required that a statement of values be written and endorsed. President Shaw's plan mandated that codes of conduct be written, but did not give specific guidance on what those codes might have been. The latter two reports provided the framework and the authority from which UWS-17 eventually emerged.

Racial incidents (described earlier) occurred before, during and after the development of these reports. The racial climate was tense as the reports were written, and this may have affected the ways in which they were interpreted. On a more positive note, a UW-Madison librarian wrote,

[t]hese reports have created a great sense of solidarity among various minority groups on campus. I have been on campus for 14 years and for the first time, the blacks, Hispanic Americans, Native Americans and Asian Americans smile and greet each other. 154

Students of color may have found solidarity over a cluster of issues being addressed at UW-Madison and at the UWS; however, their feelings of discomfort with the campus environment continued.

153K.Shaw. Design for Diversity, supra note 3 at 3.

${ }^{154} \mathrm{M}$. Jesudason. Letter to K. Shaw (UWS President) June 8, 1988. 


\section{Discussion and Development of UWS-17.06}

\section{Impetus for the UWS-17.06 Debate}

The discussion of a discriminatory verbal harassment policy and plans to create a more comfortable

environment for minority students both had roots in the series of racial incidents described in section II of this chapter. ${ }^{155}$ Interview participants cited the Fiji Island Party most often as the precipitating event leading to the adoption of UWS-17.156 Other bias events that followed the Fiji party served to reinforce the perception that the environment was unacceptable for minority students.

UWS-17 did not develop in isolation. Concurrent debates on a variety of plans to improve campus environments occurred, and all were intended to achieve similar outcomes. One of the most controversial measures designed to improve the recruitment and retention of minority students was a scholarship plan for minority students adopted in Design for Diversity. ${ }^{157}$ Another controversial proposal, especially among

155This belief was held widely by administrators, faculty and students. There was only one notable exception to this view -- an administrator at UWS -- who held the opinion that work on Design for Diversity had already begun for a number of reasons, only one of which was racial harassment. This respondent felt that racial harassment was a subsidiary concern of a broader focus of improving campus environments ( $\# W-5$ at 1 ).

156 Supra, note 35.

157 A review of the UWS President's Office (Kenneth Shaw) files in the UW Memorial Library Archives revealed that most of the complaints received by the president about Design for Diversity responded to the financial costs of the initiatives (just under $\$ 9$ million), or to the controversial scholarship plan contained in the report. There was no correspondence in opposition to the request for changes in the conduct codes, perhaps because the actual changes were not revealed until the following year. 
faculty, discussed during this same time period was an undergraduate ethnic studies requirement. ${ }^{158}$ These and other educational efforts were discussed as part of a comprehensive approach to ending the racial problems on Wisconsin's campus. These other efforts are important in providing a context in which UWS17 can be understood. Efforts to restrict offensive and harassing speech occurred simultaneously with attempts to educate members of the UWS campuses. It can be interpreted that UWS-17 was just part of a broader focus and that in and of itself did not grow out of specific incidents. However, it appeared to most informants that the entire range of efforts taken by the University (including UWS-17) grew out of the Fiji Island incident.

\section{Progression of UWS-17.06}

This sub-section provides a brief description of the path of UWS-17 from early discussions at the UW-Madison in February, 1988, until its promulgation in September, 1989. Clear distinctions between activities at the UW-Madison and the UWS are not made easily because of frequent communication among faculty and administrators at the two entities regarding UWS-17 as it developed.

On February 9, 1988, Chancellor Shalala requested the Student Conduct Policy Committee (SCPC) to "consider the feasibility" of a policy on discriminatory verbal harassment.159 The Madison Plan

$158 \# W-5$ at 1,$5 ; \# W-10$ at $1 ; \# W-11$ at $2 ; \# W-12$ at 4.

159B. Durand (Co-Chair of SCPC, 1988-89) report to Donna Shalala titled: "Report on Proposed Amendments to UWS Chapter 17 Concerning Prohibited Verbal and Physical Conduct," March 20, 1989. The SCPC was asked officially to begin work on the policy on the same day that The Madison Plan was released. The Committee was assisted by two third-year law 
indicated only that the SCPC would address the issues of penalty enhancements and it would propose a succinct statement of the University's "aspirations for a non-discriminatory community."160 Although these were related issues, the chancellor's request to the SCPC took the task one step further than the public report.161 The request allowed the ideas of discriminatory conduct codes to develop beyond the early attempt published in the Holley report.

A white administrator remembered some roadblocks as the committee began stating, "what they were told essentially was that there was no way that this policy would be accepted....the court has been real sensitive about this issue."162 Also, in the early stages of the committee's work, the two law students who assisted the SCPC reached a conclusion similar to the one that was filed later by the District Court Judge in the ACLU's case challenging the University's policy. In February 1988, the law students concluded:

students who had done preliminary work on verbal harassment policies for a course assignment during the fall 1987.

160D.Shalala. The Madison Plan, supra note 80 at 4. The Wisconsin ACLU opposed the idea of penalty enhancements for crimes committed with racial malice. Penalty enhancement statutes allow for greater penalties to be imposed when the target of a crime was subjected to an illegal activity because of his/her race. The subjective intent of the perpetrator during the commission of the crime must be determined to have been based on the target's protected status. In the ACLU's view, penalty enhancement legislation punishes mere thought. See G. McQuillen (President, ACLU of Wisconsin), supra note 137.

161 In The Madison Plan, the chancellor noted that "[s]tudent disciplinary rules do not now prohibit racial and other discriminatory epithets uttered by students about other students, or about University faculty and staff. This community is firmly committed to the protection of the First Amendment. Therefore, any effort to discipline students for speech, as contrasted with conduct, will require careful and extensive deliberation." This is not a direct request to the SCPC. 
[t]he University will have difficulty fashioning a rule, penalizing the use of racial epithets, which withstands First Amendment scrutiny. The University may, however, be able to impose sanctions against the use of racial epithets if violent or disruptive conduct results from their use. 163

One of the SCPC's co-chairs, Carin Claus, was a faculty member at the UW-Madison law school.

She had served previously as the chief counsel to the United States Department of Labor under President

Jimmy Carter. As a result, she was well-versed in labor law and workplace harassment regulations. 164

During the spring 1988, the SCPC met nine times and, in addition, committee members consulted several other law professors, the Dean of Students Office and key campus leaders. ${ }^{165}$ Based on their legal research and on the advice of internal consultants, the SCPC members proposed new revisions to UWS-17 (including a prohibition of discriminatory verbal harassment) to the faculty senate, gaining its unanimous approval on May 2, 1988.166 Chancellor Shalala approved the recommendations and forwarded them to

163S. Ludwig and J. Kloppenburg memo to M. Liethen (UW-Madison general counsel), University of Wisconsin-Madison, February 24, 1988.

$164 \# W-13$ at $1 ; \# W-11$ at 7.

165B. Durand, supra note 159. The UW-Madison law professors most often mentioned as consultants on UWS-17 were Gordon Baldwin, Ted Finman and Richard Delgado (eg., see \#W3 at 2; \#W-5 at 3; \#W-11 at 8). Messrs. Baldwin and Finman were long-time faculty members at the University. Delgado arrived at UW-Madison in the summer of 1988, and went to the University of Colorado in 1991. Regarding UWS-17, the professors were most often remembered for their differing perspectives about how narrowly or broadly the policy should be written. Consistent with the observations of others, at the Wisconsin ACLU Panel Discussion (supra note 34 at 2), UWS general counsel Patricia Hodulik described them as follows: "Richard Delgado...argued for broad restrictions or limitations on speech. Gordon Baldwin...represented a more conservative approach. Ted Finman....was somewhere in the middle ground."

166D.Shalala letter to K.Shaw, UW-Madison, May 4, 1988. See also, B. Durand, supra note 159. 
UWS President Shaw. 167

The Madison proposal 168 contained five main elements: 1) intentional interference with a

University activity; 2) persistent use of expressive behavior; 3) behavior directed at an individual; 4)

behavior demeaning to its target because of his/her race, gender, etc.; and 5) creates a hostile, intimidating

167 Id. (D.Shalala) Shalala wrote, "regarding the discriminatory harassment proposal, I am particularly pleased that a strong and clear consensus has developed among UW-Madison students, faculty and staff."

168B. Durand (co-chair, SCPC). Memo (with enclosures) to UW Board of Regents, UWMadison, May 12, 1989. The UW-Madison proposed policy read:

"UWS 17.06 Offenses defined. The University may discipline a student in nonacademic matters in the following situations.

(2) (a) For intentional interference with the education, university-related work, or other university-authorized activity of a university student, employe, official, or guest, by persistently directing to that individual or to different individuals on separate occasions explicit comments, epithets, or other expressive behavior that:

1) explicitly demeans the race, sex, religion, color, creed, disability, sexual orientation, national origin, ancestry, or age of the individual or individuals, and

2) creates an intimidating, hostile or demeaning environment for education, university-related work, or other universityauthorized activity.

(b) In determining whether alleged conduct constitutes an offense under (2)(a), the University will look at the record as a whole and at the totality of the circumstances, such as the nature of the comments, etc., and the context in which the alleged incident(s) occurred. The determination of whether a particular action by a student is punishable under (2)(a) will be made from the facts, on a case by case basis.

(3) For intentional conduct that seriously damages or destroys private property of any member of the university community or guest. This offense includes conduct perpetrated because of the victim's race, sex, religion, color, creed, disability, sexual orientation, national origin, ancestry or age." 
or demeaning environment. 169 The policy focussed on the effects of the intentional interference with

students' educational and other University activities, not on speech. Requiring proof that a student intended to interfere with a university activity of another student sets a different (higher) standard than requiring proof that one student intended to demean another student.

The use of the word, "persistently," had several functions. First, it was designed to help show the intentional nature of the activity--if one persists in an activity, it is unlikely that the activity is inadvertent. 170 Second, it was used to convert speech into conduct. For example, if one persists in berating another person, despite the target's protestations or opposition, then the ideas expressed initially are merely repeated and therefore have diminishing speech value. 171 Third, it was meant to enable deans and student judicial officers the flexibility to allow students to learn from their errors thereby relying on education over punishment in judiciary matters. ${ }^{172}$ Persistence could be demonstrated in a single, egregious

169B. Durand. "The University of Wisconsin Policy on Derogatory Speech," UWMadison, April 12, 1990, at 2-3 (report prepared for The Annenberg Washington Program of Northwestern University).

${ }^{170}$ B. Durand. "Proposed amendments to Regents' version of 17.06," May 10, 1989. This document, prepared on behalf of the UW-Madison SCPC, superimposes the UW-Madison proposal onto the UWS proposal, maintaining agreed upon wording, striking out unwanted wording from the UWS policy, and adding language changes proposed by the SCPC. Explanations are provided for each change suggested. The document was submitted to the Board of Regents on May 12, 1989, in preparation for the Regents' June 1989 meeting.

171 ld. 
incident, but it was more likely to be proved in repeated incidents by the same individual(s). ${ }^{173}$

Representatives from Wisconsin's four-year campuses attended a racial harassment workshop in September 1988, at which a revised student conduct policy statement was discussed. Fourteen campuses were represented at the workshop, including the UW-Madison.174 Soon afterward, the UWS directed institutions to submit policies and procedures by January 15,1989 , "to protect students, employees, officials and guests from racist and discriminatory conduct and to ensure prompt corrective action whenever it may occur."175 Institutions were given guidance on language which might have been acceptable, including a statement about the need for consideration of First Amendment rights in harassment case decisions. 176

In November 1988, System vice president for academic affairs, Eugene Trani, appointed a working group to begin drafting revisions to UWS-17, specifically with regard to racial harassment. 177 The eightmember group included two persons from the UW-Madison (a member of the law faculty and an ex-officio

$173 / d$.

$174 \mathrm{~J}$. Sulton memo to participants in the UWS racial harassment workshop, University of Wisconsin System, September 26, 1988.

1750ffice of the Special Assistant to the President for Minority Affairs. "Policy Statement and Guidelines on Racist and Discriminatory Conduct" (Draft), UWS, September 1988 , at 1.

176 Id. at 2. The guidelines also required institutions to develop a process for resolving complaints of bias and to devise mechanisms to educate the campus community about the negative consequences for racist and discriminatory conduct.

177 "Report of the Deliberations of the UW System Working Group to Revise UWS-17," UWS, February, 1989, at 1. See also, P. Hodulik memo to Board of Regents, March 31, 1989, at 2. 
member of the SCPC from the Dean of Students Office) with staff assistance provided by three members of the UWS adminstration. 178 The working group met twice during December 1988 , and once on January 19, 1989. The group used the work done by the UW-Madison SCPC as a starting point for its discussion and, as at the UW-Madison, law faculty were consulted on Constitutional matters. 179 The working group created a draft policy by the end of its second meeting that had several constitutional defects. A respected white Constitutional Law professor believed the draft "preach[ed] an orthodoxy--a proper way of talking about race, religion, sex, etc."180 A white faculty member stated the climate in the working group was such that

They [the working group] were not in the mood to listen to case law. They were in a mood to have a rule which would satisfy the minority community so that they would never have anyone say a bad thing to them again without that person being punished. It seemed as though it was just important to have something, anything. 181

The feeling among the members of the UW-Madison's SCPC was that "[t]he System version of proposed

178 /d. It is curious that the law faculty member selected for the UWS working group had not been a primary participant in the development of the policy recommendation put forth by the SCPC at UW-Madison. Also curious is the appointment of an ex-officio member of the SCPC rather than one of the co-chairs of the SCPC. See also, B. Durand report to D. Shalala, supra note 159, suggesting that the law faculty member was added to the working group after UW-Madison pushed for greater faculty representation (the final group has two faculty members).

179 /d. at 2.

180 G. Baldwin memo to P. Hodulik, January 11, 1989. See also, \#W-8 at 2.

$181 \# W-13$ at 7. See also, \#W-5 at 3. 
changes to 17.06 , dated February, 1989, has generated consensus on only one point: it must be

changed."182 A white faculty member remembered that,

in March I got really alarmed because I saw the first version of it [the System working group draft policy] that had been made public. I think what Ted Finman found was a mess, because what eventually came out was a mess and he purportedly did a lot of fixing of it. 183

The UWS campuses submitted their proposed policies and procedures as required by the UWS, 184 and the working group's efforts culminated in its report, distributed on February 22,1989.

On March 2, 1989, UW-Madison's acting vice chancellor for legal affairs recommended to Chancellor Shalala that the University support the UWS working group's draft revisions to UWS-17.185 Nearly a week later, he asked the SCPC to review and comment on the working group's recommendation by March 20,1989.186 The one week delay between the acting vice chancellor's advice to the chancellor and his request for the SCPC's review may suggest that the chancellor requested the acting VC for legal affairs to ask the SCPC to review the policy. The request for the SCPC's review may have been recognition of the group's authority, influence or expertise on this issue.

182B. Durand, supra note 159. See also, \#W-6 at 5; Although for different reasons, both those who argued against any policy and those who argued for an even broader policy were dissatisfied with the system draft of UWS-17.

$183 \# W-13$ at 5 ; See also $\# W-8$ at $1,2$.

184Office of the Special Assistant to the President for Minority Affairs, supra note 175.

185S. Gullickson memo to D. Shalala, UW-Madison, March 2, 1989.

186B. Durand, supra note 159. The SCPC met three times in twelve days and the leadership of the committee held numerous consultations with UW-Madison law professors Baldwin, Finman, Claus and Delgado. 
On March 9, 1989, one of the co-chairs of the SCPC, three UW-Madison law faculty, and staff

members from the UWS working group attended the Education Committee meeting of the Board of

Regents. ${ }^{187}$ The UWS working group on racial harassment presented its draft policy on revisions to UWS-

17 to the Regents at this meeting, and this draft formed the basis of the discussion at the meeting. The law

faculty provided divergent legal advice on the policy to the Regents, heard the Regents' suggestions, and

were urged to incorporate these suggestions into another draft of the policy. ${ }^{188}$ A State Representative

from Milwaukee, Spencer Coggs, also addressed the Regents regarding legislation he had introduced in order

for the Regents to promulgate rules on conduct codes on an emergency basis. According to a black

administrator,

[t]he purpose of the legislation was to force the UW to implement a policy to stop discriminatory verbal harassment. There was some competition generated over who could get it done first. I don't just say that facetiously because the Regents were very sensitive (as in any state) to the legislature making policy on their turf. The legislator had a legitimate concern about students of color which he perceived as more important than the Regents' concern about turf. He did come to the Regents meeting and made his case clear. The Regents made it clear that they thought this was their area or terrain. And his position was, 'fine, you do it first, we've got not problem, but I'm going to....push it until I see it enacted.' ...We had just been through a change in Chapter 18 of the Code which took 18 months to complete. Representative Coggs' position was not to wait that long because he had students coming to his office now with a different incident to report every day. 189

Representative Coggs' proposal had an impact. The Regents asked the three UW-Madison law faculty to

187Minutes of the Regular Meeting of the Board of Regents of the University of Wisconsin System, March 10,1989, at 19. See also, B. Durand, supra note 159 at 2. See also, \#W-5 at 4 .

$188 \# W-3$ at $2 ; \# W-5$ at 5.

$189 \# W-5$ at 5. See also, Minutes of the Board of Regents, supra note 187 at 19. 
work with the UWS general counsel "to develop revised language upon which they could agree, to be

considered by the Board of Regents in April, perhaps as an emergency rule effective on publication."190

The revised language to UWS-17 was to be placed on the following month's agenda as an action item.191

On March 20, 1989, Professor Finman presented the conclusions reached by Professors Baldwin, Delgado and himself to the UWS general counsel.192 The three faculty members agreed that if a speaker's intent was to make the educational environment hostile for the individual being addressed, the communication could lead to disciplinary action for this improper purpose. 193 However, they still had not reached agreement on the entire policy. Professors Delgado and Finman believed that "epithets directed at a member of the group the epithets attack are subject to greater regulation than other forms of speech," because such speech has a negative impact on the educational environment, and because name-calling has little value as part of the exchange of ideas protected by the First Amendment.194 Professor Baldwin was

190 Minutes of the Board of Regents, supra note 187 at 19. The law faculty were asked for recommendations on which they could agree, an acknowledgment that during the session with the Regents the faculty members disagreed over the acceptable wording of the policy. See also, \#W-13 at 6.

$191 / d$.

192T. Finman memo to P. Hodulik, UW-Madison, March 20, 1989.

193 /d. This agreement made necessary some revision of two of the examples cited in the policy so that they were consistent with the text of the rule.

194 (d. Finman suggested adding the following section:

"3. Whether the intent required under (1) and (2) above was present shall be determined by consideration of all relevant circumstances. For these purposes, epithets (but not racist or discriminatory comments or other expressive behavior) shall be presumed to have been uttered with the required intent." 
concerned by the presumption that one could assume the necessary intent by the utterance of an epithet.195

Baldwin found no legal authority for the presumption that epithets were not protected speech and was

uncomfortable with the burden of proof of intent being shifted to the speaker. 196 Also, the change

proposed by Finman and Delgado suggested that there were forbidden epithets, but the punishable words

were not listed. 197

The UWS general counsel favored Finman and Delgado's proposal and recommended it in the

revised policy provided to the Regents for the April 5 meeting. 198 Baldwin appealed to President Shaw and the Regents to revisit the issue, warning that "to shift the burden of proof to the speaker is deeply offensive to First Amendment law."199 One white administrator stated, "frankly, the Board of Regents went right down the line with Gordon Baldwin."200

The Wisconsin ACLU was active during this period trying to persuade the Regents, the UWS

195G. Baldwin memo to P. Hodulik, UW-Madison, March 20, 1989. Baldwin eventually prevailed on this point.

$196 / d$.

197 ld.

198P. Hodulik memo to Board of Regents, UWS, March 31, 1989, at 5. Hodulik included arguments on both sides of the epithets issue in this memo.

199G. Baldwin letter to K. Shaw, UW-Madison, April 4, 1989. See also, G. Baldwin letter to E. Davis, Jr. (UWS Regent and member of Education Committee), UW-Madison, April 5, 1989. Davis accepted Baldwin's advice and voted against the section which presumed the speaker of epithets to have the required intent under the policy. Professor Baldwin argued that the 'fighting words' doctrine had been diluted to the point that fighting words are those which are intended, and likely, to produce imminent lawless action (Brandenburg v. Ohio 395 U.S. $444,1969)$ 
administration, supporters at the UW-Madison, state legislators and others that almost any version of the revisions to UWS-17 was offensive to First Amendment principles. ${ }^{201}$ Also, about this time, examples of situations which may be considered violations of the policy were added and modified to help clarify the language of the policy.202 Four examples were retained in the adopted policy.

The Regents' discussed the revisions to UWS-17 at its April meeting. ${ }^{203}$ The Education Committee heard testimony from seven persons. Eunice Edgar, executive director of the Wisconsin ACLU, who spoke against the policy, said that the section which Professor Baldwin had found objectionable was particularly offensive to the First Amendment. The Committee then voted to delete the sentence which would have created a presumption of intent upon the utterance of an epithet. With the exclusion of this provision, the Regents had before it a proposal on which all three UW-Madison legal scholars agreed.

The Regents then discussed at length the process of adopting, and the need for, the revisions to be promulgated on an emergency basis. 204 Some Regents believed that the problems of racial harassment had been in existence for some time and did not then suddenly constitute an "emergency." Others sensed more urgency and wished the new rules to be implemented with dispatch. President Shaw reminded the Regents

201E. Edgar, supra note 137 (letter to H. Grover). The letter noted that copies were sent to State Senator Lynn Adelman, President Shaw, Chancellor Shalala, and the secretary of the Board of Regents.

$202 \# W-6$ at 5; \#W-13 at 5. See also, T. Finman, supra note 192. Also, P. Hodulik, supra note 198 at attachment \#1.

203Minutes of the Board of Regents, supra note 22 at 20-26 (April 7, 1989). Four persons favored the revisions and three were opposed. None of the UW-Madison law faculty who were consulted earlier spoke at the April meeting.

204 ld. 
of its commitment to these issues prior to the publication of Design for Diversity, and he petitioned for the approval of the policy revisions. Regent Laurence Weinstein also favored the revisions to UWS-17.205 A resolution to approve the revisions to UWS-17 on an emergency basis was defeated 8-7 in a roll call vote. Immediately after this vote a motion was made to submit the proposed revisions to UWS-17 through the regular administrative rule-making process in order to allow for more extensive debate. The Regents adopted this motion 8-7 in another roll call vote. The Regents' student member, John Jarvis, who had indicated earlier the reason for his vote against the first proposal was his concern for freedom of speech, provided the swing vote. Had Jarvis not changed his vote, the policy revisions would not have been promulgated through any process at that time.

The University was made aware of the risks involved in its reliance on the fighting words doctrine as the primary justification for the rule. The Legislative Council Rules Clearinghouse 206 issued a report which analyzed the University's rule and found that,

as drafted, the proposed rule does not include the requirements of inciting or producing imminent lawless action or the requirement that the speech be likely to produce such action. To the extent that the [UWS] justifies the rule based on the need to control certain threatening speech and relies on the "fighting words" line of cases supporting restriction of speech in these circumstances, it appears that the standards for the restrictions are not as stringent as required under that line of cases. 207

205 Id. Weinstein also supported the proposal by Finman and Delgado.

206 This office is an arm of the State Legislature and is responsible for analyzing any new rule or policy for its legal implications.

207Wisconsin Legislative Council Rules Clearinghouse Report, Wisconsin State Legislature, May 15, 1989, at 2. 
Professor Finman argued in response that the purpose of the proposed policy was "to reach only speech that constitutes egregious personal insult...precisely the kinds of speech that evokes violent reactions."208

Professor Delgado continued to assert that the proposed regulations were constitutional and that they may go even further and still comport with First Amendment law.209

The proposed revisions to UWS-17 passed through the legislative and public hearing processes, and were adopted without modification by a vote of $12-5$ by the Regents on June 9, 1989.210 Efforts by the ACLU, the UW-Madison SCPC and others failed to sway the Regents' and legislators' opinions sufficiently to change or rescind the policy. ${ }^{211}$ Laurence Weinstein, a member of the Regents, later characterized the testimony of the UW-Madison SCPC at the public hearing as "favorable" toward the system policy, even though the co-chair of the SCPC had informed the Regents that the committee could

208T. Finman. Memo to Regents' President, Paul Schilling, UW-Madison, May 31, 1989.

${ }^{209}$ R. Delgado. Memo to P. Hodulik, UW-Madison, May 30, 1989.

210C. Friewald. "Regents pass racism rule," The Badger Herald, June 19, 1989, at 1. See also, \#W-11 at 8, who remarked that "most often there are no hearings held on administrative codes like this, but there was a hearing held on this one." See also, \#W-5 at 5.

$211 \mathrm{~A}$ review of some evidence suggests that supporters of the UW-Madison version were asked not to impede the progress of the system version of UWS-17 because of intense political pressure from various constituencies in the state. First, \#W-8 at 5 indicated that "the politics of the situation" limited one's ability to tone down or otherwise modify the questionable language of the system policy. Second, \#W-13 at 7 said that s/he had been requested directly by a UWS administrator not to place any roadblocks in the way of the system policy. Third, the Wisconsin ACLU testified in support of the Madison version, with the addition of a provision stating that the expression or behavior "resulted in a denial of equal access to programs or facilities;" see B. Durand, supra note 169. 
not accept the system version.212 One white faculty member explained the Board's decision was because,

[t]his was a Board that was appointed primarily by the Democratic governors, so it did not have a conservative image. I think they wanted to take a lead. That's one of the reasons they did not want to simply ratify the Madison campus draft--they wanted a new one which wasn't associated with the Madison campus. That would make it more palatable to Milwaukee and Eau Claire and the other campuses. 213

The policy was supported without amendment by the Wisconsin State Legislature in July, 1989.214

However, because key legislators expressed concern about the policy, the University agreed to submit periodic reports on the application of the new rules. 215 The revisions to UWS- 17 became effective September 1, 1989.216

During the spring 1989 and afterward, disagreement continued over what form of policy on discriminatory verbal harassment was best. Some individuals on the UW-Madison campus believed that the adoption of the system version of UWS-17 over the Madison version was a mistake both for its applicability to actual situations and its legal basis. A white administrator reflected,

212L. Weinstein. "Policing Prejudice," AGB Reports, January/February 1990, at 7. Weinstein refers to the SCPC as the "UW-Madison faculty committee." Even if he meant to write "faculty senate," it would be an error because the UW-Madison faculty senate supported the version put forth by the SCPC. See also, B. Durand, supra note 169: "I was the spokesperson for the policy in the spring of 1988 and testified before the Regents in...June of 1989, as Co-Chair of the Madison Student Conduct Policy Committee, that we could not accept the system version."

$213 \# W-6$ at $4 ;$ See also, \#W-13 at $1 ; \# W-3$ at 6.

$214 \# W-5$ at 4. See also, K. Shaw memo to Education Committee and All Regents, "Report on Implementation of UWS-17," UWS, August 29, 1990, at 1.

215 ld.

$216 \# W-5$ at 4. See also, Id. 
...[O]ne of the sad parts of this is that the original rule that was crafted at Madison had a couple of additional components that we thought made it tighter, and would have increased the likelihood of the court decision being upheld instead of overturned. The version that the system adopted was weaker legally than what we had wanted.217

Opponents of the system version argued it was inconsistent with existing standards for employee conduct.

Another white, UW-Madison administrator stated that when the language about persistent use was removed,

...it was a critical problem which prevented this case from being the test of the possibilities of transferring work-place standards to an educational setting. What we ended up with, in a bizarre fashion (once the system removed the 'repeated' language), was a standard for students which is stronger than the standard that we have announced for our own employees. With our employees, repeated behaviors attest to intentionality; for students, a one time behavior was sufficient.218

The point essentially became moot when the U.S. District Court ruling in UWM Post rejected the

University's arguments that workplace harassment codes should apply in educational settings. ${ }^{219}$ Since the

UW-Madison proposal also contained language from Federal workplace guidelines, it would have likely

suffered the same fate.

$217 \# W-4$ at 1 . See also, \#W-4 at 3; \#W-11 at 8; \#W-13 at 2,6. See also, B. Durand, supra note 169.

218 \#W-11 at 8. See also, Faculty Document 786, "Prohibited Harassment: Definitions and Rules Governing the Conduct of UW-Madison Faculty and Academic Staff," UW-Madison, February 6, 1989. The faculty/staff policy says, in part, that "[a] member of the University faculty or academic staff is subject to discipline if, in a noninstructional but work- or learningrelated setting, he or she: repeatedly addresses or directs to University employees, students or recipients of university services epithets, comments or gestures that explicitly demean their gender, race, etc...." The expression must be commonly understood to be demeaning to members of the group in question, and the repetition of the expression must "seriously interfere[s] with the work or study performancen of the target, or make the environment hostile, demeaning, or intimidating to members of the target group.

219 UWM Post V. Board of Regents of the University of Wisconsin, 774 F.Supp. 1163 at 1177 (E.D. Wis. 1991). The case was decided on October 11, 1991. Affidavits and other supporting materials are marked, "Case \#90-C-328." 
Others at the UW-Madison and UWS believed that there was no substantial difference between what the UW-Madison proposed and what the UWS eventually adopted.220 It should not be surprising that the lack of consensus evident prior to the Regents' action would continue after a decision was made. And, one can only surmise what would have happened in terms of adjudication of cases, campus relations, or judicial treatment by a court had the Madison version emerged from the deliberative and political processes described in this section.

\section{Supporters of UWS-17}

This section describes rationales used by various individuals who have supported some form of a policy to curtail discriminatory expression. As the previous section indicated, persons who agreed that the University should have a policy to sanction discriminatory verbal harassment may have disagreed over the purpose and the breadth of the policy. Interviews at Madison and the UWS suggested that support for revisions to UWS-17 was given for both practical and symbolic reasons.

The major public incidents catalogued in section 2 of this chapter and minority students' descriptions of their experiences as the targets of racial harassment and hatred earned them a great deal of support among other students, administrators, faculty, Regents, State Legislators, and others. Pat Hodulik, senior system legal counsel, remarked that,

... as I went through the process and as I heard the students come and talk about their experiences, I was very moved and I think everybody else was, too. There were a number of minority students

$220 \# W-3$ at $2 ; \# W-6$ at $4 . \# W-8$ at 5 . 
sharing the things that they had experienced on our campuses and the kinds of harassment, and the things that they took home with them and felt bad about.221

Mario Mendoza, a UW-Madison junior who is Puerto Rican, said that he would "expect and prefer to go into an environment which is not as hostile as the rest of this society is to me and to people like me."222 Again, the policy was one of many ways that the University was trying to address the problems of campus community and the recruitment and retention of students of color. To one white administrator, the policy was a predictable extension of the racial events occurring at the UW-Madison and elsewhere:

The pressure on the institution to take disciplinary action in such incidents was going to be strong, and we had better have that clear edge--a definition as to what we were able to do. We went into that, not with a presumption about where the 'edge' should be, but with the thought that there ought to be an edge. That we ought to define under what conditions, if any, the University is able to take disciplinary action. We needed that edge in order to inform our response to these very loud calls, and to give guidance to the future [administrators] who might be here.223

The pressure asserted by the Minority Coalition both on campus and off led some persons to support the policy. Spencer Coggs, the State Representative from Milwaukee who introduced legislation to try and force the UWS to implement a policy to stop discriminatory verbal harassment, supported the policy because many of his constituents were concerned about what was going on at the UW-Madison.224

The Regents' goal, according to member Laurence Weinstein who supported the policy, was "to help create an environment that would give each student--regardless of race...--equal access to campus 221 Wisconsin ACLU Panel Discussion, supra note 34 at 7. 222 /d. at 6.

$223 \# W-11$ at 6. 
educational opportunities." 225 Three related goals were attributed to the Board of Regents (and others). The rule was intended to 1) do something to say to minorities that the University wanted them to stay on the campus, 2) offer a civil environment for students' work and study, and 3) insure that people continue to have opportunities for speech in the classroom and other public contexts without interference. 226

When drafters of the policy began to try to put these goals into written form, they found the range of legal options open to them was small. The legal precedents available centered around the "fighting words' doctrine, work place harassment codes, and the University's interest in maintaining order on campus through student regulations. 227 Supporters of the Madison version believed that it focused on repeated or egregious conduct rather than on speech; they thought the policy had been drawn narrowly enough not to pose any serious threat to the expression of ideas. 228 Supporters of the system version believed that a limitation on speech in situations with face-to-face epithets imposed very little on freedom of speech, and that this was a kind of speech that really was conduct.229 Board of Regents' members who supported the policy expressed concerns about the potential for infringement on freedom of speech, but they were reassured by what they perceived to be a difficult burden of proof and "by the intent to regulate only the

225L. Weinstein, supra note 212 at 2.

226Wisconsin ACLU Panel Discussion, supra note 34 at 3 (comments of P. Hodulik). $227 \# W-3$ at $3 ; \#-11$ at 5.

$228 \# W-11$ at $5 ; \# W-13$ at $2,3$.

$229 \# W-3$ at $3 ; \# W-8$ at 4. 
most demonstrably harmful forms of expressive behavior and to do so very narrowly."230

Faculty and administrator informants perceived that both Chancellor Shalala and President Shaw were highly committed to creating more hospitable environments and doing so even through the use of the University's student conduct codes.231 A white faculty member stated:

[t]here [was] a lot of leadership from the top on this issue, and it is unusual in the respect that more pressure came from the top than from the bottom. The pressuring came also from the black student groups, but it caused some considerable resonance at the Chancellor's level and the Board of Regents' level. That's very rare here. I don't recall any other instance...here where rules were inspired by the top management rather than coming in at some lower level.232

Several sources spoke of the policy's symbolic value, and like many symbols, it had different meanings for different groups of people. To some administrators, the policy symbolized the University's commitment to equal educational opportunities for all students. 233 Some faculty and administrators expressed concern during the policy's development that its symbolic value would be perceived as only a token gesture toward minority students. 234 Although some minority students initially voiced skepticism, later they perceived the symbolic importance of UWS-17 in cases of racial abuse.235 After UWS-17 was found unconstitutional in court, the policy's symbolism and the value ascribed to it as a symbol became

230Minutes of the Board of Regents, supra note 22 at $23,25$.

$231 \# W-3$ at $4 ; \# W-7$ at $7 ; \# W-6$ at 7.

$232 \# W-6$ at 7 . See also, \#W-3 at $4 ; \# W-7$ at $7 ; \# W-5$ at 5.

$233 \sharp W-5$ at $6 ; \# W-7$ at $5 ; \# W-11$ at $10 ; \# W-6$ at 6.

$234 \# W-5$ at $3 ; \# W-13$ at 5.

$235 \#$ W-2 at 3. See also, Wisconsin ACLU Panel Discussion, supra note 34 at 6. 
more obvious and more highly prized among some students. An Hispanic student explained:

...what I worry about now that it's been overturned is that it sends a subliminal message that it doesn't matter how you speak to people; it doesn't matter if you degrade them or not; it doesn't matter if they are hurt by what you say because you are free to do that. I think it makes a bigger statement that the policy was overturned than was made when it was instated. 236

When the symbolism of the policy becomes the primary rationale for its existence, it could be an indication either of the extreme value of the policy or its hollowness. In either case, the importance of having a policy to punish the extreme forms of discriminatory speech is evidence that the racial climate at the UWMadison required every means of support possible in order to improve.

\section{Qpponents of UWS-17}

This section describes rationales used by various individuals who opposed some form of a policy to curtail discriminatory expression. UWS-17's critics opposed it from opposite poles; some argued that the policy did not go far enough in proscribing the kinds of activities which undermine community, while others (the majority) argued that the policy infringed on students' free speech rights. ${ }^{237}$ Informants identified the Wisconsin Chapter of the ACLU as the primary opponent throughout the development and application of UWS-17. Others identified as opponents to UWS-17 included specific legislators, faculty

$236 \#-1$ at 3.

$237 \# W-4$ at $4 ; \# W-5$ at $6 ; \# W-6$ at 5. 
members (especially in theatre and drama), and the Mayor of Madison.238

Minority Coalition members (and some faculty and administrators) who opposed UWS-17

reportedly did so because they believed the rule would be ineffective in stopping most forms of racial

harassment.239 Some directed their frustration at the University for its unwillingness to reach beyond legal

boundaries in fashioning a rule sufficient to match the commitment to minority students articulated in The

Madison Plan and Design for Diversity; part-way was not far enough for these students. 240

There is little evidence to suggest a groundswell of student opposition to the rule. However, some

opponents, including this Hispanic student, were concerned about enforcement issues:

For some, UWS-17 is perceived to have serious enforcement [problems] because of the vague language. Others said that the policy would drive the racists underground--that they would not be open about their racism, so students would not be able to tell who supported and who opposed them. Some argued that nothing was accomplished by expelling a student for calling someone an epithet because the net result of the expulsion was to create resentment in that student and their like-minded friends--it is not educating them about the problem. 241

The legal arguments of vagueness and overbreadth were of particular concern to many opponents of the policy. Vagueness was cited both in the text of the policy revision and in the examples that

$238 \# W-3$ at $4 ; \# W-5$ at $5 ; \# W-11$ at 8.

$239 \# W-2$ at $2 ; \# W-6$ at $5 ; \# W-13$ at 6.

240 Id.

$241 \# W-2$ at 2, 3. See also, \#W-4 at 4, who confirmed the assertion by $\# W-2$, that generally white males had opposed the rule, while women and persons of color had supported it. 
accompanied it. 242 Overbreadth was cited where the policy covers not only epithets, but "comments and

other expressive behavior." 243 The policy was argued also to be too broad in its treatment of the "fighting words' doctrine because the policy made no mention of an 'imminent threat of violence' resulting from the words used--the standard which the Federal Court used to interpret the meaning of 'fighting words.'244 The overbreadth and vagueness arguments were used to cast doubt on enforcement issues. One of the attomeys representing the ACLU plaintiffs in their case against the University asked,

Where do you draw the line on "the line of epithets"... take the mildest. The rule prohibits epithets based on ancestry. Is calling someone a "bastard" an epithet based on ancestry? I suppose it is. Do we think that people should be punished for calling someone a bastard? I think we would have a lot of people being disciplined. 245

Many Regents who voted against the policy cited First Amendment concerns as their primary reason, while others voted against it because of their convictions against any speech restrictions at a University. 246 Faculty members in the Consortium for the Arts expressed concern over the dangers of restricting free expression, especially as it related to artistic expression. Members of the Consortium thought it "pedagogically unwise and educationally counterproductive" to adopt a rule punishing

$242 \# W-6$ at $5 ; \# W-8$ at $5 ; \# W-9$ at $3 ; \# W-13$ at 5.

243 \#W-8 at 5. See also, Wisconsin ACLU Panel Discussion, supra note 34 at 4 (comments of J. Kassel).

244 \#W-9 at 2. See also, U.W.M. Post, supra note 219 at $1169-1177$. Also, E. Edgar, supra note 137.

245Wisconsin ACLU Panel Discussion, supra note 34 at 12 (comments of J. Kassel).

246 Minutes of the Board of Regents, supra note 34 at 23-26. 
discriminatory speech while concurrently imposing an ethnic studies requirement in the undergraduate curriculum. 247 Faculty, in general, seemed not to be concerned about the reach of the policy in the classroom.248 One explanation for this may have been that the policy only applied to students, and only in certain settings (i.e., not in classrooms, theatres, forums, etc.) Another reason offered by a white faculty member was that "it is only in the context of a progressive Madison or in the context of truly academic, ungrounded settings where limiting free speech starts to seem like any kind of good idea."249

\section{Conditions Following the Adoption of UWS-17 \\ Introduction}

The University of Wisconsin, as outlined earlier, took several steps to help create more productive and satisfying campus environments for its minority students. The adoption and promulgation of UWS-17 was only one of these steps. Because multiple methods were implemented to achieve the University's community enhancement goals, changes in campus racial relations cannot be attributed to one source, nor can the force or weight of the individual events or programs be reduced to numerical representation. Care has been taken in answering the research questions in order to portray accurately the distinct outcomes related to UWS-17. The academic behavior of students and faculty and the campus racial climate were

247E. Cronon (dean, College of Letters \& Sciences) letter to D. Shalala, UW-Madison, April 22, 1989.

248 The faculty senate's unanimous support for the Madison version of the policy supports this idea. Also see, $\# W-6$ at $2 ; \# W-10$ at 3 . 
affected profoundly by other variables in addition to UWS-17.

Another significant factor affecting the impact of UWS-17 began in March, 1990, when several student-plaintiffs (sponsored by the Wisconsin ACLU) filed suit against the University claiming that UWS17 was an abridgement of their First Amendment rights. 250 The policy had been in force only seven months when the lawsuit was filed. The University continued to operate under the regulation, but the legal challenge may have cast a shadow of doubt over the permanence of the policy both for those who applied it and for the students who were subjects under it. The legal challenge was settled in October, 1991, in favor of the student-plaintiffs. 251 The University was permanently enjoined from enforcing UWS-17.06 and it was ordered to remove sanctions from the student-plaintiffs punished under the policy. 252

\section{Racial Relations after September 1, 1989}

The beliefs of administrators and minority student leaders evidence no visible changes after the

policy was adopted. Some students suggested that conditions improved for a brief time in the fall of 1989 , but that they had deteriorated once again by the fall 1991.253 Minority student informants indicated that racism was still present, but it had become more subtle. When asked about the changes in racial relations between the time of the promulgation of the revised UWS-17 and the court decision to overturn it, an

250 U.W.M. Post, supra note 219 at 1164.

251 /d. at 39.

252 ld.

$253 \# W-1$ at 5. 
Hispanic student said,

things have mellowed down a lot since that time. I have seen students of color still feeling very uncomfortable on this campus. Racism on this campus is still very strong, but the fact that we had UWS-17 and other efforts to address racism, racism became a conscious issue....now, the ways in which racism is expressed are more subtle. Minority students still complain about things which are said to them or things that happen to them--things about affirmative action like, 'you just got in here because of affirmative action. 254

The demographic situation that helped create a sense of isolation among minority students at the

UW-Madison in the late 1980s worsened in the fall of 1991.255 In a prepared statement, Chancellor Shalala wrote, "[w]hat we have been doing to increase new minority enrollment has simply not worked."256 This condition could also be perceived as a continuation of minority enrollment declines which began around 1980.257 Recruitment issues continued to be difficult for minority students after UWS-17 was implemented.

Administrators, when questioned about the effects of UWS-17 on racial relations, believed that at

$254 \# W-2$ at 4. See also, $\# W-1$ at 3.

255D. Magner, supra note 88 . The reader will recall that the total number of new minority students dropped from 305 (1990-91) to 252(1991-92) while the number of entering black students during that period fell from 105 to 77 .

$256 / d$.

257UW-System, supra note 8. See also, J. Sarder, "UW minority enrollment misses Madison Plan," The Badger Herald, September 27, 1989, at 1. This article noted that in the fall of 1989 , the incoming freshman minority enrollment was $18 \%$ lower than the previous year (it went from 232 to 191), and the total freshman enrollment was $16 \%$ lower. This enrollment decrease preceded any effects of the revised UWS-17. The Madison Plan had indicated a goal of recruiting 400 minority students per year by 1993. 
worst, conditions had not deteriorated in the past few years and at best, there has been a gradual improvement. 258 No single cause was identified as paramount in the improvement effort. Instead, a variety of programs implemented both at the System and the institutional level were perceived to contribute to more positive relations. 259

The UW-Madison took steps to address complaints of harassment long before the revised UWS-17 was approved. During the spring, 1988, UW-Madison increased its efforts to publicize ways for students to report incidents of racial bias. The Dean of Students' Office published brochures which encouraged students to contact the Dean of Students in cases where students" "experience or witness racial or ethnic harassment, conflict, misunderstanding or perceived unfaimess."260 This marked a new level of publicity for the Dean of Students Office, but the policy of handling every case of harassment on campus that was brought to their attention had been in place for many years. 261 The brochures also publicized a "racism hotline," sponsored by the Wisconsin Student Association (student government organization), where students could call to register complaints and to get information and advice. Another brochure, first published in the summer of

$258 \# W-4$ at $5 ; \# W-5$ at 7.

259 ld.

260 Office of the Dean of Students. "Racism at the UW-Madison: let us know!" UWMadison, Spring, 1988. 
1989 by the Dean of Students Office, promoted the "Race Relations Education Program."262 This program organized training sessions to prepare leaders to conduct race relations workshops, and served as an agent to arrange speakers for campus organizations who wanted to discuss race relations.

\section{Application of the Policy}

Just after the revised UWS-17 took effect on September 1, 1989, the UWS Office of Minority

Affairs distributed a brochure containing the new policy and five questions and answers related to it.263 The brochure was disseminated widely and was used as the basis of educational programs and new student orientation sessions.

President Shaw filed the first report on the implementation of UWS-17 in August 1990.264 The report catalogued 21 complaints filed by students in which $\$ 17$ was cited. One complaint resulted in a suspension and four resulted in probation for the named students. In some cases judicial officers determined that other sections of the student conduct code had been violated, and those students were disciplined under rules other than UWS-17. In some cases, the complaints were found not to violate any student conduct rules, including UWS-17.

262Dean of Students Office. "Race Awareness Committee (RAC) Race Relations Education Program (RREP)," UW-Madison brochure, Summer, 1989.

263University of Wisconsin System, Office of Minority Affairs. "Discriminatory Harassment: Prohibited Conduct Under Chapter UWS 17 Revisions," UWS brochure, (no date).

264K. Shaw. "Report on Implementation of UWS-17, Wisconsin Administrative Code," UWS, August 29, 1990. The report was made to the Board of Regents. 
The summaries in the report provided only limited details about each case and their outcomes. At the UW-Oshkosh, a white student had said to an Asian American student that "it's people like you that's the reason this country is screwed up," and "you don't belong here."265 The offending student was placed on probation, required to obtain counseling, and agreed not to harass other students. 266 At the UW-Stevens Point, a male student and two non-student guests entered the room of another student, falsely claimed to be immigration officials, and then harassed the resident concerning his immigration status based upon his national origin. 267 The offender in this case was placed on probation, required to write a paper on a related subject and restricted from inviting the guests to his residence hall. At the UW-Parkside, an uninvited male student entered the dorm room of a woman student whom he did not know, caused a disruption and referred to the woman as "Shaka Zulu."268 Although the president's report indicates the incident was not considered a violation of UWS-17, the student received several sanctions for his behavior including probation, alcohol counseling, and required reading on racism. ${ }^{269}$ At the UW-Eau Claire, a male studentathlete responded to anti-athletics remarks made by a woman in a university newspaper by repeatedly calling Oshkosh).

265 U.W.M. Post, supra note 219. Affidavit of Mary Skorheim (dean of students, UW-

266K. Shaw, supra note 264.

267 Id.

$268 / d$.

269 U.W.M. Post, supra note 219 at 1180. 
her a "fucking bitch" and "fucking cunt." 270 The University placed the student on probation and required him to perform twenty hours of community service at a shelter for abused women. A student at the UWStout presented false identification in attempting to enter a campus dorm. When challenged, the student initiated a physical altercation and called one residence hall staff member a "South American immigrant" and called another a "piece of shit nigger."271 The student received a seven month suspension.

Other cases led to different outcomes. Eight complaints occurred at the UW-Madison, but all were found not to violate the relevant portions of UWS-17. Among the UW-Madison cases was one where a student used the term 'redneck' to describe a particular group of students at a debate in the student senate. ${ }^{272}$ Another case involved a complaint against a campus newspaper for publishing a cartoon thought to be offensive to Christians and therefore demeaning on the basis of religion.273

In another case where UWS-17 was found not to apply, a white student and a black student at the UW-Whitewater were involved in an argument during which the white student decided that he wanted to physically fight and he said (among other things), "come on nigger."274 After several meetings with the students the acting associate dean of students determined that no violation of UWS- 17 occurred because the 270K. Shaw, supra note 264 . This incident occurred at a local off-campus pub. 271 Id. 272 ld. 273 Id.

274 U.W.M. Post, supra note 219. Affidavit of Richard Bailey, acting associate dean of students at the UW-Whitewater during this incident. The incident occurred on September 20 , 1989. 
white student's experiences while growing up in Chicago led him to believe that it was common for whites and blacks to use the term nigger to refer to a black person who was not respected or liked.275 In that environment the term "nigger" was not intended to be racially demeaning, but was used in the same way that another person might have used the word "asshole" or "bastard."276 The black student agreed that a black person may call another black person a "nigger" in a name calling situation without the term being considered racially demeaning. 277 Judge Warren agreed that the case was consistent with the policy because "Whitewater reasonably found that the student charged did not demean the race of his addressee." 278 This case can be distinguished from the situation at the UW-Stout in which the rule was applied because at the UW-Stout the offender was found to have intended to demean his targets.

At its meeting in September 1990, the UWS Regents supported UWS-17 and the University's application of it during its first year. 279 Eunice Edgar indicated her surprise that the Regents had not questioned some of the complaints filed and expressed concerned that the outlying campuses might enforce

275 Id.

$276 / d$.

$277 / d$.

278 Id. at 1180.

279 N. Shively. "Anti-racism rule seen as working," The Milwaukee Sentinel, September 8, 1990. See also, J. Kassel and B. Williamson, "Brief in support of Plaintiff's Summary Judgement Motion" at 10, 23 (in U.W.M. Post, supra note 219). 
the policy more strictly.280. Edgar also suggested that the Regents did not make any changes to the language of the policy because the case before the court was still pending. ${ }^{281}$ If the Regents changed the wording of the revisions to UWS-17 it could have been perceived as an admission that the policy was flawed for exactly the reasons stated by the ACLU and other opponents of the policy.

In August, 1991, Acting UWS President Lyall reported to the Regents that 14 complaints had been filed under UWS-17 and that seven of these cases resulted in disciplinary probation.282 At the UWStevens Point, a white student stole his Japanese roommate's bank teller card and withdrew money from the account.283 During the investigation of the offense, the accused student acknowledged that his behavior was motivated by his resentment for his roommate because the roommate was Japanese and did not speak English well. The accused student was placed on probation, required to provide a written account of the incident, and forced to enroll either in a course in ethics or in East Asian history. UW-Eau Claire administrators reprimanded a student and placed him on probation for sending a computer message to an Iranian faculty member that said "Death to all Arabs!! Die Islamic Scumbags!"284 A female student at UW-

280 /d. (N. Shively). .

281 ld.

282K. Lyall. "Second Annual Report on the Implementation of UWS-17, Wisconsin Administrative Code," UWS, August 28, 1991.

$283 / d$.

284 U.W.M. Post, supra note 219 at 1180. 
Oshkosh was disciplined for calling another student a "fat ass nigger" during an argument.285 The

University required the student to view a video about racism, write an essay and letter of apology, and reassigned her to another residence hall. The UW-River Falls disciplined a male student under UWS-17 for yelling "you've got nice tits" at a female student in a public place. ${ }^{286}$ The male student was placed on probation, required to apologize to the woman and avoid further contact with her, and ordered to obtain psychological counseling. Two UW-Oshkosh students and one UW-Stevens Point student were placed on disciplinary probation for making harassing, threatening, and discriminatory phone calls which were found to violate UWS-17.287

In U.W.M. Post, Inc., Judge Warren catalogued the cases of nine of the students who had been sanctioned under UWS-17, described above. In his review of the policy, Warren determined that the phrase, "discriminatory comments, epithets and other expressive behavior" and the term "demean" did not suffer vagueness problems. ${ }^{288}$ However, Warren found the rule vague because "it fails to make clear whether the speaker must actually create a hostile educational environment or if he must merely intend to do so."289

\author{
$285 / s$. \\ $286 / d$. \\ 287K. Lyall, supra note 282. \\ 288 U.W.M. Post, supra note 219.
}

289 U.W.M. Post, supra note 219 at 1179 . This distinction was made moot by the Judge's finding that the rule was overbroad on its face. The Judge ruled that the only speech that the UWS could prohibit was speech that is likely to cause an immediate violent response. Since UWS-17 could have covered situations in which no breach of the peace was likely to occur, the policy was not consistent with the fighting words doctrine. This was exactly the 
Since the court found the rule to be overbroad on its face for its treatment of the fighting words doctrine, the issue of whether the policy had been applied Constitutionally was never addressed in the opinion. Judge Warren concluded, "...nothing in the UW rule prevents it from regulating speech which is intended to convince the listener of the speaker's discriminatory position. Accordingly, the rule may cover a substantial number of situations where students are attempting to convince their listeners of their positions." 290

Even if the UWS had adopted a policy which incorporated the fighting words definition of individually abusive language directed at an individual which is intended and likely to provoke a violent response, campus adjudicators would still have faced difficult decisions. One white informant explained:

The epithet example that bothered me the most was 'Shaka Zulu.' Maybe calling someone 'Shaka Zulu' is insulting--I guess the black student to whom it was addressed found it offensive....I think most people would agree that a white person calling a black person a 'nigger' to his or her face--if that's not a fighting word, then what is? On the other hand, a white person calling a black person 'Shaka Zulu'? I don't think it's a fighting word, but I don't know.291

If a speaker used language that was personally offensive to the hearer, judicial officers may have difficulty determining whether the speech was likely to produce a violent response.

UWS-17 prohibits individualized discriminatory comments, epithets or other expressive behavior which intentionally demean another person and intentionally create a hostile environment. Administrators

position taken by the Legislative Council's Rules Clearinghouse in its report advising against UWS-17 as drafted (see supra note 207 and accompanying text).

290 U.W.M. Post, supra note 219 at 1174.

$291 \# W-9$ at 3,4. The reader will recall that the UW-Parkside disciplined the student using the term, "Shaka Zulu," for violating policies other than UWS-17.06. 
(not attorneys) who applied sanctions under UWS-17 believed that the criteria were met in the cases cited above. Others who reviewed the cases disagreed. A white administrator said:

the other unfortunate part about the rule is that the application of the rule at some of the other UWsystem campuses has not been as careful as it should have been. There have been some instances where the rule has been applied where I never would have thought of applying it. Its application across the system has been inconsistent and that is worrisome.292

Several explanations arose in response to the issue of inconsistent and improper application of the policy. First, some suggested that campus administrators charged with the enforcement of UWS-17 received insufficient training. 293 Second, since some of the incidents involved fights, or near fights, other policy violations occurred making it unclear that the speech rule component was an important part of addressing the incidents. 294 This implies both that the speech rule is unnecessary because existing policies are sufficient to guard against harassment, and that the standard of 'intended and likely to provoke a violent reaction' is present in the University's existing policies. Third, according to a white administrator, "the rule has been consistently misunderstood" because of excessive media attention and the media's use of misleading short-hand phrases, like "hate speech rule," to describe the policy.295 Fourth, many persons have difficulty reading the rule and understanding clearly what it means because "it takes a very sharp

$292 \# W-4$ at 2 . See also, \#W-3 at 7; \#W-5 at 8; \#W-6 at 6.

$293 \# W-3$ at $7 ; \# W-5$ at $8 ; \# W-8$ at 6.

294 Wisconsin ACLU Panel Discussion, supra note 34 at 10 (comments of J. Kassel). $295 \# W-11$ at 7. 
appreciation of what all is required to properly administer this rule."296 Fifth, the rule operates in a way

such that a campus administrator reviews each case and then charges the student with anything in the rule

book that seems appropriate; several rules violations may be charged in connection with one episode or

course of conduct. Instead of appealing decisions, students generally looked at the list of charges, admitted

they did the behavior, and accepted the judicial sanction.297 Despite these explanations, some found the

disposition of the cases unsettling. A white faculty member described his reaction:

When I saw the rule, I thought it was doubtful that it would ever be applied. Then Brady

Williamson, the ACLU's volunteer attomey, finds these half dozen or so incidents. As soon as we saw that we knew the case was lost. We urged the University lawyers to confess error, but it was in the hands of the Attomey General's Office...298

\section{Effects of UWS-17 on the Academic Behavior of Faculty and Students}

The drafters of UWS-17 and the Board of Regents were particularly concerned about the impact of

the policy on academic behavior at the University's campuses.299 A variety of opinions were expressed

$296 \# W-8$ at 5 . See also, \#W-11 at 7.

$297 \#$ W-3 at 5: "This rule was cited in a number of cases in which the students did not go to a hearing. The result is, when you look at it after the fact, it appears that we applied this rule in cases where we should not have applied it. On the other hand, there were other factors which led the students not to contest any of the issues. So it's not to say that the violation was ever proven by anybody--it was just conceded. If we had more hearings, we might have had more interesting cases to talk about." This opinion is confirmed by the disposition of the cases presented in the reports by K. Shaw and K. Lyall to the Regents on the implementation of UWS17. Two cases at the UW-Stevens Point that were appealed by the students were eventually dismissed because UWS-17 was found not to have been violated.

$298 \# W-6$ at 6.

299 Minutes of the Board of Regents, supra note 22 at 20-26. See also, "Report of the Deliberations of the UW System Working group to Revise UWS-17," February 1990. See also, 
regarding the impact of the revised UWS-17 in the classroom. However, most campus interviews revealed that the rule, properly understood, would not apply to academic situations. 300 One administrator believed, “...if we have been successful at anything, we've been successful at making it clear that it's got nothing to do with the classroom." 301

Even those who were aware of instances of self-censorship did not focus on UWS-17 as the impetus for the behavior. Some faculty and administrators linked students' (especially 1st-year and 2nd year students) hesitancy to discuss issues of race or gender to students' fears of stating unpopular opinions or making factual misstatements and being perceived negatively by others rather than a fear of being sanctioned under UWS-17.302 A white professor postulated,

there are some professors who are afraid of being called racist if they come out in opposition to affirmative action or if they criticize the university's admissions policies for minority students. There is some fear on campus, but many forms of this fear are misplaced. Some of the incidents that I am familiar with...had partially to do with [the professor's] arrogance. The combination of an arrogant professor who thinks that students don't know anything with a highly emotionally charged topic can produce all sorts of bad outcomes. 303

All of the concerns expressed about UWS-17 reaching into the classroom were hypothetical. No evidence

P. Hodulik, "Prohibiting Discriminatory Harassment by Regulating Student Speech: A Balancing of First Amendment and University Interests," Journal of College and University Law, 16:4 (Spring 1990), at 579-80.

$300 \# W-1$ at $5 ; \# W-3$ at $6 ; \# W-4$ at $6 ; \# W-6$ at 7 ;

$301 \# \mathrm{~W}-11$ at 10.

$302 \# W-7$ at $7 ; \# W-10$ at 1.

$303 \# W-10$ at 3. 
suggested that anyone was sanctioned for their classroom expression, nor did any evidence indicate that the University prevented anyone from making a speech or writing a document because it contained racist messages. Even the concems expressed by the Consortium for the Arts were anticipatory. The one (white) professor interviewed who voiced some doubt about the policy applying in the classroom vowed to leave before s/he self-censored classroom activities. ${ }^{304}$ However, some of the hypothetical scenarios were quite believable. For example, one white informant hypothesized, after a heated, controversial discussion in class students walk out and continue the argument in the hall...[where] somebody [is] saying "gay people have an immoral lifestyle and shouldn't be allowed to adopt children." If you made that generally to the class, the University would say that it was protected speech. But if you turned to the gay student next to you and said,"gay people like you are immoral and shouldn't be allowed to adopt children," or if you walked out into the hall and said "I think your lifestyle is sick and you shouldn't be allowed to adopt children," then the policy may apply...Just the fact that it's directed at someone isn't enough. 305

None of the complaints brought under UWS-17 which resulted in sanctions involved cases of academically related behavior.

\section{The Second Revision of UWS-17}

The U.W.M. Post, Inc. ruling left the University with three options: appeal the decision, draft another revision to UWS-17 or do nothing. The University confronted these options just as it revealed that 
minority enrollment had fallen. 306 Editorials in both a campus newspaper and Madison newspapers urged the University not to consider an appeal.307 In addition, 29 Wisconsin legislators signed a letter asking the Board of Regents not to appeal the District Court Ruling. ${ }^{308}$

The Regents voted not to appeal the case at its November meeting, but opened up the possibility of a redraft. ${ }^{309}$ The UW-Madison quickly began the process of re-drafting the rule. After an "emotional debate," the UW-Madison faculty senate approved a redraft of UWS-17 on March 2, 1992.310 Two alternate proposals were presented to the faculty senate. One, presented by the Wisconsin Student Association, proposed a 'content neutral' draft of the code that did not list the protected categories of persons to receive protection under the rule. 311 The other proposal, offered by a political science professor, asked the faculty senate to reject the re-draft and to support other measures of creating an open and welcoming campus

306D. Magner, supra note 88.

307Editor. "Give up on speech rule," Wisconsin State Journal, October 16, 1991, at A13. See also, J. Kaphingst (ed.); "UWS-17 appeal is a waste of money," The Badger Herald, October 18, 1991, at 3.

308R. Berg, supra note 136.

$309 \sharp W-3$, letter to T. Jennings, November 29, 1991.

310B. Schneider. "New 'hate speech' code gets OK'd," The Daily Cardinal, March 3, 1992 , at $1,7$.

311B. Schneider. "Students shut out in redrafting of code," The Daily Cardinal, March 3,1992 , at 1,7 . Student government leaders complained that they were not consulted in the re-drafting process. 
community. 312 The faculty senate rejected the alternative proposals and endorsed the redraft of UWS-17.

The re-draft was forwarded through Chancellor Shalala to the Board of Regents where it received

preliminary approval on March 6, 1992.

The second draft of UWS-17 (see appendix C-3) limits the proscribed speech specifically to

epithets that are

... intended to demean the race, sex, religion, color, creed, disability, sexual orientation, national origin, ancestry or age of the person addressed, and ... would make the educational environment hostile or threatening for a person to whom the word, phrase or symbol is directly addressed, and without regard to the gender or other physical characteristics of the individuals involved, would tend to provoke an immediate violent response...313

The rule incorporated language addressing the strongest criticism of Judge Warren and the ACLU plaintiffs.

The new wording more closely tracked the fighting words doctrine as outlined in the judge's opinion. The Regents' added an amendment requiring that any application of the rule would be reviewed by a person designated by the UWS President. ${ }^{314}$ At the March 6 meeting the Regents also adopted a resolution promoting tolerance of different ideas and backgrounds and condemning discriminatory harassment. ${ }^{315} \mathrm{~A}$

312B. Schneider, supra note 310.

313 Draft policy of $\$ 17.06$ (2) of the Student Nonacademic Disciplinary Procedures, approved by the Board of Regents of the University of Wisconsin System for submission through the administrative rule-making process, UWS, March 6, 1992.

314 ld.

315 Resolution \#6041 of the Board of Regents of the University of Wisconsin System, March 6, 1992. 
public hearing on the second draft was held on May 7, 1992 in Milwaukee.316 The Regents approved the second revision of UWS-17 by a vote of $9-6$ on May $8,1992.317$ The rule was then sent to the state legislative committee for review. The committee returned the policy to the Regents following a 5-5 tie vote. 318 The U.S. Supreme Court decided the matter of R.A.V. v. St. Paul in June 1992 during the legislative committee's review. 319 Consensus developed among the Regents to postpone enforcement of the rule (scheduled to take effect in July 1992) until the Board could vote again on the policy in September, 1992.320 At its September meeting, in light of R.A.V., the Wisconsin Board of Regents voted 10-6 to repeal UWS-17.06.321

\section{Conclusion}

The University of Wisconsin is unique among the three cases in this report in several respects.

316Draft policy of $\$ 17.06$ (2), supra note 313.

317N. Shively. "UW regents back 'hate speech' rule," The Milwaukee Sentinel," May 9, 1992, at 1 .

318M. Dorsher. "Hate-speech rule sent back to UW," Wisconsin State Journal, July 3, 1992, at 3. See also, D. Fuselier, "Hate is no longer a 4-letter word?" LaCrosse Tribune, July 3, 1992, at 9. S. Walters. "Regents to take 2 nd vote on UW hate speech rule," Milwaukee Sentinel, July 9, 1992, at 5.

${ }^{319}$ R.A.V. v. City of St. Paul, Minnesota. No. 90-7675, The United States LAW WEEK (60 LW 4667), June 23, 1992.

320 S. Walters, supra note 318.

$321 \mathrm{M}$. Jordan. "College repeals speech code as national backlash grows," The Washington Post, September 12, 1992 at A1. See also, (no author listed) "U. of Wisconsin Repeals Ban on "Hate Speech," New York Times, September 14, 1992 at A10. 
First, it has the most complicated organizational structure and the only state-wide system governance

structure. Second, it had the most attempted interventions from external constituencies, including the state legislature and the general public. Third, UW-Madison had more reported public racial incidents than the other institutions. Fourth, the UWS and the UW-Madison enrolled the lowest percentage of minority students. Fifth, it was the only institution of the three which had applied a policy prohibiting discriminatory verbal harassment. Finally, it was the only university among the three forced to test its policy in the Federal legal system.

Many of these factors served to complicate the racial situation and the policy-making environment at UWS and UW-Madison, making the overall environment more difficult in many respects than similar situations at either Stanford or Virginia. This does not imply that the racial incidents or contextual factors at the other universities were simple by any measure. However, the cluster of factors listed above combined with the efforts of an effective minority student coalition created greater conflict and complexity than were found at Stanford and Virginia. The recruitment and retention of minority students and the goal of creating more welcoming environments sustained the development of the policy. The Board of Regents' adoption of its second harassment policy suggested a continued commitment toward creating such an environment even at the risk of being criticized (or over-ruled) for limiting freedom of speech. 


\section{Chapter Five}

\section{Stanford University}

This chapter describes the considerations and events preceding and following the adoption of the 1990 Interpretation of the Fundamental Standard (see Appendix D) at Leland Stanford, Jr. University (Stanford). The first section presents the historical, structural and organizational factors and conditions that provided the context in which the Fundamental Standard Interpretation (FSI) developed. Next, a description is provided of the racial climate prior to the adoption of the revised policy. The third section relates political factors and conditions important to the development of the FSI. The fourth section includes a general chronology of events during the drafting of the rule and a discussion of the rationales of the policy's supporters and opponents. The last section delineates some of the outcomes of the University's adoption of the FSI, including its application and its impact on racial relations and academic behavior.

\section{Historical_Structural and Organizational Factors and Conditions}

\section{Historical Factors and Conditions}

Stanford University was founded in 1887 by Leland Stanford as a memorial to his son, Leland Stanford, Jr. ${ }^{1}$ Leland Stanford selected David Starr Jordan as the University's first president, and it was Jordan who developed Stanford University's "Fundamental Standard" of student conduct. 2 The Fundamental Standard was the only written rule of student conduct from its inception in 1896 until the

1L. Veysey, The Emergence of the American University. (Chicago: The University of Chicago Press, 1965) at 397. 447).

2/d. at 398. Jordan served as Stanford's president from 1891 to 1913 (/d. at 407, 
addition of an academic honor code in 1921.3 Three other policies which elaborate on the general guidelines of the Fundamental Standard have been adopted since 1967; they are the policy on campus disruption, the policy on combatting sexual harassment, and the prohibition of the possession of dangerous weapons. 4 However, these policies were not intended or perceived to be "interpretations" of the Fundamental Standard. Each policy was considered separate and distinct from the Fundamental Standard. The academic honor code was "interpreted" at least four times between 1973 and 1985, and the new interpretations served to explain specific circumstances not obvious under the original document. 5

The original Fundamental Standard states:

Students at Stanford are expected to show both within and without the University such respect for order, morality, personal honor and the rights of others as is demanded of good citizens. Failure to do this will be sufficient cause for removal from the University. 6

In Stanford's early years, the implementation of the Standard was at President Jordan's discretion and he was known to apply the rule aggressively to root out the moral evils of the day, especially during crises. ${ }^{7}$ As the University grew more complex, responsibility for the application of the Fundamental Standard was delegated.

As a matter of principle and institutional policy, Stanford abides by the principles embodied in the First Amendment as they have been interpreted by the United States Supreme Court. ${ }^{8}$ As a private institution, Stanford is not obligated legally to protect speech or other rights guaranteed by the U.S.

3Stanford University. Student Conduct Policies, Office of the President, 1990, at 29.

4/d. at 13-16.

$5 / d$. at 9.

$6 / d$.

7L. Veysey, supra note 1 at 106-7.

8J. Schwartz and I. Brest. "First Amendment Principles and Prosecution for Offensive Expression Under Stanford's Student Disciplinary System," Stanford University; February 1989 , at 4. See also, \#S-5 at 3; \#S-4 at 2 (notation for interview data will follow this format so that "\#S-5 at 3 " refers to Stanford interview number five at page three). 
Constitution to the same extent as a public university. In a well-publicized case involving the role of

First Amendment rights of a Stanford professor, Bruce Franklin, the Advisory Board of the Academic

Council (an elected faculty body) stated:

It is open to a private university to impose constitutional limitations on itself as a deliberate choice of policy; in advance of the hearing the Board committed itself to at least this much in undertaking to provide for Professor Franklin "no less protection of his constitutional rights at Stanford than that to which he could be entitled as a member of the faculty of a state university. 9

The Franklin case was the first and only time Stanford formally had considered the First Amendment rights and responsibilities of faculty members. 10

As a result of campus unrest in the 1960 s, Stanford promulgated a policy on campus disruption in 1967 that applied to faculty, staff and students. In relevant part, it states:

Because the rights of free speech and peaceable assembly are fundamental to the democratic process, Stanford firmly supports the rights of all members of the University community to express their views or to protest against actions and opinions with which they disagree.

All members of the University also share a concurrent obligation to maintain on the campus an atmosphere conducive to scholarly pursuits; to preserve the dignity and seriousness of University ceremonies and public exercises; and to respect the rights of all individuals.

The following regulations are intended to reconcile these objectives:

It is a violation of University policy for a member of the faculty, staff, or student body to:

(1) prevent or disrupt the effective carrying out of a University function or approved activity, such as lectures, meetings, interviews, ceremonies, the conduct of University business in a University office and public events.

(2) obstruct the legitimate movement of any person about the campus or in any University building or facility. 11

9/d. See also, Franklin v. Leland Stanford Junior University 218 Cal. Rptr. 228 (Cal.App. 1 Dist. 1985) Franklin was dismissed by Stanford in 1971 for neglect of duty and for violating the Stanford Policy on Campus Disruption, following his leadership role in protesting the Vietnam War. Franklin argued that his conduct was protected by the First Amendment and that the University's policies on disruption were unconstitutionally vague. A California court of appeals rejected Franklin's claims and found, "plaintiff's expressive conduct in our view was well out of constitutional bounds. Speech which results in disruption, which materially interferes with school activities, or impairs discipline is not constitutionally protected against an employer's response" (at 240).

10/d. See also, \#S-5 at 3.

11Stanford University, supra note 3. 
Prior to the incidents resulting in the 1990 interpretation of the Fundamental Standard, problems of student conduct involving expression were generally handled under the policy on campus disruption.12

\section{Structural Factors and Conditions}

Stanford University is a private, highly selective and academically prestigious university. It draws its students from a national and international pool of applicants. The campus is located in Palo Alto, California , approximately twenty miles from San Francisco. California is one of the most (if not the most) ethnically diverse states in the United States. ${ }^{13}$ The largest group of students, $33 \%$ of Stanford undergraduates, came from the state of California, followed by New York (7\%), Texas (5\%), and Illinois (5\%). ${ }_{r}^{14}$ Total enrollment is just over 13,000 students, with about equal numbers of undergraduate and graduate students.

Student residences form the center of student life for undergraduates as $87 \%$ live on campus and all freshman are required to live on campus. 15 They are used as a means to implement an extensive program of residence education designed for students to explore social, political, and other issues in addition to formats offered in classroom settings. ${ }^{16}$ Campus residences generally are viewed positively by residents,

12J. Schwartz and I. Brest, supra note 8.

${ }^{13}$ Table of the "Proportion of students who are minority group members." The Chronicle of Higher Education Almanac, September 1, 1988, at 81. Thirty percent of the students in California in 1988 were minority group members (only New Mexico had a higher percentage of minority students). This figure is a stark contrast to Wisconsin (4\% minority students in the state) and Virginia (17\% minority students in the state). 1987, at 2.

${ }^{14}$ College Guidance Counselor's Update. Stanford University Admissions, September,

15A. Camarillo (chair). Final Report of the University Committee on Minority Issues (hereafter called "U.C.M.I. Report"), Stanford University, March 1989, at 191. See also, Stanford interview \#10, at 2.

$16 / d$. at 192. 
and they serve as an important source of information about campus life. 17 Several ethnic theme houses were established in the early 1970 s to respond to the needs of minority students, including houses for Mexican Americans/Chicanos, Asian Americans, Blacks, and American Indians. ${ }^{18}$ The theme houses provided a residential option, both for minority and white students, who were interested in one of these cultures. Community perceptions of the theme houses varied, and the houses were the source of some controversy during the 1980 s concerning the question of whether the theme houses promoted positive relations among different ethnic groups. 19

Of the three universities in this research, Stanford is the most ethnically diverse. Among undergraduates who entered the university in $1988,10 \%$ were black, $9 \%$ were Mexican-American, $1 \%$ were American Indian, and 16\% were Asian-Americans. 20 In all, more than one third of Stanford undergraduates are members of minority groups. Among Stanford graduate students in 1988, 3\% were black, $3 \%$ were Mexican-American, $0.6 \%$ were American Indian, and $7 \%$ were Asian-American. 21 Trends among targeted minority graduate students (blacks, Mexican-Americans, and American Indians) indicated a decline from 10\% to 7\% between 1974 and 1988, while the percentage of Asian-American graduate student enrollment nearly tripled during the same period. 22 Among Stanford's nearly 1200 tenure-line faculty

$17 / d$.

18/d. at 193. The American Indian theme house was not established until 1988. Alaskan Natives were included also in this house.

19/d. See also, K. Tinkleburg, "Mural displayed at Zapata Rally," The Stanford Daily, January 21,1986 , at 1 . This controversy will be developed further in section two of this chapter.

20/d. (U.C.M.I. Report) at 62.

21/d. at 109-110. The original data in the U.C.M.I. Report were gathered from the Graduate Student Affirmative Action Reports from 1979 through 1984 and from the Director of Research in the Registrar's office.

$22 / d$. 
members, eight percent are members of minority groups. 23

The statistics of ethnic representation hide an important feature of Stanford's diversity. For example, thirty distinct Asian ethnicities fall under the designation of "Asian" and more than fifty Asian and Asian American student organizations exist at Stanford. 24 The numbers of American Indian (from more than 40 tribes), black and Hispanic students are also sufficient to create considerable diversity of backgrounds, attributes and talents within each group. This blend of ethnic groups makes Stanford students even more complex and difficult to describe in general terms than those at the other institutions in this study. It may also result in a more complicated set of circumstances for students, faculty and staff to navigate during the academic year.

\section{Organizational Factors and Conditions}

\section{Administrative Process for Adopting Nonacademic Regulations}

The Student Conduct Legislative Council (SCLC) is the entity at Stanford empowered to promulgate legislation affecting both the Honor Code and non-academic student conduct. ${ }^{25}$ The group consists of six faculty, five students, and student affairs staff member (ex officio). Legislative action requires seven affirmative votes. The SCLC has the authority to determine the range of possible sanctions, and its policies prevail over all other campus constituencies, with the exception of the President of the University.

The Legislative and Judicial Charter indicates that to create or revise student conduct policies, the SCLC presents a draft or alternative drafts of proposed legislation to the President and others, and the draft(s) is published. For at least 21 days following the publication of the draft(s), any group or

23/d. at 20. Of those faculty listed as members of minority groups in $1987,3.8 \%$ were Asian, $2 \%$ were Black, and $2 \%$ were Hispanic. The original source of the data was the "Professorial Faculty Data File" located in Stanford's Provost Office.

${ }^{24}$ Asian American Sourcebook, Asian American Activities Center, Stanford University (no date), at 10. See also, \#S-12 at 2.

25 The Legislative and Judicial Charter of 1968 (as amended in 1969, 1975, and 1981), Stanford University, Office of the President. 
individual at Stanford may respond in writing to the SCLC. After the comment period, the SCLC may vote to pass a rule relating to the subject of the original publication. If a rule is passed, it is distributed and published again, this time followed by a 14-day comment period. After reviewing the second round of comments, if the SCLC votes to approve the identical language of the first proposal, the rule becomes University policy. If the SCLC modifies the language of the draft policy, there must be additional 14-day comment periods and voting by the SCLC until identical language is approved at two consecutive voting sessions.

Charges of conduct violations against students may be filed only by the university administration, and charges must be proved beyond a reasonable doubt. Cases may be heard either by the Stanford Judicial Council (SJC) or by the dean of student affairs (or a designee thereof) in cases where the person charged admits to a violation as charged. Generally, the judicial affairs officer (who reports to the dean) makes a determination of what, if any, policies were violated and then charges a student only when the facts support a conviction beyond a reasonable doubt. The dean of students provides support for students accused of misconduct and resolves cases in which students admit wrong-doing and desire a non-adversarial setting for their disposition. The accused students' pleas generally determine the process by which the case will be adjudicated, either by the SJC (for pleas of not-guilty) or the dean of students (for admissions of guilt). However, students accused and admittedly guilty of misconduct may, for any reason, choose to have the SJC hear the case and determine the sanction.

The President of the University retains what is called "residual authority" over the promulgation and enforcement of regulations governing student conduct.26 Thus, the President may prevail over the SCLC, the SJC, or the dean. Even if legislation is adopted by the SCLC, the President can exert influence over the charges brought and/or the sanctions applied by the dean of students' office. However, Stanford presidents reportedly have never used their residual authority, and it is thought to be reserved for highly unusual circumstances, for example, changes involving wide and sweeping alterations to the 
judicial or legislative processes. ${ }^{27}$ The President reports to the Stanford Board of Trustees, although the Legislative and Judicial Charter of 1968 does not indicate that the Board is ever involved in student conduct policy. All references to authority beyond the SCLC point to the President.

\section{Key Personnel in the Development of the Fundamental Standard Interpretation}

Donald Kennedy was the President of Stanford throughout the entire debate over the interpretation of the Fundamental Standard. There was no evidence to indicate that the Stanford Board ever became involved in the discussion over the FSI, nor was there evidence to indicate that its members exerted any influence on the outcome of the policy. Kennedy was important primarily for his authority to quash a policy which he did not favor. Available data do not indicate that he was an active public participant in the FSI debate at Stanford.

The Dean of Student Affairs Office was a focal point for discussion of the FSI because of its role in bringing charges (or for not bringing charges which occurred in this case) against students for violating the Fundamental Standard and because it contained an ex officio member of the SCLC. Two members of this office played important parts in the development of the FSI. Jim Lyons was the Dean of Student Affairs (chief student affairs officer) from the early 1970s until 1990. The judicial affairs officer, Sally Cole, has occupied her position since 1982, and she had worked in other administrative roles at Stanford since the late 1960s. Mr. Lyons and Ms. Cole were perhaps the most knowledgeable about the Fundamental Standard since they were responsible for its application. Others on staff became experts after the public incidents prompted the policy discussion.

Following some of the major public incidents (described in section 2) at Stanford, other individuals and groups became involved. A coalition of minority student leaders and members of the Council of Presidents (student government leaders) became strong, vocal advocates of the FSI.28 The Black Student

27S. Cole. Letter to T. Jennings, October 12, 1992. See also, \#S-4 at 2.

28G. Liu. "Standard will face new interpretation," The Stanford Daily, February 16, 1989 , at 1. See also, Stanford interview \#1 at 6. 
Union was the most influential among the groups involved in the minority coalition. 29 Leaders of the SCLC who favored an interpretation of the Fundamental Standard included John Perry (co-author of the first draft with Canetta Ivy, a student government leader) ${ }^{30}$ and George Parker (chair of the SCLC, 198889).31 Also entering the fray were two members of the General Counsel's Office, John Schwartz (VP and General Counsel) and Iris Brest (Associate General Counsel) with the publication of an interpretation of the ways in which First Amendment principles applied in cases of offensive speech under the original Fundamental Standard. 32

Several law professors played important roles in the debate over the FSI. Professor Tom Grey, who was the principle author of the FSI, was helpful to the SCLC during its drafting of the FSI and a proponent of the policy during the campus-wide discussion of the FSI. 33 Charles Lawrence, a law professor who has written recent articles in favor of broader speech-restrictive policies joined Grey in supporting the policy.34 Two notable professors of Constitutional law, Gerald Gunther and William

29 \#S-1 at $6 ; \# S-8$ at $4 ; \# S-13$ at 4.

30G. Liu, supra note 28.

31"For the Record," Campus Report, March 1, 1989, at 1.

32J. Schwartz and I. Brest, supra note 8. This document was written while the Assistant Dean for Judicial Affairs (Sally Cole) considered whether to file charges against the two men involved in the Ujamaa House incident (see section 2 of this chapter). The document was released at approximately the same time as Ms. Cole decided not to file charges against the students.

33T. Grey. "Responding to Abusive Speech on Campus: A Model Statute," Reconstruction, Winter 1990, at 50-54. See also, \#S-1 at 5; \#S-3 at 2. See also, "The Free Speech at Stanford," a videotape of a forum held at the Stanford law school in the Winter of 1990 in which law professors Gerald Gunther, William Cohen, Thomas Grey, and Charles Lawrence debated the merits of the then FSI proposal. The videotape is located in the Stanford Law Library.

34C. Lawrence. "If He Hollers Let Him Go: Regulating Racist Speech on Campus," Duke Law Journal, 1990:3 (June) at 431-483. See also, Id. ("The Free Speech at Stanford"). See also, C. Lawrence, "Acknowledging the Victim's Cry," Academe, November-December 1990 , at $10,13-14$. 
Cohen opposed the legislation.35 Finally, the 1989-90 chair of the SCLC, law professor Robert Rabin supported the legislation and shepherded the policy to its eventual adoption. ${ }^{36}$ Several of the law professors named above participated in the national debate over speech codes in addition to the debate at Stanford.

\section{Racial Climate Prior to the Adoption of the Fundamental Standard}

\section{Interoretation}

\section{Introduction}

This section describes two major public situations with racial content and other bias-related circumstances present on campus. Next, a description is provided of the issues of recruitment and retention of minority students. Third, students' characteristics and their perceptions about racial issues at Stanford are discussed. Most of the statements made in this section refer to events and discussions during the mid- to late-1980s and 1990. Assertions about the racial climate reflect the beliefs of campus informants, newsprint articles, institutional self-studies, other public documents and some internal correspondence.

Stanford, although historically a predominantly white institution, began to experience substantial growth among its minority student populations during the 1970s and 1980s. By the late 1980s, more than a third of Stanford undergraduates were members of racial minority groups. In 1989, the University Committee on Minority Issues concluded,

We observe two compelling ironies .... First, racial problems have been increasing at a time when

35G. Gunther. Letter to Professor George Parker (then chair of the SCLC), March 10, 1989. See also, G. Gunther, "Freedom for the Thought We Hate," Academe, NovemberDecember 1990, at 10, 13-14; see also, W. Cohen, letter to Professor George Parker, March 10, 1989; See also, supra note 33, ("The Free Speech at Stanford").

36P. Rapalus. "Free speech debate slated for spring," Campus Report, March 21, 1990, at 1, 4. See also, "Excerpt from the Minutes of the Senate, May 3, 1990," Stanford University, at 2-3; K. Bartholomew, "Anti-harassment measure approved," Campus Report, May 30, 1990, at 1, 9. 
the University has achieved unprecedented racial diversity. Second, racial tensions have been more openly expressed during a time when University leaders are stating vigorously to students the importance of concepts such as "diversity," "pluralism," and "appreciation of differences."37

Others observed the difficulty of the transition. One white faculty member remarked,

....I saw the University commitment to bringing a presence of minority students grow, mature, and go through some early rocky times. I would say that in the decade of the 1970s and early 1980 s that a lot of our attention was focussed on strategies that would both attract and keep students here. By the 1980s, we were pretty successful...we had the numbers here. And it was then I suppose (I am speaking now in broad strokes) that things still weren't good. As one who came out of the John Kennedy era, I saw this as a short-term thing--we were going to tackle this like getting to the moon. We would get the numbers up and everything would be OK. I can remember discussions where some of us were mystified and surprised; "we have the numbers up, how come it doesn't feel good? As a matter of fact, it feels worse than it did before.'38

Inter-racial relationships grew more tense at Stanford during the mid to late 1980s. Several political and social issues emerged as points of contention, especially for minority students, including divestment of the University's holdings in South Africa, ethnic theme housing, under-representation of women and minorities on the faculty, alleged bias of the Western Culture curriculum, Stanford police treatment of ethnic minority students, and alleged bias in the student government constitution.39 During the spring of 1986, while articles and editorials on divestment from South Africa appeared daily and the debate over the Western curriculum gained momentum, President Kennedy remarked that racism should be seen as a chronic problem at Stanford, not an acute flare-up.40 A white administrator suggested that racial relations

37U.C.M.I. Report, supra note 15.

38 \#S-6 at 1, 2.

39M. Lawrence. "S.O.S.A. (Stanford Out of South Africa) to stage sit in," The Stanford Daily, October 11, 1985, at 1. See also, M. Lawrence, "Police arrest 9 Apartheid protesters," The Stanford Daily, October 14, 1985, at 1; M. Lawrence, "Police arrest 23 more protesters," The Stanford Daily, October 17, 1985, at 1; K. Tinkleburg, "Mural displayed at Zapata Rally," The Stanford Daily, January 21, 1986, at 1 (Casa Zapata is the Mexican American theme house at Stanford); S. Smith, "Minorities rip constitution," The Stanford Daily, January 28, 1986, at 1.

40S. Kasierski. "Kennedy talks on racism, police, tenure," The Stanford Daily, March 12, 1986, at 1. See also, F. Paik, "BSU renews call for world studies," The Stanford Daily, April 24, 1986, at 1; Editors, "Amend Western Culture," The Stanford Daily, April 25, 1986, at 4; C. Saucedo, "Shanty town destruction decried as 'racist' action," The Stanford 
during the mid- late-1980s were:

...widely variable. There were examples of caution and distrust across racial lines and there were examples of rapport and mutual respect across racial lines. Not only was it variable, it was variable in unpredictable kinds of ways. It is a large campus with a lot going on. There might be a bad advisor in one department, or an insensitive R.A., or other pockets of trouble. Those tended to be more idiosyncratic than systematic or institution-wide problems. ${ }^{41}$

During the fall of 1986 , the student newspaper continued to publish almost daily articles and editorials on controversies over divestment from South Africa, Western culture in the curriculum, and ethnic theme housing. Articles on these themes continued through the winter and spring of 1987 , and intensified in April and May, 1987. Racial tensions continued to escalate until they exploded with several actions of a coalition of minority student leaders, including the students' presentation of demands to president Kennedy, a walk-out during Stanford's 100th anniversary celebration, and the takeover of the President's Office (these and other events are described in more detail in section three of this chapter). 42

Undergraduate students' perceptions about the campus racial climate generally came from their own personal experiences, from information passed through an informal grapevine, and from reports in the campus newspapers. Student affairs administrators relied primarily on their interactions with students and their experiences with campus incidents. Faculty members based their judgments about campus life on their conversations with students and their reading of campus publications. Stanford's Campus Report is one of the publications and, although published by Stanford University, it operates more like a typical

Daily, February 10,1986, at 1; R. Pierce, "Forum to address issue of racism," The Stanford Daily, February 26, 1986, at 1; C. Gofen, "University policies challenged at forum," The Stanford Daily, May 12, 1986, at 1 (450 persons attended this forum); See also, full-page advertisement paid for by five minority student groups and an undergraduate dean titled, "Western Culture: education or miseducation," The Stanford Daily, May 19, 1986 , at 3.

\section{$41 \#$ \#-1 at 7.}

42M. Lemley. "Minority students present demands," The Stanford Daily, May 6, 1987, at 1. See also, R. Korobkin, "Minorities attack Kennedy's response," The Stanford Daily, May 8, 1987, at 1; D. Bisgeier, "Students rally against racism," The Stanford Daily, May 12, 1987, at 1; J. Pollack, "Minority students walk out," The Stanford Daily, May 15, 1987, at 1 (about 300 protesters, mostly minority students walked out of the anniversary ceremony with raised fists amidst helium-filled black balloons); J. Pollock, "Students stage 5-hour sit-in," The Stanford Daily, May 19, 1987, at 1. 
newspaper than a promotional arm of the University. Policy issues and controversial matters are covered openly, and opinions at odds with the University's are included frequently. The Stanford Daily was referenced with respect by administrators and faculty as a credible, high-quality student newspaper. Some respondents remarked that the Daily had been accused of biased reporting and editorials, but that the situation seemed to have improved recently. 43

Other formal sources of information among students about racial issues included first-year orientation programs and on-going programs in the undergraduate residence halls. The fall orientation program was identified as an important factor in setting the tone for race relations by many student affairs professionals and almost every student interviewed.44 Unfortunately, one of the reasons that the orientation was so memorable, especially among white students, was a consistent perception that the focus on diversity and multiculturalism was overdone or force-fed.45 Students heard that the University valued an inclusive and welcoming environment for all students to the point that some students felt unable to avoid a nearly constant promotion of ethnic minority cultures. Many white student perceived the Stanford environment to be separatist, even during their first days as Stanford students.

\section{Major Public Incidents}

Two incidents occurred at Stanford in 1988 that informants related most closely with the adoption of the Fundamental Standard Interpretation. Both incidents involved white male students whose conduct and expression were offensive to many persons at Stanford, and particularly to blacks. The first incident, commonly known as the "Otero House incident," occurred in May, 1988. The second and more highly publicized situation, the Ujamaa House incident, occurred during September and October, 1988. Both incidents were the subject of investigations by the Stanford administration and the detailed findings of each

43\#S-2 at $5 ; \# S-6$ at $4 ; \# S-13$ at 4. 17 at 1.

44\#S-2 at $2 ; \# S-6$ at 8,$9 ; \# S-8$ at $6 ; \# S-9$ at $8 ; \# S-10$ at 1,$2 ; \# S-14$ at $7 ;$ \#S-

45\#S-2 at 2; \#S-6 at 8; \#S-14 at 7; \#S-17 at 1. See also, T. McBride letter to D. Kennedy and J. Rosse, November 18, 1988, Stanford University. 
investigation were re-printed in campus publications. The incidents are summarized below.

Otero House is an undergraduate student residence hall. A first-year student in the hall was removed from housing for his repeated harassment of a resident advisor because of the advisor's sexual orientation. 46 A feature in The Stanford Daily 47 reported the student's eviction and sparked a discussion among several members of Stanford's chapter of the Phi Delta Theta fraternity over the evicted student's free speech rights. 48 Seven members of the group decided to protest what they perceived to be heavyhanded administrative action in violation of the First Amendment by the University. 49 To communicate their displeasure with the University's action, the seven protesters "donned masks of various kinds (e.g., a motorcycle helmet, a hockey mask, goggles, shirts, scarves) and went with candles to Otero House."50 The protesters stood outside of Otero House just before midnight in a silent vigil, while inside the House some residents became agitated by the protesters' behavior. ${ }^{51}$ Most onlookers perceived the event to be evocative of a Ku Klux Klan (KKK) meeting, and they may have erroneously believed at first that the protesters were racially motivated.52 The protesters refused to reveal their identity or the full purpose of their vigil to the onlookers, who numbered about 50 students. 53 At one point, one of the protesters wrote a note in response to an onlooker's request. The note, which was read aloud to the observers, said the

46 \#S-1 at 3-4.

47D, Dirks. "Freshman loses housing for insensitive conduct," The Stanford Daily, May 23, 1988, at 1.

48D. Conklin. "Final report on the vigil at Otero House," Campus Report, June 8, 1988 , at 2 .

49 \#S-1 at 3-4.

50D. Conklin, supra note 48.

$51 / d$.

$52 / d$.

53/d. Students who confronted the protesters informed them immediately that their actions were similar to the KKK. 
vigil "was not a racist protest, that the vigil participants did not intend to antagonize anyone, and that they were present at Otero to protest the University's unfair and unjust eviction of Kenny Ehrman."54 Throughout the incident and its aftermath, the participants contended that they did not intend their actions as a racial protest, nor did they intend to alarm anyone. 55

The protesters continued their protest even after it should have been obvious that they were not accomplishing their goals and that they were being misunderstood.56 As the vigil continued the protesters received several verbal threats from onlookers and repeated requests to reveal themselves, and "although many witnesses were increasingly angry, BSU members present were instrumental in calming them."57 At some point during the event, the protesters determined that the crowd had grown too large and too hostile to continue the vigil safely. 58 The protesters split up and hastily left the area, followed by some of the onlookers who continued to pressure the protesters to remove the masks and take responsibility for their actions. 59 Two of the men eventually removed the masks and discussed the incident with some of the observers in an attempt to explain the protest and dissolve some of the hostility that had built up during the vigil. 60 The final report on the incident noted that,

[t] ]he effect of the event on residents of Otero was extreme stress....The vigil and its consequences have caused some residents to feel that their home has been violated and their security breached. During the night in question, many residents found themselves in tumult of fear and confusion.

$54 / d$.

55K. Ferguson et.al. "Vigil not intended to be racially biased," The Stanford Daily, May 27,1988 , at 2 . This was a letter of apology signed by all seven participants in the Otero Vigil.

$56 \#$-1 at 4.

57D. Conklin, supra note 48.

$58 / d$.

$59 / d$.

$60 / d$. 
Many also felt that there was no one in control of the situation, which seemed deeply volatile.61 Later in the week the seven protesters appeared at both Otero House and the Black Community Services Center and apologized for the consequences of their actions.62 Apology letters about the incident, reprinted in campus publications, were issued by the fraternity and by the seven participants. The participants' apologies were perceived generally to be genuine and sincere, and their tone was conciliatory toward the groups that took offense. They claimed their protest plans were innocent, but ignorant, and readily agreed that they would have benefitted from more educational activities regarding ethnic groups at Stanford.

The Otero House incident raised several issues. First, the vigil generally was perceived to be racially offensive, but the issue of homophobia was obscured in the fallout from the incident. The protesters ostensibly supported the right of one student to harass another student because of that student's sexual orientation and chose a means of expression which aroused imagery of the most notorious organization associated with racial superiority, the KKK. It was clear from the campus response to the vigil that racism was considered deeply offensive, but the issue of harassment of homosexuals for their sexual orientation was interpreted by some students as having been either diverted or forgotten. 63 Second, the students wore masks to conceal their identity, perhaps because they feared reprisals for their views. 64 Others may label this behavior as cowardice for the protesters' unwillingness to take a public position on an important issue. This suggested that the campus environment was perceived by some students to be unsupportive of those who held certain beliefs that were at odds with the prevailing political and social climate. Third, since the object of the Otero protesters was the perceived violation of another student's right to free expression, the case began as a free speech case. The conduct of the protesters was well

\section{$61 / d$. \\ $62 / d$.}

$63 \#$ \#-8 at 3. See also D. Conklin, supra note 48.

64J. Lyons. Statement on Otero incident, as re-printed in S. Cole, "Stanford Cases in Student Affairs Administration: When Fundamental Values Conflict," Judicial Affairs Office, Stanford University, November, 1988, at 6. 
within established First Amendment guidelines -- the "tumult" and potentially violent situation occurred because of the onlookers' reactions to the protesters' mode of communication. If this point was lost in the protesters' apology, the official report or the public reaction to the incident, it was revisited by a Stanford professor in a letter to Dean Conklin challenging her report on the vigil for not stating that the protesters were exercising Constitutionally protected rights to express unpleasant views in an unpopular manner.65

The Chair of the Stanford BSU wrote to President Kennedy following the Otero vigil and complained that,

These students contend that their actions were not racially motivated, but the problem is not simply their motives, but the fact that these students are not sensitive enough to perceive what is and is not a racist, sexist, or homophobic action. Presently, a small group of white students have apologized and been reprimanded for their actions, but the basic problem is why white male students on this campus feel that wearing hockey masks and carrying fire is an appropriate response to minority actions. This student ignorance is a major problem, when the administration approaches the increasing number of bigoted actions as isolated incidents and not a symptom of the pervasive atmosphere of ignorance, insensitivity, and intolerance for difference, which have not been directly addressed at Stanford. 66

The BSU chair points to several problems faced by minorities at Stanford and describes them with unmistakable anger and frustration. The remainder of the letter did not address students' rights to free expression, focussing instead on the pain experienced by minority students and on perceptions of institutional neglect. 67

Expectations that judicial action would be taken by the Dean of Student Affairs Office were raised by a public statement from the Dean (who was white) released just after the Otero incident:

For now, though, let me put it as simply and directly as I can: members of the Stanford community must know that conduct which seeks to or has the effect of discouraging the full participation in the life of this University by any student on account of his or her sex, race, color, religion, sexual orientation, or national and ethnic origin is in violation of University principles

$65 / d$. (S. Cole) at 12-13.

66/d. at 10. The letter was reprinted later in Campus Report.

$67 / d$. 
and policy. Such conduct cannot and will not be tolerated.68

The decision whether to charge the student protesters with a violation was not resolved until the fall of 1988 since the incident occurred late in the 1986-87 academic year. Ultimately, the Otero vigil participants were not charged with a violation of Stanford's Fundamental Standard. Judicial Affairs Officer, Sally Cole, was persuaded that charging the students under the Fundamental Standard for their behavior in the Otero vigil was such a close call, and that such strong arguments could be made on both sides of the issue, that the University's judicial process would not yield a clear and decisive outcome.69 In Stanford's judicial process, which requires proof beyond a reasonable doubt, a 'not guilty' verdict was likely. ${ }^{70}$ In her public response regarding her decision not to charge the seven men, Ms. Cole noted,

The summer discussions also attended to arguments deriving from free speech protection, the right to protest, and other First Amendment concerns. In an academy that protects academic freedom with professorial tenure, one can understand that these were weighty issues. That same academy, however, also cherishes other values that are central to a university community, especially a respect for others and a concomitant sensitivity to their opinions, beliefs, and backgrounds. The point, though, is that reasonable people can see important values to be in conflict in the Otero incident. 71

The decision not to charge the vigil participants was printed on the front page of The Stanford Daily on the same day as another article that reported two other racial incidents had occurred in Stanford's AfricanAmerican theme house (Ujamaa House). ${ }^{72}$ The timing could not have been more unfortunate for the Stanford administration.

If the Otero vigil can be likened to a hail-storm on campus, the situation that evolved following incidents at Stanford's Ujamaa House most resembled a hurricane spinning off multiple tornadoes. When news of the incident became public it was described as surfacing in the form of enormous pressure and

\footnotetext{
$68 \mathrm{~J}$. Lyons, supra note 64.

69S. Cole, supra note 64 at 18.

$70 / d$.
}

71/d. The letter was also printed in The Stanford Daily.

72 The Stanford Daily, October 17, 1988, at 1. 
tension, symbolizing everything that was wrong with black-white relationships at Stanford.73 The incident was believed to be so highly charged that the President asked the associate dean of the Stanford Law School and the associate general counsel to conduct an investigation into the events at Ujamaa House and report their findings to the Stanford community. ${ }^{74}$ The following description of the Ujamaa incidents is based upon McBride's and Williams' investigative results, except where noted.

During the evening of September 29, 1988, a group of about 10 students, mostly Ujamaa residents, discussed many issues including race relations and black influences on music. 75 As the group discussed musical influences, one of the black Ujamaa residents, sophomore "QC" Robbins remarked that all music in America has African origins. ${ }^{76}$ One of the white participants challenged this assertion and asked, 'what about classical music...Beethoven?` $Q C$ responded that Beethoven was a mulatto. The discussion continued on about other topics of race until the group eventually disbanded.

The following night, two of the white students who participated in the music discussion, Alex and Fred, visited friends and reportedly became "drunk and stoned." At some point in the evening these firstyear students found a Stanford Symphony poster advertisement that featured a picture of Beethoven and returned with the poster to Alex's room. The two used pastel crayons on the poster to color the face brown, enlarge the lips, add black frizzy hair, and draw red eyes to focus attention on Beethoven's "demonic look." Just after midnight that evening (October 1, 1988) Fred taped the defaced poster to a

\section{3 \#S-6 at 5.}

74T. McBride and J. Williams. "Final Report on Recent Incidents At Ujamaa House," Campus Report, January 18, 1989, at 15.

75Ujamaa is one of several ethnic theme houses at Stanford. In 1988, there were 65 black and 62 non-black residents of Ujamaa.

76The report used pseudonyms (for a variety of reasons) to refer to the students involved in the Ujamaa incident, but most importantly to protect them from continuing attention in a national audience. Although the names are obtained easily through the campus newspapers and other sources, they are not included in this research report. The incidents in which the students were involved were internal affairs at Stanford and need not include the students in a wider audience. The information provided about the Ujamaa incident is in no way diminished by the omission of the names. 
posting board adjacent to QC's door that was often used to post quotations and notices. There was no signature or mark on the poster to indicate its authors. During the investigation Alex said he intended the Beethoven poster as a parody or satire to indicate to QC that Alex did not agree with some of QC's assertions during the September 29 conversation that Beethoven's being 1/4 black made Beethoven "all black." Fred, frustrated with his inability to express himself adequately during the Beethoven discussion, drew the picture to look like a "stereotype" of a black man to show how ridiculous stereotypes are. Black students at Ujamaa described their reactions to the poster as "flabbergasted," "sickened," "outraged" and, perhaps most profoundly, "saddened." Many residents felt that "the details of the poster were not important; what was important was the drawers' intent to offend by portraying a black person in a negative stereotype."

A series of behind the scenes meetings and conversations about the Beethoven poster occurred among Ujamaa House staff and residents for two weeks after the Beethoven poster was discovered. On October 14 , a poster advertising a dance at a black fraternity was found in Ujamaa House with the word "niggers" scrawled diagonally across it. Upon leaming about the second defaced poster the residence staff at Ujamaa called an emergency house meeting that evening to discuss both posters. 77 The meeting was characterized as heated and emotional as black Ujamaa residents expressed their displeasure and anger over many issues in addition to the posters. 78 Alex and Fred were identified as the culprits in the Beethoven poster incident soon after the meeting; upon learning this, the residence staff scheduled a second emergency house meeting for October 16. It is likely that there were several versions of facts and interpretations of the poster incidents circulating around Ujamaa House prior to the second meeting; the posters had been a primary topic of conversation among Ujamaa residents since the first meeting, based mostly on speculation. One of the many rumors was that $\mathrm{QC}$ had placed the poster on his own door to

77QC and Alex attended the meeting; Fred did not.

78 Alex had an opportunity to confess to the Beethoven poster at the meeting, but chose not to because he perceived the audience to be potentially violent toward him. 
start a controversy. ${ }^{79}$

The second house meeting was "emotionally charged from the start." 80 A student staff member gave a perfunctory introduction and introduced Alex and Fred. Fred acted as spokesperson and provided an explanation of the events and their rationale for defacing the poster. Both Fred and Alex were perceived by the residents to be "arrogant, insincere, and condescending." When confronted with their lack of an apology, Fred responded in a patronizing sarcastic voice, "Ok, 1,2,3, we're sorry." 81 The flippancy of his remark unleashed a level of anger in the audience that no one had predicted. Many audience members shared their hurt and anger about racism and about the posters. Emotional speeches were also given by an assistant dean of student affairs (telling Ujamaa residents to handle this problem internally) and by QC (describing his background and the betrayal he felt by Fred). By the end of his own speech QC was crying, as were many (if not most) members of the audience. 82 In what some participants described as an 'emotional fit' QC moved toward Fred and Alex, made threatening gestures and comments to them, collapsed and had to be carried from the room.83 What happened next was described as "mass chaos," and "people were crying, screaming, hysterical and distraught." 84 "As many as 60 students were crying with various degrees of hysteria." 85 The associate dean of student affairs was called in at the end of the meeting and observed that "it was really one of the most distressing things I've seen in the time I've been at

79 \#S-13 at 2. See also, T. McBride, supra note 74 at 17.

$80 / d$. (T. Mcbride) at 16.

81See also, \#S-13 at 2.

82This speech was considered the emotional peak of the meeting.

83There were conflicting reports about what QC did or did not do when he concluded his comments.

84T. Mcbride, supra note 74 at 18.

$85 / d$. 
Stanford." 86

The emotional impact on residents and interested observers of the series of events at Ujamaa was described as profound. In retrospect, the decision by the residence staff in Ujamaa to take no immediate action was believed by some students and administrators to have added pressure to the situation when it did surface.87 The staff explained that their delay was related to their desire to have all of the facts before alarming the residents of the House. 88 One white faculty member suggested that "no matter what would have happened about that time, that year, we would have had some sort of reaction."89 President Kennedy responded to the incident in a letter to the editor, saying that

I told the freshmen at Orientation that bigotry was OUT, and I mean it. That message was intended for everyone, in all segments of the Stanford community. Behavior of this kind is not excusable on the grounds of ignorance, or of being drunk, those explanations do not work here. We are investigating this incident, in preparation for possible charges under the Fundamental Standard.90

The day after the second house meeting, President Kennedy and other senior administrators met with about 200 students at Ujamaa House where they heard frank discussion about the poster-related incidents. 91 Two prominent black student leaders accused the university of refusing to make a commitment to educate people about minority issues and of failing in its responsibility to do so.92 One

86B. Hayward and A. Marsh. "Two racial incidents strike Ujamaa House," The Stanford Daily, October 17, 1988, at 1.

87 \#S-6, at 4. See also, T. McBride letter to President Donald Kennedy and Provost James Rosse.

88B. Hayward and A. Marsh, supra note 86 at 2.

$89 \# S-6$ at 5.

90D. Kennedy. "All must fight bigotry and build a better community," The Stanford Daily, October 19, 1988, at 2.

91D. Bisgeier. "Stanford's commitment to racial harmony questioned," The Stanford Daily, October 19, 1988, at 1.

92/d. 
white faculty member recalled,

I remember a couple of meetings where Don Kennedy and I were sitting there and we just got verbally abused. I am used to that, but that didn't strike me as much as when I looked around the room there were tears and emotions and students crying. So, it was a very powerful thing, and there was something else operating there that this had unleashed.93

Editorials in the student newspaper framed the incident as the tip of the iceberg of racist incidents at Stanford and urged strong action because, as one student wrote, "[t]o ignore the problem, downplay its significance, or not deal with those responsible in a severe fashion is to tolerate its existence and even advocate the display of hatred through racial slurs." 94 There was a great deal of confusion, and conflicting stories emerged about what actually happened at Ujamaa after the story became public. Some students were not sure who or what to believe.95 Recounting the Ujamaa incident in 1991, some students and administrators (mostly whites) pointed out that the Beethoven poster was intended as a joke or satire, and therefore should not have brought all the negative consequences it did for the two freshmen who altered the poster.96

Around October 19,1988, the investigation into the Ujamaa incidents was commissioned by the President.97 Early comments by the Dean of Student Affairs indicated that Alex and Fred would be

$93 \#$ S-6 at 5 .

94B. Coan. "Ujamaa incidents are signs of deeper problems in the community," The Stanford Daily, October 20, 1988, at 5. See also, T. Goode, "Kennedy and others dodged issues," The Stanford Daily, October 20, 1988, at 5; R. Joss, "Racism is not unique to Stanford," The Stanford Daily, October 20, 1988, at 5.

95 \#S-17 at 1.

96 \#S-6 at 5; \#S-14 at 6; \#S-17 at 1. See also, M. Edwards, "Prof offers new view of poster defacement," Campus Report, November 9, 1988, at 4.

97D. Kennedy, supra note 90. 
charged with a violation of the Fundamental Standard.98 The investigation progressed throughout October and November amidst further administrative discussion about whether to charge the two students and when to release the final report of the investigation. ${ }^{99}$ The document's release was delayed from December until January in order to allow for full press coverage and to raise the issue for full campus discussion at the beginning of the new academic term. 100

In early January, Alex and Fred's housing was revoked for two academic quarters by the chief housing officer. 101 The University released the final report on Ujamaa House on January 19, 1989.102 A report outlining the application of the First Amendment to the Otero and Ujamaa cases was prepared by

98J. Lyons. Electronic mail message (hard copy) to D. Conklin, October 26, 1988. Lyons contrasted the Otero incident with the Ujamaa incident, noting that the latter "was not a protest. It was an engagement in a couple of kids, drunk as it was, who engaged in simple pure acts of offending others. No matter what the investigation will show, it is not likely to alter the previous statement. Mitigate or aggravate -- yes. But not alter. So they WILL be charged with a violation (emphasis in original). What will be the result is really the issue here. Not whether or not they will be charged."

99J. Lyons. Electronic mail message to S. Cole (hard copy), November 15, 1988, Stanford University (Dean of Student Affairs Office). See also, J. Lyons, memo to D. Kennedy et.al., December 6, 1988, Stanford University (Dean of Student Affairs Office).

100 Id. (J. Lyons, memo to D. Kennedy et.al.). Lyons noted, "[f]rankly, it makes more pedagogical sense to release it early next quarter; especially since we mean the release to both stimulate and inform campus discussion." The administration could have easily chosen to try to bury the issue by releasing the report during students' exam week .. a time when campus newspapers and students have little time for campus social issues. Instead, administrators elected for a full and open airing of the issues.

$101 \mathrm{~N}$. Robinson. Letter to Alex and Fred, January 9, 1989; reprinted in The Campus Report, "Robinson revokes dorm privileges of two who defaced poster," January 9, 1989. Students living on campus sign an agreement which obligates them to "be considerate of other residents and the residence staff; and to respect the rights of others at all times." Robinson concluded that Alex and Fred had violated this agreement because, he said, "[b]ehavior which harasses or otherwise disrupts the educational and social life of residents is unacceptable. Your behavior in producing and posting in Ujamaa House an insulting caricature of a black man violated your undertaking to be considerate of other residents and to respect their rights at all times." Robinson also indicated that he had read the fact-finding report on the incidents at Ujamaa house and that the report had informed his ruling in this case.

102B. Hayward. "Report on incidents at Ujamaa released," The Stanford Daily, January 18,1989 , at 1. 
the vice president and general counsel and the associate general counsel at the request of the president and the dean of student affairs. The report was released on February 8, 1989, and concluded that both the Otero vigil and the Beethoven poster situations would be considered protected speech under the U.S. Constitution, and therefore, neither case constituted a violation of Stanford's Fundamental Standard.103

\section{Anonymous Racial Incidents and Other Bias-Related Circumstances}

A series of backlash incidents followed in the wake of the Beethoven incident. Some white Ujamaa House residents found a typed note under their doors that said, "Non-blacks leave our home, you do not belong in Ujamaa."104 Later that day an unidentified person punched holes in the pictures of almost all of the non-black freshmen on a "frosh board" (a display featuring the pictures of all Ujamaa freshmen). ${ }^{05}$ About two weeks later, home-made stickers were found in at least two campus locations that read, "Avenge Ujaama [sic] Smash the Honkie Oppressors!"106 These incidents were not publicized, and were not part of the full campus discussion about race relations.

There were several other incidents involving racial issues before the Beethoven poster incident. In 1986, students supporting the divestment of University holdings in South Africa erected shanties on campus to illustrate the stark contrast between impoverished South Africans and well-off Stanford. The

103J. Schwartz and I. Brest, supra note 8.

104T. McBride, supra note 74 at 18 . The notes were distributed on October 18 , two days after the second house meeting regarding the posters in Ujamaa. The matter was discussed by staff and residents in hallway meetings throughout Ujamaa.

$105 / d$. This incident was handled by the Ujamaa staff in a meeting with non-black residents. The meeting participants agreed not to discuss the incident because they believed that public discussion would only worsen an already bad situation.

$106 / d$. The report indicated that Ujamaa residents were not likely to have been responsible for the stickers because the authors misspelled "Ujamaa" and blacks do not commonly use the term "honkie." 
shanties were destroyed late one evening by anonymous vandals. 107 Several other incidents were discussed at a 1986 forum on racism: an announcement was posted that read, "White Supremacists: C.O.P. office, 4 p.m., bring hoods;" fraternity pledges had dressed in breech cloths and performed a mock raindance outside Stanford's American Indian Organization office; a fratemity flyer depicted Buckwheat saying, "now dat's a party;" and "Kamikaze" and "South of the Border" theme parties were held.108 Another forum on racism in May, 1987, was conducted in which the following incidents were said to have occurred during the academic year at Stanford: Asian American students had received death threats; American Indian students had been called "savages;" black students had been stopped for no apparent reason by campus police and asked for identification; two white students were heard making derogatory comments about black students' SAT scores; and students had chanted outside the Mexican American theme house, "up with racism, up with fascism, down with Zapata."109

Asian and Mexican American students reportedly were the objects of less obvious forms of racism than black students. For example, some Asian students had been questioned by white students who disfavored separatism about a tendency to sit together at meals or in class. 110 Some Mexican American students perceived that non-Mexican Americans questioned their qualifications for admission and their ability to complete the work at Stanford.111 Black students were criticized in those areas in addition to more intentional ethnic attacks. ${ }^{112}$ For example, a poster with a map of Europe was placed around

107C. Saucedo, supra note 40.

108R. Pierce, supra note 40.

109J. Pollock. "Forum sheds light on racism," The Stanford Daily, May 27, 1987, at 1.

$110 \#$-12 at 4.

$111 \#$ \#-2 at 2.

$112 \# S-13$ at 4. 
Ujamaa in 1991 by a fictitious group called "Students for Historical Accuracy.113 On the map were the words, "Philosophy, Chemistry, Modern Mathematics and much much more -- brought to you by Europe."114 The poster was perceived by some residents as an affront to those who believe that African cultures were the origin of Western philosophy, religion, science, and other fields. To one black student, both the Beethoven poster and the Europe poster were offensive because,

... it was anonymous. If they would come and say 'let's talk about this; I think that modern mathematics does come from Europe and doesn't come from Africa -- let's have a debate about it, let's see what our resources find, pull some information into it and let's act like we're in college and mature enough to deal with this.' Most of the time we have a racial incident it is usually done anonymously and that is the problem. Students of color want to know who to respond to.115

Anonymous acts of bigotry were reported by black students to be even more harmful than cases in which the perpetrator was known. When particular student ethnic groups were harassed by anonymous offenders no counter-attack could be made, thus making racial incidents even more frustrating. This dynamic was present in the beginning of the incidents at both Ujamaa House and Otero House.

\section{Recruitment and Retention}

Stanford began greater efforts to enroll minority students in 1968.116 The minority groups targeted for special consideration in the admissions process included blacks, Mexican Americans and American Indians. 117 During the next 20 years the percentages of black and Mexican American students doubled from $5 \%$ to $10 \%$, while the percentage of American Indians remained a constant $1 \% .118$ By the

$113 \#$ \#-13 at 6.

$114 / d$.

$115 / d$.

116A. Camarillo, supra note 15 at 55-56.

$117 / d$. at 57 . Special consideration is also given to legacies, children of Stanford faculty and staff, and certain athletes.

$118 / d$. at $55-56$ 
mid-1980s there was an impression that minority recruitment had been reasonably successful;

“Undergraduate Admissions Office personnel told [the University Committee on Minority Issues (UCMI)] that they generally feel good about minority recruitment and that admissions procedures and results have improved over time. We agree."119 The 20-member UCMI, composed of faculty, students, administrators and alumni, issued its final report of ten recommendations for improving minority recruitment along with its acknowledgment of the University's successes. 120

In the UCMI report, $23 \%$ of blacks, $38 \%$ of Hispanics, and $50 \%$ of American Indian students "mostly" or "strongly agreed" that they felt "less prepared for Stanford academically than most Stanford students, while only $16 \%$ of whites and $13 \%$ of Asian American students responded in this manner. 121 Similarly, $25 \%$ of the American Indian students and $28 \%$ of the black and Hispanic students agreed with statements indicating that if they let up on their studying they would probably end up on academic probation; $7 \%$ of the white students and $10 \%$ of the Asian students agreed with such a statement. 122 Despite these indications of academic pressures operating among targeted minority groups, the UCMI found "no significant differences in graduation or 'survival" rates between minority and white students and, as of 1988 , higher retention rates among minority students. ${ }^{123}$ Although graduation rates among various ethnic and racial groups were comparable, the influence of hidden pressures that may deplete self-esteem may be measurable in other ways not addressed in the UCMI report. 124

$119 / d$. at 63 . See also \#S-6 at 5.

$120 / d$. (UCMI report) at 66-70.

$121 / d$. at 81 .

$122 / d$. at 81-82.

$123 / d$. at 80.

$124 / d$. at 81 . The UCMI did not include a comparison, by race, of student grade point averages (such a comparison was never even mentioned). The report addressed only the percentage of academic awards given to minority students (minorities received fewer academic awards). 
The evidence available at Stanford did not indicate that recruitment of minority students was a primary rationale for adopting the FSI in 1990. Informants, campus documents, and the UCMI report indicated that admissions efforts were, for the most part, considered successful. Instead, the debate focussed on retaining currently enrolled students and on fostering a more hospitable environment for all students. 125

\section{Students' Behaviors, Values and Perspectives}

\section{Ethnic Students' Perspectives on Race Relations}

Stanford's diverse minority student population makes generalization difficult; however, a few tendencies emerged from the data. Chicano, black, and white students believed there was peer pressure among minority students to be involved with and loyal to their respective ethnically-related organizations. The pressure was believed to be especially strong among black students and Mexican American students. 126 A black student noted that,

...there tends to be a pressure from the black community to hang out with black students. For those students who tend to hang out with other students, people will say things like "incognegro," or "sell-out" ... [It is] probably a sense of insecurity on our part, in that people want to make sure where other peoples' loyalties are. It is kind of hard for some people to see that some others can hang out with whoever and still have ties to the black community. And there are people who do that -- have strong ties with the black community and have a lot of other friends. It still seems that, for most people, it is either one or the other; there is not much of a balance. Part of the pressure may just be because this is a predominantly white campus and a relatively small black community, and the community feels like it has to come together and be together to get through it. 127

The Black Student Union maintained a policy of not allowing non-blacks to attend meetings. 128 Some white students noticed that the pressure for minority students to join groups with an ethnic focus

125Id. at 80. See also, S. Cole, "Beyond Recruitment and Retention: The Stanford Experience," Judicial Affairs Office, Stanford University, 1990; \#S-6 at 1.

126 \#S-6 at 6; \#S-9 at 2; \#S-13 at 4; \#S-17 at 2. See also, A. Camarillo, supra note 15 at $170-71$.

$127 \# S-13$ at 5 .

128 \#S-13 at $4 ; \# S-17$ at 2. 
began during first-year orientation.129 Some minority students felt forced into separate social spheres during their interactions with persons of other races; this seemed especially true when minority students were expected to be spokespersons for their race. 130 Some Chicano students indicated that they were under pressure to be involved in political causes of minority students, and that if they chose not to get involved they were thought to be against the cause.131 Asian American students were reported to be sympathetic to the concerns of other students of color, but were less vocal as a whole than black students about grievances with the University. ${ }^{132}$ One of the reasons for the pressure to join ethnic groups may be related to minority students' sense of how they "fit in" with others at Stanford. The UCMI report revealed that large percentages of black, American Indian, and Mexican American students reported feeling that they did not fit into the Stanford community. ${ }^{133}$

A second tendency among ethnic minority students was that they perceived the ethnic theme houses to be a "home" on campus in which members of that ethnicity could exist in an environment more supportive of their cultures. 134 Many minority students believed that the purpose of theme houses (and the viewpoints of minority groups in general) was misconstrued by the media and by some whites on campus. 135 The theme houses often came under attack for creating a segregated environment, and there was a particularly prickly relationship between the Casa Zapata and Stanford's Hoover Institute (the Hoover Institute is an academic think-tank associated with Stanford, but with its own governance

129 \#S-14 at 7; \#S-17 at 2.

130A. Camarillo, supra note 15 at 171-2.

$131 \#$ S-9 at 2.

132 \#S-12 at 2.

133 A. Camarillo, supra note 15 at 178.

$134 \# S-2$ at $3 ; \# S-13$ at 2.

135 \#S-2 at 5; \#S-6 at 2; \#S-13 at 4. See also, A. Camarillo, supra note 15 at $193-$ 4. 
structure). 136 One white faculty member remarked that

... theme houses became the target. In other words, if there is a perfectly normal behavior or episode in any other dorm, it would draw no attention at all. The same behavior in a theme dorm would get reported in the paper. There was kind of an electricity there.... The Hoover Institute at that time had a group of folks who were really almost in the extreme right. And, they were unable or unwilling, or both, to get beyond race and racial issues to human issues. They tended to see 'spooks behind every stone.' If there was one of those ordinary dorm incidents that happened in Casa Zapata, then it was portrayed as a racial incident. 137

This tendency of highlighting the behaviors of students in theme housing may have exacerbated the Beethoven poster situation. Since many minority students already penceived a certain level of hostility among conservative whites (exemplified by the Hoover Institute editorials against them) toward the theme houses, these minority students' natural reaction may have been defensive or protectionist. When two whites entered what many black students' perceived as their home, the Ujamaa theme house, and placed a symbol of racism there, it amplified the anger toward the encroachment. Minority students directed the feelings harbored toward those who editorially attacked the theme houses toward Alex and Fred initially, and then toward whites in the Stanford community. Alex and Fred's attack was made worse, in part, because the residents and supporters of theme housing already felt they were under attack.

A third tendency among ethnic minority students was some agreement about the lack of appreciation of "outsiders" to the wide range of cultural backgrounds within each racial category.138 For example, third-generation Japanese-Americans may or may not share the same concerns as first-generation Cambodian-Americans, although both groups of students fall under the term, "Asian-American". NonAsians were perceived to be not fully appreciative of these types of differences. The UCMI report noted

136K. Tinkleburg, supra note 39. See also, \#S-6 at 3. \#S-2 at 2. The Hoover Institute was widely perceived to have right-wing political leanings, and had several employees who were published regularly in the campus newspapers. One of their targets were Stanford's ethnic theme houses. The conflict may have peaked in the mid-1980s. The physical structure occupied by the Hoover Institute is a large, prominent tower, visible from many campus locations. It is the tallest and most noticeable building on the Stanford campus. Its physical presence may have served as a constant reminder of the Institute's activities.

$137 \#$ S-6 at 2, 3.

138For example, there are more than 30 distinct Asian ethnicities under the umbrella category of "Asian" (\#S-12 at 2) and there are 20 active groups of students of Hispanic descent (\#S-2 at 3). 
the importance of ethnic group or ethnic community identity for students' sense of self-identity. ${ }^{139}$ The UCMI also noted that

while most minority students have had a good deal of contact with whites, we found considerable variation within groups, and past exposure does not necessarily translate into good race relations. Moreover, most minorities lacked experience with other minority groups. 140

Students' lack of contact with various minority groups may have contributed to the lack of appreciation for ethnic diversity reported by some minority students.

\section{White Students' Perspectives on Race Relations}

White students were found by the UCMI to have had little exposure to minorities before coming to Stanford.141 The UCMI concluded that white students' limited exposure led to a lack of understanding, and the lack of understanding helped perpetuate racial stereotyping and misconceptions on race. 142 At the least, it is a factor that should be considered when analyzing the racial attitudes of whites. A white administrator provided this example:

We had one incident during a freshman talent show in which one student from the midwest dressed in blackface .... we have some students who have a great understanding of the complexities of race relations and we have others who have absolutely no clue. I have had people tell me when they come here that they have had very little contact with people other than white students. The student in the talent show is a good example of someone who apparently had never had any meaningful exposure to black people and had no idea what statement she was making. ${ }^{143}$

A Chicano student added,

${ }^{139}$ A. Camarillo, supra note 15 at 187.

$140 / d$. at 159.

141 /d. Among white students surveyed in the UCMI report, $26 \%$ said they had "quite a bit" or "a great deal" of exposure to blacks prior to enrollment at Stanford. $34 \%$ of whites reported "some" exposure to blacks, and $40 \%$ responded as having "little" or "none."

$142 / d$. at 162.

143 \#S-10 at 2. 
At Stanford it seems that there is racism without racists. Much of the offensive communication is by people who don't know any better--they are often not even aware that they are offending someone. If they do realize that they have offended someone, they usually don't know why the person was offended. Sometimes they just dismiss the reaction as though it was just someone with a bad attitude or a chip on their shoulder. ${ }^{144}$

Some whites perceived a strong sense of separateness among races at Stanford. These students identified minority groups as being isolated in small groups on campus. ${ }^{145}$ They believed that most minority groups had integration as a goal, but some whites believed this goal was unresolved.146 As evidence of this they remarked that students who live in ethnic theme houses who are not of the particular ethnicity of the house sometimes feel excluded from the social and other activities in the dorm. 147 Some Chicano students believed that the theme houses offered one of the few opportunities for students of different races to have meaningful interaction, but in general, they agreed that different races operated in separate spheres. ${ }^{148}$ A black student leader also perceived that whites believed the racial communities were separate, but she pointed out that whites never question their own behavior that would contribute to a separatist environment 149

First-year orientation was identified by some whites as the origin of the separatist atmosphere at Stanford. 150 One white student said,

There is an over-emphasis placed on race during the introduction to Stanford. When they get here, everybody gets an immediate dosage of "here is a black event, here is an Hispanic event, here is a this event," et cetera. The first thing they are confronted with is the separateness of Stanford rather than the community of Stanford.

144 \#S-9 at 2.

145 \#S-17 at 2.

$146 / d$.

147 \#S-17 at 3.

148 \#S-9 at 1.

$149 \#$ \#-13 at 4,5 .

150 \#S-14 at 7; \#S-17 at 1. 
Other white students recalled orientation speeches by black student leaders that whites perceived to be aggressive and accusatory, placing blame on whites for social problems and appealing to "white guilt" to effect change. 151 Still other white students were observed going along with what they perceived to be the "party line" during orientation by remaining quiet and not speaking up about race. 152

\section{Political Factors and Conditions}

This section will focus on the coalitions formed, demonstrations held, relationships among key participants, and other political factors present before the adoption of the FSI. Several reports are outlined in this section that contributed to the discussion about the Fundamental Standard. Stanford's discussion of the limits of free expression occurred primarily among internal constituents, and it was not the focus of any political action among any government agency, nor the A.C.L.U. As a private institution, Stanford retained its autonomy throughout the debate, and although its policy received considerable attention in the national news media, there was no evidence that it influenced the campus debate.

Faculty, students and administrators indicated that recent developments on issues of importance to minority students at Stanford were influenced heavily by a well-organized minority coalition. ${ }^{153}$ Several other related factors were believed to be important. A black administrator observed,

On a lot of college campuses it is hard for a silent majority to win the day. It may happen in the nation because you can rely on a ballot box, but when you are trying to build consensus (which is the way most things happen on most college campuses), if you are not out there debating you are not going to be heard, and you are going to lose....Students, nationally, who were more conservative learned a lot about losing that battle. They realized that they had to be much more up front about their opinions, much more intellectual in describing their views, and much more

$151 \#$ S-17 at 1.

153 \#S-2 at $4 ;$ \#S-6 at 6,$7 ; \# S-8$ at $1 ; \# S-9$ at $2 ; \# S-10$ at $3 ; \# S-12$ at 3 ; \#S13 at $7 ; \# S-14$ at 2. 
willing to debate publicly views that differed from theirs. 154

This administrator and others believed the actions of Stanford's minority coalition to be, in part, a reaction to conservative political activities on a national and a local level. 155 The Hoover Institute was identified closely with U.S. President Ronald Reagan's administration by many at Stanford, and the editorials published by some of the Institute's researchers generally were considered politically conservative. 156 Reports of racial incidents at other colleges and universities were well publicized during the late 1980s, and some Stanford students wanted to take a lead in preventing those kinds of occurrences at Stanford. 157 Administrators and students who were interviewed acknowledged, however, that the main reason for the political activity was in response to many complaints among minority students about the campus climate at Stanford. 158

One white student believed that a very small group of students pushed the social agenda at Stanford. 159 He perceived divisions on the issue within the Hispanic and Asian communities and said, "the progressive voice is the loudest voice, but not necessarily the majority voice, even among those communities."160 Some Hispanic students at El Centro Chicano (Stanford's activities center for Mexican American students) confirmed this view. They perceived internal disagreements among students who were forced to choose among competing political perspectives of groups such as the League for Revolutionary

$154 \#$ \#-8 at 5.

155 \#S-6 at $4 ; \# S-8$ at $1 ; \# S-12$ at 2 ;

156 \#S-6 at 3; \#S-8 at 1.

157 \#S-8 at 3.

158 This is also the predominant perspective of the UCMI report.

159 \#S-14 at 8.

$160 / d$. 
Struggle or the Nationalists. 161 These groups were portrayed by students as maintaining strict loyalty requirements, and those who opposed any part of the groups' agendas were said to have been treated as outsiders. ${ }^{162}$ Administrators and students interviewed believed that students at Stanford, in the main, were politically moderate. 163

\section{Political Activities}

Political action to address minority students' concerns was underway well before the discussion about the FSI began. 164 In response to campus social conditions they believed to be hostile toward minority students, members of the Black Student Union (BSU), the Movimiento Estudiantil Chicano de Aztlan (MEChA), the Stanford American Indian Organization, and the Asian American Student Association (AASA) coalesced in May 1987 forming the "Rainbow Agenda." Representatives from the Rainbow Agenda presented several demands to the Stanford administration, including: 1) to hire consultants to study racism and the quality of minority student life at Stanford, with their

161 \#S-9 at 2. Both Chicano students and white students interviewed characterized the League for Revolutionary Struggle as an organization that operated off-campus and used cultlike techniques to indoctrinate members. \#S-14 recalled that the organization emerged at about the same time as the Ujamaa incident, and he implied that the League and other political action organizations influenced the level of emotional reaction to the Ujamaa incident among many minority students. One of the techniques reportedly used by members of the League was to "encircle" and shout at persons whose views conflicted with the League's values (\#S14 at 6). Nationalists were vocal public supporters of separate social environments for individual ethnic/cultural groups.

162 \#S-9 at 2; \#S-14 at 2, 3. See also, B. King; "BSU chair attacks student ignorance, passivity and racism," The Stanford Daily, May 12, 1989, at 3. King, the chair of the BSU in 1988-89 wrote, "most white students at Stanford don't care or act on anything except their own experience, and I don't like people who don't care. To overcome the effects of living in a racist, sexist, exploitative society calls for active people, not passive ignorant fools who don't mind their own apathy. If you are fuming mad at me, you are probably one of those fools that most students of color don't like or even worse are a student of color who is not planning on helping their own people."

$163 \#$ \#-8 at $4 ; \# S-14$ at 2.

164 The UCMI Report noted seven examples of political demands issued by minority group members during the 1970 s and early 1980 s similar to those of the late 1980s. 
recommendations to be binding on the University; 2) to develop an ethnic studies department; 3) to create a new position for a vice president for minority affairs; 4) to require the Admissions Office to recruit more low-income students and adopt goals of proportional representation (using national demographic data); and, 5) to build a campus multi-cultural center. 165 Then president Donald Kennedy delegated responsibility for study and comment on the group's demands to the appropriate areas of the University -- a move that was characterized by some minority students as lack of support for their concerns. 166 The next week, the Rainbow Agenda members held a rally against racism, followed three days later by a walkout during Stanford's centennial celebration. ${ }^{167}$ The Rainbow Agenda's protest activities culminated in a five-hour sit-in in the President's Office, where they reiterated their demands (President Kennedy was out of town). 168 The actions of the group led to the creation of the UCMI and its subsequent report on minority issues. 169 During the debate over the FSI, members of the Rainbow Agenda were perceived to have exerted considerable influence to promote the adoption of the FSI. Administrators perceived the most forceful leadership within the Rainbow Agenda was among the members of the Black Student Union. 170

The Rainbow Agenda remained active throughout the FSI debate. One outgrowth of the group became known as the "People's Platform," a progressive student political party that was elected to the

165 M. Lemley, supra note 42.

166R. Korobkin, supra note 42.

167D. Bisgeier, supra note 42. See also, J. Pollack, supra note 42 . An estimated 300 students participated in the centennial celebration walk-out.

168J. Pollock, supra note 42.

${ }^{169}$ A. Camarillo, supra note 15 at 1.

170 \#S-6 at 6 ; \#S-8 at 4. 
Associated Students of Stanford University (ASSU), Stanford's student government association. ${ }^{171}$

Stanford's executive branch of student govemment operates under a party system, so that all four members of the Council of Presidents are elected as a group. One white student remarked that when the People's Platform entered office,

the agenda of the ASSU got completely changed in one year from condom machines and change machines to divestment and multicultural education....The ASSU eventually shifted from Stanfordfocussed issues, like change of educational curriculum, to even more outside interests. They [People's Platform] became interested in the struggle of California farm workers and Central American govemments. 172

One of the ways that the ASSU asserted influence was through the appointment of students to various committees, including the Student Conduct Legislative Council. The People's Platform was perceived by some of their opponents to be effective in influencing institutional policy through these committees. ${ }^{173}$ For example, Canetta Ivy was elected on the People's Platform to the Council of Presidents and then became a member of the SCLC (and a primary drafter of the first attempt at the FSI). ${ }^{174}$ The People's Platform was in power during the late 1980 s and 1990 . A more moderate platform was elected to serve during the 1991-92 academic year.

The Rainbow Coalition held another sit-in at the President's Office in May, 1989, advocating many of the same issues asserted in 1987 and adding some of the concerns addressed in the UCMI report, described later in this section. This event was characterized as the peak of the Coalition's influence by three students, one white and two Chicano. 175 A white faculty member remarked of both sit-in's

$171 \#$ S-10 at $3 ; \#$ S-14 at 1-2.

$172 \# S-14$ at 1, 2.

173 \#S-14 at 2, 3.

174G. Liu, supra note 28.

175 \#S-9 at 2; \#S-14 at 2, 3. 
that they were "another example of political action getting results."176

\section{Reports and Institutional Self-Studies}

Three reports at Stanford were influential in the debate over the wisdom of adopting a policy on offensive speech. The first report detailed the events at Ujamaa House, specifically the poster incidents which began the debate over the FSI. 177 The authors conducted interviews with many of the persons present during the initial Beethoven conversation, the residence hall staff (students, faculty and student affairs staff), the participants in the emergency house meetings, the creators of the poster, and the poster's target; a total of about 40 persons were interviewed. 178 The report quotes the participants extensively and the reader is left with an understanding of the powerful emotional dynamics of the situation. The authors did not atuempt to explain why the emotional pitch of the incidents was so high, perhaps because the reasons were not known. Names were disguised in the report because of the predicted distribution and interest among a national audience. The incidents described in the report have been (mis)represented widely in newsprint editorials, articles and at least one book. 179

The second document was written by two senior attomeys in the office of the University's general counsel, John Schwartz and Iris Brest, at the request of the President and the Dean of Student Affairs. 180 This eleven page report provided an analysis of First Amendment precedents important to interpretations of the Fundamental Standard in the Otero House vigil and the Ujamaa House incident. It

$176 \#$ S-6 at 3.

177T. McBride, supra note 74.

178B. Hayward, supra note 102.

179For example, see F. Barringer. "Free Speech and Insults on Campus," The New York Times, April 25, 1989, at A-1, 11. See also, W. Buckley, Jr. "The shortcomings of the Stanford model," Norfolk Virginia Pilot, January 19, 1990, at A-14. Also, D. D'Souza; Illiberal Education: the Politics of Race and Sex on Campus, New York: The Free Press, 1991, at 133-4. note 99.

$180 \mathrm{~J}$. Schwartz and I. Brest, supra note 8. See also, J. Lyons memo to S. Cole supra 
also explained the University's policy of abiding by First Amendment principles and provided examples of previous cases involving free expression. In the Otero case, the report noted that the protesters' expression was protected expression under the First Amendment because the behavior of the vigil participants could not be construed as a threat to the Otero residents' safety, and because the University would have engaged in content discrimination had it banned this particular demonstration while allowing other demonstrations to occur in or near its residence halls. The authors also found that when Stanford's speech-related policies were applied to the Beethoven poster incident the University's standards

counsel against seeking disciplinary action: there is no evidence of the intent necessary to prove a violation of the Policy on Campus Disruption or the Fundamental Standard; interpreting those rules consistent with the First Amendment principles, there was no violation even apart from motivation. And again, the conduct was expression, which the University seeks to permit to the greatest extent possible. ${ }^{181}$

The Schwartz/Brest report was criticized for omitting any mention of Alex and Fred's action of placing the Beethoven poster on QC's poster board, and for characterizing the entire incident as protected expression because the creation of the poster involved the communication of an idea. ${ }^{182}$ It was also criticized for misleading readers about the University's policy on adherence to First Amendment principles by mistakenly creating the impression that the Bruce Franklin case (described in section one of this chapter) generally was intended to apply to all of Stanford's internal policies. 183 The report was criticized further for ignoring students' right to be free from harassment so that they may participate fully in University

181/d. (J. Schwartz and I. Brest) at 9.

182E. Thomas. "University would be justified in seeking disciplinary action in Ujamaa incident," Campus Report, Stanford University, February 22, 1989 at 7. Thomas was the dean of the School of Humanities and Sciences.

183J. Perry and C. Douglas. "First Amendment principles have not informed campus policy," Campus Report, Stanford University, February 22, 1989 at 8 . Perry was a professor of philosophy and residence fellow; Douglas was a graduate assistant and former resident advisor. 
activities. 184

The third report related to the development of the FSI was released in March, 1989, by the University Committee on Minority Issues. ${ }^{185}$ The UCMI was established by the President and Provost as a response to a demand in 1987 by the Rainbow Agenda. ${ }^{186}$ The UCMI based its findings on the results of a 20-page, 84-item survey completed by more than 1,300 Stanford students, a lengthy survey completed by over 200 Stanford faculty, information from more than 200 student interviews (conducted by a consulting firm), and a review of the practices and policies of many Stanford departments. The 240-page final report described issues and made recommendations in the following areas:

- Undergraduate curriculum,

- Faculty,

- Undergraduate students (recruitment, financial aid, retention \& performance),

- Graduate students (enrollment, retention, Office of Graduate Studies, each graduate school),

- Student Life, and

- Staff.

The University's consultants collected the data for the report during a period of race relations on campus characterized in the UCMI report as "highly volatile."187 The UCMI concluded that Stanford admitted a student community that had little other-race interactions prior to enrolling at Stanford,

$184 \mathrm{~J}$. Perry and C. Douglas. "Freedom of expression policy does not give absolute right to chill others' participation," Campus Report, February 8, 1989, at 8. See also, D. Matthies, "Matthies: Freedom from harassment remains a basic right, doesn't it?" Campus Report, February 15, 1989, at 9. Matthies was the resident fellow in Otero House during the vigil in the spring of 1988.

185 A. Camarillo, supra note 15. The UCMI issued an interim report in May, 1988. The release of the final report coincided with the publication of the highly controversial first draft of the FSI (see section four of this chapter)

186 The 18-member committee included faculty, staff, students, and outsiders.

187 A. Camarillo, supra note 15 at 158 . The timing of the research undoubtedly affected the survey and interview results in the "Student Life" section of the report, since race relations were thought to be particularly tense. 
especially among whites. ${ }^{188}$ The committee also determined that many minority students experience forms of "covert racism or devaluation" that caused them to feel self-doubt or diminished levels of confidence. 189 The report identified areas of social interaction and social distance, the latter amplified by increased publicity about racial issues. 190 The UCMI commended the Office of the Dean of Student Affairs for substantial progress in its attention to issues of diversity and minority student concerns. However, it faulted the office for undervaluing the importance of ethnic group identity, and for its "quietistic leadership style, emphasizing behind-the-scenes education and resolution of conflicts."191 The report called for the University to make a transition "from numerical diversity to interactive pluralism."192

Overall, the report reads like a long list of complaints, only some of which were based on the empirical evidence collected. The recommendations for student life had little to do with the results of the surveys and interview data. 193 The issue of the FSI was not addressed directly in the report. However, many of the reasons given in support of the FSI are discussed in the report, and the premises and conclusions of UCMI report may have provided strong supporting material for persons favoring the FSI.

$188 / d$. at 159.

$189 / d$. at 162 .

$190 / d$. at $168-172$.

191/d. at 187. This leadership style criticized at Stanford was similar in form and philosophy to the approach at the University of Virginia. In this approach, students are given as much freedom as possible to govern their own affairs and resolve their own conflicts, with the assistance of the professional staff in the roles of consultant and mediator rather than commander and decision-maker. It requires reliance on persuasion over authority.

$192 / d$. at 1.

$193 \#$ \#-6 at 2. My own review of the report also supports this claim. 


\section{Discussion and Development of a Policy Regulating Discriminatory Verbal Harassment}

\section{Progression of the Policy}

Section two of this chapter describes how both the Otero vigil and the Ujamaa poster incidents prompted the campus discussion about amending the Fundamental Standard to define the limits of free expression among students. The Ujamaa incident focussed the community's attention directly on what some perceived to be an inadequacy of the existing code, and the Ujamaa situation was cited by most informants as the impetus for the FSI.194

One of the first indications that the Fundamental Standard might be amended was made by President Kennedy during a meeting with Ujamaa residents on October 17, 1988, the day after the emotionally charged emergency House meeting at Ujamaa. Kennedy allegedly suggested that modifying the Fundamental Standard was a possible solution to problems like those recently encountered at Ujamaa, but he only offered support in helping to draft a policy to accomplish this goal; no commitment of support for such a policy was promised.195 The issue was raised again on November 18, 1988, by the associate dean of the Law School (co-author of the Ujamaa House report) as the Ujamaa investigators discovered that there was no clear understanding among residence hall staff of how the Fundamental Standard applied in this case.196 Memoranda written by the Dean of Student Affairs Office staff indicated that during November and December, 1988, the Dean and his staff were operating under the assumption that judicial charges would be brought under the Fundamental Standard against Alex and Fred for hanging the racially offensive Beethoven poster. 197

194 For example, see \#S-3 at $1 ; \#$ S-4 at $1 ; \# S-6$ at $5 ; \# S-8$ at $2 ; \# S-13$ at 1.

195D. Bisgeier, supra note 91 at $1,8$.

196T. McBride. Letter to Donald Kennedy (president) and James Rosse (provost), Stanford University, November 18, 1988, at 2.

197J. Lyons, supra note 99 (memo to S. Cole). See also, N. Robinson, Electronic mail message (hard copy) to J. Lyons, et. al. regarding "Ujamaa report update," Stanford University, December 30, 1988. 
As the investigation into the Ujamaa incident progressed through November and December, 1988, one white administrator recalled,

[I]t was a time of enormous confusion; we didn't know what to do. One of the things that made the year so difficult was that everybody wanted to do the right thing and we couldn't agree on what the right thing was. People who had been allies and colleagues over a twenty year period found themselves screaming at each other from opposite sides of the fence....People were taking sides so fast. The minute anyone was identified with one camp or the other then significant communication simply ceased. That was completely new in my experience on this campus. It was a very difficult time. 198

In January, 1989, the housing privileges of the culprits in the Beethoven poster incident were revoked for two quarters. 199 Two days later, President Kennedy noted the need for more attention to the issues of free expression in the Ujamaa case, perhaps as precursor to the Ujamaa House final report that was released the following week.200 On February 9, student judicial affairs officer Sally Cole made public her decision not to bring charges under the Fundamental Standard against the two students responsible for the Beethoven poster. 201 Deans Lyons and Cole released a second statement on February 9, moving the discussion about the boundary between the First Amendment and the Fundamental Standard into the policy arena, stating in part,

We believe that current policies are not as clear as they can and should be. Students need more guidance in locating the boundary between respectful and disrespectful speech. We also believe that it is a bad idea to use students and the disciplinary process to raise and address lack of precision in policies....The Student Conduct Legislative Council needs to continue its work in developing a statement of Interpretations and Applications of the Fundamental Standard.202

By this time the SCLC had already begun to discuss the possibilities of drafting clarifying

198 \#S-1 at 5, 6.

199 N. Robinson, supra note 101 at 8.

200D. Kennedy. "Reflections on racial understanding," Campus report, January 11, 1989. See also, B. Hayward, supra note 102.

201S. Cole. "Freshmen won't face charges of violating Fundamental Standard," Campus Report, February 15, 1989, at 16.

202J. Lyons and S. Cole. "Cole, Lyons ponder ways to respond to offensive behavior," Campus Report, February 15, 1989, at 15. 
language to the Fundamental Standard. By February 14, the group had agreed, in principle, on what the new policy draft would say. Canetta Ivy, a black leader in student government and co-author of the draft policy, said that "under the Council's proposed guidelines, the students [Alex and Fred] most definitely would have violated the Fundamental Standard."203

On March 1, 1989, the SCLC released its draft additions to the Fundamental Standard.204 The Council left the original Standard intact and proposed additional interpretive language to explain areas in which freedom of expression and freedom from harassment came into conflict. The first paragraph of the draft policy affirmed the University's commitments to personal, cultural, and intellectual diversity. The second item acknowledged the high value placed on free expression in the United States, especially at a university, and the need to tolerate even offensive ideas. The third paragraph noted that the interplay of these two values may cause conflict in some situations, and offered the following two paragraphs as a means to clarify instances of that conflict:

4. PERSONAL ABUSE. Students and other members of the Stanford community have the right to be free from personal attacks which involve the use of obscenities, epithets, and other forms of expression that by accepted community standards degrade, victimize, stigmatize, or pejoratively characterize them on the basis of personal, cultural, or intellectual diversity.

5. DEFAMATION OF GROUPS. Members of the Stanford community have the right not to be inescapably and involuntarily exposed to obscenities, epithets, and other forms of expression that by accepted community standard stigmatize, victimize, or pejoratively characterize persons or groups on the basis of personal or cultural differences. ${ }^{205}$

Reactions to the first draft were strong and mostly negative. A comment period followed the release of the draft as required by University policy during which intense discussion occurred in almost every quarter of campus. ${ }^{206}$ Residence hall staffs arranged discussions among residents, interested groups

203G. Liu, supra note 28.

204 Student Conduct Legislative Council (S.C.L.C). "Interpretations and Applications of the Fundamental Standard in the Area of Diversity," Stanford University, March 1, 1989.

$205 / d$. 
held open forums, and numerous letters were written to the campus newspapers. 207 The University created an electronic mail message board as one mechanism to facilitate responses to the Council through which over 100 responses (mostly opposed) were received.208 A group of students calling themselves the "Committee for First Amendment Rights" formed soon after the draft was released and collected over 800 signatures on a petition within a short period of time.209 The draft also sparked discussion at meetings of the faculty, alumni, and the Board of Trustees. 210 One faculty member said

... it is evident that this is an issue that the University, collectively, takes seriously. We didn't do what a lot of schools do, where the president or the dean writes a policy and puts it out for approval and there it is. This has been a bottom-up thing all along with hearings and a very careful (cumbersome) process. 211

Two senior professors of Constitutional law, Gerald Gunther and William Cohen, were among the most respected and eloquent opponents of the draft. Both professors argued to strike paragraph five and substantially limit paragraph four because of vagueness and overbreadth problems under the First Amendment (discussed later in this section).212 The depth and breadth of opposition to the initial draft caused the SCLC to abandon it completely. 213 A white administrator described the situation as one

207 \#S-3 at 3; \#S-5 at 2; \#S-8 at 3. Some of the residence hall discussions were said to have lasted two to three hours with a high level of reasoned discussion.

208 \#S-5 at 1. Hard copies of the electronic mail responses were available at the Office of the Dean of Student Affairs. My review of these responses revealed that more than three fourths of the responses opposed the first draft of the FSI.

209 \#S-1 at 5; \#S-4 at 2.

210 \#S-4 at 2; \#S-8 at 3.

211 \#S-6 at 8.

212G. Gunther, supra note 35; see also, W. Cohen, supra note 35. Both letters were reprinted in Stanford's Campus Report on March 15, 1989. Portions of professor Gunther's letter was published in Academe (November-December 1990).

213G. Parker. Letter to T. Boykin acknowledging receipt of his comment letter to the SCLC, Stanford University, March 29, 1989. The letter noted that the SCLC received “...more than 25 others representing a similar point of view and numerous outspoken 
in which

...the first attempt to draft an interpretation in the area of discriminatory harassment and free expression brought everyone out of the woodwork. It was written primarily by a well-intentioned philosopher who...knew exactly the behavior that he wanted to stamp out and it was clear to him what language would suffice to do that -- that is basically what he wrote. If you think some of the policies that have been struck down in the courts were vague and overbroad, the SCLC's first effort was a model of vagueness and overbreadth. And then the campus just exploded.214

The SCLC returned to the drawing board, this time with the assistance of Stanford law professor Thomas Grey as its invited legal consultant.215 Student members of the SCLC were skeptical about seeking legal assistance at first because most of the public opposition had come from the University's legal counsel and the Law School. 216 A SCLC member recalled that Grey supported the Council's goals and told the group that its goals could be achieved without severely threatening free expression.217 Grey, aware that participating in drafting the FSI would also create conflict with some of his legal colleagues, approached the policy by adopting a civil rights theory, then using First Amendment categories to define what is harassment.218

The SCLC's second draft was released on April 4, 1989, and included three and one half pages of explanatory comments about the draft interpretation (see Appendix B).219 The second draft was also hotly debated, although most of the First Amendment issues were addressed in the re-draft. An administrator remembered that

additional communications to the committee..."

$214 \# S-1$ at 5 . See also, \#S-5 at 1.

$215 \#$ S-1 at $5 ; \# S-4$ at 2.

216 \#S-1 at 5.

$217 / d$.

218T. Grey. "Civil Rights vs. Civil Liberties: The Case of Discriminatory Verbal Harassment," Social Philosophy and Policy, 8:2 at 102. See also \#S-1 at 5; \#S-3 at 2.

219 Student Conduct Legislative Council. "Proposed Interpretation of the Fundamental Standard," Stanford University, April 4, 1989. 
[Tom Grey] drafted the interpretation and the interpretation of the interpretation, which was all published as a piece. And there was a fair amount of debate about it, but it was all basically a lot less terrifying than the first version. 220

Both William Cohen and the Committee for First Amendment Rights retracted their opposition after the Grey proposal was published.221 Several minority student groups at the Stanford Law School joined in applauding the SCLC's effort, but suggested that a broader rule would be more effective and Constitutional.222 A black student leader at Stanford argued that she was much more satisfied with the first SCLC proposal and asked the SCLC to eliminate the intent requirement in the second FSI draft.223

The number of signatures on the petition by the Committee for First Amendment Rights forced the faculty senate (as a matter of institutional policy) to review the FSI draft.224 Minutes of

220 \#S-4 at 2. Some informants called the second SCLC proposal the "Grey proposal" after its author.

221 W. Cohen. Letter to George Parker (chair of SCLC), Stanford University, May 1, 1989. See also, \#S-1 at 6.

222D. Lee (spokesperson). Memo to the Student Conduct Legislative Council regarding "Free Speech and Discriminatory Harassment at Stanford," Stanford University (no date). Although the document is not dated, the draft policy language cited indicates the group sent the memo in April, 1989. The memo was signed by representatives of the Asian Law Students Association, Black Law Students Association, Jewish Law Students Association, Native American Law Students Association, and Asian American Students Association. The groups were concerned particularly with the "intent" requirement of the proposed FSI, noting that proving a speaker's malicious intent to harass, beyond a reasonable doubt, would be nearly impossible.

223M. Dillard. Letter to the SCLC, Stanford University, May 9,1989. The author is a former BSU chairperson and former Ujamaa residence staff member.

224 A. Coladarci. The Student Conduct Legislative Council Proposed Interpretation of the Fundamental Standard," Campus Report, May 10, 1989, at 17 (this news article was a reprint of the faculty senate meeting on April 20, 1989). The petition was signed in opposition to the first draft, but that draft was withdrawn before the faculty senate met to discuss it. The May senate meeting included discussion of the second draft. The faculty senate has no legislative authority and discussed the matter in order to provide further input to the SCLC. 
the April 1989 faculty senate meeting detailed a lengthy discussion on the FSI.225 Attending the meeting as guests were representatives of the SCLC, student government, law faculty (including Gerald Gunther, William Cohen and Tom Grey), and president Kennedy. Kennedy asked about the status of the 'comments' section of the proposal to determine how they would be used in actual cases under the FSI (eg., used as "legislative history, report language, or something else"). George Parker, then chair of the SCLC, responded that the SCLC viewed the comments as explanatory rather than legally binding, but admitted that he was unsure. Tom Grey remarked that he viewed the comments section as legislative history. Toward the end of the senate meeting, President Kennedy concluded that he was not a supporter of the legislation because it would present more difficulties than advantages. He further argued for a longer period of time in which the campus community should consider the issues involved in adopting an FSI, rather than rushing to a decision in order to achieve closure for the academic year.

The FSI debate stalled in May 1989, after Kennedy's remarks at the faculty senate meeting. George Parker's term as chair of the SCLC ended with the school year, and no replacement was named for nearly six months. ${ }^{226}$ There was some speculation that no suitable faculty member wanted to take on the role as SCLC chair.227 Law Professor Bob Rabin was named chair of the SCLC in November 1989, and the Council resumed work on the FSI.228 The Council released Tom Grey's proposal of the FSI again in December 1989, thus initiating the process of public review.229 Four Stanford Law Professors (Gunther, Cohen, Lawrence, and Grey) met with the SCLC at its first formal meeting in

$225 / d$.

226J. Brock. "After 2-month wait, SCLC ready to meet," Stanford Daily, November 30,1989 , at 1.

227R. Mowatt. "Chair vacancy keeping this year's SCLC in starting blocks," Stanford Daily, October 5, 1989, at 1 . It is possible that any faculty reluctance to serve on the SCLC was related as much to the amount of time interested faculty anticipated the committee would require of them as it was related to the volatile nature of the issues before the committee.

228J. Brock, supra note 226.

229P. Rapalus, supra note 36. The SCLC in effect, started over in the fall, 1989. 
Cohen, Lawrence, and Grey) met with the SCLC at its first formal meeting in late January, 1990.230

Professors Gunther and Cohen acknowledged that Grey's proposal was an improvement over the SCLC's

first draft, but they argued it remained vague and overbroad.231 Professor Lawrence spoke in favor of Grey's proposal and supported additional language to broaden the scope of the draft policy to apply to the entire Stanford community, rather than applying only to students. ${ }^{232}$

The SCLC discussed subsequent versions of the draft in February and again in March 1990, each with minor modifications of Tom Grey's initial proposal. 233 The changes in the proposed policy centered on the precise definition of "fighting words" in section 4.c. (see Appendix D). The first sentence of section four remained constant, with the exception of the word "personal" which was added in December, 1989. The relevant changes are shown below it. Additions/modifications are underlined and deletions indicated by brackets.

4. Speech or other expression constitutes harassment by personal vilification if it:

April 1989 (c) amounts to "fighting words" or their functional equivalent; that is, in addition to its insulting or stigmatizing content, is expressed in words, pictures or symbols that, by virtue of their form, are commonly understood to convey, in a direct and visceral way, hatred or contempt for human beings of the sex, race, color, handicap, religion, sexual orientation, or national and ethnic origin in question.234

December 1989 (c) makes use of "fighting words" or non-verbal symbol. In the context of discriminatory harassment. "fighting words" or non-verbal symbols are words, pictures or other symbols that by virtue of their form, are commonly understood to convey [ ] direct and visceral [ ] hatred or contempt for human beings on the basis of their sex, race, color, handicap, religion, sexual orientation, or

230P. Rapalus. "Taking the "chill' off open discussion key issue for SCLC," Campus Report, February 7, 1990, at 1.

$231 / d$.

$232 / d$.

233P. Rapalus, supra note 36 . Each time the group chose to modify the draft policy, a new 'comment period' was required.

234SCLC, supra note 219. 
national and ethnic origin [ ].235

April 1990 (c) makes use of "fighting words" or non-verbal symbols. In the context of discriminatory harassment by personal vilification, insulting or "fighting" words or non-verbal symbols are [ ] those "which by their very utterance inflict iniury or tend to incite to an immediate breach of the peace " and which are commonly understood to convey direct and visceral hatred or contempt for human beings on the basis of their sex, race, color, handicap, religion, sexual orientation, or national and ethnic origin.236

Each alteration of subsequent drafts narrowed the scope of the phrase "fighting words" until, in the final version, prohibited expression was limited to that which would actually tend to incite the intended target to violence. The Council also changed the 'comments' section of the draft FSI to more closely track the policy changes between December 1989 and April 1990; sections of the "comments" describing the origin and meaning of the "fighting words" doctrine were explained in more detail in the later version. 237

The SCLC released for public comment an updated version of the Grey proposal on April 4, 1990.238 Several indicators were available to gauge the campus perceptions of the $1990 \mathrm{FSI}$ proposal. The faculty senate discussed the issue again at its May meeting (1990). ${ }^{239}$ The

SCLC majority opinion was presented by the Council's chairperson, followed by dissenting views from invited speakers, Gerald Gunther and William Cohen.240 Opinions on the FSI reportedly were

235T. Grey. "Responding to Abusive Speech on Campus: A Model Statute," Reconstruction, Winter 1990 , at 50-54.

236 SCLC. "Fundamental Standard Interpretation: Free Expression and Discriminatory Harassment," Stanford University, April 4, 1990.

$237 / d$.

238 No author. "Council set to vote on proposed rules dealing with speech," Campus Report, May 23, 1990, at 1.

6.

239Faculty Senate. "Minutes of the Senate," Stanford University, May 3, 1990, at 2 - 
evenly divided among the other senators who spoke at the meeting. ${ }^{241}$ The SCLC received about 35 written responses during the comment period, of which 25 were in opposition to the FSI proposal. A poll of nearly 300 Stanford graduate and undergraduate students suggested student opinions were divided almost evenly. About $37 \%$ of students polled thought that the proposal was fair, and $3.5 \%$ believed that the proposal was not broad enough. 242 Thirty-five percent of those students polled believed the SCLC proposal went too far in restricting expression. 243

The SCLC made some minor revisions to the comments following the initial proposal and voted "first passage" of the legislation on May 7, despite the divided opinions generated by the proposal.244 Another comment period of fourteen days followed this vote. ${ }^{245}$ A lack of evidence suggested little reaction to the vote occurred. On May 24, 1990, the SCLC voted 8-3 to adopt the FSI on discriminatory harassment, and the interpretation took effect on June 11.246

\section{Supporters of a Fundamental Standard Interpretation}

The strongest supporters of an FSI were the members of the Minority Coalition, members of the People's Platform, three law professors, and several other faculty and administrators. ${ }^{247}$ Many of the faculty and administrators who supported an FSI had some experience living in residence halls with

241 No author, supra note 238.

242J. Friendly, "Students split on SCLC proposal," Stanford Daily, May 7, 1990, at 1. The surveyors reported a $6 \%$ margin of error.

$243 / d$.

244 Student Conduct Legislative Council. "Interpretation of the Fundamental Standard," Stanford University, May 24, 1990, at 1.

$245 / d$.

246K. Bartholomew, supra note 36.

247There was disagreement among the supporters over what form the policy should take. Many of the "supporters" named actually opposed the final version of the FSI because it did not prohibit the types of behavior that were most problematic for minority students. 
students or otherwise had significant levels of social contact with undergraduates. ${ }^{248}$ The primary reason given in support of the FSI was that the policy purportedly would help establish and maintain an environment in which each and every student could engage in university-related activities free from harassing speech and conduct. 249 This rationale was summarized best by a black administrator who recalled that "the phrase that people really wanted to keep in front of folks [was] that 'this institution should take a stand" against " $X$ " kind of behavior or speech that affects the ability of people to have good educational and social experiences at Stanford."250 Some black student leaders complained about the way in which the FSI debate was characterized, and they suggested that the presentation of the issue under the auspices of free speech ignored students' right to be free from insult, assault, and verbal harassment, especially in the residential areas. 251

Several legal arguments were advanced in support of the draft policy. The author of the first (and widely rejected) draft of the FSI, John Perry, argued that the proposed restrictions were not an attempt to restrict thought and expression of offensive ideas. $252 \mathrm{He}$ contended that his draft policy would not "rule out expressing the same content in a different situation, where it will not constitute personal abuse or defamation that cannot be avoided."253 Perry argued that students who placed others in a "captive audience" situation or those who subjected others to personal harassment had exceeded their First Amendment rights.

$248 \#$ \#-1 at 5.

249 \#S-8 at 2. See also, J. Perry, supra note 184 at 15; D. Matthies, supra note 184 at 14.

$250 \# S-8$ at 2.

251 M. Dillard, supra note 223. See also, L. Jackson; "BSU: Issue is freedom from racist harassment," Campus Report, May 10, 1989, at 13.

252J. Perry. "Stricter Standard and First Amendment are not in conflict." The Stanford Daily, March 7, 1989, at 5.

$253 / d$. 
Five minority student groups at Stanford's Law School wrote the SCLC in support of a broad, wide-ranging version of the FSI. ${ }^{254}$ These students argued that professors Gunther and Cohen had engaged in "mere speculation" about the Supreme Court's views on racist and sexist speech. The students believed that "students most often victimized by discriminatory forms of speech must bear the burden for the community's freedom to engage in those forms of speech." They also contended that members of traditionally disadvantaged groups did not agree with Supreme Court rulings on social issues, and that Stanford should expand the reach of its harassment policy because the Court's rulings did not prevent minority members from feeling the hurts of racially offensive and hostile expression. Restrictions on racist speech, they argued, would actually promote speech by freeing minority students from their perceptions of being intimidated or unwelcome by whites; in other words, allowing racist expression served to intimidate minority students and inhibit their willingness to participate in campus debates about race-related issues. 255 The groups' representation of the Ujamaa incident was that

[i]t was no joke at all. The Beethoven poster told him and other Blacks to shut up or suffer some adverse consequence. Minority students want the University to uphold their freedom to speak and not allow students to engage in tactics that threaten to silence them and prevent their participation in the education life at Stanford. 256

The minority law students' representatives believed that the Grey proposal failed to protect students from harassment by vilification. They rejected the argument that the FSI would lead the way for other prohibitions on 'offensive' speech because they believed that the categories included in the FSI (race, gender, etc.) were clearly defined, and that procedural safeguards existed that prevented overzealous application of the policy (including the evidentiary standard, "beyond a reasonable doubt').

Law professor Charles Lawrence believed that racist expression should be codified as a violation of the Fundamental Standard, but he argued that the responsibility for the acts should be on the community

254 D. Lee, supra note 222.

255 /d. See also, P. Rapulus, supra note 36 at 1. Ingrid Nava, a black student member of the ASSU council of presidents who supported the policy, remarked that "you have to consider whose free speech is being checked on this campus every day -- people of color, homosexuals, etc. Their freedom of speech is being checked in a lot of de facto ways."

$256 / d$. (D. Lee). 
as a whole. 257 Lawrence, who is black, suggested that in addition to punishing the individual perpetrators, the University should apply self-sanctions that would benefit minority students each time a racist incident occurred. 258

Others argued that the Otero vigil and the Ujamaa poster incidents showed how vague the original Fundamental Standard was as a stand-alone policy. One white faculty member said,

For those who are critical of the vagueness of the current interpretation, it is important to remember that a repeal of the new policy would mean a return to the vague Fundamental Standard. Cases of discriminatory verbal harassment brought under the original Fundamental Standard relied even more on the interpretation of the person who administers the policy, and there may have been even more potential for infringement on First Amendment values. 259

Robert Rabin, law professor and chair of the SCLC in the spring of 1990, echoed this remark to the faculty senate and added,

"[a]lmost all the criticisms of the proposed interpretation proceed as though we are operating in a vacuum. The critics, almost invariably, fail to ask, 'This standard as compared to what?' The question is critical because the institution is not operating in a vacuum. The present situation is that any incident is governed by an overly broad, exceedingly vague Fundamental Standard exhortation to behave as 'a good citizen.' 260

This rationale was consistent with the statement released by the Dean of Student Affairs Office that moved the debate into the policy arena because of the unclear nature of the Fundamental Standard's application in the major public events described earlier. ${ }^{261}$

The final draft of the FSI was criticized by some opponents for being largely symbolic. The critics included egalitarians who believed the proposal to be patronizing to minorities and civil libertarians

257P. Rapalus, supra note 230.

$258 / d$.

259 \#S-3 at 1.

260Faculty Senate, supra note 239 at 3 . Rabin is white.

261J. Lyons and S. Cole, supra note 202. 
who argued that a symbolic gesture was hardly worth the risks to free expression on campus. ${ }^{262}$ Thomas Grey, a Stanford law professor who is white, suggested that Stanford would make its most effective statement through its honest concern to do more than make a statement, and he wrote that the FSI was "justifiable independent of the statement it makes."263 Robert Rabin acknowledged the criticism that the policy would be merely symbolic, but he asked,

"what's wrong with that? The proposed standard is meant to send the message that the University cares deeply about creating an atmosphere where those who have suffered discrimination in the past... can take full advantage of everything a Stanford education has to offer."264

Support for the policy was given by a faculty leader of the American Association of University Professors (AAUP), Denis Phillips. Phillips voiced strong support for the FSI at faculty senate meetings in April 1989, and May 1990.265 Phillips rejected constitutional arguments as irrelevant, and interpreted the proposal as a partial solution to a situation in which speech had become dysfunctional. $266 \mathrm{He}$ believed that community members voluntarily associated with Stanford, in part, because they agreed with the institution's ideals, including fundamental respect for others in the community. 267 Phillips supported the Grey proposal because it protected students against intimidation and threats, conditions that were acceptable in a university setting. 268

A white student who opposed the FSI believed that traditionally oppressed groups rely on the University to protect their rights and provide a defense or security. He linked the 1991 ASSU debate over

262T. Grey, supra note 218 at 104.

$263 / d$.

264 Faculty Senate, supra note 239 at 3.

265 Id. See also, A. Coladarci, supra note 224.

$266 / d$. (Faculty Senate).

$267 / d$.

${ }^{268}$ A. Coladarci, supra note 224. 
the standard of proof required in disciplinary cases with the debate over the FSI.269 According to this student,

You would observe that the same people who supported the "clear and convincing evidence" standard of proof would support the Grey Standard. The reason is that right now....they have given up on hoping that the government is going to give them the satisfaction they require, so they are looking to the University. They would like the University to be the authority figure to enforce the beliefs that they would like everybody on campus to have. 270

Under this rationale, for example, the student $(\mathrm{QC})$ who was the target in the Beethoven poster incident may have believed that he had no recourse against Alex and Fred's actions or that the hurdles were to high and too many, had he tried to bring criminal charges against them or had he sued for civil damages. Instead, QC (and those who identified with his situation) would expect the University to offer protection against offensive expression which hindered his ability to function effectively in Stanford's academic and social community. This perception seems to be consistent with the view advanced by the law students who argued that the Supreme Court did not provide adequate protection for minority group members.

\section{Opponents of a Fundamental Standard Interpretation}

Opponents of modifying the Fundamental Standard were most vociferous following the release of the first proposal in March, 1989 (see pages 204-6). The second SCLC proposal, written by Tom Grey, and its subsequent refinements mollified many of the early opponents of the FSI. Opponents' concerns focussed on the First Amendment values embraced by the University and on the potential impact of the FSI on campus debates and discussions.

The release of the first FSI proposal prompted an avalanche of opposition that led eventually to its

269 Stanford's evidentiary standard in disciplinary cases was "beyond a reasonable doubt." In 1991, the ASSU considered a proposal to ease the standard to "clear and convincing evidence" - a change that would make it easier to achieve convictions in the Stanford judicial system. The proponents of this proposal were prompted, in part, by frustration associated with cases of sexual assault and date rape initiated by female students that resulted in non-convictions because the case could not be proven beyond a reasonable doubt.

270 \#S-14 at 3. \#S-14 believed that Stanford's policies should not exceed the limitations of the laws of the state of California, and that students should look to the state legal system for relief in criminal cases, not the University judicial process. 
early withdrawal. Most notable among the opponents were law professors Gerald Gunther and William Cohen, the Committee for First Amendment Rights, and various faculty members and students who responded on the electronic mail bulletin board. Many of the persons who responded on the electronic bulletin board were from more technically oriented fields - computer science, engineering, physics, etc. 271

In a letter to George Parker (then chair of the SCLC), Professor Gunther made several arguments against an interpretation of the Fundamental Standard.272 In his explanation of First Amendment principles he wrote that "among the core principles is that any official effort to suppress expression must be viewed with the greatest skepticism and suspicion."273 Gunther also noted,

...speech should not and cannot be banned simply because it is 'offensive' to substantial parts or a majority of a community.... Freedom of expression -- and especially the protection of dissident speech, the most important function of the First Amendment -- is an anti-majoritarian principle....The power to ban speech merely because it is offensive is an "inherently boundless" notion....Y You have couched the standard in quite open-ended, unclear terms that put the vigor of expression on campus in genuine peril; more basically, you have adopted an expansive version of the group libel concept profoundly hostile to core principles of the First Amendment and especially inappropriate on a university campus. ${ }^{274}$

Gunther specifically objected to the SCLC's definition of forbidden expression in terms of "accepted community standards," which he argued was "vague, open-ended, and , above all, reeks of majoritarian suppression of the unorthodox minority." $275 \mathrm{He}$ also criticized the draft for applying the "personal abuse" provision to instances of "intellectual diversity," and for using the term "obscenities" to describe

$271 \#$-4 at 1. My review of the hard copies of the responses confirmed this statement.

272G. Gunther, supra note 35. Gunther has been a professor of constitutional law for 37 years, nearly 32 of them at Stanford. $\mathrm{He}$ is the author of the most widely used textbook on constitutional law in America, which devoted about 600 pages to First Amendment issues.

$273 / d$.

$274 / d$.

$275 / d$. 
profane expletives. 276 Gunther wrote that the need for restrictions on intellectual diversity was curious, and the potential applications unclear. Also, the word "obscenity," as a legal term applies only to sexually explicit materials. His greatest concern was with the draft's treatment of defamation of groups because the restricted expression was unclear, thus increasing the threat of self-censorship among persons who would express unpopular views.

Professor William Cohen faulted the SCLC's first draft for its omission of a requirement that the speaker intend to harm the target.277 Without an intent requirement, he argued that "the multiplicity of vague terms will lead to a considerable amount of self-censorship in intellectual discourse in the University."278 Cohen further criticized the SCLC proposal for exceeding its authority in going beyond the area of student discipline to "create a personal right to be free from involuntary exposure to any form of expression that gives certain kinds of offense. It could become a sword to challenge assigned readings in courses, the showing of films on campus or the message of certain speakers."279

Professors Gunther and Cohen shared similar conclusions regarding the First Amendment problems in the first draft of the FSI. They both agreed in principle with the report prepared by the University's general counsel explaining the application of the Fundamental Standard in the Otero and Ujamaa cases. Both professors conceded that a narrowly written policy aimed at verbal harassment could be written without offending First Amendment principles.

Other opponents suggested reasons why the FSI was an inappropriate policy for Stanford. Computer science professor Pierre Bierre stated four reasons: 1) the policy focusses attention on specific events rather than the underlying causes of conflicts, 2) it weakens "victims" skills in responding and fosters dependence on the University to protect them from harm, 3) the University would have to

$276 / d$.

277W. Cohen, supra note 35. Cohen had taught constitutional law for 32 years, and nearly 22 of them at Stanford. He is responsible for chapters on freedom of speech in two casebooks on constitutional law.

$278 / d$.

$279 / d$. 
adjudicate a potentially large number of embarrassing cases of racial insult, and 4) it would inhibit the expression of unpopular opinions and force them underground, thus eliminating the opportunity to expose and confront biased attitudes. 280 A graduate student criticized the policy for targeting only students, and he suggested that faculty, students and staff should be treated equally.281 Another student complained that the policy ignored insults that were equally as damaging as those that were prohibited, and that the FSI served to further a uniformity of opinion and inhibited individuality and independence.282 Stuart Reges, a white faculty member in the computer science department, suggested that Stanford should promote the language of "harmony" rather than the language of "politics." The distinction came from Reges' own experience in which

...[s]everal young men at Stanford have called me "faggot" to my face. With the SCLC rule, I could have them suspended for a quarter. Will that make them respect gay people more? I think not. Perhaps it would silence them. Again, I think not. It might make them less bold, but not less belligerent. Just two weeks ago someone sent an anonymous message through the computer to me saying, "You disgusting fag." How will the SCLC rule stop that?....Prejudice is one of the most intractable facets of the human soul. You can cage it in, but that only makes it more angry and more dangerous, more likely to explode unexpectedly with even greater ferocity....For me it boils down to whether I want to settle for a well-regulated society of hypocrites where correct behavior is constantly debated in University committees, or whether I'd rather have a community of imperfect people who sometimes hurt each other but who also sometimes help each other, through open and loving sharing, to become better people. ${ }^{283}$

The Grey proposal was released by the SCLC in April 1989 prompting continued discussion about the First Amendment issues and the wisdom of an FSI. Several early opponents modified their positions. Professor Cohen admitted that the Grey proposal would likely be constitutional if adopted by a public university, but he argued that it could be improved by narrowing the definition of 'fighting words' and by

280P. Bierre. Letter to G. Parker, Stanford University, March 16, 1989.

281E. Heit. Letter to the Student Conduct Legislative Council, Stanford University, March 7, 1989.

282T. Boykin. Letter to S. Cole, Stanford University, April 14, 1990.

283S. Reges. Memo to Student Conduct Legislative Council, Stanford University, May 23, 1990. 
clarifying the intent requirement. ${ }^{284}$ Leaders of the Committee for First Amendment Rights withdrew the group's opposition following the SCLC's publication of the Grey proposal.285 Gerald Gunther maintained that the policy was unwise and perhaps, unconstitutional.286

Publicly, Stanford president Donald Kennedy neither supported nor opposed the legislation, although the tone of his comments leaned generally toward opposition. During the April 1989 faculty senate debate Kennedy questioned the status of the "comments" section of the interpretation.287 He also voiced great concern over the symbolism expressed by adopting (or not adopting) such a policy. The minutes from that faculty senate hearing indicated that Kennedy delayed action on the proposal until the following academic year because he was concerned that

...[i]ts adoption might invite the inference that the University has made only a limited or marginal commitment to the social justice side of the equation, and that what is not explicitly prohibited is permitted. Although not closed-minded about the matter, he is inclined to the view that enactment of such legislation would present more difficulties than advantages....It would be very important for the SCLC to afford the community more time to comment, even though to do so would delay action. 288

Kennedy took no public position during the 1990 debate over the FSI, although his predecessor, Richard Lyman, was a vocal opponent.289 Conflicting stories surfaced after the SCLC approved the policy. One report indicated that Kennedy "endorsed the tight limits on harassing language in a statement...on the campus radio station."290 Another source quoted Kennedy to have said, "I'm not sure that codifying harassment in the long run is the best thing to do, but I've been impressed with the process, which has

${ }^{284}$ W. Cohen, supra note 277.

285 \#S-1 at 6.

286A. Coladarci, supra note 224.

$287 / d$.

$288 / d$.

289 No Author, supra note 238.

290B. Workman. "Stanford Cracking Down Against 'Fighting Words," San Francisco Chronicle, May 31, 1990, at 1. 
been thoughtful....there are phrases I would have put differently, and .... I've had assurances that there will be no interference with freedom of speech."291 Campus informants did not mention Kennedy as a factor on either side of the debate. However, the evidence suggests that he had serious misgivings about the policy and therefore did not actively support it. He is included among the opponents because his absence from the debate implied a tacit disapproval.

Public opposition also was voiced by University vice president and general counsel, John Schwartz, and associate counsel, Iris Brest, co-authors of the report that outlined the judicial application of the First Amendment to charges under the Fundamental Standard.292 Schwartz contended that the new proposal would prohibit conduct that was already prohibited under the Fundamental Standard.293 Schwartz and Brest noted the 'fighting words' exception to the First Amendment in their report and defined it in ways similar to the Grey proposal. One important difference in the Schwartz/Brest report description of fighting words was its omission of the protected categories enumerated by Grey (race, gender, etc.). The general counsel's construction of the fighting words exception to protected speech was content-neutral and did not favor any particular group. Some in the Office of the General Counsel believed that the FSI did not raise serious legal risks, and that the debate over the FSI should be decided on the basis of policy considerations rather than legal considerations. ${ }^{294}$ Their advice to the SCLC was given, not in their official capacity as members of the University general counsel, but as citizens in the Stanford community who believed the FSI to be an unwise policy decision for the University. 295

When the FSI debate resumed in 1990, Cohen and Gunther met with the SCLC and advised them

291F. Hechinger. "About Education," New York Times, June 6, 1990, at B-7.

292K. Bartholomew, supra note 36 at 5.

293Faculty Senate, supra note 239 at 5.

$294 \#$ \#-4 at 3.

295 Id. 
to proceed carefully. 296 They agreed that Tom Grey's second draft was a substantial improvement over the draft written by John Perry. 297 Cohen seemed unsure whether it was possible to draft a policy that identified the specific types of expression for prohibition without having a chilling effect on speech.298 Gunther was certain that any form of the policy would chill classroom speech.299 Opponents of the FSI on the SCLC included white graduate student, Perry Friedman, and mechanical engineering professor, Tom Kane. 300 Both Friedman and Kane cited ambiguities in the policy and its potential impact on controversial but important campus discussions as reasons for their opposition. 301

\section{Conditions Following Adoption of the Fundamental Standard Interpretation}

\section{Introduction}

Like the University of Wisconsin, Stanford University took several steps to help create a more productive and satisfying environment for its minority students. The adoption and promulgation of the FSI was only one such step. Because multiple methods were implemented to achieve the University's community enhancement goals, changes in campus racial relations cannot be attributed to one source, nor can the force or weight of the individual events or programs be reduced to numerical representation.

Likewise, the academic behavior of students and faculty, and the racial climate on campus are affected by

296P. Rapalus, supra note 230.

297 Id.

$298 / d$.

$299 / d$.

300P. Rapulus, supra note 36.

$301 / d$. 
other variables in addition to the FSI. Time could be considered such a variable. Because the major

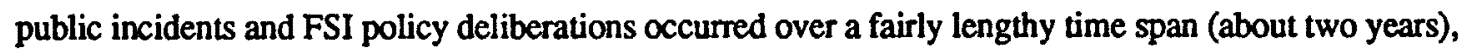
the community's ability and willingness to sustain interest in the issue probably ebbed and flowed.

\section{Racial Relations After June 11.1990}

The complexity of Stanford students' racial and ethnic backgrounds existed before, during and after the policy's adoption. The University's non-policy community enhancement efforts also continued after the promulgation of the FSI. Although not necessarily related to the FSI, several informants (of different races) said that social segregation was a strong force affecting racial relations at Stanford in 1991. White students interviewed reported sensing divisions among races early in the first year.302 One white student commented,

[M]ost minority groups are isolated in small groups on campus. I realize they need to feel supported. They all seem to have a goal of integration with the larger community, but it is unsolved. There is pressure for minority students to become involved in minority student groups. ${ }^{303}$

A white administrator found misunderstandings about the issues and the needs of various communities by non-members of those communities. She associated the lack of understanding among the groups with a lack of interaction among them. 304 A black student acknowledged that many blacks were perceived by non-blacks to be separatist, and that this perception affected non-blacks reactions to black students. ${ }^{305}$ Some inter-racial relationships among students were characterized as insincere and/or superficial, but these

$302 \#$ S-17 at 2.

$303 / d$.

304 \#S-10 at 4. This interview participant remarked the group that suffered most from the misunderstandings of others were students with physical disabilities. 
critics also believed that meaningful relationships could grow out of initially superficial interactions. 306 One white student characterized racial relations as a "systematic estrangement," and an "us-them set up between the African American and the balance of the Stanford community." 307

Some black students continued to experience incidents of prejudice toward them following the adoption of the FSI. Examples of racial bias included non-supportive relationships with certain faculty members, hate-mail received by a black student leader, and an anonymously placed flyer in Ujamaa House that mocked Afro-centrism. 308 One black student compared the content of the negative flyer on Afrocentrism with a party advertisement that had "a picture of Africa and a black warrior with a sword in one hand and the head in another," perceiving the latter to be less offensive to community standards of respect because the authors placed their group's identity on the posters. 309 Since the poster mocking Afrocentrism was anonymous, students who wanted to respond had no individual or group to which they could direct their response. Some Chicano students observed defensive behavior among students who did not support progressive views, and believed that some white students felt attacked when faced with students who asserted opinions about their ethnicity. 310 These students attributed much of the racist behaviors they saw to naivete among white students. ${ }^{311}$

Some students perceived a backlash against "progressive" opinions among a large segment of the

$306 \#$ S-2 at $4 ; \# S-9$ at 1.

$307 \#$ S-14 at 8.

$308 \# S-13$ at $4,6,7$.

309 \#S-13 at 7.

$310 \#$ S-9 at 2.

$311 \#$ \#-9 at 2. 
University community, and they linked the political correctness debate with the adoption of the FSI. 312 In other words, some "progressive" black students believed that following the adoption of the FSI, "conservative" students at the University were empowered to speak out more during a time when it became fashionable (nationally and locally) to criticize political correctness. 313 Some black students believed that racial relations had not changed as a result of the FSI, and that relations might have grown more tense and more separate. ${ }^{314}$ A white student leader thought that students with more moderate political beliefs had been elected to the ASSU during the 1991-92 academic year because, in part, several of the aims of the People's Platform and the Minority Coalition had been achieved in 1990 (including the adoption of the FSI). ${ }^{315}$ A black administrator believed that the adoption of the FSI helped galvanize the more conservative political members of campus to speak out about their concerns. 316

Thus, one's view of whether racial relations were better or worse after the FSI was adopted depended on the beliefs and values held prior to the FSI decision. Students with progressive political beliefs may have perceived their ascension to power in student government and their making changes as better race relations. The subsequent election of political moderates (and conservatives) may have triggered doubt among progressives about the commitment and support for their changes among Stanford students generally, or among University administrators. Students with moderate and conservative political

312 \#S-13 at 9. "Progressive" in this context describes attitudes, values, and political opinions which support fundamental changes in the University's approach to minority issues. Many students associated with "progressive" views supported a broad interpretation of the Fundamental Standard (similar to professor Lawrence's view) that would have proscribed more categories of speech offensive to traditionally disadvantaged groups.

313 "Conservative" in this context describes attitudes, values, and political opinions which supported the maintenance of the University's traditions. Many students associated with "conservative" views supported a narrow interpretation of the Fundamental Standard (similar to professor Gunther's view) that would have proscribed fewer categories of speech offensive to traditionally disadvantaged groups.

314 \#S-13 at 9.

$315 \#$ \#-14 at 3.

316 \#S-8 at 4. 
views likely perceived the events of the late 1980 s to be a time of great tension and frustration. The subsequent election of student moderates may have given other moderates a sense of stability (i.e., "better" race relations for them), even if only temporary. Politically progressive students who believed that they were just starting to be heard in the late 1980 s and in 1990 may have felt that their cause had stalled after the second sit-in in the Presidents' office, described earlier. ${ }^{317}$

Some interview participants observed behaviors among white students best characterized as a kind of disgruntled compliance. The University unequivocally supported diversity, but the language it used to describe the values associated with diversity may have confused students. A graduate student who had examined Stanford's orientation/aculturation process found "people were using as interchangeable [the terms] pluralism, multiculturalism, community, and interactive."318 Some students and student staff members understood "diversity" to be the 'party line' for the University, and believed that this value was one with which they should simply go along and use their best judgment. 319 There was some student resistance to an imposed definition of appropriate culture and community. ${ }^{320}$ There were some white students who felt the FSI imposed a burden upon them. One way the imposition was expressed was through humor.

For a while it got to the point that when a potentially controversial subject was being discussed people would make jokes about the policy. For example, a student might pretend that he was just about to say something racially offensive and then say "oops, I can't talk about that -- I'll get thrown out of housing." 321

Resistant compliance among students may be another form of backlash against the FSI. Although no specific evidence was found indicating a direct link between these attitudes and hostile behaviors among whites toward minority students, one could reasonably argue that repressed resentment among white

317 \#S-9 at 2; \#S-14 at 3.

$318 \#$ \#-6 at 8.

$319 / d$.

$320 / d$.

$321 \#$-17 at 3. 
students would prevent racial relations from moving beyond superficial levels of interaction.

\section{Application of the Fundamental Standard Interpretation}

The FSI was not applied in any case of student misconduct during the first two years of its existence. 322 A few students complained of being victims of discriminatory harassment, but their cases were found not to meet the requirements of the FSI. ${ }^{323}$ One could speculate about the reasons for the lack of judicial activity, but no clear reasons emerged from the data. 324 Most of the cases brought were not considered to present difficult questions of policy interpretation. 325

As related by one campus interview participant, two incidents would likely have violated the FSI had one additional factor been present in each situation. 326 The first case involved two students who were too drunk to remember what happened. An observer heard one of the students call the other students discriminatory terms which would have been punishable under the policy. Charges could have been filed had either the offender or the target remembered the event. According to the FSI interpretation, third party observers (eavesdroppers) have no standing to file charges against offenders. The second situation, according to an administrator, involved a first-year law student, who also attended Stanford as an

322 Phone conversation with \#S-1, July 13, 1992.

$323 \#$ \#-1 at 7.

${ }^{324}$ Here are some of the speculations: 1) white students interviewed did report that they felt more cognizant of their speech about controversial social issues around minority students, making it possible that lack of judicial action is associated with students being more cautious about their public communication on such matters; 2) some critics of Stanford's policy complained that it was written so narrowly as to be meaningless in its practical application, so that the number of cases meeting the interpretation's requirements could be associated with the infrequency of face-to-face racial epithets uttered with the requisite intent to harm; or 3 ) the FSI interpretation was so powerful that it prevented people from violating the civil rights of others. Caution among students in their public discourse may reflect their increased attention to the civility of their communication, or it may indicate that expression was chilled (a fear of FSI opponents). 
undergraduate. 327 The student yelled homophobic epithets at the apartment of a residence hall staff member thought to be homosexual. The staff member was not home at the time, although others witnessed the event. Had the staff member been home, the situation would have warranted charges under the FSI. Since no judicial charges were filed, the secrecy of a judicial trial was irrelevant and the event was well-publicized. Law students signed petitions condemning the actions of the student. The offending student claimed he was testing the FSI, but some observers believe that he was only emboldened to speak because he was drunk at the time. The publicity and the outpouring of opposition to the student's epithets served as an educational experience for the community about the FSI and its limits.

\section{Effects of the Fundamental Standard Interpretation on the Academic Behavior of}

\section{Faculty and Students}

Many of the opponents of the FSI were concerned particularly about the impact of the policy on discussions of controversial subjects dealing with race or other personal characteristics covered in the policy. Most campus informants believed that students and some faculty had been cautious about discussing racial issues in the classroom for a few years before the FSI was adopted. Interviews for this research did not reveal evidence that the policy had any direct impact on the academic behavior of University community members -- behavior that was acknowledged by many persons to be affected already by the cluster of issues commonly referred to as "political correctness."

Some examples of responses related to academic behavior and political correctness are given below. For example, one white student said,

"you can't say some things, and students are cautious to say anything about racial issues. There was definitely a PC attitude among a lot of people that you couldn't talk about racial issues if you were white, and you couldn't talk about gender issues if you were male... and it still exists to some extent." 328

This student identified one of the potential sources of backlash among opponents of the FSI. When students feel shut out of the debate, they may vent their frustration in other ways. This argument works

327 Phone conversation with \#S-1, July 13, 1992. 
for minority students also, who have reported feeling unwelcome and shut out in other venues on campus.

White males, until recently, may not have been aware of this phenomenon. Another white student

believed that the attitude of caution was waning, but he remarked that

...there was a very severe political correctness problem on campus....As an individual it affects me that I am cognizant at all times about what I say. It is not as bad now as it was two years ago (in 1989). In other words, there is less pressure now to not say things that are even remotely controversial in light of a progressive agenda. Here is an example of something you couldn't say; 'the amount to which they are willing to lower their standards for certain groups of students is devaluing a Stanford education.' That is sufficiently far from the acceptable range of speech at Stanford -- you just couldn't say that in public....if you were loud enough, you might actually get sanctioned by the University, but in general, it is just the sanction of social pressure. 329

The editorial staff of The Stanford Daily wrote,

Already the code has had a chilling effect on speech. Although the interpretation is narrow, many students are now more worried about what they say arid more closely guard the expression of their ideas, whether those ideas would actually violate the new speech code or not. 330

This was the only account found at Stanford that accused the FSI of inhibiting speech on controversial matters after the policy's adoption. In response to this editorial, a white administrator believed that the pressure and worry among students existed before Stanford had the new code.331 The student editors wrote the editorial, probably while reflecting on their own understanding of events surrounding the FSI during the previous two years. They may not have been aware of any climate of caution regarding racial issues prior to their arrival at Stanford. A faculty member who confronted issues of government policies and race in his classes believed that

...there is a chilling effect present, not because of any policy, but because of the subject matter. Affirmative action is a particularly controversial issue, and there is a sensitivity among students about offending others and about being perceived negatively...In class only one side is often heard from students regarding affirmative action -- those who speak are for it. ${ }^{332}$

Another faculty member agreed that there was some caution on the part of students to speak up in the

329 \#S-14 at 2, 8.

330Editor. "A chilling effect," The Stanford Daily, November 4, 1991, at 4.

331 \#S-10 at 4.

$332 \#$ \#-5 at 2. 
classroom and other parts of campus, but he believed that is was not related to the FSI since students were afraid of being labelled a racist or a sexist before the policy existed. ${ }^{333}$ A white administrator added,

Outside commentators have identified the policy as responsible for what they see to be a reluctance to express politically unpopular opinions. Anybody who studies the policy would draw the opposite conclusion -- that it is so narrow as to be reassuring. That one is not going to stumble into trouble with the policy that we've got. It is also using the policy as a scapegoat for an era of caution that preceded the development of the new policy....it is just convenient to point at the policy. Those of us who were here before the policy were expressing concern about peoples' reluctance to speak out in classrooms. It is a serious concern, but the caution in expressing opinions is not really related to the policy. 334

One white professor believed there was an anti-intellectual environment in the residence halls because students tended to place greater emphasis on getting along with each other rather than on speaking openly with each other about controversial issues. 335 Thus, she assigned responsibility for students' cautious speech to the influence of social factors rather than any written policy. Finally, a black administrator believed that, at Stanford,

We have a much broader spectrum of viewpoints being heard on campus than was heard several years ago. Part of that related to political correctness and people trying to figure out 'how do we get our ideas and initiatives across.' [Their first attempt was] to do this by saying that people are being forced to be politically correct and that they are not really speaking their mind.... From my perspective the debate about PC is subversive in the sense that it tries to intimidate, and it is lazy. I tell students to stop trying to hide under the cover of $P C$ and talk about what you want to say -say what is on your mind. We acknowledge that there is this thing called "politically correct" and then ask them to move on and say what they have to say. ${ }^{336}$

Most of the evidence indicated that social pressure was responsible for students' (and faculty) behaviors of self-censorship, not the FSI. Too, several sources of data suggested that social pressure to self-censor had been in place well before the FSI was adopted. Some members of the community may have perceived that the FSI was a form of official support for "politically correct" beliefs about race. Students fear of speaking out on issues of race was linked also to their desire to be accepted by their peers

$333 \#$ \$ -3 at 1.

334 \#S-1 at 1.

335 \#S-16 at 1.

336 \#S-8 at 5. 
and with their naivete and inexperience with persons from other races. Still others at Stanford thought of the FSI as a statement of institutional values promoting equal educational opportunity and the assurance of freedom from personal harassment while on campus.

No charges have been filed in classroom settings (or anywhere else on campus) under the FSI. The two cases described above as potentially close judgment calls were both in nonacademic settings. Some students and administrators believed that clever Stanford students could achieve the effect of demeaning their targets without offending the FSI. 337 If students with bigoted agendas could still achieve the same outcome without punishment, simply by selecting more sophisticated language (i.e., no epithets), perhaps it was the mode of communication that was being suppressed at Stanford rather than the content of the speech.

\section{Conclusion}

The most consistent positive result attributed to the FSI was that it allowed for a tremendous amount of discussion about the values associated with free expression and about how those values affect various stakeholders in the University. One faculty member described the FSI discussion as a "three year teachable moment" at the University. ${ }^{338}$ Nearly everything that was said about the FSI was written and preserved. The University administration purposefully used the issue as an educational tool while working to reach an acceptable resolution to the issues. Stanford also used the policy as a means to spark discussion among first-year students about issues of diversity and respect for others.

At this writing, the future of the policy is unclear in light of the Supreme Court's decision in R.A.V. v. St. Paul, and due to the arrival of Stanford's new president, Gerhard Casper, whose academic area of expertise is constitutional law. The majority opinion in R.A.V. seems to reject both the FSI and the rationale developed for its support. The part of Stanford's policy most offensive to the recent Court ruling is the policy's uneven application. Under the FSI, traditionally disadvantaged groups receive

337 \#- 1 at $8 ; \# S-9$ at 3. 
greater protection than whites. Even the R.A.V. Court's minority opinion supported the even-handed application of similar speech policies.

The impact of the policy also remains unclear, in part, because it has yet to be applied to a specific judicial case. No sociological or psychological study exists to substantiate the claim that Stanford students have self-censored their expression from a fear of punishment under the policy. Much of the anecdotal evidence collected for this case study indicated the presence of self-censorship during students' controversial discussions long before the FSI. The absence of negative evidence regarding the policy's impact should not be sufficient, in and of itself, to evoke endorsement. The issue may fade further from the foreground of the community's attention until a new bias-related controversy tests the policy, or until the University attempts to rescind the FSI for legal reasons presented recently by the U.S. Supreme Court. 


\section{Chapter Six}

\section{University of Virginia}

This chapter describes the considerations and events preceding and following the decision to reject a policy specifically designed to define and limit racially offensive speech at the University of Virginia (UVA). The first section presents the historical, structural and organizational factors and conditions that provided the context in which the proposal for an additional, or thirteenth standard of student conduct (13th Standard) developed.1 Next, a description is provided of the racial climate prior to the development and eventual rejection of a proposed policy. The third section documents political factors and conditions important to the development of the 13th Standard. The fourth section includes a general chronology of events surrounding the presentation of the proposed policy and a discussion of the rationales of the policy's supporters and opponents. The last section delineates some of the outcomes of the University's rejection of the 13th Standard, including the application of the existing relevant standards of conduct, and the impact of the decision on racial relations and academic behavior.

\section{Historical. Structural and Organizational Factors and Conditions}

This section presents some of the historical factors, traditions, and values that shape the environment at UVA. Included among the structural factors presented are student demographic data and descriptive information about the institution. Organizational factors are detailed relating to the process for adopting non-academic regulations and to the key persons involved in the discussion of a 13th Standard.

1 The University of Virginia's student conduct code contains twelve Standards of Conduct. The code is described and analyzed in Chapter Two (pp. 32-35). Appendix " $E$ " lists the twelve standards. 


\section{Historical Factors and Conditions}

The University of Virginia was conceived, designed, and founded by Thomas Jefferson in 1819.2 The University was chartered by the General Assembly of the Commonwealth of Virginia in that same year. ${ }^{3}$ Mr. Jefferson's University welcomed its first students in 1825 to study areas of practical importance for their future lives of public service. 4 Jefferson's novel ideas included the inclusion of a wider range of study than was available at other universities, religious freedom, and student selfgovernance.5 His ideas are also preserved in the architecture of the University in the "academical village" he designed, now widely acclaimed for its style and functional character. 6 Jefferson's influence on the current life of the University and on its history are unmistakable and profound. An understanding of the University of Virginia requires an appreciation for the lingering influences of its founder and his values.

Several Jeffersonian traditions still exist. Jefferson wrote of the land occupied by the University as the "Grounds" rather than as the campus. At UVA, when addressing male faculty members who hold the Ph.D. (but not the M.D.), it is considered proper to use the term "Mr." rather than "Dr." in order to keep the faculty from holding a title of higher stature than Thomas Jefferson, since Jefferson did not hold a doctorate. The University is often called "Mr. Jefferson's University" to recognize his contributions and his influence over the institution. One Jeffersonian scholar noted,

The most distinctive and significant element in Jefferson's design for the University of Virginia was his commitment of the institution to the principle of intellectual freedom. "This institution of my native state, the hobby of my old age," he wrote in 1820 , "will be based on the illimitable freedom of the human mind to explore and expose every subject susceptible of its contemplation. For here we are not afraid to follow truth wherever it may lead, nor to tolerate any error, so long as

2Rector and Visitors of the University of Virginia. Graduate Record 1990-91, Charlottesville (VA): Office of the University Registrar, 1990, at 6.

3Id. at 8.

4ld. at 6.

5ld.

$6 / d$. 
reason is left free to combat it."7

Some of the enduring reminders of Mr. Jefferson at UVA include several statues, his quotations in nearly every University promotional publication and every speech on Grounds, the preservation of historical gardens with plants from his day, and pictures of him in the student newspapers.

Student self-government remains a strong tradition at UVA. Both the academic and non-academic student judicial bodies are nu completely by students. ${ }^{8}$ Cases are initiated, investigated and tried by students. ${ }^{9}$ Students affairs professionals are available for consultation and to assist with training of student members of the judicial bodies. The staffs' operating philosophy (for educational and historical reasons) allows students to manage their own affairs to the greatest extent possible. Many members of the UVA community regard the Honor System as the best and most important example of student selfgovernment. 10 Other examples of student self-government include: the Inter-Fratemity Council (IFC) which is responsible for setting policies and assuring compliance among Greek organizations; two daily student newspapers and several weekly and monthly student publications (operated without faculty or administrative oversight); residence hall governments; and student representation on most campus committees. Members of the University community, and students in particular, hold high expectations in

7J. Wagoner. "Thomas Jefferson: America's First Education President," Briefing paper prepared for the Presidential Summit at the University of Virginia, September, 1989, at 3. Jefferson was particularly concerned about the religious freedom of Americans of his day. The second sentence of this quote by Jefferson appears as a permanent heading above the opinion section of The Cavalier Daily, and it is used regularly in other publications around The Grounds.

${ }^{8}$ Cases are reviewed by the vice president for student affairs, and they are reportedly seldom overturned (\#V-3, p. 3). The president is authorized by the Board of Visitors "to impose such penalty as he may deem appropriate" (UVA Graduate Record, "Non-Academic Regulations," at 27) and this authority has been delegated to the student-run, University Judiciary Committee.

- Faculty members can bring honor charges against students and they can appear as witnesses at trial, but faculty play no part in the decisions of the Honor Committee or the University Judiciary Committee. The Dean of Students Office (and other college officials) can initiate non-academic charges against students, but the investigations and trials are completed by students.

10The Honor System applies to cases of lying, cheating or stealing only. 
theory and practice for student self-government.11

The University of Virginia's fairly recent history as an all-male and all-white university may affect current race relations on Grounds. UVA is part of a larger social and educational history that was influenced by its legal relationship to the Commonwealth of Virginia and its location in the southeastern United States. Vestiges of slavery and of separate social and educational spheres for blacks and whites remained in parts of the South well into the 1960s, and some linger in the 1990s. Virginia was among 17 southern states that made racial segregation part of state law following the U.S. Supreme Court's decision in Plessy v. Ferguson in 1896.12 Higher education in Virginia included institutions for whites and institutions for blacks. The Commonwealth contains five historically black universities, two of which are state supported. Even the state's black graduate students who were studying subjects taught only at the University of Virginia were denied access to the University -- the Commonwealth had enacted a fellowship program that gave the students vouchers to attend institutions outside of Virginia. ${ }^{13} \mathrm{~A}$ lawsuit against segregation in Virginia resulted in a federal court order requiring the University to enroll its first black student in the Law School in 1950.14 The first black student was admitted to the Undergraduate College of Arts and Sciences (the heart of the undergraduate education) in 1961.15 In 1969, 37 blacks were enrolled at the University, and by 1975 , the number of blacks had risen to almost 500.16

11The successful implementation of this philosophy, especially the judicial functions, is somewhat unusual in a setting as large as the University of Virginia.

12M. Reisler (chair). "Report of the Task Force on Afro-American Affairs," University of Virginia, June, 1987, at 3. Plessy v. Ferguson 163 U.S. 537 (1896).

13M. Reisler, id. at 3.

$14 / d$. at 4 .

$15 / d$.

16/d. at 1,5 . 
By 1991, nearly 1700 black students were enrolled at UVA. 17

Because of the long legal, social, and educational history of the segregation of blacks in the South, most compensatory programs instituted by Virginia's traditionally white universities target black students.

A dominant element that has overshadowed the process by which the University has attempted to come to grips with the presence of blacks has been the Virginia Plan for Equal Opportunity in State-Supported Institutions of Higher Education [(the Virginia Plan)]. This plan, which was first developed in 1974 and reformulated in 1977 and again in 1978 and 1983, was the Commonwealth of Virginia's response to a federal court order to desegregate the state's racially divided system of higher learning....Virginia's response to this legal mandate...included the setting of numerical objectives and timetables for the enrollment of black Virginians in each of the state's formerly allwhite institutions and of white Virginians in each of the state's formerly all-black institutions.... The impetus to recruit blacks did not emanate from within the institution, but was superimposed by an outside and, to some, alien, even illegitimate authority. Thus, the University's compliance over the years has often been characterized more by proper form than heartfelt substance. 18

Hispanic, Native American, Asian, and other ethnic minority students generally have not been considered traditionally disadvantaged groups to the same extent as blacks. 19 Virginia's situation differs from both Stanford and Wisconsin where targeted minority groups included Native Americans and Hispanics.

The University of Virginia began to enroll undergraduate women on a similar basis as men in 1970.20 This situation differs from the other universities in this research in that Stanford was founded as

\footnotetext{
17Office of Institutional Planning and Studies. "Fall 1991 Enrollment," University of Virginia, 1991.
}

18M. Reisler, supra note 12 at 25-26. The Commonwealth of Virginia developed the "Virginia Plan" in response to a federal court order issued by a Washington, D.C. judge. The court order responded to a case (Adams v. Richardson) filed by the NAACP Legal Defense and Education Fund against the then Department of Health, Education, and Welfare. The NAACP contended that the Department failed to enforce Title VI of the 1965 Civil Rights Act. The Adams cases originated in 1970 and continued in appeal through 1987. The appeal process resulted in the three reformulations of the Virginia Plan.

19This condition is evolving as more Hispanic and immigrant Asian populations move into Virginia. Still, in 1992, the University's legal obligations and affirmative duties related specifically to blacks.

20The situation at UVA was not unique in the Commonwealth of Virginia which, in general, operated only single-sex colleges and universities. This policy was ended by many 
a coeducational university, and Wisconsin began admitting women as early as 1863.21 The University of Virginia's relatively recent exclusion of women, like its exclusion of blacks, influences the way in which traditionally excluded groups approach the University with their concerns. That is, traditionally excluded groups may use the exclusioniary parts of the University's history as a political rallying point.

There was an attitude among some members of the UVA community (including alumni) that "THE University" was different (i.e., perhaps better) than other institutions of higher education.22 The attitude existed in the late 1960s during the University's debate over coeducation when opponents of change warned of creeping "State-U-ism," and they believed that UVA should not follow the direction of its contemporaries on this and several other issues. "State-U-ism" referred to some characteristics associated with large state universities, such as nationally competitive athletics programs, large marching bands, agricultural and technical courses of study, and homecoming parades. All of these programs have been criticized at UVA. The arguments against State-U-ism were made by persons who valued tradition and sought to maintain those traditions. This attitude persisted among some segments of the University in the 1980s, and it may have influenced some community members' attitudes as they contemplated changes in the existing Standards of Conduct.23

The University culture preserved and defended many traditions. Traditions generally were accorded more prestige and respect than were changes and innovations. Although each campus values its own

Boards of Visitors of individual institutions in the late 1960 s under the threat of courtimposed coeducation. By 1984, there were five all-male colleges in the United States --three were located in Virginia (Washington \& Lee University, Virginia Military Institute and Hampden-Sydney College).

21B. Solomon. In the Company of Educated Women, New Haven: Yale University Press, 1985 , at 53,57 .

22Students' automobiles frequently display a window decal that says, "THE UNIVERSITY." The inference one is intended to draw from this is that UVA is the preeminent institution of higher learning. The phrase, "THE University" (pronounced thee university) is understood widely in the state of Virginia to refer to the University of Virginia. Many members of the University community may perceive this phrase as a symbol of institutional pride, while others (especially outsiders and egalitarians) may perceive that those who use the phrase are smug and haughty. 
traditions, UVA promoted its traditions as part of the institutional ethos in more overt and identifiable ways than either Stanford or Wisconsin.

\section{Structural Factors and Conditions}

The University of Virginia is a public research I university (Camegie Foundation classification), and it is the flagship university of the Commonwealth of Virginia. Among the University's 17,600 students, the College of Arts and Sciences enrolls nearly three fourths $(8,300)$ of the 11,300 undergraduates and about one fourth $(1,700)$ of the 6,300 graduate students. 24 UVA is also home to highly selective professional schools of law, business, and medicine, in addition to six other schools. Virginia's state government recommends to its public universities that $65 \%$ of their undergraduates should be Virginia residents. 25 The University's 1987-88 Annual Report stated that "one survey found the University to be one of the twenty most selective universities and colleges in the nation -- and the most selective of all state universities." 26 Over 17,000 applicants competed for 2,500 spaces in the $1987-88$ first year class. 27 In 1991, UVA's operating budget exceeded $\$ 750$ million while it employed over 2,000 full-time faculty members and totalled over 9,000 full-time employees. 28 The University of Virginia, considered one of the "public ivy"s," has the largest endowment of any single public university or college in the U.S.29 The University, located centrally in the state, occupies over 1,000 acres of land in

24 Office of Institutional Planning and Studies, supra note 17.

$25 \# V-2$ at 1.

${ }^{26}$ Rector and the Board of Visitors. The University Report 1987-88, Office of University Publications, University of Virginia, 1988, at 11.

$27 / d$.

28Rector and Board of Visitors. President's Report 1990-91, Office of the President, University of Virginia, 1991, at $30,38$.

29 The Chronicle of Higher Education Almanac. "College and University Endowments over \$65-Million, 1991," August 26, 1992, at 35 (original source: National Association of 
Charlottesville, Virginia. ${ }^{30}$ Richmond, the state capital, is situated 70 miles to the east, and Washington, D.C. is 120 miles to the northeast.

Black students make up the University's largest racial minority group. In 1981, there were 1,100 black students (graduate and undergraduate) comprising nearly $7 \%$ of the student body. ${ }^{31}$ The percentage of black students dropped slightly during the mid-1980s to $6.5 \%$ in 1987.32 Substantial increases in black first-year student enrollments began to occur in 1988.33 By the Fall, 1991, there were 1366 black undergraduates (12\%) and 323 black graduate students (5\%) comprising almost $10 \%$ of the total student body. 34 The first-year class in the Fall, 1991, consisted of approximately $14 \%$ black students. ${ }^{35}$ Nearly $19 \%$ of all Virginia state residents are black. 36

College and University Business Officers). UVA's endowment ranks 26th overall in the U.S., and it is exceeded among public institutions only by the Texas A\&M University System and the University of Texas System.

30Rector and Visitors of the University of Virginia. Graduate Record, 1990-91, at 6. Clinch Valley College, located in Wise, Virginia, exists as a self-supporting satellite campus of UVA to serve the needs of southwest Virginia. The Chancellor of Clinch Valley College reports to the President of UVA. Policies relating to student life at Clinch Valley College originate and apply only to that campus, subject to Board approval, and an analysis of its policies and situations are not included in this case study.

31M. Reisler, supra note 12 at 11. The UVA enrollment patterns followed national trends of predominantly white institutions throughout most of the 1980 s during which the percentages of black undergraduates exceeded the percentages of black graduate students.

$32 / d$. at 21.

${ }^{33}$ A. Griffiths. "University steps up 1988 black enrollment," The Cavalier Daily, August 30, 1988, at 1. See also, T. Scott, "Few blacks drawn from small field," The Cavalier Daily, September 2, 1986, at 1.

34 See supra note 17.

$35 \# \mathrm{~V}-7$ at 8.

${ }^{36}$ No author listed. "Virginia," The Chronicle of Higher Education, August 28, 1991, at 97. This statistic is listed primarily as a comparison with black demographics in Wisconsin and California. The reader will recall that there are two state-supported historically black 
Asian American and Hispanic groups have experienced similar growth at UVA. In 1991, Asian American students accounted for $8 \%$ of all undergraduates and $3 \%$ of all graduate students. 37 The percentage of Asian American students increased at a rate of about $1 \%$ per year throughout the mid1980s. 38 Hispanic students made up about $1 \%$ of all students, and Native Americans comprised about $0.1 \%$ of all students. 39 About $6 \%$ of the University's students are from foreign countries. 40 Approximately 14,000 white students (79\%) are enrolled at UVA.41

\section{Organizational Factors and Conditions}

\section{Administrative Process for Adopting Non-Academic Regulations}

The University's Board of Visitors has authority over all policy, personnel and financial matters of the University. The Governor(s) of Virginia, who, through the 1980 s and 1990 s have been Democrats, appointed UVA Board of Visitor members. Each university in the Commonwealth operates under the guidance and authority of its own Board of Visitors. The State Council of Higher Education in Virginia (SCHEV) serves as the coordinating agency for higher education institutions in Virginia. Unlike the University of Wisconsin System, individual university Boards may promulgate their own policies and

universities in Virginia, in addition to several other historically black institutions in and near Virginia. The racial composition of many predominantly white universities is affected by the presence and strength of Virginia's historical black institutions.

37Office of Institutional Planning and Studies, supra note 17. See also, id. at 97; Asian Americans represent less than three percent of the population of Virginia.

${ }^{38}$ A. Griffiths, supra note 33.

39See supra note 17. See also, supra note 36 at 97 . Hispanics represent less than $3 \%$ and Native Americans less than $0.2 \%$ of Virginia's population.

$40 / d$.

$41 / d$. 
regulations consistent with state and federal law. At UVA, changes in the Standards of Conduct for students require Board approval.

The student-run University Judiciary Committee (UJC) took a lead role in approving any policy changes or additions to the existing Standards. 42 The UJC's primary functions are to oversee the adjudication of cases of students charged with violations of the University's twelve Standards of Conduct and to sponsor educational programs about student conduct matters. 43 Other individuals and/or groups on Grounds may bring issues to the attention of the UJC in order to seek its advice, approval or support. A group or individual desiring changes in the Standards would have had to build consensus among all of the groups -- including the UJC -- affected by the policy change. Student policies that have legal and public relations ramifications are reviewed by the Office of the General Counsel, the chief student affairs officer, and the president. 44 No other committee or administrative structure existed solely for the purpose of creating conduct rules.

When asked who would have to be influenced favorably in order for a 13th Standard to be adopted, a senior administrator responded, "the dean of students, the vice president for student affairs, the president, and the Judiciary Committee." 45 To that same question, an elected student leader believed the required support must come from the president and the Board of Visitors. 46 Another senior administrator stated,

42The UJC is composed of judges, elected annually, from each of the academic schools of the University. The Committee hears all cases of alleged student misconduct, except cases involving sexual assault, student health services, or a student's contractual responsibilities with the University. Investigators are selected among student candidates by the Committee to gather and present the facts of each case. A separate First-Year Judiciary Committee exists to handle the special issues associated with first-year undergraduates. The UJC reviews all of the decisions made by the First Year Judiciary Committee. (T. Butler, ed. The Hook Book, University of Virginia Student Council, 1991-92, at 17).

$43 \#$ V-3 at $1,3$.

$44 \# \vee-7$ at 5 .

$45 \# V-4$ at 3. This participant also said that the general counsel would be consulted because of the legal issues involved.

$46 \# \mathrm{~V}-3$ at 2. 
Our challenge was to make clear to everyone that the Board of Visitors has really delegated the initiation of the process to the UJC. If the dean of students or the vice president for student affairs or the president were to recommend a student conduct policy without a recommendation from the UJC, the Board ought simply to reject it. The administration had no standing to bring it forward.47

Typically, the president of the University would present proposed changes in the Standards of Conduct to the Board of Visitors following this ad-hoc process of consensus-building. Members of the Board of Visitors preferred to act on policy matters, such as student conduct, that had been widely addressed by the campus community, and the Board members expected the University administration to have developed a position on the issues presented. 48 The Board of Visitors' Manual indicated that the president had the responsibility for the discipline of students with the power to impose appropriate penalties. 49 The Board may choose to hear issues that are of importance to particular Board members or issues that could lead to litigation. A student affairs administrator observed that "you're not going to get much done at the University of Virginia if you don't do it in a cooperative manner. I don't care who you are." 50 This may have been especially true in a policy-making arena like UVA's that had few written rules.

\section{Key Personnel in the Development of the Proposed Policy}

The persons who were involved most closely in the 1988-90 discussions about the proposed 13th Standard were many of the individuals who held positions noted in the previous section. However, the debate occurred primarily among students within particular student groups. The most active students in the discussion were the leaders of the Black Student Alliance (BSA), the Lesbian and Gay Student Union (LGSU), Student Council, the University Judiciary Committee (UJC), and the student newspaper staffs (The Cavalier Daily (CD) and The University Journal (UJ)).

Administrative offices with substantial involvement in the discussion of the 13th Standard included

$47 \# V-8$ at 2.

$48 \# V-7$ at 5.

$49 \#$ V-4 at 3.

$50 \# V-6$ at 2. 
the Offices of the Dean of Students, Vice President for Student Affairs, General Counsel, and President. The most active staff member in the Dean of Students Office was a young assistant dean who was a recent graduate of UVA. 51 The vice president for student affairs, Emest H. Em, has worked at UVA for more than 25 years, most of which time he has served as vice president. The general counsel, James J. Mingle, advised the president on all legal matters affecting the University. Two presidents served during the relevant time period of the discussion at UVA. Robert M. O'Neil served as president of UVA from 1985 1990. Mr. O'Neil's academic background is in constitutional law and, more specifically, in First Amendment law. He has published articles on discriminatory harassment in several journals, including AGB Reports and The Chronicle of Higher Education. 52 Mr. O'Neil argued consistently that educational alternatives to speech codes should be implemented. John T. Casteen succeeded O'Neil as president during the Summer of 1990. Casteen, a former UVA dean of admissions and English professor, arrived most recently from the University of Connecticut at Storrs where he served as President. While President of the University of Connecticut, his administration implemented a policy prohibiting discriminatory verbal harassment that was later found to be unconstitutional.53 The Connecticut policy on harassment was rewritten and adopted in February, 1990.54

$51 \# \mathrm{~V}-2$ at 4.

52R. O'Neil. "Colleges Should Seek Educational Alternatives to Rules That Override the Historic Guarantees of Free Speech," The Chronicle of Higher Education, October 18, 1989, at B-1, 3. See also, "The Pitfalls of Stifling Campus Speech," AGB Reports, January/February 1990, at 12-14.

53B. Zenner. "Sticks and Stones: What can be done about campus hate speech?" Albemarle Magazine, Fall 1990, at 46-47, 72-77.

54J. Casteen. "President's Policy on Harassment," Student Handbook 1990-91, University of Connecticut, at 83-84. The policy was not challenged prior to the R.A.V. v. St. Paul decision in 1992. 


\section{Racial Climate Prior to the Rejection of a 13th Standard of Conduct Introduction}

Most of the data described in this section relate to events and conditions during the 1980 s and 1990 , and specifically from 1986-1990. Statements reflect the views of campus informants, newsprint articles, institutional self-studies, and other documents. This section chronicles the major public racial incidents important to the discussion about a 13th Standard. Non-public and other bias-related circumstances are also described. Next is a summary of the University's experiences with the recruitment and retention of minority students. The conclusion is a presentation of students' perceptions of campus race relations. A substantial portion of the data presented in this section came from student newspaper accounts.

A group of black and white students occupied President O'Neil's office during the Spring, 1986, protesting the University's investment policy in South Africa, and to express their anger with the university administration's alleged caution in confronting racial issues at the University. 55 Events in the Spring led the University to re-evaluate the role of the Office of Afro-American Affairs prompting President O'Neil to convene a task force during the summer of 1986 to study issues of importance to black students. 56 In October, 1986, the Board of Visitors expressed its increasing concem about race relations. 57

During the 1986-87 academic year student newspapers at UVA published frequent commentary and articles about racial issues. Major features detailed calls for divestment of the University's endowment funds from businesses in South Africa. Also questioned were black athletes' admissions credentials, the selection practices of the UVA Law Review, and allegations of bias against black students in the

55M. Reisler, see supra note 12 at 13.

56/d. at 14.

$57 / d$. at 15. 
University's Honor System. 58 One student editorial stated,

The University of Virginia, for all of its many merits and qualities, has been plagued for years by a problem that can no longer be ignored. Not only has the status of minority students at the University been a consistent topic of debate in student media, but recently released Class of 1987 exit interviews list minority-related issues as the most pressing problem at the University. 59

A few months earlier, the Task Force on Afro-American Affairs had concluded,

The mere elimination of flagrant and overt racial barriers, the admission, under legal pressure, of black students,...the recruitment of a relatively small number of black faculty members and lower level administrators (many of whom have chosen not to remain here), the initiation and tenuous maintenance for the past decade of a student-demanded, unclearly defined Office of Afro-American Affairs, and the less than enthusiastic offering over the years of a handful of transitory, underfunded academic programs for students with special needs do not, taken together, constitute achievement of genuine integration at the University of Virginia. 60

A fourth-year student observed that "blacks and whites consistently and constantly accuse the other of being at fault. Rarely is there a search for conciliation that can last and, most importantly, there is negligible self-examination as to the causes of continued discord."61

When asked about race relations at UVA during the late 1980s, interview participants indicated that there were some problems, but the levels of tension and interaction were not unusual. One black administrator stated that "people seemed to get along pretty well. But black students and white students don't do much together except go to the same classes....Students tolerate each other, but don't do much

58 See e.g., J. Bostic, "O'Neil discusses black recruitment," The Cavalier Daily, September 24, 1986, at 1; See also, T. Theiss, "Honor jury convicts Sweat in open trial," The Cavalier Daily, November 3, 1986, at 1; T. Scott, "Black leaders air criticisms," The Cavalier Daily, November 12, 1986, at 1; D. Lewis, "Blacks express concerns," The Cavalier Daily, November 19, 1986, at 1. L. Wilson and I. Ellis, "Furthering a racially explosive atmosphere," The Cavalier Daily, November 20, 1986, at 3; A. Conner, "Racial issues addressed," The Cavalier Daily, February 2, 1987, at 1; M. Ahearn, "A year of controversy for Honor Committee," The Cavalier Daily, April 24, 1987, at 6; C. Smilk, "Progress characterizes minority groups' efforts," The Cavalier Daily, April 24, 1987, at 6.

59D. Yalof. "Glaring Problem," The Cavalier Daily, September 1, 1987, at 2.

60M. Reisler, see supra note 12 at 21.

61D. Fowler. "Self-education can help resolve racism," The Cavalier Daily, October 9, 1989 , at 2. 
more than that."62 Others' perceptions may have been influenced by their previous experiences or their expectations for racial harmony. A white student said,

I'm from Georgia, so coming to UVA was like arriving in daylight out of midnight. There were some problems. Any environment in which [racial incidents] can occur obviously has some problems. There was a higher degree of openness than I was accustomed to, and....almost all of the various minority groups have some support group. 63

One white administrator believed that race relations during the late 1980 s were "quite good....a healthy environment," and he pointed to many educational events and forums as evidence of the kinds of positive communications that were occurring among the races. 64

\section{Major Public Incidents}

In March, 1987, during an already racially tense period, vandals attacked a bulletin board located across from the University's Upward Bound Program Office. 65 Upward Bound offered basic skill development and educational counseling for educationally disadvantaged students. 66 The vandals tore down all the flyers from the bulletin board and etched into the board a large swastika with the letters KKK underneath. 67 The program's director stated that the office was "victimized by racist vandalism because no other bulletin board or door was defaced, despite one being directly across the hall from ours. ${ }^{468}$ President

$62 \# V-6$ at 3. See also, \#V-1 at 2; \#V-4 at 4.

$63 \# V-3$ at 3.

$64 \# V-8$ at 4.

65C. Miller. "Staff wishes to halt Cabell vandalism," The Cavalier Daily, March 31, 1987, at 1.

$66 / d$.

$67 / d$.

68/d. Reports of the incident never stated that the Upward Bound Program was created 
O'Neil condemned the act in an open letter to the community released the day after an account of the story was published in the student newspapers. ${ }^{69}$ O'Neil said that the penalty for such offenses could be as high as is legally permissable, but emphasized that "the appeal is to the conscience."70 There was no evidence to suggest that the incident prompted any public discussion about how the Standards of Conduct might apply in this situation.

Although no major racial incidents were reported during the 1987-88 academic year, the University community publicly dealt with many racial issues. Student editorials addressed issues of honor system racial bias, affirmative action, and the separateness of black and white communities. ${ }^{71}$ Student media attention focussed on rallies against Apartheid in South Africa and the University's investment policies, as well as the University administration's reaction to the Report of the Task Force on Afro-American Affairs. 72 A large group of black students, disappointed with the University's response to the Task Force Report and to race relations in general, held an "emergency meeting" that was closed to reporters who

for and utilized by a large number of black students, although this was clearly implied by the program director's statements. 1 .

${ }^{69} \mathrm{C}$. Smilk. "Vandalism denounced by O'Neil," The Cavalier Daily, April 3, 1987, at

$70 / d$.

71See, e.g., T. Theiss. "Leaders plan interracial action, The Cavalier Daily, September 1, 1987, at B-11; B. Rathet, "Put an end to 'separate but equal," The Cavalier Daily, October 16, 1987, at 2; T. Fessenden, "Rejecting false "community of togetherness," The Cavalier Daily, October 22, 1987 at 2; T. Gross, "Racial tolerance should be stressed," The Cavalier Daily, December 1, 1987, at 2.

72See, e.g., L. Magee, "Rally gathers following," The Cavalier Daily, October 16, 1987, at 1 (400 students participated in a rally for racial justice focussing on South Africa); C. Repak, "Coalitions plan 50-hour vigil," The Cavalier Daily, January 20, 1988, at 1; M. Perry, "O'Neil reacts to report," The Cavalier Daily, February 5, 1988, at 1; M. Perry, "BSA annoyed by O'Neil's response," The Cavalier Daily, February 17, 1988, at 1; M. Perry "Report causes tension," The Cavalier Daily, February 18, 1988, at 1; One story reported that race relations had improved during the Fall, 1987; see M. Perry and T. Theiss, "Cultural diversity at the University," The Cavalier Daily, February 5, 1988 at 5. 
refused to sign a pledge agreeing not to report what happened at the meeting. ${ }^{73}$ Later that week, about 100 black students expressed their displeasure with President O'Neil's response to the Task Force Report by refusing to attend a dinner at the president's home to which they had been invited. ${ }^{74}$ In April, 1988, four student groups at the UVA Law School initiated petitions calling for an investigation into remarks allegedly offensive to blacks made by law professor, Douglas Leslie. 75 Leslie vehemently defended his conduct as being neither racist or sexist but closely related and appropriate to the subject matter of the employment discrimination class. 76 In a year-end summary a student reporter wrote, "[t]his year, minority students were anything but quiet. From the black student community's protest on Carr's Hill to the Lesbian and Gay Student Union's public display of affection, 1987-88 was a year of minorities

73A. Bell and B. Rathet. "Black leaders hold emergency meeting," The Cavalier Daily, February 25, 1988, at 1 . See also, F. Guckes, "Community responds to chapel event," The Cavalier Daily, February 26, 1988, at 1 . The black students' requirement of the no reporting pledge for members of the press brought negative reactions from student reporters and editors, and it raised the issue of the newspapers' portrayals of black students.

74M. Perry. "Blacks stage demonstration," The Cavalier Daily, February. 26, 1988, at 1. Students' letters to the editor criticized the caption for the story. See, K. Bland and D. Mosley, "Black students' meeting unjustly criticized," The Cavalier Daily, February 29, 1988, at 2; B. Galinsky, "Newspaper deserves mistrust of Alliance," The Cavalier Daily, March 2, 1988, at 2; Galinsky wrote,"I think the BSA members have a legitimate concern about surrendering themselves to the irresponsibility of a newspaper that lets sour grapes color its view of events. It is also funny that The Cavalier Daily, which purports to support the concerns of the BSA, should use this one event to try to give it as much negative publicity as it possibly can." The newspaper staff's actions are open to interpretation. The quotation is included to illustrate the distrust that developed between the newspaper and some black students.

75W. Alcorn and E. Thiel. "Professor's Comments Questioned," The Cavalier Daily, April 15, 1988 at 1. Leslie was not confronted by members of the class. Instead, students in the class who were offended brought their complaints to one of the groups sponsoring the petition (Black Student Law Association, Virginia Law Women, Jewish Law Students, and Association of the National Lawyer's Guild).

76K. Hurdman and M. Ahearn. "Leslie gives response to allegations," The Cavalier Daily, April 19, 1988, at 1. Leslie argued that his remarks were misrepresented and taken out of context. 
speaking out about their grievances."77

In October, 1988, the first of two incidents occurred that were most often associated with the discussion about need for a 13th Standard. The situation began when members of Phi Gamma Delta fraternity (Fiji) created and distributed a party advertisement that was found to be offensive by some black students and black student leaders. 78 The flier depicted the "Fiji man," a symbol used by Fiji chapters nationwide, standing by a doorway and acting as a bouncer at the party.79 On the drawing of the party entrance, two signs appeared which read: "UVA I.D. required," and "no: geekins, fish or short wops, and please, no nega babes." 80 The reaction by some black students to what became known as "the Fiji flier incident" marked the first time in which persons in the UVA community suggested a policy to restrict racially offensive speech at UVA.

The vice president of the Council of Black Student Leaders (CBSL), an umbrella organization of black student leaders stated "we believe it is an atrocity. We don't support it and we are trying to stop it from happening again....we ask that other minority groups and University groups, specifically Student Council, get together about this type of problem to stop it from recurring." 81 The chair of the BSA

77M. Perry. "Minorities speak out," The Cavalier Daily, April 29, 1988, at 5.

78A. Griffiths. "BSA questions fraternity fliers," The Cavalier Daily, October 4, 1988, at 1. The fliers were actually posted during the week of September 26, 1988, for a party held on September 29, 1988. The posting of the fliers and the party occurred during the same week that national news articles reported that a New York grand jury determined that Tawana Brawley had fabricated her charges of racial discrimination. Brawley, a black teenager, reported in 1987 that she had been kidnapped and forced to endure four days of sexual abuse by four white men. Brawley's story had attracted national news attention earlier, and, to some persons, was symbolic of black-white and male-female discrimination. See, V. Haller (A.P.). "Gang rape fabricated, jury says," The Cavalier Daily, September 29, 1988 , at 1 . The fliers probably were drawn before the Brawley story was published.

79/d. (A. Griffiths).

$80 / d$.

81J. Hubbard. "Council of Black Student Leaders discusses fliers," The Cavalier Daily, October 4, 1988, at 1. 
requested that the Fiji's issue a public apology and that they apologize to the BSA at its next meeting. ${ }^{82}$ A newspaper report indicated that the BSA chair "also requested that a University policy be developed which would denounce the use of offensive fliers so that organizations suffer a punishment because of their actions." 83 The Dean of Afro-American Affairs condemned the fliers and called for increased educational programming to address issues of multiculturalism. 84

Fiji brothers consistently argued that they meant no offense by either the Fiji man caricature nor

by the words on the flier. Below are excerpts from a public statement written by the fraternity.

...We did not intend to offend any racial or ethnic group, but unfortunately we did. The flier said "no short wops" This was a reference to one of our brothers whose nickname is "Wopwa." He is also short....We should have realized that although to us this was a cut on our brother, for many Italian-Americans it is offensive. We are very sorry about any offense that was taken....The next problem arose because of the use of one of our chapter's slang words. "Nega" is short for negative and, conversely, "posa" is short for positive. These are general adjectives, used to express the good and bad in anything, not just people. Unfortunately, this term was taken to be some masked form of the word "nigger." To us, the presumption that we would put such a thing on our flier is abhorrent and inconceivable.....we are sorry if people were antagonized by it and we hope that they understand that it was not meant to be a racial slur. ${ }^{85}$

A white administrator stated,

The Fiji's had voluntarily considered changing the "south sea islander" caricature where they would not portray it as a person of color, although it had some obvious ethnic characteristics. When the Fiji flier came out, it was colored. That was the first thing that jumped out at us. Second, it was announcing a social event. Allegedly one clever individual decided to add to the announcement "no short wops or nega babes invited." He happened to have been short and Italian.... The vemacular was that "nega babe" was one who wouldn't cooperate with the needs and desires of the brotherhood. It was not a racial slur, but it raised (or could have raised) a whole different series of

82A. Griffiths, see supra note 78 at 7.

$83 / d$.

${ }^{84} \mathrm{M}$. Turner. "Offensive fliers require action by the University," The Cavalier Daily, October 5, 1988, at 2.

85J. Golos (president, Phi Gamma Delta). "Fliers not intended to insinuate racism," The Cavalier Daily, October 6, 1988, at 2. The Fiji's apology did not address the meaning of the word "babes" in the poster, for which they were criticized (for being sexist) in several other student editorials. 
issues. ${ }^{86}$

Despite the apology, the Fiji flier came to symbolize for some students what was wrong with black-white relations at UVA. The vice chairman of the BSA stated that "we see this as a community issue. It's not BSA versus Fiji."87 Several meetings followed involving the dean of students, the BSA, the Fiji's, and the Inter-Fraternity Council.88 One white administrator believed that,

for most of the black persons who participated in the meetings it was the first time they were ever in that fraternity house (perhaps for many of them it was the first time they had been in any fraternity house) and it was foreign turf. The general interpretation [of the fraternity's reaction] was one of being receptive to the concern. In the main, the brotherhood at Fiji felt remorseful about what had happened. The way the flier had been interpreted, they understood that events would evolve as they did. 89

Another white administrator observed that the Fiji flier incident had been perceived by some persons as a First Amendment issue.90 This administrator characterized the University's approach to the situation as an "educational opportunity" in which the student affairs staff met with the members of the groups involved and encouraged them to think through how their behaviors might be interpreted by outsiders in ways that the group never intended. 91

During the remainder of the 1988-89 academic year student newspapers published articles and editorials weekly on racial issues. There were additional incidents, but none reached the proportion of the Fiji flier incident or the incidents that would follow in 1989 and 1990. Some of these incidents are

$86 \# \mathrm{~V}-7$ at 1 . The Fiji's agreed to discontinue the use of the fraternity mascot called "Fiji man" in response to UVA community members' protests that the figure was a nationally recognized racial caricature. See id.

87K. Hyde. "BSA dissatisfied with response," The Cavalier Daily, October 7, 1988, at 1.

${ }^{88}$ A. Griffiths. "Phi Gamma Delta faces charges," The Cavalier Daily, October 12, 1988, at 1. See also, \#V-7 at 1.

$89 \# \mathrm{~V}-7$ at 1.

$90 \# \mathrm{~V}-2$ at 3.

$91 / d$. 
described in the next section of this chapter.

The 1989 Fall semester opened with news of Virginia Beach riots during a week-long black fraternity event known as "Greekfest."92 There was no indication that any UVA students were involved, but news and videos of the event were well-publicized in Virginia. Confrontations between blacks and white police officers, looting, and the perceived threat of violence prompted Virginia's governor to call in the National Guard to quell the situation.93 Many blacks believed that Virginia Beach officials overreacted to the black students' presence.94 Although over a hundred miles off campus, the event sent ripples through the UVA community. When asked about Greekfest, BSA chairperson Jamelle Smith said, "at the University when black students and other people see these events, it sends a message of racism. If you experience racism at a state government level, then it is very easy to deduce that racism abounds at a University level."95 Smith was concerned that black students at UVA would be associated with the behavior of some black students and other non-students in Virginia Beach. She feared blacks would suffer within the UVA community because of the association however attenuated. 96

Early in the 1990 Spring semester, to curb racial harassment, members of the BSA again proposed the adoption of a 13th Standard of Conduct.97 The second major racial event occurred two months later, rekindling debate over a 13th Standard. In the early moming hours of March 28, 1990, vandals spray-

92A. Griffiths. "Riots open racial wound," The Cavalier Daily, September 6, 1989, at 1. Greekfest is a series of social events which attracts several thousand black greek college students from nearby colleges and universities to predominantly white Virginia Beach, Virginia.

$$
\begin{aligned}
& 93 / d . \\
& 94 / d . \\
& 95 / d . \\
& 96 / d .
\end{aligned}
$$

97A. Kumar. "Former chairman disappointed with BSA," The Cavalier Daily, January 29,1990 , at 1 . 
painted anti-gay and anti-black sentiments in three conspicuous locations on Grounds. ${ }^{98}$ The painted areas consisted of an image of two males engaged in anal intercourse surrounded by a circle with a line through it symbolizing "no homosexual sex." On the same drawing were the phrases, "no niggers" and "no faggots." 99 The paintings appeared in a parking lot adjacent to the Afro-American Affairs Office, at a University bus stop frequented by black students, and on the walls of "Beta Bridge."100 The graffiti was reported to the Dean of Students Office early in the morning on March 28.101 The Dean contacted various offices to inspect the graffiti, including the University Police, Facilities Management staff, and the Dean of Afro-American Affairs. ${ }^{102}$ A police car was parked to obscure the graffiti until the facilities management staff could paint over the offensive symbols and remarks. Because of the incident's timing and the quick response by the University, few actually saw the graffiti.103 Student newspapers published accounts of the graffiti the following day with concurrent editorials condemning the vandals' actions and ideas. 104 University administrators condemned the graffiti and quickly organized a public forum for

98D. Hallock. "Graffiti sparks outrage, anger in community," The Cavalier Daily, March 29, 1990, at 1.

$99 / d$.

100 The bus stop targeted by the vandals was known as the "black bus stop" among many students at UVA because the stop (in comparison with other bus stops) had become an informal gathering place for a disproportionately large number of black students. The vandals choice of this particular bus stop was probably deliberate, especially in light of the graffiti found near the Afro-American Affairs Office. "Beta Bridge," located in a neighborhood containing most of the greek organizations, is painted almost every night (usually not with racial slurs) by different groups and individuals to advertise events and to make various personal and political statements.

101D. Hallock, see supra note 98. See also, \#V-2, at 4.

$102 \# V-2$ at 4.

103W. Mataya, M. Howie, and R. Hohouser. "Hate evinced," The Cavalier Daily, March 29,1990 , at 3 .

${ }^{104}$ Editor. "Graffiti," The Cavalier Daily, March 29, 1990, at 2. See also, R. Canevari, R. Turner, et.al., "Deans Respond," The Cavalier Daily, March 29, 1990, at 3; 
students to express their views. ${ }^{105}$ The perpetrator(s) were never found.

The graffiti appeared the same day that lesbian and gay students had publicized an event, "jeans day," to raise the awareness among the University community toward the homosexual community. Gays, lesbians, bisexuals, and their supporters were encouraged to wear blue jeans to show support for these alternative lifestyles. "Jeans day" was one of several events during that week promoting nontraditional lifestyles. The vandals probably timed the display of the graffiti to coincide with the events of the bisexual, gay and lesbian community. The reason for the vandals' inclusion of racial epithets at this particular time is unclear.

During the open forum about the graffiti, the Dean of Afro-American Affairs responded to the incident in this way:

The results of the lack of a clear racial harassment policy and the failure to incorporate ethnic studies courses into the existing curriculum are exacerbated by the absence of a clear message from administration and faculty that harassment of any kind -- racial, ethnic, sexual -- will not be tolerated in the University community. I am concerned that the cowards who are guilty of this ugliness feel comfortable and perfectly free to continue their activity because the University does not have a clear, written policy against such actions. 106

Also at the forum, a spokesperson for the BSA read a list of ten demands to be presented to the University administration. 107 Included on the list was a demand for the implementation of a 13th Standard of Conduct. ${ }^{108}$ An outgrowth of the graffiti incident was the formation of a group of students who called themselves "Students Toward a New Diversity" (STAND), discussed later in part IV of this chapter. 109

See also, R. O'Neil, "Cowardly Act," The Cavalier Daily, March 29, 1990, at 3; See also, Id.

105/d. (R. Canevari, R. Turner).

106A. Gordon. "Community debates legacy of graffiti," The Cavalier Daily, April 2, 1990 , at 1.

$107 / d$

$108 / d$

109K. Yankosky. "STAND to meet Board," The Cavalier Daily, April 12, 1990, at 1 , 
A fourth major public incident occurred in April, 1990. Most interview participants did not link the incident to the discussion of the 13th Standard, but it was relevant to an understanding of the racial climate during the discussion of the proposed policy. Early in April, 1990, Lee Barnes (a black male 4thyear student) was elected president of the student body for the 1990-91 academic year. Two weeks later, Barnes claimed that someone had tampered with his mail and he had received a threatening racist letter. 110 Newspaper accounts of his claim also stated that some of Bames' critics, including the (white) student council president who preceded him, accused Barnes of being ineffective in his 1989-90 role as vice president. ${ }^{111}$ In what seemed at first to be an unrelated event on April 19, a few hundred students protested the University's investment policy in businesses operating in South Africa by encircling the Rotunda while the Board of Visitors and University administrators met inside to discuss investment policy. 112 While the demonstration was occurring, three student council vice presidents-elect met with Bames and formally requested for reasons of incompetence his resignation as president of the student body. 113 Having just returned from speaking at the divestment rally Barnes met with his three adversaries on student council. ${ }^{114}$ Hours after the meeting, the vice presidents-elect released their formal request to Bames to the press. 115 Next, it was reported that;

A member of the Black Student Alliance brought the letter to the on-going divestment rally on the Lawn, which had disintegrated into a confrontational sit-in after the Board of Visitors Finance Committee refused to decide on divestment. The letter was read over the loudspeaker to the

9.

110A. Kumar. "Barnes claims sabotage," The Cavalier Daily, April 19, 1990, at 1. $111 / d$.

112D. Hallock. "Board's divestment stance fuels protest," The Cavalier Daily, April 20,1990 , at 1 .

${ }^{113}$ A. Kumar. "Council officers call for Barnes' resignation," The Cavalier Daily, April 20, 1990, at 1.

${ }^{114}$ Editor. "Five stooges," The Cavalier Daily, April 20, 1990, at 2.

$115 / d$ 
protesters who wrongly assumed that the resignation request was directly related to Bames' speech at the rally earlier that aftemoon. 116

Subsequently, members of the group attempted to break into the Rotunda (which was locked at 5:00 p.m) resulting in a physical altercation between the BSA president and a University police officer as University officials tried to keep protesters out of the Rotunda. 117 The rally resulted in 31 students receiving summonses to appear in court for trespassing. 118 After the letter requesting Lee Barnes' resignation was read at the rally (and after the arrests), the remaining protesters went to President O'Neil's home to further contest the University's position on divestment, and to denounce what they perceived as a racially motivated request for Barnes' resignation. 119

The vice presidents-elect, the outgoing president, and an outgoing vice president of Student Council issued an apology for the timing of the resignation request, but they did not apologize or recant on the accusations in the letter. A public forum on April 20, on the request made of Barnes, resulted in a heated debate among black student leaders and Student Council representatives. 120 Rick Turner, dean of Afro-American affairs, stated his belief that Bames would not have faced attacks of incompetence if he were not black. 121 Organizers of the forum had planned a discussion of the necessity and/or possibility of Barnes' recall, intending the session to be one in which those with concerns about Barnes' prior

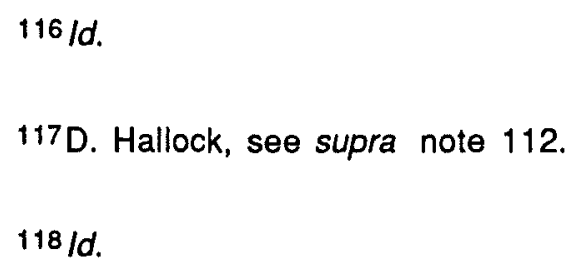

119 M. Trott. "March moves on to Carr's Hill," The Cavalier Daily, April 20, 1990, at 5. The Board of Visitors subsequently revised it's investment policy and approved a gradual divestment of its holdings in companies that do business in South Africa. See, D. Hallock, "Board approves full divestment proposal," The Cavalier Daily, June 14, 1990, at 1.

120A. Plemmer. "Meeting finds little support for recall," The Cavalier Daily, April 23,1990 , at 1 .

121/d. See also, A. Gordon, "Resignation request called racially motivated; Dean's remarks draw criticism," The Cavalier Daily, April 23, 1990, at 1. 
performance in Student Council could voice their opinions.122 During the meeting, white LGSU spokesman and student council representative Doug Chambers argued that the recall election issue was moot because the Council's bylaws allow recall elections only for officers who had taken office; Barnes had not yet assumed his office.123 A white senior administrator who was present at the forum observed,

[Doug] Chambers pointed out to the great embarrassment of Barnes' opponents that their effort was premature and that the procedure they proposed to invoke could not be used against a student body president who had not yet taken office. They were about a week ahead of time. The office does not change until the end of the school year, by which time [all of the students] would be gone. I think that was a critical turning point in several ways: 1) a gay student standing up on a matter of principle that really wasn't his own, it was Lee Bames' issue; 2) you had people who were faulting the competence of a newly elected black student being terribly embarrassed themselves for a serious lapse in the understanding of the Student Constitution; and 3) there was one leading member of the black community -- the dean of Afro-American affairs -- willing to come forward that this would not have happened if this person were white....If the [dean of students] had come in and read the Student Constitution it would not have been a tenth as effective as having Doug Chambers do it. I don't know if the newspaper stories fully captured the poignancy of that moment. 124

Another administrator (who is white) believed that the call for Barnes' resignation was not racially motivated. ${ }^{125}$ He characterized Barnes as a "very productive president," but said that up until that time Barnes was an unknown participant who did not really fulfill his responsibilities. ${ }^{126}$ The Barnes incident added more discomfort to an already tense time for race relations.

\section{Anonymous Racial Incidents and Other Race-Related Circumstances}

Although less publicized than the Fiji flier and bus stop graffiti incidents, other race-related incidents occurred at the University. The events described in this section were reported in the student

$122 / d$.

$123 / d$.

$124 \# V-8$ at $7,8$.

$125 \# \mathrm{~V}-7$ at 5.

$126 \# \mathrm{~V}-7$ at 5 . This person also said that the timing and the manner in which the other Student Council members handled the situation was "wretched." 
press, but they did not elicit the same level of community reaction. Both black and white students were perpetrators in the events described.

The first less publicized incident following the Fiji flier occurred at a concert in the student center attended predominantly by black students. It was reported that an intoxicated black Charlottesville resident arrived at the concert and verbally abused two white student concert employees. ${ }^{127}$ Sometime later, the black city resident first attempted to enter a closed section of the facility and then tried to jump on the stage.128 When the white employees "tried to subdue" the visitor "he [the visitor] began hitting them."129 When members of the predominantly black audience saw the employees struggling with the visitor, many audience members allegedly joined the fight against the white students. ${ }^{130}$ The initial article, written by student reporters, did not mention the race of any participants. 131 The article (and the incident) was perceived by some students as an attempt to hide a black-on-white racial incident. 132 Some observed an irony in the black community's outrage over the Fiji flier, which some students understood was intended to be a joke, versus what they perceived to be the black community's indifference toward a racially motivated assault by blacks against whites. 133

Two other incidents of violence by blacks toward whites were reported during the Spring, 1989. In each of these, white students were struck in the face after approaching an automobile in which the black

127K. Morton and A. Kogelnik. "Fight spurs reappraisal of policies," The Cavalier Daily, November 22, 1988, at 1. See also, A. Wilder; "Pavilion XI incident reveals blatant racism," The Cavalier Daily, November 29, 1988, at 2.

$128 / d$.

$129 / d$.

130/d. See also, R. Frisbie, "Racism travels in many directions," The Cavalier Daily, April 24, 1989, at 2.

$131 / d$

132 /d. (A. Wilder).

133 R. Frisbie, supra note 130. 
passengers (presumably not UVA students) asked for directions. 134 Editorials during the Spring, 1989, revealed a debate over the practices of initiating new members into some black fratemities and a controversy about a satirical cartoon intended to mock bigotry that was perceived by some students as being highly offensive toward blacks and gays. 135 Questioning black fraternity members' actions was perceived by some students as a racially motivated attack on black greek system values by intolerant whites. 136

The 1989 Fall semester passed with few racial incidents. One black student reported observing several white men dressed in black-face riding in the back of a pick-up truck. The same student took offense at a student wearing a t-shirt bearing a picture of the "Fiji man."137 In response to the complaint about the Fiji man t-shirt, another student questioned the motives of black students who wore t-shirts saying, "It's a black thing, you wouldn't understand," claiming that the shirt promoted racial divisions, not unity. 138 Late in the semester, the Honor Committee revealed statistics that suggested black students were more likely than whites to be charged with honor offenses and, once charged, they were more likely than whites to be convicted.139 The Honor System's status as the primary symbol of student self-

134G. Weilacher. "Racism rears its ugly head another time," The Cavalier Daily, February 23, 1989, at 2. See also, J. Connor, "Violence propagates thoughts of racism," The Cavalier Daily, February 14, 1989, at 2.

135K. Hobbs. "Black greeks uphold tradition," The Cavalier Daily, March 21, 1989, at 3. See also, P. Soderquist, "Letter defending pledge process out-of-line," The Cavalier Daily, March 23, 1989, at 2. See also, Editor, "Misperception," The Cavalier Daily, March 31,1989 , at 2.

$136 / d$

137D. Mangum. "Racist University traditions must end," The Cavalier Daily, October 24,1989 , at 2 .

138A. Frye. "Racist shirts," The Cavalier Daily, November 7, 1989, at 3.

139 K. Hyde. "Statistics may show honor bias," The Cavalier Daily, November 22, 1989, at 1. See also; Editor, "Honor and justice," The Cavalier Daily, November 22, 1989 , at 2. The honor system had been the subject of annual accusations of racial bias for several years before the statistics were released. The statistics seemed to confirm what 
govemance and as the supporting structure for the University's "community of trust" made the charges serious. The UJC was also reviewing the Standards of Conduct during the Fall of 1989.140

During the 1990 Spring semester race and sexual orientation issues dominated both student newspapers. In addition to the graffiti incident, three events occurred that were related to the 13th Standard discussion. The first event happened a few weeks before the graffiti incident. On March 3, 1990, the Omega Psi Phi fraternity (an historically black fraternity) held several events, including an auction of the students seeking membership in the fratemity. 141 The six partially clothed black students paraded on a platform before an audience bidding on their services. ${ }^{142}$ One student noted the irony of the auction in which black students re-enacted the slave system of the old south, thus degrading themselves and compromising their effectiveness in fighting stereotypes and racism on Grounds. ${ }^{143}$ The second event was a campus-wide educational program called "Apartheid Simulation Day," sponsored to raise awareness of the social conditions in South Africa.144 Large numbers of students participated and wore different colored armbands throughout the day to symbolize their assigned social classes, similar to those in South Africa. ${ }^{145}$ The release of the results of the $1987 / 1990$ surveys on racial and cultural issues at UVA

many black students had been saying for several years.

140A. Plemmer. "Judiciary Committee reviews conduct rules," The Cavalier Daily, November 9, 1989, at 1.

141D. Wheeler. "Auctioning," The Cavalier Daily, March 22, 1990, at 2. $142 / d$.

$143 / d$. Wheeler wrote, "the African American male cannot endure such self-inflicted injustices as these from his own people. The auction portrayed a double standard of racism which is hypocritical and weakens our struggle against the real fight.... If the black community is battling to create a sensitive University, such acts of insensitivity must not be tolerated from within."

13,1990 , at 1 .

144D. Hallock. "University observes apartheid for a day," The Cavalier Daily, April

$145 / d$. The researcher participated in this event and estimates from personal 
(described later in this section) was the third event. The survey results helped maintain the University community's focus on racial issues.

\section{Recruitment and Retention}

One of the most striking ironies in this case study is that while racial tension was considered a major campus issue among all races of students, throughout the late 1980s and early 1990s, African American students matriculated in record numbers. Some of the University's successes were described in section one of this chapter. Black, Hispanic and Asian American student enrollments all increased in the late 1980s, but, as outlined earlier, black enrollment was of particular importance at UVA. Table 1 shows enrollment patterns in the first year classes from the 1987-88 through the 1990-91 academic years. 146

\section{TABLE 1}

$\underline{1987-88} \quad \underline{1988-89} \quad \underline{1989-90} \quad \underline{1990-91}$

Total number of new 1st year and transfer students:

Number of black new first year and transfer students:

Percentage of black new first year and transfer students:

The trend continued in 1991, as black students comprised $14 \%$ of the entering first year class. 147 UVA, the most selective public institution in Virginia, is highly attractive (both educationally and financially) to students in the mid-Allantic and northeastern states. In addition, the Admissions Office

observations that several thousand other students participated by wearing the armbands they were assigned. It was truly a "campus-wide" event.

${ }^{146}$ A. Kumar. "Record minority numbers enroll," The Cavalier Daily, August 28, 1990 , at 1. 
took several successful steps to increase black enrollment. It hired counselors to target African Americans and sponsored recruitment weekends for blacks offered admission. ${ }^{148}$ These weekend recruiting programs were particularly successful in 1990 and 1991 when many of the student leaders introduced to the prospective students were also black. 149

\section{$\underline{\text { Students' Behaviors, Values, and Perspectives }}$}

\section{Ethnic Minority Students' Perspectives on Race Relations}

This section focuses on African American students' perspectives on race relations at UVA. ${ }^{150}$ Although opinions about race relations undoubtedly vary among the over 1,600 black students at the University and among those interviewed for this research, some patterns emerge. These patterns are described below. Almost every statement by interview participants --both black and white -- about race relations at UVA included mention of students' voluntary racial segregation.

Social segregation among races of students at UVA was apparent during the 1980s.151 In The Report of the Task Force on Afro-American Affairs, black students' written descriptions of their experiences at UVA frequently included comments about voluntarily separate organizations and social

$148 \# \bigvee-7$ at 7.

$149 \# \bigvee-7$ at 6, 7. For example, during 1990-91, black students held the offices of president of the student body, president of the honor committee, president of the graduating class, and more than one fourth of the representative positions on Student Council. In addition, the University's first black Rhodes Scholar, selected in 1991, spoke to the prospective students (See L. Lazarus, "Braxton among 32 chosen as Rhodes Scholars," The University Journal, January 14, 1991, at 1).

150 As indicated in section one of this chapter, black students at UVA are better organized and historically oriented more than other ethnic student groups toward addressing race-related community issues. Other ethnic minority groups at UVA have not been considered traditionally disadvantaged groups to the same extent as African Americans.

151 See, for example, T. Scott, "Separatism a difficult problem," The Cavalier Daily, January, 19, 1986, at 1. See also, B. Rathet, supra note 71; T. Fessendor, supra note 71; M. Kindle, "Mixing it up," The University Journal, September 14, 1990, at 2. M. Combs, "A Separate Pride," The Virginia Advocate, November 1990, at 6. 
structures. ${ }^{152}$ Black students made the following statements when asked by the Task Force to describe both their positive and negative experiences at UVA. The students' descriptions reveal a wide range of experience with racist behavior, and a wide range of reactions toward the campus environment for black students. A fourth-year, male student wrote,

My first two years were extremely positive in my eyes. However, I have become disillusioned with UVa. I have problems with how black students are treated with the Honor System and with the separatism between blacks and whites. I also have a problem with the black Greeks -- seem to be rather 'cliquish.' 153

Fourth-year female student;

Negative experience centers around racist professors and administrators throughout the school. I have been told I can't do the work and must prove myself everyday. White students are so withdrawn/apart from the blacks. ${ }^{154}$

Second year male student;

My experience here has been great. I see no real negative aspects, racially, here at the University. Maybe I am blind or maybe I don't hunt these things out like others. ${ }^{155}$

Fourth-year female;

During my four years at the University, I have been exposed to prejudice on a daily basis...both subtle and blatant. After coming to the sad realization that this is a prejudiced school, you just learn to take it in stride to some extent. 156

Fourth-year female student;

I am not happy when I hear UVa referred to as a racist institution. I have never had any negative experiences here at UVa. I feel that certain people may just be having adjustment problems at this solely white university...everyone has to learn to adjust at one time or another to this white

152M. Reisler, supra note 12 at 191-195.

$153 / d$. at 194.

$154 / d$. at 192

$155 / d$.

$156 / d$. 
controlled world in which we live. 157

Several other factors were described in relation to black students' perspectives on race relations. A black student interviewed for this research believed that many black students arrived at UVA weary from racial situations at home. 158 He also observed a heightened awareness of the racially tense environment. 159 Some black students believed they were misrepresented and portrayed negatively by the student press, and that the presentation of blacks in student publications contributed to negative perceptions of blacks toward whites and of all races toward blacks. 160 Reliance on support groups among black students were believed to be one outgrowth of the campus racial tension. 161 Support organizations targeting black students were said to provide a source of identity and strength.. ${ }^{162}$ Although most participants in this research said that voluntary racial segregation was commonplace, one black student finding daily casual and friendly inter-racial relationships, gave another explanation for self-segregation (paraphrased);

One of the reasons for black students "clumping" together is that, in my case, I never had been exposed to so many black people on the same intellectual level. I think that many black students had high school experiences in which there were not many other intellectually oriented blacks, so when we arrived here we wanted to hang around together. There also seems to be another group of black students that clump together, and they are all from the inner city. There are several different groups within the black community. I think some of the lines among student groups are drawn more by geographic differences than socio-economic reasons. I tend not to get along well with people from big cities; I don't like the music they like, and I don't want to sit around and

$157 / d$. at 194.

158

$\# \mathrm{~V}-11$ at 1.

159

$\# \vee-11$ at 1.

160 \#V-13 at 1. See also; supra note 74 (B. Galinsky). V. Weekfall, "Misused quotes pin poor image on black leaders," The Cavalier Daily, December 7, 1988, at 2. N. Reynolds, "Closed, but only to bias," The Cavalier Daily, November 22, 1991, at 2; Reynolds (199192 chair of the BSA) wrote in her article that, "the reigning negative perception of the press among some members of the black community is a direct result of a historical lack of objectivity that seems to newly infect the papers annually."

$161 \# \mathrm{~V}-9$ at $2 ; \# \mathrm{~V}-10$ at $2 ; \# \mathrm{~V}-11$ at $1 ; \# \mathrm{~V}-13$ at 1

$162 \# \mathrm{~V}-9$ at $2 ; \# \mathrm{~V}-10$ at $2 ; \# \mathrm{~V}-11$ at $1 ; \# \mathrm{~V}-13$ at 1. 
complain about how bad things are, because there are a lot of positive things happening also. 163

This student's more complex description of the variety within the black community at UVA was

consistent with the views of some administrators who believed that the larger number of black students on campus led to a wider range of opinions. 164 One white administrator stated,

Increased numbers of black students have allowed them to be more free to do what they want to do and not feel as much pressure to conform to the black student group as a whole. Peer pressure 10 years ago was so great among black students that most black students could not say or do what they wanted. 165

A survey on racial and cultural issues at UVA was conducted in 1987 and again in 1990.166 The results of the survey indicated that black students -- as compared with all other races of students -- believed that racial concerns should be a higher priority at the University. Uniquely, blacks had witnessed or experienced racial discrimination in their academic departments, felt less comfortable, and believed that the University should have a more ethnically diverse faculty. ${ }^{167}$ Responses also revealed that black students believed that racial and cultural groups were not adequately represented in the various branches of student government, and that the Honor System and the University Judiciary Committee did not handle

$163 \# V-14$ at $2-3 \quad(\#$-14 was a group interview that included both black and white undergraduate male students).

$164 \#$-2 at 2.

$165 / d$.

166 Ad Hoc Committee on Racial Awareness, University of Virginia, "Results of the 1987/1990 Surveys on Racial and Cultural Issues: Preliminary Tables for the Press Conference," April 5, 1990. Over 2,900 surveys were returned in 1987 and about 2,400 surveys were returned in 1990. The sample was relatively large, but the committee's distribution methods were questionable. Surveys were left unattended on tables in various locations around the Grounds, where students who passed by could fill out a survey if they had the time and interest to do so. A survey on racial and cultural issues may have attracted students with particular interests in such issues to fill out the survey, thus skewing the results. Also, it would have been easy for a student to fill out multiple surveys. 
cases in an equitable and fair manner. ${ }^{168}$ Finally, black students more than any other cultural group, were more likely to respond negatively to statements about the University's sensitivity to racial issues and to statements about the faimess and equity of institutional policies and practices. 169

\section{White Students' Perspectives on Race Relations}

In contrast to African American students, white students surveyed in 1987 and 1990 were likely to be more positive about the racial faimess and equity of student governance structures and University policies and practices. ${ }^{170}$ Editorial/opinion letters published during the late 1980 s from both blacks and whites promoted racial integration, often arguing that racial violence had occurred against students of both races. ${ }^{171}$ The thrust of these and other similar articles was toward a commitment among blacks and whites to end racially motivated offensive behavior.

Like black students, many white students were cognizant of de facto social segregation among different races, and especially between black and white students. White students gained their awareness of segregation from articles published in the student newspapers, from observing the racial mix at different bus stops, from classroom seating behaviors, and from the separate social structures on Grounds. ${ }^{172}$ Most white students did not want to be associated with the kinds of racially offensive messages like those

$168 / d$.

$169 / d$.

$170 / d$. The responses of students who reported being neither caucasian nor African American were, in general, more positive toward the University and student structures than black students and more negative than white students. However, these students' responses were, in general, more closely aligned with the responses of white students.

171 See, e.g., B. Rathet, supra note 71 ; R. Frisbie, supra note 130. A. Wilder, supra note 127; M. Combs, supra note 151 .

172Examples of segregated social structures mentioned by white informants included: separate black and white greek organizations, whites socializing/partying on Rugby Road at fraternity and sorority houses, disproportionately large numbers of black students socializing/partying in the student center, and the existence of organizations specifically for blacks, Asians and Hispanics. 
in the Fiji flier or graffiti incidents. ${ }^{173}$ One white student said (paraphrased),

One thing that is bad about those kinds of incidents is that minorities can get the impression that all white people are racists or that all heterosexuals hate homosexuals, and that is really not the case. Those acts are not representative of white peoples' attitudes, and it hurts me, as a white person, when someone does that kind of thing. It only makes it that much harder to try to meet and get along with black students here. 174

This student aptly observed that public incidents with racial overtones strain interpersonal relationships among students of different races.

\section{Political Factors and Conditions}

This section focuses on the coalitions formed, demonstrations held, the relationships among key participants, and other political factors present during the 13th Standard debate. The primary report on black-white relations is outlined. Discussion of the need for a 13th Standard occurred primarily among students and those administrators concerned with student policy issues. The University was not substantially influenced on the issue of discriminatory verbal harassment by such outside organizations as state govemment or the ACLU, perhaps because UVA never adopted a new conduct code or because other issues were considered to be of greater importance to such organizations.

Three plausible explanations emerged among interview participants for the ultimate failure of the 13th Standard: 1) lack of support for a policy, primarily for legal reasons, among key administrators and student leaders, 2) the role and composition of the BSA leadership during discussions of the proposed Standard, and 3) competition with other issues for public attention during the final stages of the debate over a speech policy. The explanation of lack of support among key players stems from the notion that changes in the Standards of Student Conduct require consensus-building among students and student groups, faculty, administrators, and members of the Board of Visitors. Changes involving student life generally require some agreement among student leaders as to what the changes should be. The BSA and

$173 \# \vee-14$ at 4.

$174 / d$ 
the UJC did not agree on an approach to discriminatory verbal harassment. One white student leader remembered meetings between the BSA and UJC that gave him the impression that the UJC had a negative image among black students at UVA. ${ }^{175}$

There were lots of vocal, almost radical, students there who raised some of the radical defense mechanisms of some of our members....The image problem of the UJC has been that its membership and leadership has been almost exclusively white and male. That has changed some in the past two years, but that was a big obstacle facing the BSA in trying to get a 13th Standard to pass through the UJC. They probably wondered why a committee with white male membership would be receptive to the idea of a policy restricting verbal harassment....I think it got better as the discussion of the policy moved along. But there are definitely some histories to deal with in the institutions here. 176

Some BSA members believed that it was "ridiculous" (i.e., unrealistic) to expect the UJC or other students to support a 13th Standard since the university administration was thought not to be supportive. 177 In other words, some students believed that even with student consensus the 13th Standard would not be approved by the Board of Visitors because of the university administration's non-support. Students who favored the 13th Standard and who met with senior administrators to push its adoption were directed back to the student group responsible for student conduct...the UJC. 178 Some students believed that the administrators' referrals back to the UJC were a subterfuge for their lack of support. However, evidence indicated that several key administrators were skeptical, primarily for legal reasons, about the wisdom of such a policy. ${ }^{179}$ Administrators' approach of letting the UJC consider the issue was consistent with the University's model of student self-governance and not merely a strategy for quashing the issue.

During the policy debate, some administrators identified the BSA leadership as an important factor in the outcome of the policy decision. BSA leadership, like almost all other student groups, changes each

$175 \# \bigvee-3$ at 4.

$176 / d$.

$177 \# V-13$ at 2.

$178 \#$ V-7 at $4 ; \# V-8$ at $3 ; \# V-9$ at 5

$179 \#$ V-2 at $4 ; \#$ V-4 at $1 ; \#$ V-8 at 4. 
academic year making the continuity of goals and issues a perennial challenge. Both black and white administrators praised the BSA leadership during the late 1980s, but expressed disappointment with the 1990-91 BSA chairman because of his difficulty in working with the leaders of other student groups and because, without warning, he left the University mid-year to transfer to another institution. 180 The 1990 91 chairman was in office during the final stages of the discussion of 13th Standard, and he was an appropriate spokesperson for the BSA in promoting the proposed policy. During the University's summer leadership program (1990),181 he had declined invitations to meet with the UJC to discuss the issue of a 13th Standard, leaving some student leaders with the perception that he was unapproachable. ${ }^{182}$ One administrator observed that the 1990-91 BSA chairman "was an absolute wall as a summer player in the program," while at the same time the chairman was criticizing the University and the president in the student papers. 183 Another administrator who worked with many black students recalled that the 1990-91 BSA chairman "wasn't well respected, so if he had anything to do with an issue it was unlikely to be accepted."184 The chairman's strained relationships with others on Grounds were by no means the sole or deciding factor in the 13th Standard decision, but his individualistic approach to promoting a 13th Standard was reported to have had more negative than positive consequences at a critical time for the proposed policy.

Others interviewed indicated that the speech code was not among the BSA's top priorities in the Fall, 1990, and as a less important objective it did not receive the level of attention required to build University-wide consensus. One black student interviewed reported that she was more involved in the

$180 \# V-6$ at $4 ; \# V-7$ at 4.

181 This program involves meetings and leadership training for student leaders from many of the primary student associations and governance bodies. It is sponsored annually by the Division of Student Affairs.

$183 / d$. 
issue of the University's investments in businesses operating in South Africa than she was with the speech policy. 185 A white administrator remembered that most of his discussions with BSA leaders were related to the University's support of the Office of Afro-American Affairs and financial support for students, not to the speech issue. 186

A third possible explanation rests with the timing of the prospect for a 13th Standard among the many issues competing for attention. One administrator stated,

The most recent documents in my file [regarding the 13th Standard proposal] are dated December, 1990. The racial harassment issue seemed most intense in late 1990, then sexual orientation in January-February [1991], the drug raid in March, 1991, then the athletics issue in May....The public and the University have a limited appetite for how many issues can be digested at one time or in one academic year. ${ }^{187}$

Another administrator raised the issue of timing within the academic calendar, observing that,

Students don't beat issues to death after they get a little satisfaction.... Things will be 'hot' up until this week [exam week]. Now, if you can get anybody to be concerned about anything but exams then you let me know. If there were a racial incident out here tomorrow you would be most unlikely to get anybody to do anything...in terms of mobilizing people or a demonstration. What you hear is, "it is exam time" and "I've got to home for Christmas," and so on. So the students got told "no 13th Standard," and they went and moved on to the next thing. It could be the food in the dining hall or anything. 188

In short, the 13th Standard was proposed over the course of about eighteen months to a Judiciary Committee and university administration that did not support such a policy, as they believed the current Standards of Conduct adequately addressed the matter. The 1990-91 BSA chairman -- perceived both by students and administrators as uncooperative -- proposed a specific 13th Standard during the last six months of the policy debate. Late in the 1990 Fall semester, following the UJC's announcement of nonsupport and unfavorable newspaper editorials, support for the proposal waned. The then BSA chairman, who served as a primary spokesperson on the issue, left the University in December, 1990, for reasons

$185 \# \mathrm{~V}-13$ at 2.

$186 \# \vee-8$ at 3.

$187 \# V-4$ at 3,5 ; See also, \#V-6 at 5; \#V-7 at 9.

$188 \# V-10$ at 8. 
unrelated to the proposed policy. The ensuing semester commenced with a series of new controversial issues ${ }^{189}$ supplanting the community's interest in older issues like the 13th Standard.

\section{Political Activities}

Although there were coalitions of students that formed at UVA, they did not act with the same force nor did they meet with the same success in achieving their objectives as the coalitions at Stanford and Wisconsin-Madison. The cluster of issues at UVA garnering the support of progressive students at UVA were South African Apartheid, sexual assault prevention, and ending tensions among majority and minority group members. More specific issues tended to rally support only from the particular group affected by an issue. For example, the issue of racial bias against black students in the honor system was vigorously supported by BSA members. Non-black students may have supported racial equality in the honor system at an intellectual level, but a review of the evidence indicated that they were less likely to spend time actively working to eliminate it.

There were no rallies, demonstrations, or other organized protests targeting the 13th Standard. ${ }^{190}$ Those coalitions that did form at UVA demanded a policy on discriminatory verbal harassment as one of many issues. Typically, these demands occurred only after a major public incident of "hate speech."191 One white administrator observed that in the discussion about a 13th Standard,

...at least for a time there was an interesting alliance of minority students and gay/lesbian students.

189 Three incidents gained widespread public attention in Virginia. In January-February of 1991, sexual orientation was added as a protected class in the University's nondiscrimination policy, fueling the issue of whether employers that discriminated against homosexuals (U.S. military, C.I.A., etc.) should be allowed to recruit and interview students on campus. In March 1991, three UVA fraternity houses were seized by federal authorities because of drug use and drug sales by fraternity members (the seizure made national headlines). In May 1991, the University self-reported possible NCAA violations and began an internal investigation.

$190 \# \bigvee-6$ at 4.

191 Calls for the 13th Standard followed several public incidents of offensive expression without regard for whether the expression might have been Constitutionally protected. 
Both were seeking some kind of a policy for somewhat similar reasons. I don't recall any specific involvement of women's organizations, perhaps because there was greater concern among women on other issues like sexual assault, and less concern with words....There was no evidence of support from other minority groups....I am sure there were representatives who spoke....in support of it, not because it was [their] issue, but because there was a kind of a coalition. In the absence of any reason to oppose it, there was some sympathy for it. In terms of active, personal participation, I do not recall support from any quarter. 192

Another administrator perceived the relationship between the BSA and the Lesbian and Gay Student Union

(LGSU) differently. When asked about the coalition between the BSA and the LGSU he stated,

That was the way it was portrayed, but my particular impression was that the black students and the BSA in particular did not cotton to the gay and lesbian student unions moving into an area where they [BSA members] were getting top billing. In fact, there were some behind the scenes verbal confrontations in which the BSA was telling the gay and lesbian groups that 'you are riding our coattails, and we don't want you on our coattails.' I think the gay and lesbian student groups very cleverly moved in to enjoin the issue, but they were not welcomed to be a player. That is not denying in any way that it was anything but a dual issue; it was. 193

This evidence suggests a certain lack of unity between the two most outspoken minority groups at UVA -a factor that may have affected the outcome of the policy -- and it may reveal an interesting dynamic about the various stigma associated with groups that perceived themselves to be disadvantaged.194 LGSU members were willing to join BSA members to fight for a 13th Standard, but the reverse was not necessarily true among BSA leaders. Although members of both groups supported the 13th Standard, their approach with the administration may have appeared disjointed and separate.

\section{Reports and Institutional Self-Studies}

The principle report published in the late 1980s concerning race relations was the Report of the Task Force on Afro-American Affairs. A bi-racial panel of 16 persons (faculty, staff and students),

$192 \# \vee-8$ at $2,4$.

$193 \#$ \#-7 at 5.

194 It is beyond the scope of this study to examine the dynamics of lesbian and gay student organizations or their members' experiences at UVA. It is reasonable to assume that a variety of opinion about homosexual lifestyles existed among black students at UVA. Likewise, homosexual students may have held a variety of opinions about racial issues at UVA. 
appointed in the summer of 1986 by then President O'Neil, completed the 300-page report. The panel made 27 recommendations to the president to enhance the University's efforts in the recruitment and retention of black faculty and black students, to change student academic services, to increase education and communication in the UVA community, and to modify the University's administrative structure and employment policies. The panel's over-arching goal was the genuine integration of the institution, defined as:

full participation by blacks at all levels (i.e., senior administration, faculty, student organizations, etc.) and in all meaningful ways in the mainstream of all University endeavors. Genuine integration, it should be stressed, does not require the loss of a minority person's cultural identity; rather, it calls for an acceptance and promotion of minority cultures within the context of a continually enriching and vibrant multiculturalism. 195

The most difficult issue before the panel was its recommendation for the future of the Office of AfroAmerican Affairs. 196 Authors of the report repeatedly accused the University's white community of relative indifference toward blacks' concerns and of resisting meaningful changes in the environment for blacks. The report did not address any issues associated with the Standards of Conduct or the UJC.

In 1987 and 1990, the Ad Hoc Committee on Racial Awareness distributed, collected and analyzed surveys on racial and cultural issues and disseminated the results through campus publications. The Task Force on Afro-American Affairs and others relied upon these surveys as an important source of data available on race relations at UVA. The Committee's methods of distributing the surveys (i.e., leaving multiple copies of the survey available in multiple public locations and reliance on the honor system to prevent multiple responses from individuals) drew criticism. The results of the two Racial Awareness Surveys were reported in three racial categories: African-Americans, Caucasians, and all other races. Excerpts from the responses of undergraduate students in this study are shown below. Numbers represent the percentage of respondents who agreed or strongly agreed with an item.

${ }^{195}$ M. Reisler, supra note 12 at 28.

196/d. The panel concluded that, at least in the short-term, the Office was necessary and should be supported. 
Item

Caucasians African Americans All Other Races

$\begin{array}{llllll}1987 & 1990 & 1987 & 1990 & 1987 & 1990\end{array}$

1. Racial concerns should be a high priority

$74 \% \quad 79$

$97 \quad 96$

$80 \quad 76$

at the University.

2. Racial concerns are a high priority at the Univ. 6973

$\begin{array}{lllll}73 & 42 & 35 & 56 & 63\end{array}$

3. Race relations generally pose a problem at the $49 \quad 42$ University.

4. I feel comfortable at this Univ. and have a $89 \quad 88$

66
$\quad 68$

85

79 sense of belonging.

5. There should be more students from diverse

$43 \quad 41$

$91 \quad 90$

54

55

racial backgrounds at UVA.

6. Professors at this Univ, interact well with students of all races.

$81 \quad 78$

$59 \quad 48$

$82 \quad 79$

7. There is a lack of communication among

$67 \quad 73$

82

89

70

76 students of different races.

8. I frequently study or work on projects with students of other racial and cultural groups.

$49 \quad 58$

66

57

75

71

9. Opportunities for cross-racial and cultural student interaction are limited at UVA.

$55 \quad 50$

75

67

56

54

In response to almost every question, African American undergraduates, graduate students and faculty/staff responded that they were less comfortable and more dissatisfied with the University's environment (in both 1987 and 1990) than respondents who were caucasian or other races.

\section{Discussion \& Development of the Proposed Thirteenth Standard of Conduct}

\section{Progression of the 13th Standard}

The origin of support for a 13th Standard at UVA can be traced directly to the aftermath of the Fiji flier incident. The apology letter and the public forums held in response to the Fiji flier were perceived generally to be positive steps, but leaders in the BSA turned their attention from the actions of the 
fraternity toward the University's administration. Then vice-chairman of the BSA, Darius Withers, stated "we are still looking for more on behalf of the administration. We would like to see, if not a sanction against Fiji, some type of policy put into effect that will allow administrators and community members to sanction organizations for racist perceptions."197 At its meeting on October 25, 1988, the BSA considered an anti-racism regulation it planned to present to the University administration and the UJC in order to prevent similar incidents in the future. 198

Also on October 25, 1988, the UVA Student Council considered proposals in response to the Fiji flier incident. Among the resolutions in the draft proposal was a statement requesting "the administration to state the University's inclusion of racism and prejudice in its definition of lewd, indecent, obscene, and constitutionally unprotected acts."199 The terms "lewd, indecent, and obscene" were found by some council members to be offensive to the First Amendment and were struck from the final version. After some debate, the Student Council passed a resolution urging President Robert O'Neil to write to Virginia Governor Gerald Baliles to request the enactment of laws to curb racist and discriminating acts.200 Student Council also requested that President O'Neil and the Board of Visitors act immediately to clarify the University's commitment to the creation of a multicultural environment, to include acts of racism and prejudice in the University standards of conduct, and to incorporate the intolerance of racism and prejudice

$197 \mathrm{~A}$. Griffiths supra note 88 . This report marked the first occasion in which the possibility of a prohibition on discriminatory verbal harassment. An editorial opinion published just one month prior to the Fiji incident focussed on censorship in the abstract, citing cases of censorship at other universities but not mentioning UVA at all. See, B. Hinkle, "Racist speech should not be censored," The Cavalier Daily, September 5, 1988, at 2.

198M. Kurzweg. "BSA proposes regulation," The Cavalier Daily, October 26, 1988, at 1. No copy of the proposal was available.

199 Student Council. University of Virginia, "Resolution sponsored by Reps. Eisenbach and Pritchett," October 25, 1988.

200 Student Council. University of Virginia, Minutes from the meeting of October 25, 1988. The request to the governor was somewhat misplaced since the executive branch of state government of Virginia does not have the authority to enact laws. This power is vested in the state legislature. 
into UVA's non-discrimination clause. 201 Student Council's resolution made no reference to the UJC or to the UJC's authority in the area of student conduct rules. In effect, the resolution approved by Student Council bypassed the appropriate channels for student self-governance structures to address the issue.

A memo from an assistant dean of students to the director of equal opportunity/affirmative action (EO/AA), indicated that the issue was being studied by the University administration. ${ }^{202}$ In December, 1988, the EO/AA director proposed definitions of both racial and sexual harassment to President Robert O'Neil.203 Late in the fall, 1988 (or early 1989), a student committee formed called the "Judiciary Ad Hoc Committee on Racism."204 Copies of five universities' policies on discriminatory verbal harassment were distributed to committee members with the following instructions:

Please take the time to read them over and assess what language you think might work best within the Judiciary system at Virginia....Please try and decide if we need a new standard at all or if the situations that we might want to include under this new proposal might already be encompassed in one of the old Standards of Conduct. 205

The instructions are important for understanding the way the debate and the arguments about a 13th Standard were structured. There was a presumption against additional standards of any kind, primarily to maintain parsimony in the existing Standards of Conduct.

The issue of an additional Standard of Conduct appeared to lie dormant until the fall, 1989. At an annual retreat in September 1989, attended by senior administrators and student leaders, the University's general counsel presented a program that outlined various bias-related incidents at other universities, the

$201 / d$.

202K. Smith (Asst. Dean of Students) memo to L. Lewis (Director, EO/AA), regarding "University of Wisconsin-Madison Proposal to Changes in Their Approach to Dealing with Racial Incidents on the Part of Students," University of Virginia, November 16, 1988. This memo was available in UJC files.

203J. Bermant. "O'Neil to discuss proposal," The Cavalier Daily, December 5, 1988, at 1. There was no public report of the outcome of Lewis's meeting with President O'Neil.

204S. Good memo to the University Judiciary Committee's Judiciary Ad Hoc Committee on Racism, University of Virginia, January 21, 1989. 
approaches taken by those institutions to address the situations, and guiding principles of the First Amendment of the U.S. Constitution relevant to university policy. ${ }^{206}$ One week after Robert O'Neil announced his resignation as president of UVA (October 1989), a student reporter wrote that Mr. O'Neil said he was opposed to broad, speech-restrictive policies, but he believed that the institution may impose sanctions on organizations without inhibiting an individual's freedom of expression.207 The UJC reviewed the Standards of Conduct during the fall, 1989.208 This review included discussion about amendments to the preamble of the Standards of Conduct, but no changes were made.209

The University saw renewed interest in an additional Standard of Conduct for discriminatory harassment during the spring semester, 1990. The 13th Standard had returned to the list of BSA objectives by January, 1990, despite the absence of any new publicized racial incidents. 210 The graffiti incident in March, 1990, prompted the BSA and the LGSU to raise the issue once again. Following the graffiti incident, the BSA issued 10 demands -- including the implementation of a 13th Standard -- to the university administration. 211 The graffiti incident also prompted the formation of an ad hoc group of students who called themselves "S.T.A.N.D.," an acronym for "Students Toward A New Diversity."212

206J. Mingle. Outline of remarks made at the President's Annual Student/Administrator Retreat, University of Virginia, Office of the General Counsel, September 21, 1989.

207K. Yankosky. "O'Neil sees black gains," The Cavalier Daily, October 10, 1989, at 1. See also, R. O'Neil; "Colleges Should Seek Educational Alternatives to Rules That Override the Historic Guarantees of Free Speech," The Chronicle of Higher Education, October 18, 1989 , at $B-1,3$.

208A. Plemmer, supra note 140.

209 University of Virginia. "University Regulations," Undergraduate Record 1988-89, $1989-90,1990-91,1991-92$.

210 A. Kumar. supra note 97.

211A. Gordon. supra note 106.

212K. Yankosky, supra note 109. 
The group's primary concern was the adoption of a 13th Standard of Conduct.213 Members of STAND met with President O'Neil and with attorneys in the general counsel's office (separately) in early April to discuss a proposed policy and other issues. 214 STAND members also met with the Board of Visitors' ad hoc Committee on Intergroup Relations a few days later. ${ }^{215}$ This committee was formed by a Board of Visitors action in March, 1990, just before the well-publicized graffiti incident.216 Student Council representatives passed a resolution condemning the graffiti directed against blacks and homosexuals, but did not address formally the issue of a 13th Standard in response to the graffiti incident.217 The president of the student body and some Student Council representatives were also members of STAND, and they supported the 13th Standard through this organization. 218

At its first and only meeting (April 1990), the Committee on Intergroup Relations heard testimony from several senior administrators, student members of STAND, BSA leaders, and two independent students. The Committee file indicated a dubious start for the group. 219 The format of the

$213 / d$.

$214 / d$. See also, \#V-4 at 1

215The Rector and Visitors of the University of Virginia, Minutes from the meeting of the Committee on Intergroup Relations, April 13, 1990.

216K. Yankosky, supra 109. See also, Minutes of the Board of Visitors, University of Virginia, March, 1990. 17. 1990.

217 Student Council, University of Virginia, Minutes from the meetings on April $3,10, \&$

218 The Rector and Visitors of the University of Virginia, supra note 215.

219 The Committee consisted of Freddie Nicholas, Evans Jesse, Arnold Leon, and Wendelin White. Mr. Nicholas, who served as the committee's chair, was the Board's only black member. Ms. White was the non-voting, student member of the Board. Mr. Jesse did not attend the first meeting and asked to be removed from the committee due to "prior commitments. Mr. Leon arrived late to the meeting. The only Board members present at the start of the meeting were the committee chair, the Rector of the Board, and the non-voting student member. At the conclusion of the meeting, Mr. Nicholas stated his commitment to keeping the Committee active, but by September, 1992, the group had not convened a second 
event more closely resembled an open forum than a typical meeting. Nine of the thirteen students who spoke voiced support for the addition of a Standard of Conduct to address verbal harassment. ${ }^{220}$ Speakers included representatives from Student Government, the BSA, the Council of Black Student Leaders, the UVA student chapter of the National Organization of Women, and the Asian American Students Association. Leaders of the BSA gave the most specific presentation on the 13th Standard by reading a proposed policy for the Committee's consideration and recommendation to the full Board.221 The policy proposed by the BSA was similar (verbatim in some parts) to the policy written by Stanford law professor, Thomas Grey, for Stanford University in December, 1989.222 The BSA proposal, delivered as follows, was broader and perhaps more speech-restrictive than Stanford's policy (language drawn from Stanford's policy is in italics):

In the context of the additional standard, the Black Student Alliance cites the Supreme Court's definition of "fighting words" within the bounds of discriminatory harassment. These "fighting words" are non-verbal symbols, words, or pictures, that by virtue of their form are commonly understood to convey direct and visceral hatred or contempt for human beings on the basis of their sex, race, handicap, color, religion, sexual orientation, or national and ethnic origin. Further harassment prohibited by the additional standard will include: Discriminatory intimidation by threats of violence and personal vilification of students on the basis of the classifications provided previously, such as sex, race, handicap, etc. Speech or other expression constitutes harassment by personal vilification if it

a.) is intended and would reasonably be expected to insult or stigmatize an individual or a small number of individuals on the basis of characteristics listed above; and

b.) is addressed directly to the individual or individuals whom it insults or stigmatizes; and/or

c.) makes use of fighting words or non-verbal symbols.

time.

${ }^{220}$ Rector and Board of Visitors' Committee on Intergroup Relations, University of Virginia, Audio-taped recording of the proceedings of the meeting on April 13, 1990.

221 The BSA's proposed policy was supported by the members of STAND. See, H. Green and D. Becher, "STAND up," The Cavalier Daily, April 13, 1990, at 3.

222Rector and Board of Visitors' Committee on Intergroup Relations, supra note 220. A type-written copy of the BSA proposal was available in the office of the UJC. The BSA leaders did not cite Stanford as their source. Stanford's policy was in the final stages of deliberation at the time of the UVA Committee's forum, and it was approved at Stanford on May 24, 1990. The version of Stanford's policy used by UVA's BSA was distributed in December, 1989. This version was modified substantially before Stanford's SCLC approved its final version. See pages 202-211 for the progression of Stanford's policy. 
The Supreme Court's definition of fighting words, unlike that of the BSA, centered on expression that is intended and likely to incite an immediate breach of the peace. Another broadening clause in the BSA proposal, found in section "a," indicated that speakers "would reasonably be expected" to know if they were insulting or stigmatizing another student. Finally, the conjunction "or" at the end of section " $\mathrm{b}$ " suggests that students who satisfy either part " $b$ " or part "c" would be in violation, instead of the student having to satisfy all three sections. This broadened the reach of the policy and may have made it more easily discredited by its opponents on First Amendment grounds. The editorial staff of The Cavalier Daily opposed the BSA/STAND proposal for a 13th Standard. ${ }^{223}$ By the following week, the issue of the 13th Standard disappeared from public discussion as students' attention turned toward protests against the University's investment policy in South Africa and the controversy surrounding the request for Lee Bames' resignation as student body president (described earlier).

The 1990-91 chairman of the UJC, Sam Famham, studied the issue of discriminatory verbal harassment and spoke with students and administrators during the summer of 1990 . He made public his personal conclusions in September, 1990, stating "... there is nothing that could be added to cover what is not already addressed in our current Standards." 224 The editorial staffs of both of the University's daily student newspapers agreed with Farnham. 225 Despite his own misgivings about a speech policy, Farnham convened a team of UJC representatives to study and report on the matter. 226 During their deliberations, the UJC team members consulted then former president Robert O'Neil for his advice on the policy issues before them. Mr. O'Neil, consistent with his writings on the subject, advised against a 13th Standard for offensive speech. No evidence indicated that a consultant with differing views was

223Editor. "SIT," The Cavalier Daily, April 12, 1990, at 2.

224J. Green. "Standard found unnecessary," The University Journal, September 10, 1990 , at 1.

225L. Bussman (ed.). "Adequate coverage," The University Journal, September 10, 1990, at 2. See also, D. DeBerry (ed.); "Twelve is enough," The Cavalier Daily, September 11,1990 , at 2. in 1988-89.

226J. Green. supra note 224. This group was similar in focus to the UJC group formed 
solicited or heard by the team. One administrator characterized the UJC team's work as a "...conscientious parsing of the existing provisions to make sure that somehow the needs weren't or couldn't be covered within the existing policies; there was a presumption against amending the standards." 227

While the UJC team was completing its work, the 1990-91 BSA chairman (who transferred from UVA mid-year) and some other BSA members began to put pressure on UVA's new president, John Casteen, to take action on a 13th Standard.228 Another senior administrator recalled that a meeting between Mr. Casteen and the BSA specifically about this issue had been scheduled for November, but the meeting was postponed by the BSA and was never re-scheduled (perhaps because of the transfer of the BSA chair). ${ }^{229}$ By November 13, 1990, it was reported that the UJC team found no reason to alter the existing code of conduct because Standards one, eight, and ten would address incidents of harassment to the extent that was legally permissable. 230 In early December, 1990, the V.P. for student affairs sent a letter to the BSA chair advising him and the BSA to take the issue to the UJC rather than the president since the UJC was the office on Grounds delegated authority to act on such matters, and that it was inappropriate to take such a matter to the president without working with the UJC first. ${ }^{231}$

After December, 1990, concern for a 13th Standard of Conduct seemed to disappear among students (faculty and most administrators were never involved in the issue). The equal employment/affirmative action officer of the University proposed several draft policies (the last one in April, 1992) on racial harassment to the senior adminstration, but each was believed by the administration to have serious

$227 \# V-8$ at 5.

$228 \# \vee-4$ at $2 ; \# \vee-7$ at 4.

$229 \# V-4$ at 3.

230Minutes of the University of Virginia Student Council, November 13, 1990. This was confirmed in writing to the vice president for student affairs; see, S. Farnham. Letter to E. Ern, November 30, 1990, University of Virginia, University Judiciary Committee. 
defects.232 These proposals, if adopted, would have applied to faculty, staff and students (and guests), and would have been resolved by EO/AA officers. The latest proposed policy would have superceded the University's Standards of Conduct for students, and it would have created two systems for adjudicating cases of student harassment, the UJC and the EO/AA office. The United States Supreme Court's June, 1992, decision in R.A.V. v. St. Paul will have the probable effect of quashing any further attempts at a speech policy (see discussion on pp. 19-22).

\section{Supporters of a 13th Standard}

It is evident from the preceding section that the public supporters of the 13th Standard included leaders of the Black Student Alliance, members of the Lesbian and Gay Student Union, student members of the ad-hoc group STAND, and a few administrators. The primary purposes that supporters articulated for having a new Standard focussed on the harm inflicted on minority students subjected to discriminatory verbal harassment. One black administrator explained that "students thought that it might stop people from making derogatory statements. They thought the proposed policy would make those problems go away. They wanted the student body to recognize that you can't get away with being disrespectful toward people." 233 Some supporters argued that the victims' rights were overlooked in the Fiji flier and the graffiti incidents. 234 Even though supporters conceded that a policy would not address incidents of anonymous behavior like many of the incidents at UVA, the Standard would have been perceived as

232L. Lewis. Memo to T. Jackson and J. Mingle regarding "Racial and Ethnic Harassment Policy," April 22, 1992. See also, T. Jackson memo to J. Casteen regarding "Lincoln Lewis' Racial and Ethnic Harassment Policy," April 29, 1992.

$233 \# V-6$ at 3.

$234 \# \bigvee-10$, p. 5. See also, comments of M. DePass at the University of Virginia Board of Visitors Committee on Intergroup Relations meeting, April 13,1990. 
symbol of the administration's commitment to ethnic diversity in the student body. 235 BSA leaders told the Board of Visitors that the undue stress and mental anguish that results from discriminatory attacks inhibit many students' ability to participate fully in University activities, and that a 13th Standard to address the problem would act as a deterrent to potential offenders.236 In April, 1990, the policy's supporters did not believe that the existing standards were sufficient, and they rejected arguments that Standard numbers one, eight and ten could be applied in cases of discriminatory verbal harassment.237

\section{Opponents of a 13th Standard}

Earlier sections of this chapter identified the policy's major opponents. They were: leaders of the University Judiciary Committee, President Robert O'Neil, the General Counsel's Office, and the editors of the student daily newspapers. President O'Neil and the Office of the General Counsel acted behind the scenes by raising pertinent questions with members of the UJC, the BSA, STAND, and other interested parties. They did not campaign actively against the proposed policy. Rather, they offered advice when asked and let the student group responsible for student conduct (the UJC) complete its responsibilities by making its own decisions. The student newspapers' editorial staffs' only visible involvement as opponents was evident in the opinion statements concurring with the UJC decision to reject the 13th Standard, published soon after the UJC's announcement that the 13th Standard was not necessary.

Thus, most of the responsibility for the decision to reject the 13 th Standard must be attributed to the UJC and its leaders. Student affairs administrators at UVA also advised the UJC, but no evidence was found to suggest that the UJC received biased advice from these persons -- either favorable or negative -toward the policy. In a letter outlining the UJC's position on the 13th Standard, the 1990-91 UJC chairman wrote:

... Standard 1 prohibits among other acts, "conduct which threatens the health or safety" of

$235 / d$.

${ }^{236}$ Rector and Board of Visitors' Committee on Intergroup Relations, supra note 220; comments of T. Jackson and M. Howie.

237 ld., comments of $H$. Green. 
university students (i.e.-- assault). To expand this clause as some schools have done (eg. -- The University of Connecticut) to further prohibit dialogue which may precipitate a fight, "fighting words," would force the committee to evaluate situations on a much more nebulous ground, ground which is not so clearly established by the U.S. Constitution. With regards [sic] to this type of change, Robert O'Neill [sic], a renowned first amendment scholar, voices strong opposition citing two primary concerns: The potential backlash in caseload as individuals may too quickly file scores of complaints which are in no way legally sanctionable; and the misdirection by members of the community to look towards the legal systems to curb condemnable attitudes rather than turning to the community itself as a harmonizing force. The members of our team found these and other parallel arguments to be highly convincing. The team then considered the fact that the average student may not quickly realize how encompassing the standards are. We pondered revising the standards with the explicit purpose of more clearly articulating their scope with regards to discriminatory acts. Realizing the massive administrative campaign necessary to bring about such a change, the team felt that its educational efforts could be more efficiently channeled directly towards the students. Currently we are designing a major educational surge aimed solely at enlightening students of the parameters of their code of conduct. ${ }^{238}$

The UJC response reveals several points. The off-hand reference to the University of Connecticut (instead of, for example, U. of Wisconsin, Michigan, etc.) may have been meant as a message to President Casteen to remind him of his unsuccessful experience in court over the University of Connecticut's policy while president there. It may also have been a subtle suggestion to supporters of the 13th Standard that Casteen may not support the policy because of his previous experience (implied to be negative in the text) at Connecticut. President Casteen did not make a public statement concerning the 13th Standard, and available records did not indicate any meetings between Mr. Casteen and the UJC on this issue. The influence of former president Robert O'Neil on the group's thinking is obvious in this passage. The UJC may have been concerned about a large number of cases because of the increased workload on UJC members, but more likely they were concerned that those who brought the cases might be disappointed in the outcome. In other words, the UJC may have feared that students seeking redress for uncivil behavior and harassment would have had higher expectations for the implementation of the rule than was legally permissible, perhaps leading the victims of the conduct (and their supporters) to become angry and blame the UJC for permitting and condoning racist behavior.

The UJC chairman noted that use of the "fighting words" doctrine would have caused the UJC to evaluate cases on more vague and overbroad grounds. However, he failed to note that Standard number eight prohibits disorderly conduct; including "acts which breach the peace or are lewd, indecent, or 
obscene, and which are not constitutionally-protected speech." Under this Standard, disorderly acts that do not breach the peace, are not lewd, indecent, or obscene, would force the UJC to determine whether the act was constitutionally protected expression in the judicial arena, perhaps during the highly-charged setting of a trial. In other words, the UJC declined to develop a position on the issue as a matter of policy, thus forcing students who felt they were the victims of harassment to bring cases, one by one, to the UJC for rulings on matters of constitutional law in the University setting. In his letter, the UJC chairman cited only the fighting words standard as problematic. The UJC had reviewed other forms of discriminatory verbal harassment policies and apparently found them unacceptable too (although this was not explained in the letter). The focus on fighting words was likely a direct response to the proposal made by the BSA and STAND in April, 1990. The UJC members considered the route taken at Stanford -- revising and clarifying existing standards as they relate to discriminatory harassment -- but decided, for whatever reasons, that the task was too large and not worth their efforts.

\section{Conditions Following the Rejection of the 13th Standard of Conduct}

\section{$\underline{\text { Racial Relations after November, } 1990}$}

Two major public events occurred at about the time the UJC reached its conclusion regarding the 13th Standard. The first incident involved a professionally printed, racially derogatory poster anonymously placed at a major intersection adjacent to University Grounds. The poster, displayed during a minority recruitment weekend, contained the words, "Welcome to Virginia...Our peanuts are bigger and our governor is a nigger" stenciled in blue and orange letters (UVA's school colors). ${ }^{239}$ Like the graffiti during the previous semester, the culprits were never identified. Editors of The Cavalier Daily raised no First Amendment issues in the incident and claimed that the sign-makers had violated state laws because

${ }^{239} \mathrm{~K}$. Bonner. "Two students discover derogatory, racist sign," The Cavalier Daily, November 6, 1990, at 1. See also, V. Martin; "Ignorance exemplified by racist sign," The Cavalier Daily, November 6, 1990, at 3. 
of their obvious intent to harass and intimidate. 240 Senior administrators and student leaders condemned the sign's message. 241

The second incident in November 1990 appeared to some observers to be the reverse of the Fiji flier incident. This time, a flier was made and distributed by the Omega Psi Phi fraternity (a traditionally black, service-oriented fratemity), and many whites interpreted the flier as racially motivated and offensive. 242 The flier pictured the muscular upper body of a black warrior carrying a sword in his right hand and the severed head of a caucasian man in his left hand. An outline of the continent of Africa was drawn in the background. The flier contained the words, "Omega Psi Phi presents not another Newcomb Party, but, a Conscious Party."243 Subsequent newspaper reports and editorials indicated that some white students interpreted the flier as a call for violence of blacks toward whites. Members of Omega Psi Phi stated the flier promoted a sense of black pride and showed the resistance of black nationalists in South Africa toward the minority white government. 244 According to the fraternity, the flier was intended to remind blacks at UVA about the continuing problems faced by blacks in South Africa. ${ }^{245}$ Student leaders and administrators -- both black and white -- stated that the flier could easily be misinterpreted, and that it was in poor taste no matter what the group's intentions. ${ }^{246}$ The Omega flier was perceived by some whites to be just as racially offensive (if not more offensive because of the violence portrayed in the picture) as the Fiji flier two years before, and it provided another incident for those who believed that

240Editor. "Sign of hate," The Cavalier Daily, November 6, 1990, at 2.

241 R. Canevari. "Racist sign," The Cavalier Daily, November 6, 1990, at 3.

242A. Rakestraw. "Flier sparks debate," The Cavalier Daily, November 15, 1990, at 1.

243 Omega Psi Phi poster. The Cavalier Daily, November 15, 1990, at 3.

244A. Rakestraw, supra note 242.

${ }^{245}$ Editors. "Ask and learn," The Cavalier Daily, November 15, 1990, at 2.

246 A. Rakestraw, supra note 242. 
racism travelled in both directions at UVA. 247 No judicial action was taken against the Omegas as a result of the flier.

News of the Brown University student's lost appeal over his expulsion for shouting racial epithets in a dormitory courtyard reached UVA in February 1991. The Cavalier Daily reaffirmed its position that any speech code at UVA would be a bad policy, citing again John Casteen's experience with a similar code at the University of Connecticut.248 This was the last public discussion about a discriminatory harassment policy.

Other news stories dominated the student newspapers in the spring of 1991. The United States armed forces involvement in the war with Iraq captured much of the public's attention beginning in January, 1991. In Virginia, the University became embroiled in a controversy over the discriminatory practices of the military and the C.I.A. toward homosexuals and whether such organizations should be allowed to recruit students on campus in light of the University's non-discrimination clause that included sexual orientation as a protected category. In March, three UVA fraternity houses were seized by federal drug enforcement authorities -- with coverage by the national news media --when student residents and members were arrested for selling and distributing illegal drugs. By April, student newspapers focussed on the issue of sexual assault and student demands for a new coordinator for sexual assault resources. In May, the University self-reported possible NCAA infractions in its Athletics Department booster club. Racial issues seemed to have been put on hold while other concerns were in the spotlight.

At the opening of the semester in 1991, President Casteen sent a letter to all University students citing sexual assault, substance abuse and incivility as threats to the sense of well-being and community at UVA. On civility he wrote,

Acts of incivility are yet another threat to our community. We cherish free speech here. This freedom carries with it responsibilities. The University will protect free expression. At the same time, it and its leaders condemn and abhor acts of discrimination, hatred, bigotry, and intolerance

247K. Swanson. "Violent poster interpreted as racist," The Cavalier Daily, November 15,1990 , at 2.

${ }^{248}$ Editor. "Gray lines," The Cavalier Daily, February 14, 1991, at 2. 
directed toward any member of the University community. Students share this responsibility. 249 A poll of first-year students on the issue of discriminatory harassment showed 60 percent of white students did not feel racial tension, while 62 percent of black students did sense racial tension at the University. 250 The poll also indicated that 52 percent of the first-year students believed that students had the right to say anything they think, no matter who is offended, and 48 percent thought the University should regulate student speech. The semester also began with reports of black Charlottesville youths assaulting white UVA students as part of their initiation rituals. 251

The issue of race continued in articles, discussions, forums, and group meetings throughout the 1991-92 academic year with the intensity and frequency of previous years, but without the accompanying protests and demonstrations. A new student organization at UVA concentrating on racial issues began while another, started in 1990, grew in popularity. The Institute for the Healing of Racism began meeting in September, 1991, to promote social action in the community and to heal the wounds of racism. 252 At the UVA law school, groups of black and white students began holding twice monthly dinner meetings to discuss topics of race, gender and class in groups of about ten students each. ${ }^{253}$ The organization, called SUPRA (Students United to Promote Racial Awareness) sponsored groups containing about equal numbers of men and women and participants of different races to reduce the barriers of a majority presence (like the ones experienced in majority-white classes) during the discussions. By

$249 \mathrm{~J}$. Casteen. Letter to all University students, Office of the President, University of Virginia, September, 1991.

250L. Urbanowicz. "A Closer Look' probes University life," The University Journal, September 15, 1991, at 1.

251E. Wong. "Youths assault students on Rugby Road," The University Journal, September 23, 1991, at 1 . These assaults did not involve any black students at UVA, but the racial motivation of the attacks may have strained some students' inter-racial relationships.

252K. Loew. "Organization commences to tackle racism," The Cavalier Daily, September 26, 1991, at 1.

253 T. Small. Letter to E. Beckham, September 18, 1991, SUPRA, University of Virginia School of Law. See also, B. Masters; "U-Va. Students Share Black, White Experiences," The Washington Post, April 21, 1991, at A-8. 
September, 1991, there were seven SUPRA groups.

Most campus informants believed that race relations in 1990-91 were much improved compared to the 1980s. Some of the improvements were attributed to the accomplishments of black students, among whom were (in 1991) the student body president ( 2 consecutive years), the Honor Committee chairperson, one-third of the representatives on student council, and a Rhodes Scholar.254 Others linked successful relations with the efforts of the entire community to be more inclusive of a variety of different individuals and groups, along with structured attempts to focus students' attention on the issues. 255 Still others attributed better relations to the presence of more minority students on campus which informants believed helped minority students feel less obvious and less isolated. ${ }^{256}$

Others believed there was an undercurrent of racial tension at the University that continued to exist, despite some of the positive gains. ${ }^{257}$ Some informants perceived the University administration to be too reactive in addressing racial issues, fixing problems instead of implementing a plan to prevent them from occurring. ${ }^{258}$ Regarding discriminatory harassment, a black administrator stated, "some people think that this environment will tolerate anything. We have not necessarily demonstrated that we won't."259 Some informants were aware of, or had experienced, recent incidents of overt bigotry, 260 Others observed that like-minded whites and blacks tended to "clump" together in single-race groups isolating themselves from

$254 \# \bigvee-7$ at $7 ; \# \vee-11$ at 5.

$255 \# V-11$ at $4 ; \# V-12$ at 5.

$256 \# V-1$ at $2 ; \# V-2$ at 2 .

$257 \# V-9$ at $5 ; \# V-11$ at 2.

$258 \# V-10$ at $3 ; \# V-13$ at 1.

$259 \# \mathrm{~V}-10$ at 4.

$260 \# V-11$ at $2 ; \# V-12$ at 6. 
inter-racial interactions, and that in general, blacks and whites do not often mix socially. 261 A white student observed that

...race is a non-stop topic of discussion here. There are always articles in the newspapers and discussions being held about the racial environment at the University. It has made me more aware of my interactions with others and it makes it more difficult to try and start a relationship with a person of another race. It gets to the point when you are thinking about approaching someone who is black, that I wonder if they are thinking ' he is just trying to talk to me because he wants a black friend, so that he can say that he has one.' Or they might think, 'he is just approaching me because he feels guilty, like he ought to go out of his way to talk to black students.' When you wonder if the other person is thinking about your motivations it makes you question your own motivation for approaching someone. It can make you pretty self conscious about what you say. That is, I think people try to be careful not to offend people they talk to that are of another race. 262

A white professor agreed that there was an air of caution in approaching racial issues and relationships because of an increased awareness of racial issues and a heightened ideological component to issues of race. 263

The decision not to adopt a 13th Standard of Conduct seemed to have little, if any effect on race relations. Some black students were not disappointed with the outcome of the 13th Standard debate because, although they hoped it would be approved, they expected it to fail. ${ }^{264}$ This was a case of these students refusing to get their hopes up in order to avoid having to experience a let-down, and for some it confirmed an already negative attitude about the University's willingness to aid minorities through structural changes. ${ }^{265}$ Relations between the BSA and the UJC were reportedly better after the decision was articulated, according to a white UJC member, but the improvements were attributed to the discussion

$261 \# V-14$ at $1,2$.

$262 \# V-14$ at 3.

$263 \# V-12$ at 1.

$264 \# \mathrm{~V}-10$ at $8 ; \# \mathrm{~V}-13$ at 2.

$265 \# V-10$ at $8 ; \# V-13$ at 2. 
about the Standards, not the final decision. 266

\section{Application of the Standards of Conduct in Cases of Discriminatory Verbal Harassment}

Cases brought before the University Judiciary Committee are kept confidential, and student members of the UJC are not allowed to discuss the cases, even after they have been resolved. By October, 1991 , no students had been found guilty of discriminatory verbal harassment under the Standards of Conduct. ${ }^{267}$ However, two cases had been filed: one against a group and the other against an individual. 268 One of the cases was described as a situation in which students approached the UJC for advice on whether a particular incident might be considered a violation of the Standards, and they were told that it would not. 269

The UJC's review of the issue led its members to believe that in cases of harassment, the line would be drawn "between something that might just hurt someone's feelings and something that becomes threatening or disorderly."270 The language of the Standards prohibits: 1) conduct that threatens the health or safety of persons at the University (\#1),2) damage to personal or University property (\#2), 3) intentional disruption of University, or other authorized, activities (\#4),4) acts which breach the peace, are lewd, indecent, or obscene, and which are not Constitutionally protected speech (\#8), and 5) violations of federal, state, or local law not covered in the Standards of Conduct which directly affect the University's

$266 \# V-3$ at 5.

$267 \# \bigvee-2$ at $4,5$.

$268 \#$ V-3 at 6.

$269 / d$.

$270 \#$ V-3 at 1. 
pursuit of its proper educational purpose (\#10).271 Harassment which crossed any of these lines could have been considered a violation of the Standards of Conduct. The students who sat on the UJC committee during a particular case would have to draw the line between protected and unprotected speech. Rather than clarify its position on what is or is not protected speech in a policy arena, the UJC determined it would be best for the judiciary members on a particular case to reach that determination during a trial (where the decision and the rationale for it would be shielded from public scrutiny by rules of confidentiality). Informants for this study were divided on how they thought the UJC would handle some of the major public incidents which had occurred here in 1988-90. One informant who had expertise in legal matters believed that many of the major public racial incidents at UVA would not be punishable under the existing Standards. ${ }^{272}$ Some student leaders believed that some judicial sanction would come from a case involving, for example, the derogatory poster about Virginia's governor. ${ }^{273}$ Editors of The Cavalier Daily cited Section 52.8.5 of the Virginia Code, establishing the illegality of acts intended to intimidate and harass, writing that "the sign clearly qualifies." 274 The student editors did not raise the communicative aspect of the sign as a complicating factor in determining that a punishment was due to the sign-makers. It remains unclear how the UJC would interpret the existing Standards of Conduct in cases of discriminatory verbal harassment. Without benefit of the knowledge of any judicial history in UJC cases, students have few benchmarks which would help them predict the types of expressive conduct that might lead to a trial or a conviction before the UJC.

\section{Conclusion}

Several factors and conditions described in this chapter led the University to maintain its existing Standards of Conduct to address problems of harassment. Three of these factors involve fairly pervasive

271Rector and Visitors of the University of Virginia, supra note 2 at 27-28.

$272 \# V-4$ at 4.

$273 \# V-11$ at 7.

274 Editor, supra note 240. 
features of the campus environment. Another factor related to the prevailing legal and social climate surrounding similar policies enacted or being considered at other universities. The ruling against Michigan's harassment policy and the case then filed against Wisconsin's UWS-17 suggested that UVA should proceed very carefully. Virginia's then president, a First Amendment scholar, was well versed in the legal risks and pitfalls associated with such policies.

The first of the campus conditions was an over-riding value of tradition, exemplified by the constant reminders of the influence of Thomas Jefferson. The University community valued tradition and stability over change, so that those who proposed changes to the environment would have to present their case well and persist in their support. For example, the UJC began its work with a presumption against change, looking first at the existing Standards of Conduct to see if they were sufficient to handle cases of discriminatory harassment. The tendency to value tradition and stability was not unique to UVA, but this inclination seemed strongest at UVA.

A second -- and considerably weaker -- related environmental factor encompasses a community attitude of independence (mixed with superiority) over the traditions, practices and approaches taken by other colleges and universities. There is a sense among many university community members that $T H E$ University is unique and therefore perhaps better than other similar institutions. Other institutions had implemented policies to combat discriminatory verbal harassment, and that may have been reason enough for some to react negatively when a similar policy was proposed at UVA.

Third, the University's system of student self-governance, although a great strength in most areas, can work against the implementation of significant changes. Students assume responsibility for many University issues and learn a great deal in the process. However, student leaders often hold their positions for only a year or two, work in these roles part-time, and must often rely on their successors to continue the fight for important objectives. Consensus-building on issues of consequence takes time, often more than one academic year, and the transient nature of student leadership limits their ability to build consensus over time. This is especially true at UVA where few rules exist for adopting non-academic regulations. 275 
The student coalitions formed at UVA were arguably weaker than necessary to make the majority of decision-makers believe in the necessity of changing the conduct codes. Too, the proposals for change at UVA, only one of which was the 13th Standard, were already numerous. The alleged bias in the University's Honor System and divestment of University holdings from South Africa were the dominant perennial issues. The attention of students supporting changes toward a more inclusive environment was diffused among their many proposals. The Black Student Alliance and Lesbian/Gay Student Union fought hardest for the new Standard of Conduct, but their uneasy partnership reduced their ultimate effectiveness. Other racial and cultural minority groups remained in the background, and few white students were ever actively engaged in support of the issue. Two of the primary influences on public opinion, the student daily newspapers, both argued against the 13th Standard every time it was raised as a realistic possibility. The University's senior administration and student affairs division kept their opinions on the issue to themselves (except when asked for advice, by student leaders) and out of public view. 276 Their lack of public support could have been perceived as tacit disapproval.

The Fiji flier situation was probably not the best incident to rally around in support of an antiharassment policy. Few believed the Fiji incident to be a case of intentional harassment. It was perceived as insensitive and adolescent, but it was neither intentional nor individually incendiary. Even the potentially racial phrase in the flier, "nega," was commonly believed before and after the event to have no racial overtones in and of itself. In combination with the Fiji man character and the phrase, "short wops," the term "nega" became more suspect. Still, the argument to be made here was one of institutional or societal racism, not harassment; the proposed response (anti-harassment policy) did not seem to match the incident (institutional/societal racism). The other potential rallying points -- the graffiti incident and the poster degrading Virginia's black govemor -- had no identifiable parties to accuse and subsequently to determine the UJC's ability to handle a test case.

committees and procedures for non-academic student conduct policies.

276 The reasons for the lack of public engagement by the administration may have been because of its strong reliance and support of the philosophy of student self-governance and because the legal issues raised by the proposed 13th Standard posed serious First Amendment problems for UVA as a public university. 
Although cases of racial insensitivity among whites were apparent every year, a number of events involving black students and local black community members may have mitigated the perceived need for a policy on harassment to protect minorities from harm. Whites, too, could point to examples of racial incidents with black protagonists. Some of the incidents involved physical violence of blacks toward whites, another involved blacks being sold as "slaves" by other blacks, and another situation developed in which a flier distributed by a black fraternity was perceived to be racially offensive. These types of incidents made it more difficult for whites to believe that blacks were being made victims by the environment because of their race.

The University's repeated successes in recruiting and retaining talented black students, and the election of many black students to the highest levels of student government reduced the "outsider" argument made by some black leaders in support of the proposed policy. Black students were included and celebrated in the most important student leadership positions on Grounds. Larger numbers of black students allowed more freedom within the black community to express divergent opinions, and increasing numbers of black students made unity among blacks nearly impossible to achieve.

Timing and serendipity may have been as important a factor as anything described above. The BSA chairman left UVA just after the UJC announced its ruling on the 13th Standard proposal (fall, 1990). The beginning of the following semester marked the start of a series of well-publicized, controversial issues at the University that had the effect of pushing the 13th Standard out of the community's consciousness. It was coincidental that the president during the start of the debate over an additional Standard was an expert in Constitutional law and ironic that his successor came from another university where its discriminatory harassment policy was found unconstitutional.

Finally, the deliberate actions of the UVA administration and concerned students and faculty helped in healing the wounds caused by the occurrence of several major racial incidents. The administration and student leadership quickly and publicly condemned racist conduct, and followed this by sponsoring and participating in numerous forums and discussions on racism. Black and white students at the law school began sharing meals and conversations about race and other social issues. Two first-year students created and implemented an Apartheid simulation event for the entire campus. Black student leaders and Jewish 
student leaders planned and held joint social and educational programs. These events and others, both public and private, helped shape the outcome of the proposal for a 13th Standard of Conduct. 


\section{Chapter Seven}

\section{Summary and Conclusions}

This summary and conclusions highlight important aspects of the case study chapters. It shows many of the similarities and differences in the approaches taken to address the problems associated with discriminatory verbal harassment by Stanford University, the University of Virginia and the University of Wisconsin-Madison. The format of this chapter resembles the case study chapters in order to maintain continuity and parallel structure among the last four chapters. The first section compares important historical, structural and organizational factors and conditions that provided the context for each university's discussion about a proposed policy on discriminatory verbal harassment. The next section provides a comparison of the racial conditions and major racial incidents at the three institutions in this study. The third section relates the commonalities and differences among the universities' political factors and conditions, and the fourth section compares the relevant events during the policies' presentation for approval at each campus. The last section contrasts some of the outcomes of adopting a new policy addressing discriminatory verbal harassment with the outcomes of not adopting a policy.

\section{Historical, Structural, and Organizational Factors and Conditions}

Several factors influenced the policy outcomes at the three universities in this study. First, differences among public and independent governance structures affected the level of institutional autonomy each university experienced. For example, a public university faces different legal and political issues than an independent university because of its incorporation as a state government agency and because it serves different constituencies. Second, the wording and structure of the student conduct codes in force when the issue of a new policy arose influenced the structure of the final policy decision. Third, the level of an institution's reliance (or lack thereof) on historical figures and traditions to guide policy decisions played a role in the harassment policy decisions. Fourth, the processes for adopting non-academic regulations may have affected the policy outcomes at each institution. 


\section{Public and Private Institutions}

One of the University of Wisconsin's distinguishing features in this policy debate was its inherently public nature. The centralized structure of higher education in Wisconsin required student conduct policies to be promulgated at the System level by the Board of Regents rather than at the individual campus level. The location of UW-Madison--the flagship campus--near the State Capitol, its size as a state agency, and its perceived influence in the region fostered great interest among legislators and the general public in this controversial issue. As a system-wide policy, UWS-17 applied to all of the approximately 160,000 students in the UW-System. The number of people touched by such a policy decision in Wisconsin far surpassed the numbers at Stanford and UVA combined. Another feature most obvious in Wisconsin was the entrance of state legislators, the American Civil Liberties Union, and the general public into the university's debate in an attempt to influence university policy.

At the other end of the spectrum, Stanford University's independent status limited outside influences during the debate over changing its Fundamental Standard. Stanford's prestigious status among the top American universities opened it to public scrutiny among journalists and others during the discussion of its controversial policy. However, a group of faculty and students made the final policy decision. Even Stanford's Trustees publicly remained silent on the proposed policy. The A.C.L.U. (and perhaps state legislature) focussed more attention on public universities in California than on Stanford. Although aware of the university's independence as a legal matter, some Stanford policy-makers and students recognized that the policy developed there may be used as a model by other campuses debating similar issues, thus making their deliberations all the more serious. 1 Constitutional law principles prevailed because of the University's institutional commitment to uphold them, but Stanford was free to

1 Chapter six showed that the Black Student Alliance at UVA was influenced by the Stanford policy and adapted it in their proposal for a 13th Standard of Student Conduct. This suggests that the responsibility assumed by some Stanford community members' for leading the national discussion on such issues was not unfounded. 
consider non-legal policy implications in ways that UVA and Wisconsin, as public universities, could not. ${ }^{2}$

Responsibilities and requirements placed upon UVA by the Commonwealth of Virginia limit the University's autonomy relative to Stanford, while UVA's standing as an autonomous state agency governed by its own board allows it more freedom than system-related, branch campuses such as UW-Madison. Policies approved by UVA's Board of Visitors must conform to prevailing interpretations of Constitutional law as a legal matter. No evidence indicated that the state legislature, the A.C.L.U., or the general public were concerned about the proposed policy at UVA (in fact, there was little to indicate that the UVA community generally was concerned about the proposed policy). The University's Board of Visitors was aware of a proposed additional standard of conduct, but the proposal never reached the Board for formal action.

\section{Existing Student Conduct Codes}

The structure and wording of the existing student conduct codes presented another important difference among the three universities. Wisconsin adopted its conduct codes in the aftermath of campus unrest in the 1960s. Policy makers wrote the codes in legalistic language with very specific terms and policies. No specific policy existed to address the cases of offensive expression, like those at UW-Madison fraternities, when the issue of discriminatory expression first arose. Wisconsin officials wrote the new policy to conform with the structure and format of its other policies. The new revisions, in theory, left little room for policy interpretations at the Wisconsin branch campuses since one policy applied to each and every setting. System-wide policies were written with great specificity and with the expectation of consistent application among the various branch campuses. In contrast, Stanford's first president wrote its 100-year old one-sentence code of student conduct. However, Stanford's code allowed for case-by-case

2The reader will remember that Stanford elected to abide by the U.S. Supreme Court's interpretation of the First Amendment of the Constitution as a matter of institutional policy. However, this policy is voluntary and not mandated by Federal or State law. 
interpretation among those delegated with its application ${ }^{3}$ Like other issues described earlier in this section, UVA's existing student conduct rules occupied a moderate position among the schools. The UVA code of student conduct included a two-paragraph preamble and twelve individual standards of conduct covering most non-academic aspects of student life. The Standards of Conduct also referred to areas of student life not addressed specifically in the Standards, such as the University's student housing regulations and the laws of the Commonwealth of Virginia. For example, students at UVA who violated state laws not enumerated in the UVA Standards of Conduct could have faced student judiciary charges for their behavior. This caveat allowed UVA's University Judiciary Committee (UJC) to argue that the existing Standards of Conduct would be applied in cases of harassment where other rules--such as state laws or student housing contracts-were violated. 4

\section{Campus Traditions and Values}

Campus traditions and values influenced the deliberations over the adoption of new student harassment policies. For example, a salient and distinguishing historical feature at the University of Virginia is the influence of its founder, Thomas Jefferson. The UVA community values its many traditions and promotes many Jeffersonian beliefs about education and university life. There is a joke at UVA that an event is considered a tradition if it happens twice. This condition helps the University sustain many valuable traditions, but on occasion it can result in community perceptions of a certain resistance or slowness to change. This does not imply that UVA does not change, or is resistent to all changes. Dramatic changes have occurred at UVA, especially in recent times, and they will continue to take place as the institution adapts to the changing demands of its many constituents. However, some constituents of the school endeavor to preserve the status quo in ways not as evident as Wisconsin and Stanford in the late

3 Stanford judicial administrators lent consistency to their policy applications over the years by periodically publishing examples of how the Fundamental Standard had been applied, thereby informing the community about traditional behavioral expectations.

4 Although this same argument was used at Stanford, that the original Fundamental Standard should be applied in cases of discriminatory harassment, it was not as effective as it was at UVA. Others at Stanford argued (more forcefully) that the existing FSI was inadequate (see Chapter 5). 
1980s. Examples of UVA's reluctance to change were evident in its (relatively recent) experiences with the admission of black students (1960s), coeducation (1970), growth in the student body (1970-90), challenges to the Honor System's single sanction, and course requirements from non-western perspectives (1990present). However, Jefferson--well known as an advocate of freedom of thought, religion and the rights of the individual--might have viewed skeptically any policy believed to limit individuals' rights. This inference did not escape the proposed policy's opponents at UVA.

Like Virginia, the Wisconsin and Stanford communities celebrate campus heroes and important local historical figures, but they did not receive the same reverence as Jefferson did at UVA. Because of the different historical factors, these communities may have been less resistant to change than UVA, and may have more quickly considered a policy change as a corrective measure to ameliorate racial hostilities and uncivil behaviors. Traditions at UVA only partially influenced the outcome there. The legal climate toward similar codes elsewhere was a dominating factor limiting support for UVA's proposed 13th Standard of Conduct. Legal opposition to the policies, for example, at the Universities of Michigan, Wisconsin, and Connecticut caused justifiable caution among students and administrators. Stanford's historical hurdle--its 100 year old Fundamental Standard of student conduct--constituted an important facet of student life. But, at Stanford the adoption of the FSI may have been related to the strength (or weakness) of support among undergraduates for the original Fundamental Standard. Administrators there observed that some undergraduate students requested more specific policies because they believed the Fundamental Standard to be too vague. With the exception of the recent FSI, some Stanford officials stated that the Fundamental Standard was a more effective educational tool without a list of specific offenses and punishments. Officials argued that the Standard's ambiguity forced students to consider and then judge their own behaviors according to local community standards, instead of calculating ways to evade punishment for specific offenses. Still, the Fundamental Standard influenced fewer aspects of Stanford's campus life than did Jefferson at Virginia. The University of Wisconsin had neither a dominating historical figure nor an historical policy to influence the adoption of revisions to its conduct codes. 


\section{Procedures for adopting non-academic regulations}

Procedures for adopting non-academic regulations influenced the policy outcomes at the three universities. Groups that supported new policies prohibiting discriminatory verbal harassment at each institution operated in campus climates of varying degrees of support for these potentially risky policy changes. Policy-making bodies began their work by examining the existing policies and procedures (within the larger context of the underlying campus climate toward new policies) before drafting new policy proposals. Then, each policy-making group worked within its campus's existing processes for adopting new policies to propose any changes. The three different processes, outlined in Chapters four, five and six, slowed the policy enactments at Wisconsin and Stanford, and helped stall Virginia's proposed policy.

Wisconsin and Stanford have lengthy and somewhat complicated written procedures for the adoption of new policies. The procedures are designed to allow for in-depth study of an issue, to permit divergent opinions to be heard, and to build consensus among different constituents. Lengthy, consensus-building policymaking processes also prevent hastily made decisions from occurring easily. Such a process also preserves campus stability, thus allowing community members to better predict the consequences of their actions.

The process at Virginia achieves similar goals. At UVA, the few guidelines for adopting nonacademic student conduct rules may require greater student persistence to achieve a desired change. Students have a limited time in which to understand the decision-making environment and a short time in which to work toward change. Student transience exists at Stanford and Wisconsin too, but the effects of students' temporary residence are exacerbated at UVA where responsibility for the judicial system has been delegated entirely to students. The tradition of student self-governance persists at UVA for many reasons. The educational and social values fostered by student participation in self-determination are believed to outweigh any potential drawbacks. Faculty and administrators serve in the judicial systems at Stanford and Wisconsin, adding stability and continuity in ways that students cannot. However, despite their transience, students at UVA may more strongly support their judicial and honor systems because they live with the consequences of their own decisions.

The rule-making process at the University of Wisconsin System typically involves soliciting 
input from each branch campus and from specific affected constituencies. The enactment of new policies requires public hearings, the approval of the Board of Regents and action by both houses of the state legislature. Under ideal conditions the process takes upwards of six months to complete after the Board of Regents approves a policy. 5

At Stanford, a committee of faculty and students considers and acts on policy matters after allowing periods of public comment and opportunities for interested groups to be heard. A strong negative community reaction received in response to a proposed policy may squelch the proposal altogether, or the committee may revise and re-submit other versions until one is adopted. New policies may be enacted in a minimum of 35 days. Stanford officially began considering changes in its Fundamental Standard in February, 1989, and after lengthy and heated debate, the FSI took effect in June, 1990.

At UVA, proposed policy changes typically originate with the office or organization directly responsible for carrying out the policy. In this case, the organization was the University Judiciary Committee (UJC), a student-run group responsible for applying the twelve Standards of Conduct for students. The UJC considered an additional standard of conduct primarily under pressure from the UVA Black Student Alliance, the Lesbian and Gay Student Union, and a few other supporters. Without the full support of the UJC, the faculty, the student body and the senior administration, the proposal was unlikely to be approved by UVA's Board of Visitors. The UJC did not support the proposal (for reasons discussed in Chapter 6). The students who supported a 13th Standard of Conduct received advice from various administrative and faculty sources concerning how best to proceed with the proposal. Ultimately, changes in student conduct policy require its supporters to be persistent and resolute. In this instance the supporters ended their fight when the UJC determined that existing standards could be invoked to address cases of discriminatory verbal harassment. 


\section{Racial Climate Prior to the Decision on a Discriminatory Verbal Harassment Policy}

\section{Characteristics of Public Racial Incidents}

The types of racial incidents (detailed in chapters four through six) that led to policy debates over harassment and protected expression shared many common traits. Stanford's Ujamaa House incident, UWMadison's Fiji Island Party, and UVA's Fiji Flier incident each involved (depending on how the events are interpreted) white undergraduate students who behaved insensitively, naively, and/or without understanding or considering fully the possible consequences of their actions. Each major public incident occurred on campuses where minority students had objected to other instances of perceived racism (both institutional racism and individual racism). Controversies involving race ebbed and flowed with various incidents and changes in campus leadership. Each campus in the late 1980s completed a lengthy study and published a detailed report on the condition of campus racial relations. None of the incidents cited above was the first racial incident reported on those campuses, but they were among the first incidents on each campus to raise the question publicly of what limits a university could or would place on student expression regarding race. Black students were portrayed as the 'victims' in each of the primary incidents, and the campus black student organizations led the fight for policy changes to address the offenses.

Several differences marked the experiences at the three universities. At UW-Madison, a series of fraternity-related incidents occurred, each with white and/or Jewish initiators and each considered offensive to black members of the University community. At about the same time, a few well-publicized incidents of violence of whites toward blacks transpired in the city of Madison (not necessarily student or University related, but perceived by many blacks as 'more of the same' type of racist behavior). The recurring episodes suggest that some white students seemed not to have learned from the earlier incidents. While one group repented for its insensitive or offensive behavior, another group created its own outrage. The University gained a reputation as a hostile place for black students among many of Wisconsin's minority residents, and the damage done to the University's ability to recruit and retain black students may have seemed almost irreparable. A sense of urgency to the situation developed among many University constituencies. These constituents recognized that the University must direct a substantial effort to solve the problem. Despite all 
of the circumstances and pressures at Wisconsin at the time, the University's first policy prohibiting discriminatory verbal harassment passed by a narrow margin of Regents' votes (8-7; The final vote widened to $12-5$ after the rule passed through the state legislative hearing process).

Stanford University experienced two major public incidents. The Ujamaa House incident, involving the defacement of a Beethoven poster, struck an emotional pitch among Stanford's black students that few would have predicted. The disingenuous and patronizing apology of one of the students who defaced the poster seemed unforgivable to many Ujamaa residents, and it served to increase even further the tension among minorities and whites. The incident became a symbol of everything that was wrong with black-white relations at Stanford. It also provided momentum for minority students at Stanford to reinforce their resolve to work toward their objectives, including the implementation of a policy to prohibit racial harassment.

The series of events at UVA differed from both Stanford and Wisconsin. The University of Virginia's first major incident sparking the discussion about new conduct policies, the Fiji flier incident, involved a more ambiguous case of racial insensitivity, unlike the major incidents at Wisconsin and Stanford. Fiji members appeared more apologetic than the culprits at Wisconsin and Stanford. The Fijis' seemed more racially naive than hostile, unlike the offenders in some later UVA incidents. The culprits of some of UVA's subsequent major public racial incidents remain unknown. These factors complicated the rationale for the proposed policy among its supporters. The Fiji flier incident rested a claim of racial harassment on a situation believed by many to be non-racial. Subsequent incidents involving anti-black graffiti and posters resulted in no identifiable malefactor. The anonymous nature of the laier acts signalled to some observers that the campus environment already was uncomfortable for people with negative feelings toward minority students (as well as being obviously uncomfortable for the targets of the attacks). Perhaps out of discomfort with what they perceived to be a prevailing view, the Virginia culprits created hateful messages under the cover of night to express their beliefs. 6 Some argued that a new

6This condition is similar in some ways to the Ujamaa incident at Stanford because the identities of the two men responsible for defacing the poster of Beethoven were not known for over two weeks following the act. The identity of the person(s) who defaced the second poster at Ujamaa House were never discovered. The Beethoven poster culprits contended that they 
policy would keep graffiti artists and other anonymous harassers underground, while educating such persons required the University to provide more frequent civilized opportunities to discuss issues of race.

Ultimately, UVA students chose educational measures to address the problem of racial hostility.

Interspersed among the racial incidents at UVA in which whites aggrieved blacks were several incidents of blacks behaving violently against whites. Another situation involved a black fratemity that held a 'slave auction'--an event reminiscent to some observers of the real slave auctions of the old south-and sold the services of its pledges to other students. These events contributed, in part, to the belief among some whites at UVA that both blacks and whites perpetuated racism, not just whites. This belief weakened the proposed policy supporters' arguments that minority students needed special protection from harassment in the form of a new policy, since whites also were the targets of harassment. It also made more legitimate the fear that such a policy might be used against minority students by offended white students, just as it could have been applied in cases where minority students had been wronged by whites.

\section{Recruitment and Retention}

One measure of student satisfaction is the rate at which current students remain enrolled at a university. Another indication can be the rate at which new students enroll (presumably, if campus life is known to be bad, then students may choose not to attend). During the period when many of the racial incidents occurred at the three universities, Stanford and UVA maintained consistent numbers of minority students. At UVA, the number of incoming black first-year and transfer students actually increased to record levels in the late 1980s and 1990 despite the University's well-publicized racial events. Some UVA administrators attributed the success in admissions to the many achievements by black students during this time period and to the number of black students who had earned the highest leadership positions in student government organizations. The reverse was occurring at UW-Madison. Some black students left UW-

intended their action as a prank toward a person whom they knew and someone who they expected would find humor in the exaggerated caricature they created. The second poster at Stanford, the professionally printed poster found at UVA demeaning Virginia's black governor and the anti-black graffiti painted in spots frequented by black students at UVA were arguably more hostile and more intentionally demeaning than the Beethoven poster. 
Madison and the recruitment of first-year black students dropped precipitously in the wake of some of the major racial incidents there. This factor may have weakened the policy supporters ' rational for the proposed 13th Standard since it became difficult to contend that the racial incidents had serious negative effects on minority student enrollment or performance. This does not imply that the events were not serious or without serious consequences for many students. However, the University of Wisconsin's enrollment difficulties escalated the level of seriousness. In contrast, Wisconsin's problems with minority student enrollment served as a primary force in moving forward the adoption of revisions to its code of student conduct.

\section{Political Factors and Conditions}

\section{Minority Student Coalitions}

Strong minority student coalitions led by black student leaders at Stanford and UW-Madison mobilized broad-based support for anti-harassment policies on the two campuses. By using major public racial incidents as rallying points, minority student leaders (including black, Hispanic, Asian, and Native American student groups) illustrated the kinds of racial insensitivity and intolerance they experienced on their campuses. In its efforts to promote a policy to curb harassment, the UVA minority coalition appeared to be the weakest of the three universities. ${ }^{7}$ Primary participants included leaders of UVA's Black Student Alliance and the Lesbian and Gay Student Union.8 Student coalition members at Stanford and Wisconsin pressured campus officials to consider their demands by holding sit-ins, demonstrations, marches and speeches, and by participating in the normal campus governance structures to effect change. Too,

7On related political matters, the minority coalition was successful in persuading the UVA Board of Visitors to divest the University's stock hoidings in companies operating in South Africa. The coalition was less successful in its attempts to change the University's general course requirements to include more non-Western requirements. Both Stanford and Wisconsin made curricular changes that instituted non-Western requirements.

${ }^{8}$ Readers will recall that there was some reluctance among the two groups to join forces on this issue. The reluctance was reportedly only on the part of the BSA. No consistent theme developed among the rationales offered to explain this phenomenon. 
students placed the proposed anti-harassment policies as a top priority among their demands for changes. At UVA, the attention of the BSA focussed more on the University's investment policies in companies conducting business in South Africa than on the proposed anti-harassment policies. At each of the three schools, harassment policies were used by minority groups and their supporters as a political device. The policies were one of many race-related demands placed before the administration by students. If a university chose not to adopt a new harassment policy, the institution's leaders faced being portrayed as racists or, at least, as insensitive to minority students' needs and concerns.

\section{Level of Faculty Involvement}

The level of faculty involvement in the development of the policies at each institution differed. No faculty involvement at UVA was recorded. ${ }^{9}$ Faculty members at UW-Madison served on the Student Conduct Policy Committee and a few law faculty consulted with the Committee on legal matters. The UWMadison faculty senate discussed and then approved the initial draft policy developed by the Madison committee, and later it approved modifications to the UW-System policy crafted after the first System-wide policy was struck in court. ${ }^{10}$ Stanford faculty members from a variety of disciplines debated the interpretation of the Fundamental Standard. They wrote editorials for campus publications, sent responses to the electronic bulletin board established to collect campus opinion, and held discussions in the residence halls where they lived and worked as faculty fellows. Some of the Stanford law faculty wrote articles for local and national publications, participated in public debates, and discussed the subject at length in law classes. The Stanford faculty senate debated proposed interpretations to the Fundamental Standard at length on two occasions (although they were not requested to take any formal vote on the proposals) where they gave bitterly divided opinions of the proposed interpretation. Many faculty there actively participated in the

9This should not be surprising because UVA's student self-governance system severely limits the influence of the faculty in policy matters affecting student life. The proposed policy was portrayed purely as a student issue from the outset.

10The UW-Madison campus is so large $(42,000$ students) that it is probably feasible only for a few representative faculty members to become engaged deeply in issues of this nature. 
debate and argued with great interest and investment in the outcome.

\section{Level of Involvment Among Goveming Boards and Presidents}

The involvement of the presidents and the governing boards varied among the three universities. Several interview participants at Wisconsin stated that Chancellor Shalala effectively promoted codifying restrictions on discriminatory verbal harassment. Kenneth Shaw, then president of the UW-System, brought a System-wide policy proposal to the Wisconsin Board of Regents for its consideration and ultimate approval. Board members and senior officials sponsored public forums regarding the policy and heard testimony from UW-Madison legal scholars, A.C.L.U. representatives and others. The level of involvement of Chancellor Shalala, President Shaw and the Board of Regents' exceeded that of their counterparts at Virginia or Stanford.

The Stanford Board of Trustees remained silent regarding its campus's proposed policy. President Donald Kennedy voiced public skepticism about the wisdom of adopting the Fundamental Standard Interpretation, but he chose to allow the decision of the Student Conduct Legislative Council (SCLC) to stand when the Council adopted the new interpretation. Kennedy was not identified as a key participant in the development of the revised policy. He allowed the SCLC to work independently and did not directly influence the outcome.

University of Virginia's president, Robert O'Neil (1985-1990), spoke publicly and published opinion pieces (after his resignation as president) opposing campus policies prohibiting discriminatory verbal harassment. However, the level of his influence during UVA's consideration of an additional standard of student conduct is unclear. The student-run University Judiciary Committee (UJC) consulted with Mr. O'Neil about possible policy changes at UVA after he announced his resignation as president of the University and after his successor, John Casteen, was named. Casteen neither spoke publicly nor published his views on such policies. Some persons at UVA who were concerned with the proposed policy may have 
assumed that both Mr. O'Neil and Mr. Casteen opposed an addition to the existing standards of conduct.11 Such an assumption may have discouraged some from the active promotion of an additional standard relating to harassment. Some supporters may have believed their attempts to persuade the Board of Visitors to be futile without the support of the president and senior administration. Interview participants and available documentation indicated that the two UVA presidents operated as consultants to students on this issue when the students approached them for input. However, by all accounts the decision whether to recommend an additional standard of conduct was presumed to be the students' purview.

Virginia's Board of Visitors was more involved than Stanford's Trustees but less involved than Wisconsin's Regents regarding its proposed discriminatory harassment policy. The UVA Board of Visitors created from among its members the Special Committee on Intergroup Relations to study racial and other similar problems at the University. In its only meeting the committee heard proposals for an additional standard of conduct designed to address cases of racial harassment against students. The Committee took the proposals under advisement. The committee never met again. The full Board of Visitors never heard or considered a proposal for the additional standard of conduct. There was no evidence of communication between members of the Board of Visitors and members of the University Judiciary Committee on this issue.

\section{Discussion and Development of a Policy on Discriminatory Verbal Harassment}

This section summarizes the positions argued by supporters and opponents of the policies designed to curb discriminatory verbal harassment at Stanford, the University of Wisconsin and UVA. The rationales advanced during the three debates contained more similarities than differences. The impetus for each policy

$11 \mathrm{Mr}$. O'Neil may have been believed by some to be an opponent to the additional standard of conduct because of his Constitutional Law background and his public statements against similar policies at other universities. Mr. Casteen may have been perceived as an opponent to the additional standard because of UVA student newspaper editorials describing his experience with a similar policy at the University of Connecticut (while serving as its president). Connecticut's initial policy was found to be unconstitutional and was revised. There was no record to indicate the two presidents' specific positions on UVA's proposed policy. 
discussion began with an incident perceived to be racially offensive toward blacks. When students and administrators tried to address the issue through the application of existing student conduct codes, the codes proved ineffective or unclear.

Supporters of Wisconsin's policy (UWS-17.06) maintained two primary arguments for change. They were: 1) to help make the campus environment more hospitable for minority students so they could pursue their scholastic work without undue interference, and 2) to help improve the University's recruitment and retention efforts for minority students. The University and its students believed that of lesser importance initially was the policy's symbolic value (symbolic as a measure of the University's support for minority students). Some campus community members who supported the concept of a policy against racist speech criticized UWS-17 for stopping short of reaching the kinds of expression -- like the series of fraternity-related episodes that negatively affected the community at UW-Madison in recent years. The issues of recruitment and retention were seldom stated as a rationale for the policy proposals at Stanford or UVA. Maintaining minority enrollments was characterized as a potential problem, not as a current problem, when the issues were raised at those universities. Stanford proponents promoted both practical and symbolic rationales for the policy. To some, the University's support for the policy became as important as the actual impact of the policy on hateful student behavior. Supporters at UVA contended that harassers could go unpunished under the University's existing policies, although this argument went untested in the University's judicial system.

Most opponents of Wisconsin's UWS-17, Stanford's FSI and UVA's 13th Standard argued that the policies went too far because they infringed on students' free speech rights. Opponents of UWS-17 criticized the policy for being vague and overbroad. They raised concerns about the enforcement of the policy, especially in cases where students could be punished for "comments and other expressive behavior." Several opponents considered the policy too broad because it did not adopt the requirement that the expression must be intended and likely to produce an imminent threat of violence. 12 Opposition to Stanford's FSI decreased markedly after the release of Tom Grey's revisions to earlier drafts. Opponents to the final FSI contended that the policy would chill discussions of controversial issues in the classroom

12 The second version of UWS-17 addressed both defects. 
and elsewhere on campus. Others complained the FSI was not even-handed because traditionally disadvantaged groups received greater protection against offensive expression than whites. Virginia's UJC rejected an additional standard of conduct because it believed the existing standards were sufficient to handle cases of individual harassment of students. The UJC also perceived potential ambiguities in the proposed policy's application. The UJC cited as additional reasons for rejecting the proposal a potentially burdensome caseload and the misdirection of the University community in seeking legal redress for issues the UJC believed would be best solved by the University community as a whole.

\section{Conditions following the Adoption or Rejection of a Policy on Discriminatory Verbal Harassment}

This section summarizes the similarities and differences of some of the campus conditions following each university's decision to adopt or reject its proposed policy on discriminatory verbal harassment. The summary focusses on campus racial relations, the policy's application (if any), and the policies' effects on academic behavior. The universities' proposed policies against harassment were but one issue among several racially charged issues debated from 1985-91. Changes in race relations resulted from a complex mix of events, persons, environments, perceptions, attitudes, policies and programs. Taken in isolation, discriminatory verbal harassment policies' impact on campus race relations cannot accurately be determined. All three universities continued to experience many of the same racial issues that were present before the policy debates. This condition alone may indicate that the policies themselves had little impact in preventing uncivil, race-related behaviors among students.

\section{Racial Relations}

Some UW-Madison students believed that racist behaviors occurred after the adoption of UWS-17, but they perceived the incidents to be more subtle than before. Declining minority enrollments continued after the adoption of UWS-17. Wisconsin administrators interviewed believed that the campus had maintained or improved the quality of its racial relations following the adoption of UWS-17. They pointed specifically to the absence of major public racial incidents (like those that led to the adoption of the policy) 
following the promulgation of the rule. Administrators attributed the improvements in race relations to a series of policies and programs--one of which was UWS-17--designed to improve the campus racial climate. No differences in racial relations were reported at Stanford following the adoption of its FSI. Some Stanford students still believed that different non-white racial groups pressured their members to practice racially exclusive behaviors. Some minority and white students continued to experience prejudiced acts. Students interviewed there also perceived some degree of backlash against positions supported by Stanford's Minority Coalition. Many of the white students and one white faculty member interviewed indicated that some first-year students reacted negatively to campus orientation programs on diversity that they believed imposed "correct" views on culture and community. Informants linked the philosophy undergirding the FSI with the principles behind diversity-related orientation programs.

The UVA Judiciary Committee's decision to reject a 13th Standard had no measurable impact on campus race relations. Some black students reportedly were disappointed, but not surprised, by the decision. For them, the decision confirmed beliefs already held about UVA's racial climate. The UVA policy decision occurred after a few other universities faced (and lost) legal challenges to their policies. The outcome may have been viewed as a foregone conclusion because of the well-publicized legal risks of such a policy. Some minority students said they never expected the UJC to adopt a new policy. The period following the policy's rejection saw little interest in challenging the decision.

\section{Policy Applications}

Administrators at University of Wisconsin campuses cited violations of UWS-17.06 in 21 cases during the 1990-91 academic year. Students in five of those cases received some sanction. The following year, fourteen complaints were filed against students and seven cases resulted in sanctions. The policy's application appeared inconsistent to many observers. The ruling against UWS-17 in a Wisconsin Federal District Court supported this view. The Regents' revised draft of UWS-17 (March, 1992) included a provision mandating that every case involving the policy be reviewed and approved by a designee of the UWSystem president. The additional centralized control over the policy's application gave further evidence of the Regents' uneasiness with the potential for the policy's misapplication. 
Neither the Stanford nor Virginia judicial systems confronted cases of discriminatory verbal harassment (with an identifiable culprit) in the eighteen months following the policy decisions there. Despite policy opponents' fears of overzealous application, Stanford's FSI remained untested. Although some students at UVA may have hoped for a test case that showed the existing Standards of Conduct to be inadequate, none materialized. Therefore, one could only speculate about how the policy might apply to specific cases at Stanford and UVA.

\section{Student Self-Censorship}

Interview participants at each of the universities observed public self-censorship among students on racial (and other) issues, both in class and outside of class. However, they observed students' cautiousness long before the speech code debates began. Caution to speak out on racial issues was linked to a fear of public reprisal for being perceived or labelled as a racist. Most campus informants believed this was part of a desire not to offend others on issues beyond race, but informants observed students to be overly cautious regarding race. The public fear that the new policies would stifle speech on controversial issues was somewhat exaggerated since the phenomenon of self-censorship already existed as a relatively common experience at the three universities. However, the policies' opponents feared that the university's codifying the social phenomenon believed to threaten intellectual discussions would then cement the phenomenon in place.

Still, worries of the new harassment codes affecting classroom behavior were not confirmed in this study. None of the Wisconsin cases resulting in punishments involved academically related behavior. Stanford never applied its policy in any setting. A Stanford student editorial was the only document found there claiming the campus harassment policy had a noticeable effect on campus speech. Even that criticism did not assert the policy interfered in the classroom setting. The University of Virginia had at least three cases in which minority students criticized professors' lectures for including racially discriminatory content 
or tone. ${ }^{13}$ Each of the three professors forcefully denied the accusations, and the University found no cause to initiate disciplinary action with these faculty members. Several UVA informants believed that 'politically correct' attitudes existed widely among UVA students. 14 Informants also revealed that even though UVA had no controversial speech policy, some campus community members spoke cautiously about racial issues. This does not suggest that UVA students were more cautious about discussing racial issues than Wisconsin or Stanford students. Interview participants at those universities also believed individuals self-censored their comments on racial issues in order not to offend minority group members. However, informants' observations that students at UVA--a university without a specific discriminatory verbal harassment policy--were cautious when discussing racial issues limits the weight of the argument that speech codes at other schools inhibited controversial discussions on race.

Students' reticence to discuss controversial social issues occurred as a social phenomenon at each university with or without a new anti-harassment policy. Their reticence may be part of a set of social values and normative behaviors created by the wider society (and fostered in higher education settings) which suggest to students that they should not offend others. In other words, self-censorship may be related as much to students' attempts to be polite and to be accepted within university social structures as it is a fear of being labelled racist or a fear of being sanctioned under a discriminatory harassment policy.

\section{Conclusion}

Many factors influenced the debates and the policy outcomes at the universities in this research. Do the policies enhance race relations? No conclusive evidence emerged to delineate particular outcomes of UWS-17 or the FSI. Race relations after UVA students rejected a harassment policy proposal seemed no different than before the decision (i.e., sometimes tense and sometimes peaceful). At Wisconsin and

13 \#V-8, p. 1; \#V-12, pp. 1-4. See also, W. Alcorn and E. Thiel, "Professor's comments questioned," The Cavalier Daily, April 15, 1988, at 1. K. Hurdman and M. Ahearn, "Leslie gives response to allegations," The Cavalier Daily, April 19, 1988. A. Groves, "Criticism of professor is unfounded," The Cavalier Daily, April 21, 1988. D. D'Souza, Illiberal Education, New York: The Free Press (1991) at 5-6. 
Stanford, racial offenses were catalogued despite the presence of a harassment policy, but few indicated that the situation had deteriorated as a result of the policies. It seems that much of what went on before the policies were adopted continued afterward. Minority students and others who fought for the policies at Stanford and Wisconsin extracted a gesture of support from their universities, but in practical effects, it is difficult to prove that the new policies changed much. Conversely, one could argue that had Wisconsin or Stanford not adopted a policy to address discriminatory harassment that campus racial conditions could have deteriorated rather rapidly, and thus, the adoption of the policy helped prevent that deterioration. One could argue further that UVA's consideration of a discriminatory harassment policy had significant symbolic value, and that the exercise of debating such a policy allowed various constituents to vent their frustration, thereby preventing the deterioration of racial relations. Although the racial climate did not improve dramatically after the implementation of the policies, neither did it seem to degenerate.

What may have changed were expectations (now lowered, especially in light of related legal decisions) for the possibility of a judicial response in cases of offensive expression. For a time, each of the three universities held a lengthy public debate on the limits of free speech, the expectations of community members, the values of open debate and equal protection, and the status of various ethnic/racial groups. The educational benefits of this debate had to be positive, even if painful for some participants. The symbolic importance of debating the policies (and the gesture of adopting them at Stanford and Wisconsin) was taken for granted by many of the debate's participants during the deliberations. Minority student leaders at Wisconsin, for example, became keenly aware of UWS-17's symbolic value after the Federal Court struck the policy. Only then did they acknowledge the importance of the policy as a symbol of the university's support for minority students.

\section{Policy Options}

University officials can address incidents of discriminatory harassment through several policy options. When the harassment includes physical damage to persons or property, conduct policies prohibiting such damages can be brought to bear against the perpetrator. Often, there are state and local criminal statutes that prohibit physical damages in addition to campus rules. Occasionally, these statutes 
address other behaviors related to harassment that may support the university's efforts to discipline its students. Public institutions' student conduct regulations should include a proviso to allow the university to discipline students for violations of federal, state, and local laws.

Students who harass others in a university-owned residential setting may be subject to the conditions of their housing contract. Since university residences generally are not considered public forums for the free flow of ideas (ie., residences have other purposes), universities may restrict student behavior to a greater extent in this setting. Residence hall contracts should avoid content-based restrictions on speech, focussing instead on the behaviors considered unacceptable in the living environment.

Some universities have adopted positive value statements, affirming the university's values of civility and open debate, and setting high standards for student conduct. Students are informed that they may retain their association with the university only if they agree to abide by the university's expectations for their conduct. Although these types of statements or creeds lack the teeth of a prohibition-type policy, they can be effective educational tools and help elevate the expectations for student conduct.

In light of the R.A.V.v. St. Paul ruling, universities may consider fighting words policies that prohibit the most extreme manner of fighting words, without enumerating protected classes of persons targeted for special protection. This policy option amounts to adopting a legal definition of harassment, one that is content-neutral and one that focusses on the behaviors that the institution finds unacceptable. The policy's application should be even-handed and not favor any particular group or ideology.

Finally, universities may consider a policy that prohibits the intentional infliction of emotional distress. Again, after the R.A.V. decision, it is problematic to list specific groups or individuals targeted for special protection based on their race, gender, religion, etc. Another risk of the emotional distress policy is that the Supreme Court has yet to rule whether the government can regulate expression (toward persons who are not public figures) intended to disturb someone and cause them severe distress. Students accused of intentionally inflicting severe emotional distress may claim they were exercising their First Amendment rights to free speech, and therefore should not be held responsible for the distress experienced by others in response to their message. Two other problems mark this type of policy: 1) the judicial administrator (or group) must determine what constitutes "severe emotional distress," thus allowing wide 
latitude for administrative rulings on matters of speech (this may be of great concern to civil libertarians); and 2) the target of the harassment must parade their psychological scars convincingly in order to achieve a conviction, thus giving the appearance perhaps that they are psychologically weak or unable to cope with an antagonist.

Other policy options exist to address discriminatory verbal harassment that do not involve the codification of unwanted behavior. University administrators should announce a position on public racial incidents, voicing disapproval of the racist act and offering support for the target of the harassment. Harassment victims often perceive a silent response as an indication that the university condones the racist behavior. Some institutions have used mediation successfully to resolve harassment cases. Mediation allows the university to work with the persons involved to reach an acceptable resolution in an environment less threatening than the campus judicial system. This approach can take many different forms, and it may be most effective in cases that do not involve intense public scrutiny. One means of addressing major public cases is through a crisis response team. Such a group would (ideally) be assembled in advance and would have multiple goals including crisis intervention, crisis communication, and on-going community education. Co-curricular discussions, forums, panels, debates, etc. on racial and cultural issues can be part of an institution's policy response, both to prevent racial incidents and to respond to them. A university that intends to create a more welcoming environment for minority students but does not regularly plan and execute such programs will find its lack of effort difficult to defend in a crisis. None of these options threatens the exercise of free speech and, if done properly, can actually promote discussion about important issues.

\section{The Future}

All three universities in this study promoted messages of diversity, openness, and acceptance through broad arrays of educational programs designed to enhance community relations and to raise expectations for civil conduct on university property and in all university-related activities. At Stanford and Wisconsin, the discriminatory harassment policy comprised a small part of the total effort; at UVA the educational effort appeared even more important since the proposed policy was never enacted. The 
universities' educational efforts continue to be the best means to achieve individual and community-related goals for open dialogue and decorum. Although many of the legal questions seem clearer after R.A.V., racerelations issues persist. With few legal policy options remaining to address discriminatory harassment, universities will have to be more resolute and more creative than ever in finding ways to affirm institutional values, to prevent (rather than respond to) harassment, and to develop opportunities for all voices to be heard. Many individuals and groups have initiated programs to begin such measures. The university will be able to free itself from its currently politicized position as racial arbiter to the extent that these private and collaborative efforts are successful. 


\section{Bibliography}

Ad Hoc Committee on Racial Awareness. Results of the 1987/1990 Surveys on Racial and Cultural Issues: Preliminary Tables for the Press Conference. University of Virginia, April 5, 1990.

Adler, J., et.al. Taking Offense: Is this the new enlightenment on campus or the new McCarthyism? Newsweek., December 24, 1990, 48-55.

Ahearn, M. A year of controversy for Honor Committee. The Cavalier Daily (University of Virginia), April 24, 1987, 6.

Alcorn, W., and E. Thiel. Professor's Comments Questioned. The Cavalier Daily, April 15, 1988, 1.

Asian American Activities Center. Asian American Sourcebook. Stanford University (no date).

Baldwin, G. Letter to E. Davis, Jr. University of Wisconsin-Madison, April 5, 1989.

Baldwin, G. Letter to K. Shaw. University of Wisconsin-Madison, April 4, 1989.

Baldwin, G. Memorandum to P. Hodulik. University of Wisconsin-Madison, January 11, 1989.

Baldwin, G. Memorandum to P. Hodulik. University of Wisconsin-Madison, March 20, 1989.

Barringer, F. Free Speech and Insults on Campus. The New York Times, April 25, 1989, A-1, 11.

Bartholomew, K. Anti-harassment measure approved. Campus Report (Stanford), May 30, 1990, 1, 9.

Bell, A., and B. Rathet. Black leaders hold emergency meeting. The Cavalier Daily, February 25, 1988, 1.

Bennaker, B. 300 rally over alleged campus racism. The Badger Herald (University of WisconsinMadison), May 5, 1987, 1.

Berg, R. Officials react to request against UWS-17 appeal. The Badger Herald, October 18, $1991,1$.

Bermant, J. O'Neil to discuss proposal. The Cavalier Daily, December 5, 1988, 1.

Bierre, P. Letter to G. Parker. Stanford University, March 16, 1989.

Bisgeier, D. Stanford's commitment to racial harmony questioned. The Stanford Daily (Stanford University), October 19, 1988, 1.

Bisgeier, D. Students rally against racism. The Stanford Daily, May 12, 1987, 1.

Bland, K., and D. Mosley. Black students' meeting unjustly criticized. The Cavalier Daily, February 29, 1988, 2.

Bloom, A. The Closing of the American Mind, New York: Simon \& Schuster, 1987. 
Board of Regents, University of Wisconsin System. Draft policy of $\$ 17.06$ (2) of the Student Nonacademic Disciplinary Procedures, March 6, 1992.

Board of Regents. Minutes of the Regular Meeting of the Board of Regents of the University of Wisconsin System. Office of the Board of Regents, April 7, 1989.

Board of Regents. Minutes of the Regular Meeting of the Board of Regents of the University of Wisconsin System. Office of the Board of Regents, March 10, 1989, at 19.

Board of Regents. Resolution \#6041. University of Wisconsin System, March 6, 1992.

Bonner, K. Two Students Discover Derogatory, Racist Sign. The Cavalier Daily, November 6, 1990, 1.

Bostic, J. O'Neil discusses black recruitment. The Cavalier Daily, September 24, 1986, 1.

Boykin, T. Letter to S. Cole. Stanford University, April 14, 1990.

Brock, J. After 2-month wait, SCLC ready to meet. Stanford Daily, November 30, 1989, 1.

Brown, D. Racism and Race Relations in the University. Virginia Law Review, 1990, 76, 295-335.

Buckley, W. Jr. The shortcomings of the Stanford model. Norfolk Virginia Pilot, January 19, 1990, A14.

Bussman, L. (ed.). Adequate coverage. The University Journal (University of Virginia), September 10, $1990,2$.

Butler, T. (ed.). The Hook Book. University of Virginia: Office of the Student Council, 1991.

Camarillo, A. (chair). Final Report of the University Committee on Minority Issues, Stanford University, 1989.

Canevari, R., R. Tumer, et.al., Deans Respond. The Cavalier Daily, March 29, 1990, 3.

Canevari, R. Racist sign. The Cavalier Daily, November 6, 1990, 3.

Carnegie Foundation for the Advancement of Teaching. Campus Life: In Search of Community. Princeton: The Carnegie Foundation for the Advancement of Teaching, 1990.

Casteen, J. Letter to all University students. Office of the President, University of Virginia, September 1991.

Casteen, J. President's Policy on Harassment. Student Handbook 1990-91, University of Connecticut, 1990.

Coan, B. Ujamaa incidents are signs of deeper problems in the community. The Stanford Daily, October $20,1988,5$.

Cohen, W. Letter to G. Parker. Stanford University, March 10, 1989.

Cohen, W. Letter to G. Parker. Stanford University, May 1, 1989. 
Coladarci, A. The Student Conduct Legislative Council Proposed Interpretation of the Fundamental Standard. Campus Report, (reprint of the faculty senate meeting on April 20, 1989) May 10, 1989, 17.

Cole, S. Beyond Recruitment and Retention: The Stanford Experience. Judicial Affairs Office, Stanford University, 1990.

Cole, S. Freshmen won't face charges of violating Fundamental Standard. Campus Report, February 15, 1989, 16.

Cole, S. Letter to T. Jennings. Stanford University, October 12, 1992.

Cole, S. Stanford Cases in Student Affairs Administration: When Fundamental Values Conflict. Judicial Affairs Office, Stanford University, November, 1988.

Collins, H. PC and the Press, Academe, January-February 1992, 12-16.

Collison, M. Fight the Power: Rap Music Pounds Out a New Anthem for Many Black Students. The Chronicle of Higher Education, February 14, 1990, A1, 29.

Collison, M. Judge cites First-Amendment protection in overtuming suspension of fraternity. The Chronicle of Higher Education. September 4, 1991, A45-46.

Combs, M. A Separate Pride. The Virginia Advocate (University of Virginia), November, 1990, 8, 16.

Conklin, D. Final report on the vigil at Otero House. Campus Report, June 8, 1988, 2.

Conner, A. Racial issues addressed. The Cavalier Daily, February 2, 1987, 1.

Connor, J. Violence propagates thoughts of racism. The Cavalier Daily, February 14, 1989, 2.

Cronon, E. Letter to D. Shalala. University of Wisconsin-Madison, April 22, 1989.

Csorba, L. Appeasing the Censors: A Special Report on Campus Free Speech Abuses. Washington: Accuracy in Academia, 1986.

Daily, M. Committee issues minority report. The Badger Herald, December 2, 1987, 1.

Daily, M. Fratemity punished by Shalala. The Badger Herald, May 6, 1988, 1.

Daniels, L. Diversity, Correctness, \& Campus Life. Change, 1991 (September-October), 18.

Davidson, C. 'PH' Stands for Political Hypocrisy. Academe, 1991 (September-October), 8-14.

Davis, R. Fijis suspend two for ZBT incident. The Badger Herald, November 4, 1987, 1.

DeBerry, D. (ed.). Twelve is enough. The Cavalier Daily, September 11, 1990, 2.

Delgado, R. Memorandum to P. Hodulik. University of Wisconsin-Madison, May 30, 1989. 
Delgado, R. Words That Wound: A Tort Action for Racial Insults, Epithets, and Name-Calling. Harvard Civil Rights \& Civil Liberties Law Review, 1982, 17, 133-181.

Dillard, M. Letter to the Student Conduct Legislative Council, Stanford University, May 9, 1989.

Dirks, D. Freshman loses housing for insensitive conduct. The Stanford Daily, May 23, 1988, 1.

Dodge, S. Campus Codes That Ban Hate Speech Are Rarely Used to Penalize Students. The Chronicle of Higher Education, February 12, 1992, A35-36.

Dorsher, M. Hate-speech rule sent back to UW. Wisconsin State Journal, July 3, 1992, 3.

D'Souza, D. Cap and Goon: Facing Up to the New Intolerance on Campus. Washington Post, April 7, $1991, \mathrm{D} 1,4$.

D'Souza, D. Illiberal Education: The Politics of Race and Sex on Campus. New York: Free Press, 1991.

Durand, B. Memorandum to University of Wisconsin Board of Regents. University of Wisconsin-Madison, May 12, 1989.

Durand, B. Proposed amendments to Regents' version of 17.06. University of Wisconsin-Madison, May $10,1989$.

Durand, B. Report on Proposed Amendments to UWS Chapter 17 Concerning Prohibited Verbal and Physical Conduct. Report to UW-Madison President, Donna Shalala, March 20, 1989.

Durand, B. The University of Wisconsin Policy on Derogatory Speech. UW-Madison, April 12, 1990.

Edgar, E. Letter to H. Grover (copy sent to Donna Shalala, University of Wisconsin-Madison). April 4, 1989.

Edwards, M. Prof offers new view of poster defacement. Campus Report (Stanford), November 9, 1988, 4.

Ehrlich, H. Campus Ethnoviolence and the Policy Options, Baltimore (MD): National Institute Against Prejudice and Violence, April 1990.

Ewbank, H. Case Studies of the AIA Movement. Paper presented at the 72nd Annual Meeting of the Speech Communication Association, Chicago, 1986.

Faculty Senate. Excerpt from the Minutes of the Senate. Stanford University, May 3, 1990.

Farnham, S. Letter to E. Em. University of Virginia, University Judiciary Committee, November 30, 1990.

Ferguson, K., et.al. Vigil not intended to be racially biased. The Stanford Daily, May 27, 1988, 2.

Fessenden, T. Rejecting false 'community of togethemess' The Cavalier Daily, October 22, 1987, 2.

Finman, T. Memorandum to P. Hodulik. University of Wisconsin-Madison, March 20, 1989.

Finman, T. Memorandum to P. Schilling. University of Wisconsin-Madison, May 31, 1989. 
Finn, C. Jr. Why Can't Colleges Convey Our Diverse Culture's Unifying Themes? The Chronicle of Higher Education, June 13, 1990 , A40.

Fowler, D. Self-education can help resolve racism. The Cavalier Daily, October 9, 1989, 2.

Fox-Genovese, E. Education and Its Discontents. Washington Post : Book World, April 7, 1991, 6.

Freeman, P. School Desegregation Law: Promise, Contradiction, Rationalization. In D. Bell (Ed.), Shades of Brown: New Perspectives on School Desegregation, 1980, 31.

Friendly, J. Students split on SCLC proposal. Stanford Daily, May 7, 1990, 1.

Friewald, C. Regents pass racism rule. The Badger Herald, June 19, 1989, 1.

Frisbie, R. Racism travels in many directions. The Cavalier Daily, April 24, 1989, 2.

Frye, A. Racist shirts. The Cavalier Daily, November 7, 1989, 3.

Fuselier, D. Hate is no longer a 4-letter word? LaCrosse Tribune, July 3, 1992, 9.

Galinsky, B. Newspaper deserves mistrust of Alliance. The Cavalier Daily, March 2, 1988, 2.

Gaumnitz, L. Madison Plan unveiled by Shalala. The Badger Herald, February 10, 1988, 1.

Gibbs, N. Bigots in the Ivory Tower. Time, May 7, 1990, 104-106.

Gilbertson, E. The Constitution and Academic Freedom. Paper presented at the Annual Meeting of the American Association of State Colleges and Universities, New Orleans, November 24, 1987.

Gilliam, H. Fijis face second suspension; Rouse calls investigation. The Badger Herald, November 2, $1987,1$.

Glaser, G., and A. Strauss. The Discovery of Grounded Theory, Chicago: Aldine, 1967.

Gofen, C. University policies challenged at forum. The Stanford Daily, May 12, 1986, 1.

Golos, J. Fliers not intended to insinuate racism. The Cavalier Daily, October 6, 1988, 2.

Good, S. Memo to the University Judiciary Committee's Judiciary Ad Hoc Committee on Racism. University of Virginia, January 21, 1989.

Goode, T. Kennedy and others dodged issues. The Stanford Daily, October 20, 1988, 5.

Gordon, A. Community debates legacy of graffiti. The Cavalier Daily, April 2, 1990, 1.

Gordon, A. Resignation request called racially motivated; Dean's remarks draw criticism. The Cavalier Daily, April 23, 1990, 1.

Gordon, L. Race Relations and Attitudes at Arizona State University. In P. Altbach and K. Lomotey (Eds.), The Racial Crisis in American Higher Education. Albany: SUNY Press, 1991. 
Graves, M. Hypocrites: Chancellors bend under pressure. The Badger Herald, June 15, 1987, 9.

Green, H., and D. Becher. STAND up. The Cavalier Daily, April 13, 1990, 3.

Green, J. Standard found unnecessary. The University Journal, September 10, 1990, 1.

Grey, T. Civil Rights vs. Civil Liberties: The Case of Discriminatory Verbal Harassment. Social Philosophy \& Policy, 1991, 8(2), 81-107.

Grey, T. Responding to Abusive Speech on Campus: A Model Statute. Reconstruction, 1990 (Winter), 50-54.

Griffiths, A. BSA questions fraternity fliers. The Cavalier Daily, October 4, 1988, 1.

Griffiths, A. Phi Gamma Delta faces charges. The Cavalier Daily, October 12, 1988, 1.

Griffiths, A. Riots open racial wound. The Cavalier Daily, September 6, 1989, 1.

Griffiths, A. University steps up 1988 black enrollment. The Cavalier Daily, August 30, 1988, 1.

Gross, T. Racial tolerance should be stressed. The Cavalier Daily, December 1, 1987, 2.

Groves, A. Criticism of professor is unfounded. The Cavalier Daily, April 21, 1988, 3.

Guckes, F. Community responds to chapel event. The Cavalier Daily, February 26, 1988, 1.

Gullickson, S. Memorandum to D. Shalala. University of Wisconsin-Madison, March 2, 1989.

Gunther, G. Freedom for the Thought We Hate. Academe, 1990 (November-December), 10-12.

Gunther, G. Letter to G. Parker. Stanford University, March 10, 1989.

Gunther, G. Letter to Professor George Parker, Chair of the Student Conduct Legislative Council at Stanford University. Campus Report, May 3, 1989, 18.

Haller, V. Gang rape fabricated, jury says. The Cavalier Daily (reprinted from Associated Press wire), September 29, 1988, 1.

Hallock, D. Board approves full divestment proposal. The Cavalier Daily, June 14, 1990, 1.

Hallock, D. Board's divestment stance fuels protest. The Cavalier Daily, April 20, 1990, 1.

Hallock, D. Graffiti sparks outrage, anger in community. The Cavalier Daily, March 29, 1990, 1.

Hallock, D. University observes apartheid for a day. The Cavalier Daily, April 13, 1990, 1.

Hayes, F. Politics and Education in America's Multicultural Society: An African-American Studies Response to Allan Bloom. Journal of Ethnic Studies, 1989, 17(2), 71-88.

Hayward, B. Report on incidents at Ujamaa released. The Stanford Daily, January 18, 1989, 1. 
Hayward, B., and A. Marsh. Two racial incidents strike Ujamaa House. The Stanford Daily, October 17, $1988,1$.

Hechinger, F. About Education. New York Times, June 6, 1990, B-7.

Heit, E. Letter to the Student Conduct Legislative Council. Stanford University, March 7, 1989.

Heldt, J. Minority rally absorbs majority student rally. The Badger Herald, November 18, 1988, 1.

Heller, S. One Year Later, Faculty Members Notice Little Impact from Accuracy in Academia. Chronicle of Higher Education, October 22, 1986, 11-12.

Heller, S. Watchdog Group Says Students at 110 Colleges Now Monitoring Classrooms for "Liberal Bias. Chronicle of Higher Education, October 16, 1985, $27-29$.

Hinkle, B. Racist speech should not be censored. The Cavalier Daily, September 5, 1988, 2.

Hobbs, K. Black greeks uphold tradition. The Cavalier Daily, March 21, 1989, 3.

Hodges, A. U.Va. recruiting ban: a skirmish in the PC war? Richmond Times-Dispatch, February 17, $1991,1,5$.

Hodulik, P. Memorandum to University of Wisconsin System Board of Regents. University of Wisconsin System, March 31, 1989.

Hodulik, P. Prohibiting Discriminatory Harassment by Regulating Student Speech: A Balancing of First Amendment and University Interests. Journal of College and University Law, 1990, 16(4), 57387.

Holland, R. An Island of Sanity in Virginia's PC Ocean. Richmond Times-Dispatch, February 20, 1991.

Holmes, D. Stalking the Academic Communist: Intellectual Freedom and the Firing of Alex Novikoff, Hanover (NH): University Press of New England, 1989.

Hubbard, J. Council of Black Student Leaders discusses fliers. The Cavalier Daily, October 4, 1988, 1.

Hundley, H. Black Students Take Action. Chicago Tribune, April 23, 1989, 4.

Hurdman, K., and M. Ahearn. Leslie gives response to allegations. The Cavalier Daily, April 19, 1988, 1.

Hyde, H. Hyde criticizes trend on college campuses to restrict free speech, introduces speech protection act. Press release from U.S. Representative Hyde's office, March 1991.

Hyde, K. BSA dissatisfied with response. The Cavalier Daily, October 7, 1988, 1.

Hyde, K. Statistics may show honor bias. The Cavalier Daily, November 22, 1989, 1.

Irwin, S. Regents pledge to address racism. The Badger Herald, May 8, 1987, 1.

Jackson L. BSU: Issue is freedom from racist harassment. Campus Report, May 10, 1989, 13. 
Jackson, T. Memo to J. Casteen. University of Virginia, April 29, 1992.

Jesudason, M. Letter to K. Shaw. University of Wisconsin System, June 8, 1988.

Jordan, M. College Repeals Speech Code as National Backlash Grows. Washington Post, September 12, 1992, A1.

Joss, R. Racism is not unique to Stanford. The Stanford Daily, October 20, 1988, 5.

Joughin, L. (Ed.), Academic Freedom and Tenure: A Handbook of The American Association of University Professors, Madison: University of Wisconsin Press, 1964.

Kaphingst, J. (Ed.). UWS-17 appeal is a waste of money. The Badger Herald, October 18, 1991, 3.

Kasierski, S. Kennedy talks on racism, police, tenure. The Stanford Daily, March 12, 1986, 1.

Kassel, J., and B. Williamson. Brief in support of Plaintiff's Summary Judgement Motion. In U.W.M.

Post $v$. Board of Regents of the University of Wisconsin, 1991.

Katz, K. The First Amendment's Protection of Expressive Activity in the University Classroom: A Constitutional Myth. University of California-Davis Law Review, 1983, 16, 904.

Kennedy, D. All must fight bigotry and build a better community. The Stanford Daily, October 19, 1988, 2.

Kennedy, D. Reflections on racial understanding. Campus report (Stanford), January 11, 1989.

Kerr, C. The Uses of the University, Cambridge: Harvard University Press, 1982.

Kindle, M. Mixing it up. The University Journal, September 14, 1990, 2.

King, B. BSU chair attacks student ignorance, passivity and racism. The Stanford Daily, May 12, 1989, 3.

Koff, K. Acacia apologizes, WBSU plans rally. The Badger Herald, April 18, 1988, 1.

Koff, K. Racism issue absorbs UW. The Badger Herald, April 22, 1988, 1.

Korobkin, R. Minorities attack Kennedy's response. The Stanford Daily, May 8, 1987, 1.

Kretzmer, D. Freedom of Speech and Racism Cardozo Law Review, 1987, 8, 445-513.

Kumar, A. Barnes claims sabotage. The Cavalier Daily, April 19, 1990, 1.

Kumar, A. Council officers call for Barnes' resignation. The Cavalier Daily, April 20, $1990,1$.

Kumar, A. Former chairman disappointed with BSA. The Cavalier Daily, January 29, 1990, 1.

Kumar, A. Record minority numbers enroll. The Cavalier Daily, August 28, 1990, 1. 
Kurzweg, M. BSA proposes regulation. The Cavalier Daily, October 26, 1988, 1.

Kutynsky, N. Threat to sue Acacia delivered at racism rally. The Badger Herald, April 19, 1988, 1.

Lawrence, C. Acknowledging the Victim's Cry. Academe, 1990 (November-December), 10-14.

Lawrence, C. If He Hollers Let Him Go: Regulating Racist Speech on Campus. Duke Law Journal, 1990(3), 431-83.

Lawrence, M. Police arrest 9 Apartheid protesters. The Stanford Daily, October 14, 1985, 1.

Lawrence, M. Police arrest 23 more protesters. The Stanford Daily, October 17, 1985, 1.

Lawrence, M. S.O.S.A. (Stanford Out of South Africa) to stage sit in. The Stanford Daily, October 11, 1985,1 .

Lazarus, L. Braxton among 32 chosen as Rhodes Scholars. The University Journal , January 14, 1991, 1.

Leatherman, C. More Anti-Semitism Is Being Reported on Campuses, but Educators Disagree on How to Respond to It. Chronicle of Higher Education, February 7, 1990, A1, 40.

Lee, D. (spokesperson). Memo to the Student Conduct Legislative Council regarding "Free Speech and Discriminatory Harassment at Stanford" (Memo signed by representatives of the Asian Law Students Association, Black Law Students Association, Jewish Law Students Association, Native American Law Students Association, and Asian American Students Association). Stanford University (no date).

Lemley, M. Minority students present demands. The Stanford Daily, May 6, 1987, 1.

Leo, J. The academy's new ayatollahs. U.S. News \& World Report, December 10, 1990, 22.

Lewis, D. Blacks express concerns. The Cavalier Daily, November 19, 1986, 1.

Lewis, L. Memo to T. Jackson and J. Mingle. University of Virginia, April 22, 1992.

Lincoln, Y., and E. Guba, Naturalistic Inquiry. London: Sage Publications, 1985.

Liu, G. Standard will face new interpretation. The Stanford Daily, February 16, 1989, 1.

Liu, K. Muhammad Speech Deters Progress. The Cavalier Daily, November 20, 1990, 3.

Locke, K. Cohen warns against racism on campus. The Badger Herald, March 31, 1987, 1.

Locke, K. Fiji fraternity party called racist. The Badger Herald, May 4, 1987, 1.

Locke, K. Minorities blame entire campus. The Badger Herald, May 6, 1987, 1.

Loew, K. Organization commences to tackle racism. The Cavalier Daily, September 26, $1991,1$.

Loughlin, S. The Student View in Black and White. Sarasota Herald Tribune (FL), December 12, 1990. 
Love, J. Discriminatory Speech and the Tort of Intentional Infliction of Emotional Distress. Washington and Lee L. Review, 1990(47), 123-159.

Ludwig, S. and J. Kloppenburg. Memo to M. Liethen. University of Wisconsin-Madison, February 24, 1988.

Lyall, K. Second Annual Report on the Implementation of UWS-17, Wisconsin Administrative Code. University of Wisconsin System, August 28, 1991.

Lynch, W. Memorandum to j. powell [sic]. Wisconsin American Civil Liberties Union, January 29, 1989.

Lyons, J. Electronic mail message (hard copy) to D. Conklin. Stanford University, October 26, 1988.

Lyons, J. Electronic mail message (hard copy) to S. Cole. Stanford University, November 15, 1988.

Lyons, J. Memo to D. Kennedy et.al. Stanford University, December 6, 1988.

Lyons, J. Statement on Otero incident. In S. Cole, Stanford Cases in Student Affairs Administration: When Fundamental Values Conflict. Judicial Affairs Office, Stanford University, November 1988.

Lyons, J., and S. Cole. Cole, Lyons ponder ways to respond to offensive behavior. Campus Report, February 15, 1989, 15.

Magee, L. Rally gathers following. The Cavalier Daily, October 16, 1987, 1.

Manger, D. Racial Tensions Continue to Erupt on Campuses Despite Efforts to Promote Cultural Diversity. The Chronicle of Higher Education, June 6, 1990, A1.

Magner, D. Wisconsin to Re-Tool Recruitment Plan as Minority Enrollment Dips 17\%. The Chronicle of Higher Education, October 23, 1991, A37.

Mangum, D. Racist University traditions must end. The Cavalier Daily, October 24, 1989, 2.

Marcus, R. Supreme Court Overturns Law Barring Hate Crimes. The Washington Post, June 23, 1992, A1.

Martin, V. Ignorance Exemplified by Racist Sign. The Cavalier Daily, University of Virginia, November $6,1990,2$.

Martin-Stanley, C. Psychosocial Factors Affecting Perceptions of Racial Inequality and Affirmative Action Policy Attitudes Among College Students. Unpublished Dissertation, DAI 50/068, 1988.

Masters, B. U-Va. Students Share Black, White Experiences. The Washington Post, April 21, 1991, A-8.

Mataya, W., M. Howie, and R. Hohouser. Hate evinced. The Cavalier Daily, March 29, 1990, 3.

Matthies, D. Matthies: Freedom from harassment remains a basic right, doesn't it? Campus Report, February 15, 1989, 9. 
Matsuda, M. Public Response to Racist Speech: Considering the Victim's Story. Michigan Law Review, 1989, 87, 2320-81.

McBride, T. Letter to D. Kennedy and J. Rosse, Stanford University. November 18, 1988.

McBride, T., and J. Williams. Final Report on Recent Incidents At Ujamaa House. Campus Report , January 18, 1989, 15.

McNew, J. Whose politics? Media distortions of academic controversies. The Virginia Quarterly Review, 1992 (Winter), 1-23.

McQuillen, G. The University of Wisconsin's anti-speech rule: an ACLU perspective. Outline for a speech to the Dane County Bar Association, Wisconsin American Civil Liberties Union, October $24,1989$.

Mill, J. On Liberty (1859).

Miller, C. Staff wishes to halt Cabell vandalism. The Cavalier Daily, March 31, 1987, 1.

Milligan, M. University takes no action against Fiji fraternity. The Badger Herald, January 11, 1988, 1.

Mingle, J. Outline of remarks made at the President's Annual Student/Administrator Retreat. University of Virginia, Office of the General Counsel, September 21, 1989.

Morgan, L. Minority coalition questions Madison Plan in its response. The Badger Herald, February 10, 1988, 1.

Morton, K, and A. Kogelnik. Fight spurs reappraisal of policies. The Cavalier Daily, November 22, 1988, 1.

Mowatt, R. Chair vacancy keeping this year's SCLC in starting blocks. Stanford Daily, October 5, 1989, 1.

Office of Admissions. College Guidance Counselor's Update. Stanford University, September, 1987.

Office of the Dean of Students. Race Awareness Committee; Race Relations Education Program (brochure). University of Wisconsin-Madison, Summer 1989.

Office of the Dean of Students. Racism at the UW-Madison: let us know! University of WisconsinMadison, Spring, 1988.

Office of Institutional Planning and Studies. Fall 1991 Enrollment. University of Virginia, 1991.

Office of Minority Affairs. Discriminatory Harassment: Prohibited Conduct Under Chapter UWS 17 Revisions (brochure). University of Wisconsin System, (no date).

Office of the President, Student Conduct Policies, Stanford University, 1990.

Office of the President. The Legislative and Judicial Charter of 1968 (as amended in 1969, 1975, and 1981), Stanford University. 
Office of the Special Assistant to the President for Minority Affairs. Policy Statement and Guidelines on Racist and Discriminatory Conduct (Draft). University of Wisconsin System, September 1988, 1.

Olivas, M. That D'Souza Book, Change, September-October 1991, 56-60.

O'Neil, R. Colleges Should Seek Educational Alternatives to Rules That Override the Historic Guarantees of Free Speech. The Chronicle of Higher Education, October 18, 1989, B-1, 3.

O'Neil, R. Cowardly Act. The Cavalier Daily, March 29, 1990, 3

O'Neil,. R. Free Expression Requires Tolerance. Richmond Times Dispatch, June 29, 1992.

O'Neil, R. The Pitfalls of Stifling Campus Speech. Association of Governing Board Reports, JanuaryFebruary, 1990, 14.

Paik, F. BSU renews call for world studies. The Stanford Daily, April 24, 1986, 1.

Parker, G. Letter to T. Boykin. Stanford University, March 10, 1989.

Perry, J. Stricter Standard and First Amendment are not in conflict. The Stanford Daily, March 7, 1989, 5.

Perry, J., and C. Douglas. First Amendment principles have not informed campus policy. Campus Report, February 22, 19898.

Perry, J., and C. Douglas. Freedom of expression policy does not give absolute right to chill others' participation. Campus Report, February 8, 1989, 8.

Perry, M. Blacks stage demonstration. The Cavalier Daily, February 26, 1988, 1.

Perry, M. BSA annoyed by O'Neil's response. The Cavalier Daily, February 17, 1988, 1.

Perry, M. Minorities speak out. The Cavalier Daily, April 29, 1988, 5.

Perry, M. O'Neil reacts to report. The Cavalier Daily, February 5, 1988, 1.

Perry, M. Report causes tension. The Cavalier Daily, February 18, 1988, 1.

Perry, M., and T. Theiss. Cultural diversity at the University. The Cavalier Daily, February 5, 19885.

Pierce, R. Forum to address issue of racism. The Stanford Daily, February 26, 1986, 1.

Plemmer, A. Judiciary Committee reviews conduct rules. The Cavalier Daily, November 9, 1989, 1.

Plemmer, A. Meeting finds little support for recall. The Cavalier Daily, April 23, 1990, 1.

Pollock, J. Forum sheds light on racism. The Stanford Daily, May 27, 1987, 1.

Pollack, J. Minority students walk out. The Stanford Daily, May 15, 1987, 1.

Pollock, J. Students stage 5-hour sit-in. The Stanford Daily, May 19, 1987, 1. 
Post, R. The Constitutional Concept of Public Discourse: Outrageous Opinion, Democratic Deliberation, and Hustler Magazine v. Falwell. Harvard Law Review, 1990 (103), 603-86.

Rakestraw, A. Flier sparks debate. The Cavalier Daily, November 15, 1990, 1.

Rapalus, P. Free speech debate slated for spring. Campus Report, March 21, 1990, 1, 4.

Rapalus, P. Taking the 'chill' off open discussion key issue for SCLC. Campus Report, February 7, $1990,1$.

Rathet, B. Put an end to 'separate but equal.' The Cavalier Daily, October 16, 1987, 2.

Rector and Board of Visitors of the University of Virginia. Graduate Record 1990-91, Office of the University Registrar, University of Virginia, 1990.

Rector and Board of Visitors of the University of Virginia. Minutes. Office of the Board of Visitors, University of Virginia, March 1990.

Rector and Board of Visitors of the University of Virginia: Committee on Intergroup Relations. Audiotaped recording of proceedings on April 13, Office of the President, University of Virginia, 1990.

Rector and Board of Visitors of the University of Virginia: Committee on Intergroup Relations. Minutes. Office of the Board of Visitors, University of Virginia, April 13, 1990.

Rector and Board of Visitors of the University of Virginia. President's Report 1990-91. Office of the President, University of Virginia, 1991.

Rector and Board of Visitors of the University of Virginia. The University Report 1987-88, Office of University Publications, University of Virginia, 1988.

Reges, S. Memo to Student Conduct Legislative Council. Stanford University, May 23, 1990.

Regeth, B. Fraternity suspension dropped. The Badger Herald, November 9, 1987, 1.

Regeth, B. Sigma Alpha Epsilon cleared, Fiji suspended. The Badger Herald, June 15, 1987, 1.

Reisler, M. (Chair). Report of the Task Force on Afro-American Affairs. University of Virginia, June, 1987, 3 .

Reitz, C. Bennett, Bloom and Boyer: Toward a Critical Discussion. Paper presented at a Conference of the Southwest Community College Humanities Association, Kansas City, 1988.

Repak, C. Coalitions plan 50-hour vigil. The Cavalier Daily, January 20, 1988, 1.

Report of the Deliberations of the UW System Working Group to Revise UWS-17, University of Wisconsin System, February, 1989, at 1.

Reynolds, N. Closed, but only to bias. The Cavalier Daily, November 22, 1991, 2.

Robinson, N. Electronic mail message (hard copy) to J. Lyons, et. al., regarding "Ujamaa report update. Stanford University, December 30, 1988. 
Robinson, N. Robinson revokes dorm privileges of two who defaced poster. Campus Report, January 9 , 1989.

Rodgers, R. To the editor. The Chronicle of Higher Education, November 8, 1989, B3.

Rothman, S. Academics on the Left. Society, 1986, 23(3), 44-49.

Rotker, K. Minority students face insensitivity. The Daily Cardinal (University of Wisconsin-Madison), February 11, 1986, 1.

Sarder, J. UW minority enrollment misses Madison Plan. The Badger Herald, September 27, 1989, 1.

Saucedo, C. Shanty town destruction decried as 'racist' action. The Stanford Daily, February 10, 1986, 1.

Schlesinger, A. Jr. The Disuniting of America: Reflections on a Multicultural Society. New York: Norton \& Co., 1991.

Schneider, B. New 'hate speech' code gets OK'd. The Daily Cardinal, March 3, 1992, 1, 7.

Schneider, B. Students shut out in redrafting of code. The Daily Cardinal, March 3, 1992, 1, 7.

Schwartz, J., and I. Brest. First Amendment Principles and Prosecution for Offensive Expression Under Stanford's Student Disciplinary System. Office of the General Counsel, Stanford University, February 1989.

Scott, T. Black leaders air criticisms. The Cavalier Daily, November 12, 1986, 1.

Scott, T. Few blacks drawn from small field. The Cavalier Daily, September 2, 1986, 1.

Scott, T. Separatism a difficult problem. The Cavalier Daily, January, 19, 1986, 1.

Shalala, D. The Madison Plan. InWisconsin Week. University of Wisconsin-Madison, February 17, 1988.

Shalala, D. Letter to K.Shaw. University of Wisconsin-Madison, May 4, 1988.

Shaw, K. Design for Diversity. Office of the President, University of Wisconsin System, April 7, 1988

Shaw, K. Memo to Education Committee and All Regents, "Report on Implementation of UWS-17." University of Wisconsin System, August 29, $1990,1$.

Shaw, K. Report to the UWS Board of Regents on Minority Students, Faculty and Staff. University of Wisconsin System, October 29, 1987.

Shaw, K. Report on Implementation of UWS-17, Wisconsin Administrative Code. University of Wisconsin System, August 29, 1990.

Shively, N. Anti-racism rule seen as working. The Milwaukee Sentinel, September 8, 1990.

Shively, N. UW regents back 'hate speech' rule. The Milwaukee Sentinel," May 9, 1992, 1. 
Small, T. Letter to E. Beckham. University of Virginia School of Law (Students United to Promote Racial Awareness) September 18, 1991.

Smilk, C. Progress characterizes minority groups' efforts. The Cavalier Daily, April 24, 1987, 6.

Smilk, C. Vandalism denounced by O'Neil. The Cavalier Daily, April 3, 1987, 1.

Smith, K. Memo to L. Lewis. University of Virginia, November 16, 1988.

Smith, S. Minorities rip constitution. The Stanford Daily, January 28, 1986, 1.

Soderquist, P. Letter defending pledge process out-of-line. The Cavalier Daily, March 23, 1989, 2.

Solomon, B. In the Company of Educated Women, New Haven: Yale University Press, 1985.

Sproule, M. Whose Ethics in the Classroom? On the Politics of Ethics. Paper presented at the 71st Annual Meeting of the Speech Communication Association, Denver, 1985.

Steele, S. The New Sovereignty. Harper's Magazine, July 1992, 47-54.

Steering Committee on Minority Affairs. Final Report. University of Wisconsin-Madison, November, 1987.

Stein, J. Groups claim ZBT auction is UW's fault. The Badger Herald, October 26, 1988, 1.

Stein, J. ZBT lawyer, BSU: UW is to blame. The Badger Herald, October 27, 1988, 1.

Steger, M. A cautious approach: racist speech and the First Amendment at the University of Texas. The Journal of Law and Politics, 1992 (Spring), 609-648.

Stimpson, C. Meno's Boy: Hearing His Story--\& His Sister's, Academe, November-December 1991, 2531.

Strossen, N. Regulating Racist Speech on Campus: A Modest Proposal? Duke Law Journal, June 1990 (3), 484-573.

Student Conduct Legislative Council. Fundamental Standard Interpretation: Free Expression and Discriminatory Harassment. Stanford University, April 4, 1990.

Student Conduct Legislative Council. Interpretation of the Fundamental Standard. Stanford University, May 24, 1990, 1.

Student Conduct Legislative Council. Interpretations and Applications of the Fundamental Standard in the Area of Diversity. Stanford University, March 1, 1989.

Student Conduct Legislative Council. Proposed Interpretation of the Fundamental Standard. Stanford University, April 4, 1989.

Student Conduct Policy Committee. Memo to D. Shalala. University of Wisconsin-Madison, March 20, 1989. 
Student Council. Minutes. University of Virginia, November 13, 1990.

Student Council. Minutes. University of Virginia, April 3,10, \& 17, 1990.

Student Council. Minutes. University of Virginia, October 25, 1988.

Student Council. Resolution sponsored by Reps. Eisenbach and Pritchett. University of Virginia, October $25,1988$.

Sulton, J. Memo to UWS racial harassment workshop participants. University of Wisconsin System, September 26, 1988.

Swanson, K. Violent poster interpreted as racist. The Cavalier Daily, November 15, 1990, 2.

Tatel, D. Clear, Narrow Policies on Offensive Speech May Not Run Afoul of the First Amendment. The Chronicle of Higher Education, February 7, 1990, B1.

Temby, J. Memorandum to the University of Wisconsin System Board of Regents. April 12, 1989.

Theiss, T. Honor jury convicts Sweat in open trial. The Cavalier Daily, November 3, 1986, 1.

Theiss, T. Leaders plan interracial action. The Cavalier Daily, September 1, 1987, B-11

Thomas, E. University would be justified in seeking disciplinary action in Ujamaa incident. Campus Report, February 22, 1989, 7.

Tinkleburg, K. Mural displayed at Zapata Rally. The Stanford Daily, January 21, 1986, 1.

Trott, M. March moves on to Carr's Hill. The Cavalier Daily, April 20, 1990, 5.

Turner, M. Offensive fliers require action by the University. The Cavalier Daily, October 5, 1988, 2.

Urbanowicz, L. 'A Closer Look' probes University life. The University Journal, September 15, $1991,1$.

Vellela, T. New Voices: Student Political Activism in the '80s and '90s. Boston: South End Press, 1988.

Veysey, L. The Emergence of the American University. Chicago: University of Chicago Press, 1964.

Wagoner, J. Thomas Jefferson: America's First Education President. Briefing paper prepared for the Presidential Summit at the University of Virginia, September, 1989, 3.

Walker, R. State university presidents discuss 'political correctness.' Richmond Times-Dispatch, March 17, 1991, 1-2.

Walters, S. Regents to take 2nd vote on UW hate speech rule. Milwaukee Sentinel, July 9, 1992, 5.

Weekfall, V. Misused quotes pin poor image on black leaders. The Cavalier Daily, December 7, 1988, 2.

Weilacher, G. Racism rears its ugly head another time. The Cavalier Daily, February 23, 1989, 2. 
Weiner. Racial Hatred on Campus. Nation, Feb. 27, 1989, 260.

Weinstein, L. Policing Prejudice. AGB Reports, 1990 (January/February).

Weinstein, L. Letter to E. Edgar. University of Wisconsin System, April 17, 1989.

Wheeler, D. Auctioning. The Cavalier Daily, March 22, 1990, 2.

White, S. ZBT cleared by WSA; action enrages students. The Badger Herald, November 15, 1988, 1.

Wilburn, A. In the Heart. The Cavalier Daily, November 13,1990, 3.

Wilder, A. Pavilion XI incident reveals blatant racism. The Cavalier Daily, November 29, 1988, 2.

Wilson, L., and I. Ellis. Furthering a racially explosive atmosphere. The Cavalier Daily, November 20, 1986, 3.

Wilson, R. New White-Student Unions on Some Campuses Are Sparking Outrage and Worry. The Chronicle of Higher Education, April 18, 1990, A1, 36.

Wong, E. Youths assault students on Rugby Road. The University Journal, September 23, 1991, 1.

Workman, B. Stanford Cracking Down Against 'Fighting Words.' San Francisco Chronicle, May 31, $1990,1$.

Yalof, D. Glaring Problem. The Cavalier Daily, September 1, 1987, 2.

Yankosky, K. O'Neil sees black gains. The Cavalier Daily, October 10, 1989, 1.

Yankosky, K. STAND to meet Board. The Cavalier Daily, April 12, 1990, 1, 9.

Zenner, B. Sticks and Stones: What can be done about campus hate speech? Albemarle Magazine, 1990 (Fall), 46-47, 72-77.

\section{Legal Citations}

Abrams v. United States, 250 U.S. 616 (1919).

Allaire v. Rogers. 658 F.2d 1055 (1981).

Beauharnais v. Illinois, 343 U.S. 250 (1952).

Bethel School District No. 403 v. Fraser, 478 U.S. 675 (1986).

Board of Curators v. Horowitz, 435 U.S. 78 (1978).

Brandenburg v. Ohio, 395 U.S. 444 (1969).

Cantwell v. Connecticut, 310 U.S. 296 (1940). 
Chaplinsky v. New Hampshire, 315 U.S. 568 (1942).

Clark v. Community for Creative Non-Violence, 468 U.S. 288 (1983)

Code of Virginia, Section 8.01-42.1, "Civil action for racial, religious or ethnic harassment, violence or vandalism."

Code of Virginia, Section 18.2-416, "Punishment for using abusive language to another."

Code of Virginia, Section 18.2-485, "Conspiring to incite to insurrection."

Cohen v. California. 403 U.S. 15 (1971).

Collin v. Smith, 578 F.2d 1197, 1205-07 (7th Cir.), cert. denied 439 U.S. 916.

Connally v. General Construction Company, 269 U.S. 385, 391 (1926).

Consolidated Edison v. Public Service Commission, 447 U.S. 530 (1980).

Cooper v. Ross. 472 F.Supp. 802 (1979).

Dennis v. United States, 341 U.S. 494 (1951).

Dixon v. Alabama State Board of Education, 294 F. 2d 150 (1961).

Doe v. University of Michigan. 721 F. Supp. 852 (E.D. Mich. 1989).

Epperson v. Arkansas, 393 U.S. 97 (1969).

Equal Employment Opportunity Commission's Guidelines on Sexual Harassment [29 C.FR \$1604.11(a) (1985)].

F.C.C. v. Pacifica Foundation, 438 U.S. 726 (1978).

Franklin v. Leland Stanford Junior University 218 Cal. Rptr. 228 (Cal.App. 1 Dist. 1985).

Gooding v. Wilson, 405 U.S. 518 (1972).

Goss v. Lopez, 419 U.S. 565 (1975).

Grayned v. Rockford, 408 U.S. 104 (1972).

Healy v. James, 408 U.S. 169,180 (1971)

Hustler Magazine v. Falwell, 485 U.S. 46 (1988).

Iota XI Chapter of Sigma Chi Fraternity v. George Mason University. WL 195325, *1 (E.D. Va. 1991).

Keyishian v. Board of Regents, 385 U.S. 589, 603 (1967). 
Kim v. Coppin State College. 662 F. 2d 1055 (1981).

Meritor v. Vinson, 477 U.S. 57 (1985).

Pickering v. Board of Education. 391 U.S. 563 (1968).

Plessy v. Ferguson 163 U.S. 537 (1896).

R.A.V. v. City of St. Paul, Minnesota. No. 90-7675, The United States LAW WEEK (60 LW 4667), June 23, 1992.

Schenck v. United States, 249 U.S. 47 (1919).

Sweezy v. New Hampshire, 354 U.S. 234 (1957).

Texas v. Johnson, 109 S. Ct. 2533 (1989).

Tinker v. Des Moines School District, 393 U.S. 503 (1969).

Title VII of the Civil Rights Act of 1964 [42 U.S.C. \$2000e-2(a)(1)].

United States v. Grace, 461 U.S. 171 (1983).

United States v. O'Brien, 391 U.S. 367 (1967).

U.W.M. Post, Incorporated v. Board of Regents of the University of Wisconsin System. 774 F.Supp. 1163 (E.D. Wis. 1991).

Weiman v. Updegraff, 344 U.S. 182 (1952).

Whitney v. California, 274 U.S. 357 (1927).

\section{References with No Author(s) Listed}

American Association of University Professors. 'Accuracy in Academia' A New Obstacle to Academic Freedom. Academe, 1985, 71(6).

American Association of University Professors. On 'Accuracy in Academia' and Academic Freedom. Academe, 71(5).

American Association of University Professors. Academic Freedom. 1940 Statement of Principles on Academic Freedom and Tenure. In L. Joughin (Ed.), Academic Freedom and Tenure: A Handbook of the American Association of University Professors. Madison: University of Wisconsin Press, 1969, 33-39.

American Association of University Professors. Recommendation of the 35th Annual Meeting. AAUP Bulletin, Spring 1949, 10.

American Association of University Professors, Declaration of Principles. Academe, May-June 1989, 9. 
Badger Herald. Rouse stops Fiji and Kappa Sig discipline. University of Wisconsin-Madison, October, 1987, 1.

Campus Report. Council set to vote on proposed rules dealing with speech. Stanford University, May 23, 1990, 1.

Campus Report. For the Record. Stanford University, March 1, 1989, 1.

The Cavalier Daily. Ask and learn (editorial). University of Virginia, November 15, 1990, 2.

The Cavalier Daily. Five stooges (editorial). University of Virginia April 20, 1990, 2.

The Cavalier Daily. Grafitti (editorial). University of Virginia, March 29, 1990, 2.

The Cavalier Daily. Grey lines (editorial). University of Virginia, February 14, 1991, 2.

The Cavalier Daily. Honor and justice (editorial). University of Virginia, November 22, 1989, 2.

The Cavalier Daily, Misperception (editorial). University of Virginia, March 31, 1989, 2.

The Cavalier Daily. Omega Psi Phi Poster. University of Virginia, November 15, 1990, 3.

The Cavalier Daily. Sign of hate (editorial). University of Virginia, November 6, 1990, 2.

The Cavalier Daily. SIT (editorial). University of Virginia, April 12, 1990, 2.

The Chronicle of Higher Education. Virginia. August 28, 1991, 97.

The Chronicle of Higher Education. Virginia Tech Bans Fraternity for 4 Years. December 6, 1989, A2.

The Chronicle of Higher Education Almanac. Wisconsin. August 28, 1991, 101-2.

The Chronicle of Higher Education Almanac. Wisconsin. September 1, 1988, 84-5.

The Chronicle of Higher Education Almanac. Campuses with the Largest Enrollments, Fall 1987. September 6, 1989, 19.

The Chronicle of Higher Education Almanac. College and University Endowments over \$65-Million, 1991. August 26, 1992, 35.

Klanwatch Intelligence Report No. 42 , February 1988.

National Association of Student Personnel Administrators. University Battles Free Speech Issue. NASPA Forum, December 1991 - January 1992, 1, 4.

The New Republic. Ugh! Oops. February 18, 1991, 39.

New York Times. U. of Wisconsin Repeals Ban on 'Hate Speech.' September 14, 1992, A10. 
Public Broadcasting Stations (PBS) Videocassette Service. Frontline: Racism 101. (FRON 612K) Alexandria (Va.), 1987.

The Stanford Daily. A chilling effect (editorial). Stanford University November 4, 1991, 4.

The Stanford Daily. Amend Western Culture (editorial). Stanford University, April 25, 1986, 4.

The Stanford Daily. Western Culture: education or miseducation (advertisement). Stanford University, May 19, 1986, 3.

Stanford University. The Free Speech at Stanford (videotape recording of a debate at the Stanford School of Law), Stanford Law Library, 1990.

Stanford University. Fundamental Standard Interpretation: Free Expression and Discriminatory

Harassment. Stanford University Student Conduct Policies, Office of the President, June 1990, 56, 17-22.

University of Texas at Austin. Report of President's Committee on Racial Harassment. 1989, 4-5.

University of Virginia. University Regulations. Graduate Record 1990-91, 1990, 23-43.

University of Virginia. University Regulations. Undergraduate Record: 1988-89, 1989-90, 1990-91, 199192.

University of Wisconsin-Madison. Document 1628A/2; Enrollment History (no date; last data indicated were from the 1985-86 academic year).

University of Wisconsin-Madison. Faculty Document 786: Prohibited Harassment: Definitions and Rules Governing the Conduct of UW-Madison Faculty and Academic Staff. February 6, 1989.

University of Wisconsin-Madison. Panel Discussion on UWS-17, sponsored by the Wisconsin ACLU, UW-Madison Memorial Student Union, October 22, 1991.

University of Wisconsin System. Enrollments, Term 1, All Levels, By Year. May 4, 1987.

University of Wisconsin System. Minority Headcount Enrollment. Table prepared by UWS administration, October 21, 1987.

University of Wisconsin System. Student Nonacademic Disciplinary Procedures. Chapter UWS 17 of the U.W.S. Register, August 1989, 404.

Webster's New Collegiate Dictionary, G. \& C. Merriam Co. (1979).

Wisconsin Legislative Council Rules Clearinghouse Report. Wisconsin State Legislature, May 15, 1989.

Wisconsin State Journal. Give up on speech rule (editorial). October 16, 1991, A-13. 


\section{Appendix A}

\section{Interview Questions}

1. Introductions

2. Provide an overview of the study and the types of questions which will be asked.

3. What factors were/are important in the university's discussion of the university's policy which prohibits racial or ethnic harassment?

a. What historical, structural, political or other factors or conditions shape the discussion?

b. Who were the primary participants in the discussion?

c. What values do these different participants hold?

4. What specific events were important in the decision to adopt or reject the policy?

a. What decision makers had to be persuaded to support the policy in order for it to be adopted?

b. What influenced the decisions of these key people?

c. Were the events spontaneous or planned? Pro-active or reactive? Inclusive or exclusive?

d. Did members of the community feel free to voice unpopular opinions?

5. What legal precedents were considered?

a. What types of expression are prohibited under the anti-harassment policy?

b. What types of expression are protected under the policy?

c. What kinds of issues were anticipated in the adjudication of cases?

d. Why were other legal precedents rejected?

e. Did specific campus incidents shape the policy which was eventually adopted?

6. What were the perceptions of the quality of inter-racial relationships among students, faculty, and staff prior to the decision to adopt or reject the policy?

a. How did you anticipate the policy would function to change the quality of those relationships?

b. What persons, events or beliefs about the university inform your opinion about the quality of inter-racial relationships?

7. How did the policy come to be adopted?

a. Who supported the policy and why did they support it?

1. What reasons were given? 
2. What reasons were attributed to the supporters by outsiders?

3. How did those in favor of the policy gain support for their views?

b. Who opposed the policy and why did they oppose it?

1. What reasons were given?

2. What reasons were attributed to the opponents by outsiders?

3. How did those who opposed the policy gain support for their views?

8. What outcomes resulted from the application of the anti-harassment policy (or lack of application)?

a. What is your perception of the quality of inter-racial relations among students, faculty, and staff after the adoption or rejection of the policy?

1. What persons, events or attitudes inform your perceptions of the quality of inter-racial relations on campus?

b. What issues have been important in the adjudication of persons charged with harassment?

1. What types of cases are being processed through the judicial system?

2. Did these cases match your expectations?

c. What impact, if any, has the policy (or the discussion of the policy) had on the academic behavior of faculty and students?

d. Have the anti-harassment policies contributed to ameliorating racial relations on campus?

1. Is the policy an effective instrument of the university for fostering a positive learning environment?

2. What evidence is available which suggests that the policy is effective?

3. In what ways does the policy fall short in meeting your expectations for shaping community members' behaviors?

4. Would you change the policy if you had the authority? If so, how?

e. What events or processes occurred after the policy was adopted which affected civility and/or inter-racial relationships?

f. What other changes on campus can be attributed, at least in part, to the application of the anti-harassment policy?

1. Have you become aware of any hesitancy to speak out among members of the university?

2. What impact, if any, did the process of deliberation and discussion about adopting the policy leave on the stakeholders in that discussion? 


\section{Appendix B}

\section{Interview Verification}

Thank you for agreeing to participate in this interview. Your name, position title, or references to you which arise during the interview will be disguised so that you will not be individually identified by your responses today in the dissertation or in any other public use of the data from this research.

The interview is being audio-taped for my personal use in this research. The only persons who will have access to the tape will be myself and a transcriber. The contents of the tape will be erased immediately after the transcription.

You will be provided with a copy of the record of the interview so that you may make comments and/or corrections to the record. You will have about two weeks from the date of receipt to return your comments. If no response is returned, I may conclude that the record represents accurately the proceedings of the interview. The short response time is necessary in order for me to meet research deadlines.

A copy of the dissertation will be provided to the chief student affairs officer at each of the three institutions participating in this study: Stanford University, The University of Wisconsin, and The University of Virginia.

Your signature indicates that the interview occurred and that you received a copy of this form.

(interviewee)

(researcher) (date)

(date)

This interview is being conducted as part of the dissertation research by Thomas W. Jennings, Jr., a Ph.D. candidate at the University of Virginia's Curry School of Education. The dissertation proposed is titled, "Speech Restrictive Codes Involving Racial Harassment at Three Research Universities." If you have questions later about the research or the interview, please contact:

Tom Jennings

Madison Hall, Level One

University of Virginia

Charlottesville, VA 22903

(804) 982-2674 (work) 


\section{Appendix C University of Wisconsin Policy}

UWS 17.06 Offenses Defined. The university may discipline a student in nonacademic matters in the following situations.

(2) (a) For racist or discriminatory comments, epithets or other expressive behavior directed at an individual or on separate occasions at different individuals, or for physical conduct, if such comments, epithets, other expressive behavior or physical conduct intentionally:

1. Demean the race, sex, religion, color, creed, disability, sexual orientation, national origin, ancestry, or age of the individual or individuals; and

2. Create an intimidating, hostile or demeaning environment for education, university related work, or other university-authorized activity.

(b) Whether the intent required under par. (a) is present shall be determined by consideration of all relevant circumstances.

(c) In order to illustrate the types of conduct which this subsection is designed to cover, the following examples are set forth. These examples are not meant to illustrate the only situations or types of conduct intended to be covered.

1. A student would be in violation if:

a.) He or she intentionally made demeaning remarks to an individual based on that person's ethnicity, such as name calling, racial slurs, or "jokes"; and

b.) His or her purpose in uttering the remarks was to make the educational environment hostile for the person to whom the demeaning remark was addressed.

2. A student would be in violation if:

a.) He or she intentionally placed visual or written material demeaning the race or sex of an individual in that person's university living quarters or work area; and

b.) His or her purpose was to make the educational environment hostile for the person in whose quarters or work area the material was placed.

3. A student would be in violation if he or she seriously damaged or destroyed private property of any member of the university community or guest because of that person's race, sex, religion, color, creed, disability, sexual orientation, national origin, ancestry, or age.

4. A student would not be in violation if, during a class discussion, he or she expressed a derogatory opinion concerning a racial or ethnic group. There is no violation, since the student's remark was addressed to the class as a whole, not to a specific individual. Moreover, on the facts as stated, there seems no evidence that the student's purpose was to create a hostile environment.

Source: Board of Regents. "Chapter UWS 17: Student Nonacademic Disciplinary Procedures," The Register (August 1989), University of Wisconsin, at 65-66. 


\section{Appendix D}

\section{Stanford University Policy}

1. Stanford is committed to the principles of free inquiry and free expression. Students have the right to hold and vigorously defend and promote their opinions, thus entering them into the life of the University, there to flourish or wither according to their merits. Respect for this right requires that students tolerate even expression of opinions which they find abhorrent. Intimidation of students by other students in their exercise of this right by violence or threat of violence, is therefore considered to be a violation of the Fundamental Standard.

2. Stanford is also committed to principles of equal opportunity and non-discrimination. Each student has the right to equal access to a Stanford education, without discrimination on the basis of sex, race, color, handicap, religion, sexual orientation, or national origin. Harassment of students on the basis of any of these characteristics contributes to a hostile environment that makes access to education for those subjected to it less than equal. Such discriminatory harassment is therefore considered to be a violation of the Fundamental Standard.

3. This interpretation of the Fundamental Standard is intended to clarify the point at which protected free expression ends and prohibited discriminatory harassment begins. Prohibited harassment includes discriminatory intimidation by threats of violence, and also includes personal vilification of students on the basis of their sex, race, color, handicap, religion, sexual orientation, or national and ethnic origin.

4. Speech or other expression constitutes harassment by personal vilification if it:

(a) is intended to insult or stigmatize an individual or a small number of individuals on the basis of their sex, race, color, handicap, religion, sexual orientation, or national and ethnic origin; and

(b) is addressed directly to the individual or individuals whom it insults or stigmatizes; and

(c) makes use of insulting or "fighting" words or non-verbal symbols.

In the context of discriminatory harassment by personal vilification, insulting or "fighting" words or nonverbal symbols are those "which by their very utterance inflict injury or tend to incite to an immediate breach of the peace," and which are commonly understood to convey direct and visceral hatred or contempt for human beings on the basis of their sex, race, color, handicap, religion, sexual orientation, or national and ethnic origin.

*Stanford's Fundamental Standard Interpretation was accompanied by six pages of text intended to explain the purpose and scope of the policy. Much of this information is included in chapter five.

Source: Office of the President. "Stanford University Student Conduct Policies," Stanford University (1990), at 5-6, 17-22. 


\section{Appendix E}

\section{Policy of the University of Virginia}

Students at the University are expected to conduct themselves as ladies and gentlemen, both within the University and elsewhere. For student conduct which is outside the jurisdiction of the Honor Committee but which tends to discredit or injure the University, the president is authorized by the Board of Visitors to impose such penalty as he may deem appropriate, including expulsion from the University. This authority has been delegated by the president to the University Judiciary Committee, subject to review by the president or a delegated representative. When the penalty for bad conduct is expulsion, the student may appeal the decision to the Board of Visitors.

Standards of Conduct. The University of Virginia is a community of scholars in which the ideals of freedom of inquiry, freedom of thought, freedom of expression, and freedom of the individual are sustained. It is committed to preserving the exercise of any right guaranteed to individuals by the Constitution. However, the exercise and preservation of these freedoms and rights require a respect for the rights of all in the community to enjoy them to the same extent. It is clear that in a community of learning, willful disruption of the educational process, destruction of property, and interference with the orderly process of the University or with the rights of other members of the University cannot be tolerated. Students enrolling in the University assume an obligation to conduct themselves in a manner compatible with the University's function as an educational institution. To fulfill its functions of imparting and gaining knowledge, the University retains the power to maintain order within the University and to exclude those who are disruptive of the educational process.

Generally, prohibited conduct for which a student is subject to discipline is defined as follows (not including violations of the honor system and motor vehicle regulations):

1. Physical or sexual assault of any person on University-owned or leased property or at Universitysponsored or supervised functions, or conduct which threatens the health or safety of any such person or the physical or sexual assault of any University student, faculty member or employee at the local residence of any University student, faculty member or employee within the city of Charlottesville or Albemarle County.

2. Substantial damage to University-owned or leased property or to property of a University student, employee, faculty member or visitor occurring on University-owned or leased property or at the residence of any student, faculty member or employee with the city of Charlottesville or Albemarle County.

3. Unauthorized entry into or occupation of University facilities which are locked, closed to student activities, or otherwise restricted as to use.

4. Intentional disruption or obstruction of teaching, research, administration, disciplinary procedures, other University activities, or activities authorized to take place on University property.

5. Unlawfully blocking or impeding normal pedestrian or vehicular traffic on or adjacent to University property. 
6. Violation of rules governing residence in University-owned or leased property as stated in The Record.

7. Alteration, fabrication or misuse of, or obtaining unauthorized access to, University identification cards, other documents, or computer files or systems.

8. Disorderly conduct on University-owned or leased property or at University-sponsored functions. Disorderly conduct is defined to include acts which breach the peace or are lewd, indecent, or obscene, and which are not constitutionally-protected speech.

9. Violations of University policies or of University regulations as described in The Record including regulations concerning the use of University facilities.

10. Any violation of federal, state, or local law if such directly affects the University's pursuit of its proper educational purpose and only to the extent such violations are not covered by the Standards of Conduct and only where a specific provision of statute or ordinance is charged in the complaint.

11. Intentional conduct which violates the rules of confidentiality, or which obstructs the operations of the Honor Committee, the University Judiciary Committee, or any subsidiary body.

12. Failure to comply with directions of University officials acting under provisions 1 through 11 set out above. This shall include failure to give identity in situations concerning alleged violations of sections 1 through 11.

Source: Office of the University Registrar. "Graduate Record, 1990-91," University of Virginia (1990) at 27-28. 


\section{$\underline{\text { Appendix F }}$}

\section{Collegiate Speech Protection Act of 1991}

A Bill: To amend title VI of the Civil Rights Act of 1964 to protect the free speech rights of college students.

Be it enacted by the Senate and House of Representatives of the United States of America in Congress assembled,

SECTION 1. SHORT TITLE.

This Act may be cited as the "Collegiate Speech Protection Act of 1991."

\section{SECTION 2. TITLE VI AMENDMENT.} following:

Title VI of the Civil Rights Act of 1964 is amended by adding at the end of the

SEC. 607.(a) A postsecondary educational institution that is a program or activity shall not make or enforce any rule subjecting any student to disciplinary sanctions solely on the basis of conduct that is speech or other communication protected from governmental restriction by the first article of amendment to the Constitution of the United States.

(b) Whoever is a student at an educational institution engaged in a violation of subsection (a) may, in civil action, obtain appropriate injunctive and declatory relief. The court shall award reasonable attorneys' fees and other litigation costs to a prevailing plaintiff in a civil action under this section.

(c) This section does not apply to an educational institution that is controlled by a religious organization, to the extent that the application of this section would not be consistent with the religious tenets of such organization. 


\section{Appendix G}

\section{Sample Cartoons}
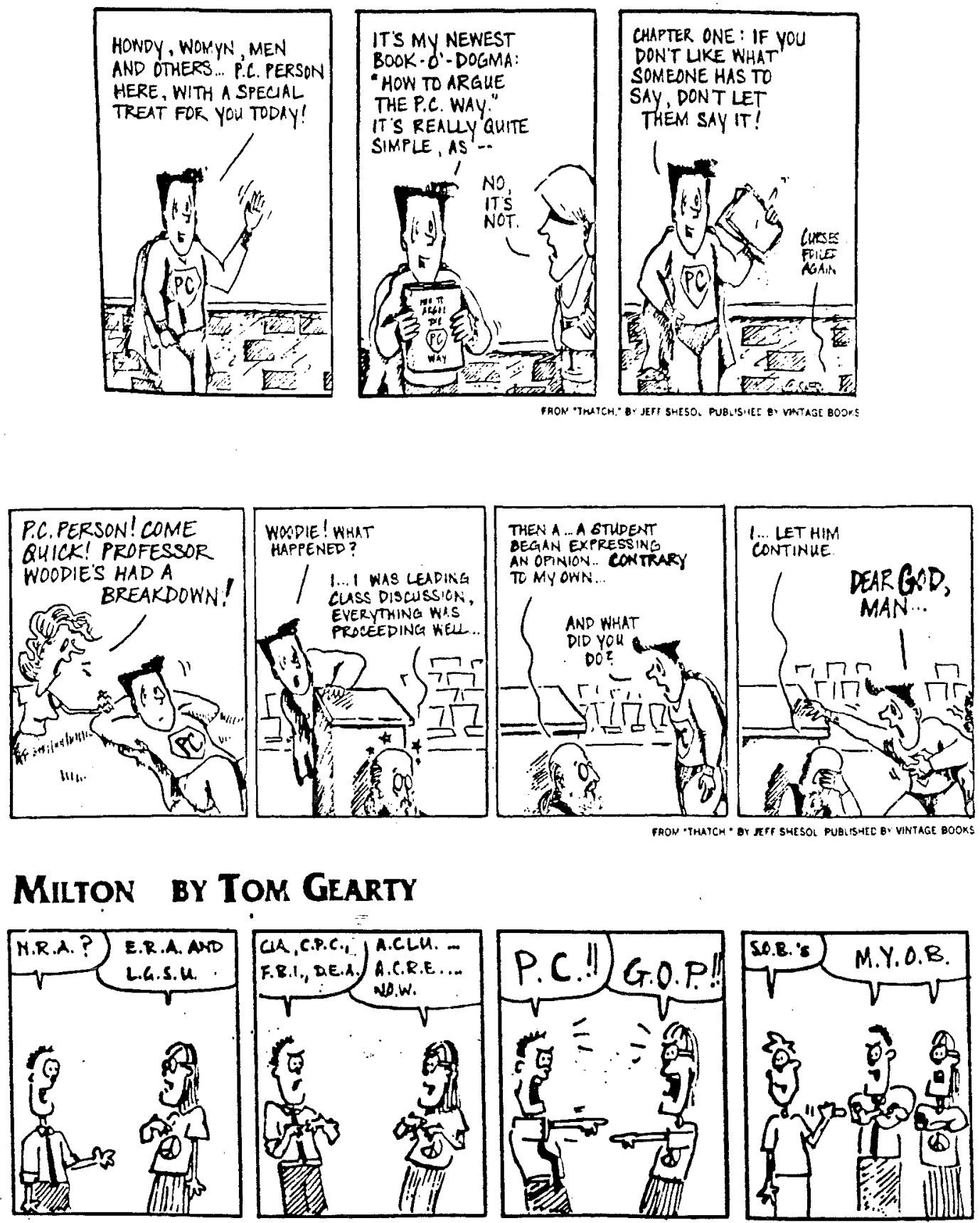

MILTON by TOM GeARTY
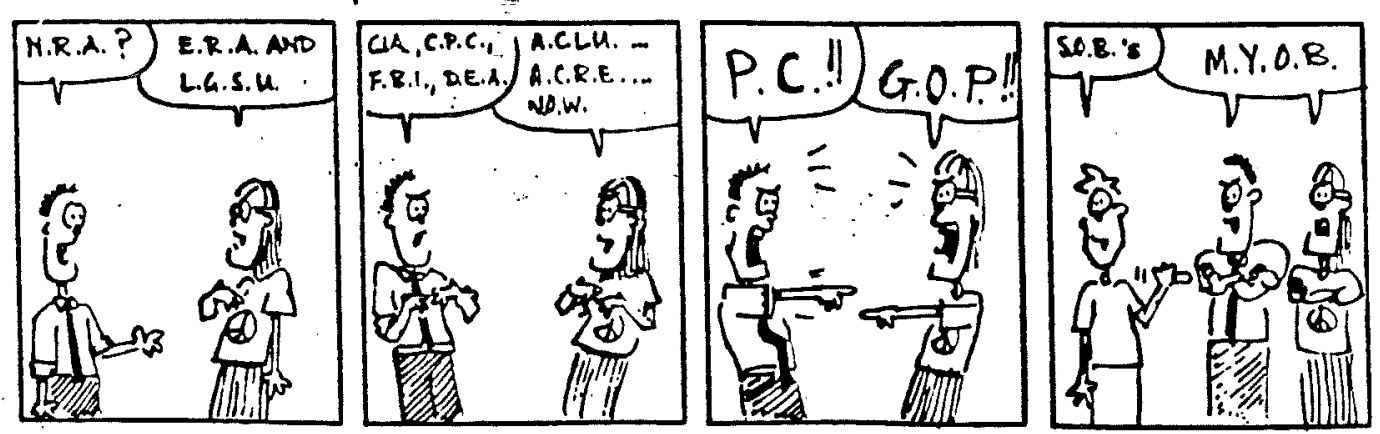